\title{
Kristallstrukturanalyse des spleißosomalen DEAD-Box Proteins hPrp28
}

\author{
Dissertation \\ zur Erlangung des Doktorgrades \\ der Mathematisch-Naturwissenschaftlichen Fakultäten \\ der Georg-August-Universität zu Göttingen \\ vorgelegt von \\ Sina Möhlmann \\ aus Westerstede
}

Göttingen 2007 
D7

Referent: Prof. Dr. Ralf Ficner

Korreferent: Prof. Dr. Oliver Einsle

Tag der mündlichen Prüfung: 23.01.2008 


\section{Inhaltsverzeichnis}

$1 \quad$ Einleitung.......................................................................................................................................... 1

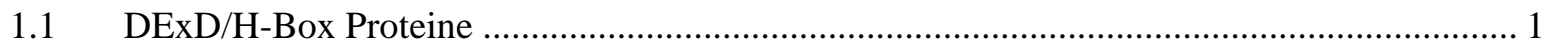

1.1.1 Die konservierten Sequenzmotive der DExD/H-Box Proteine ….................................. 1

1.1.2 Dreidimensionale Struktur von DExD/H-Box Proteinen ............................................... 3

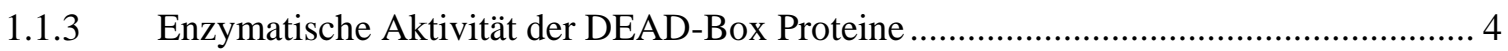

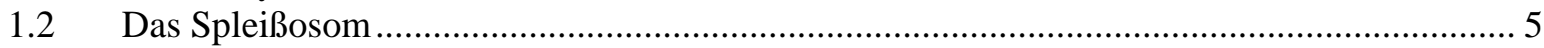

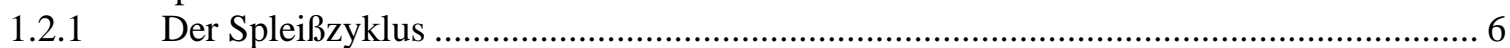

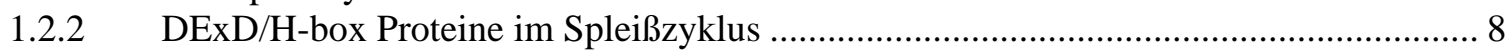

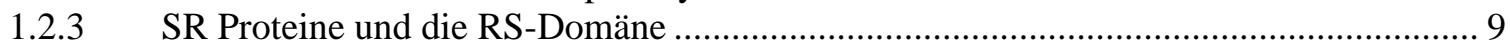

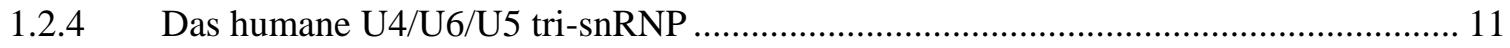

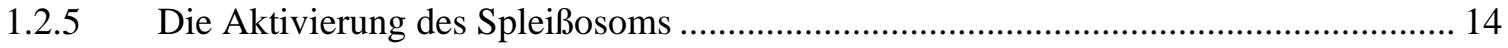

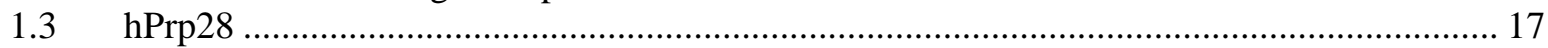

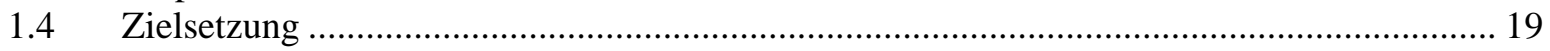

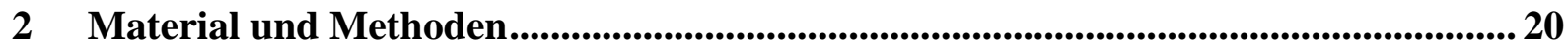

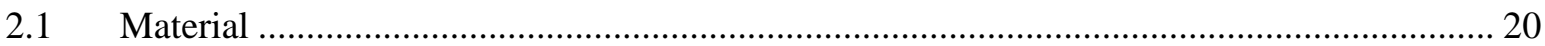

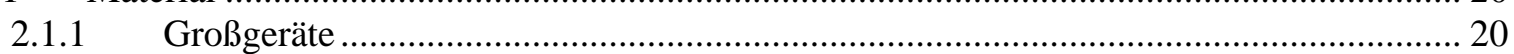

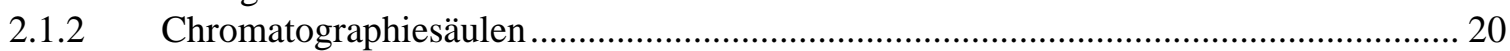

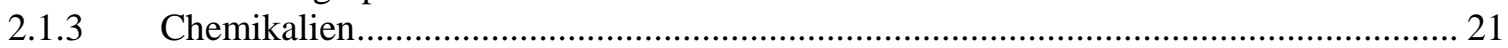

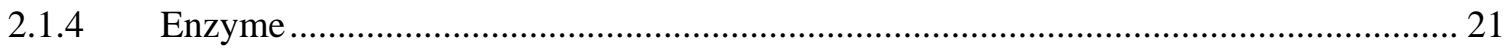

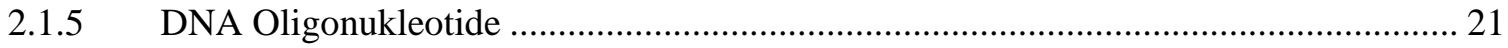

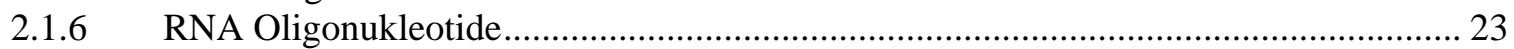

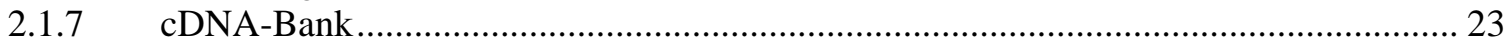

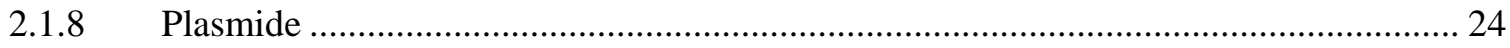

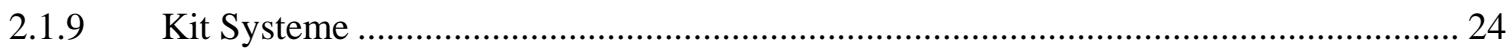

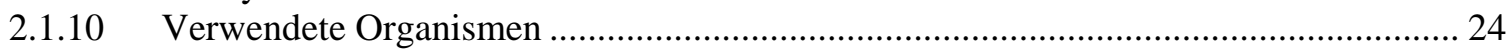

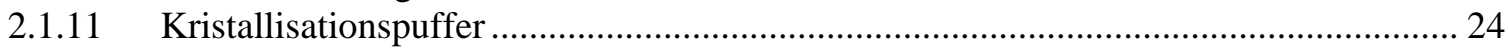

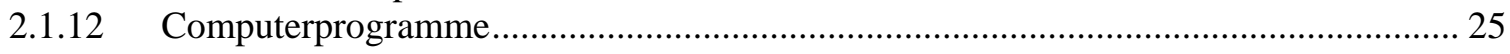

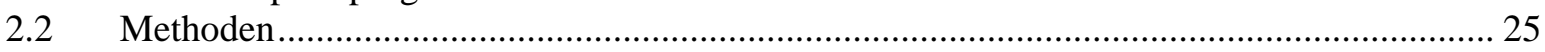

2.2.1 Mikrobiologische und molekularbiologische Methoden ............................................ 25

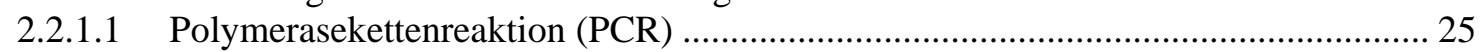

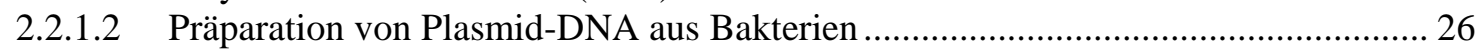

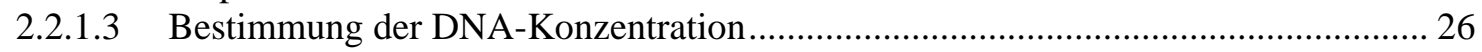

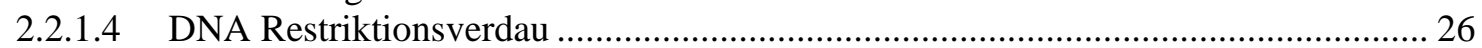

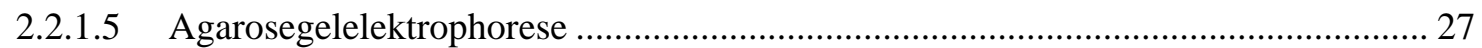

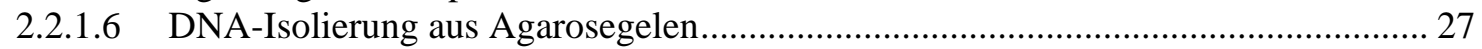

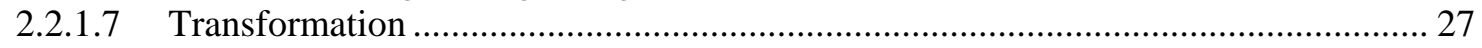

2.2.1.7.1 Herstellung transformationskompetenter Zellen (CaCl2-Methode) ..................... 28

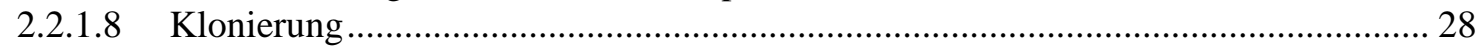

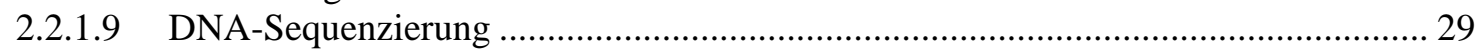

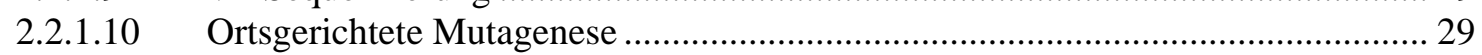

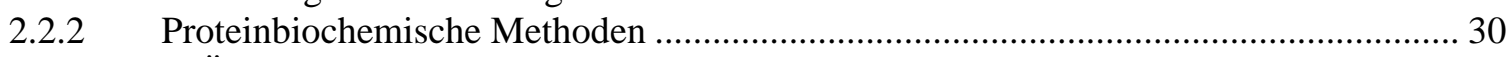

2.2.2.1 Überexpression rekombinanter Proteine in Bakterien …………............................... 30

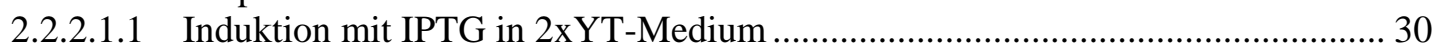

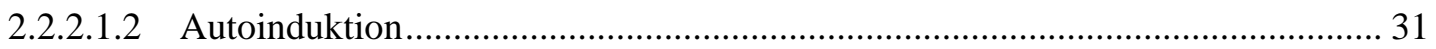

2.2.2.1.3 Induktion mit IPTG in Minimalmedium ......................................................... 31

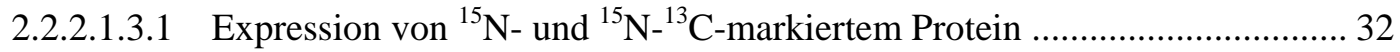

2.2.2.1.3.2 Expression von Selenomethionin-Protein ................................................. 32

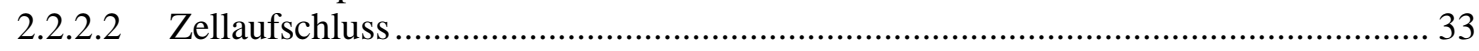

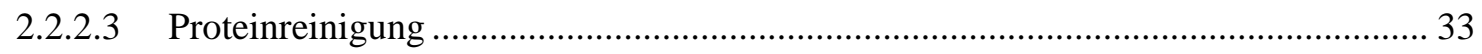

2.2.2.3.1 Hexahistidin-Affinitätschromatographie ............................................................ 34 
2.2.2.3.2 Glutathion-S-Transferase- Affinitätschromatographie........................................ 34

2.2.2.3.3 Gelfiltration (Ausschlusschromatographie)......................................................... 34

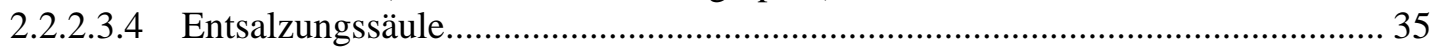

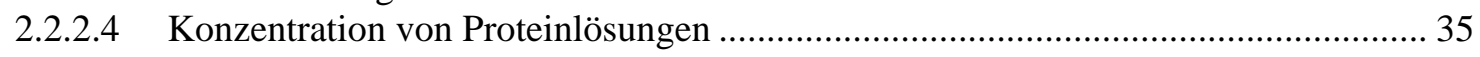

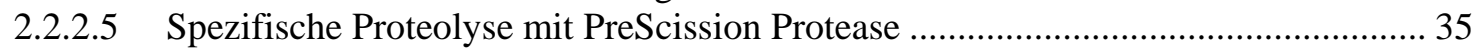

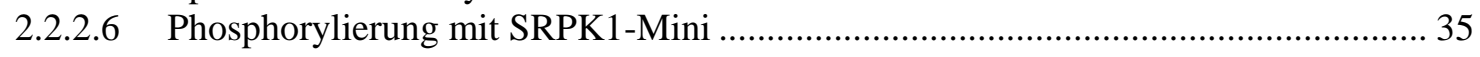

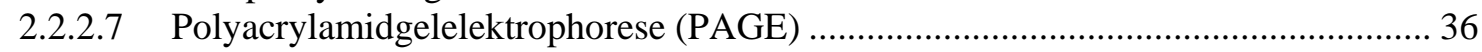

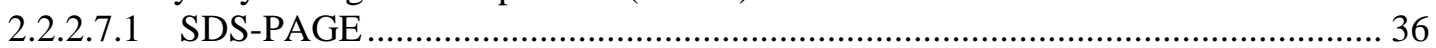

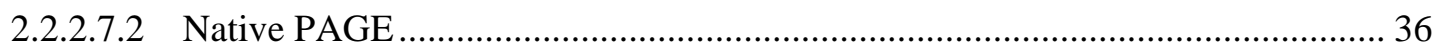

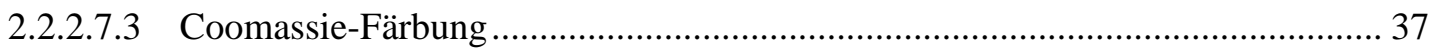

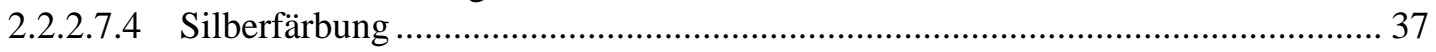

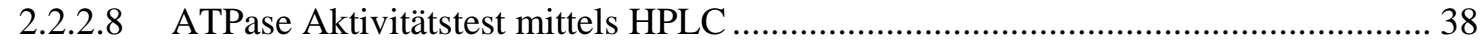

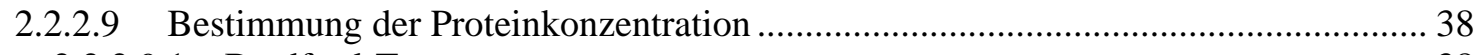

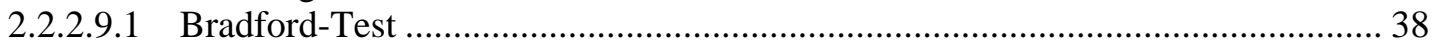

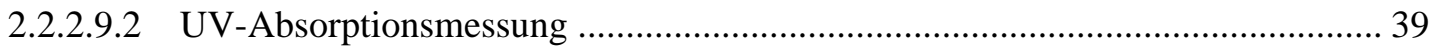

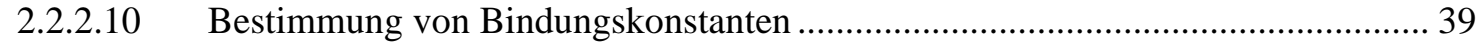

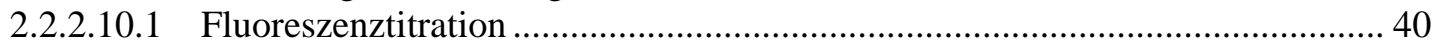

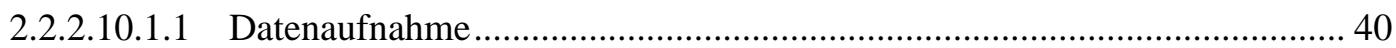

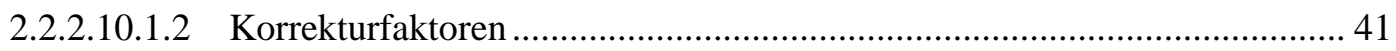

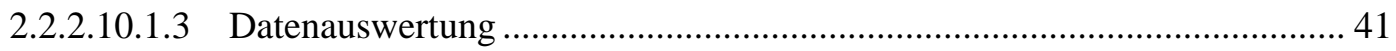

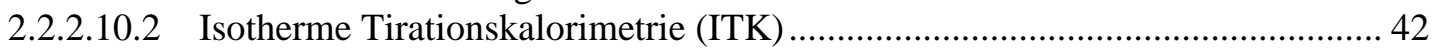

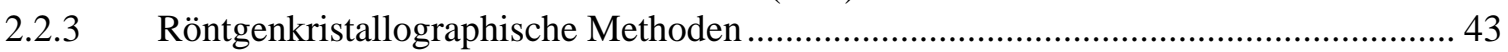

2.2.3.1 Bestimmung der Molekularstruktur eines Protein über Kristallographie .................. 43

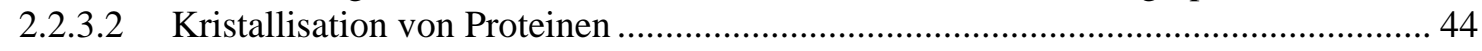

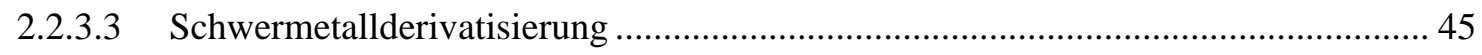

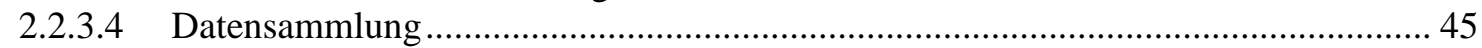

2.2.3.5 Phasenbestimmung und Berechnung der Elektronendichteverteilung ...................... 46

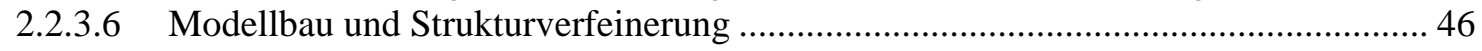

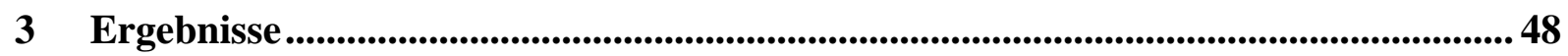

3.1 Klonierung, Reinigung und Kristallisationsversuche mit hPrp28 ................................... 48

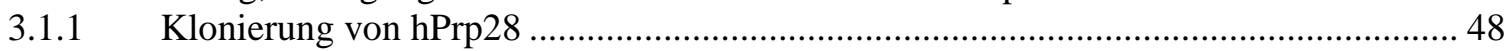

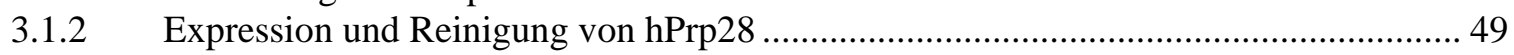

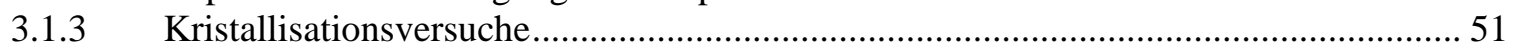

3.2 Klonierung und Reinigung von Fragmenten von hPrp28 (Überblick) ................................. 51

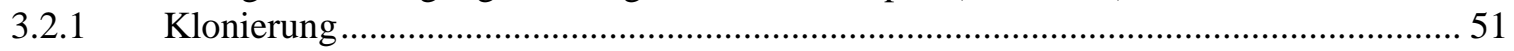

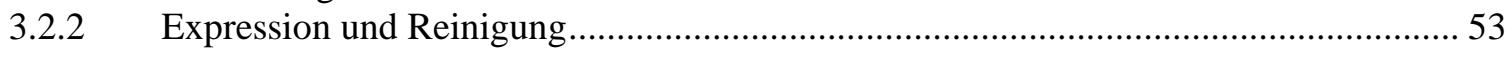

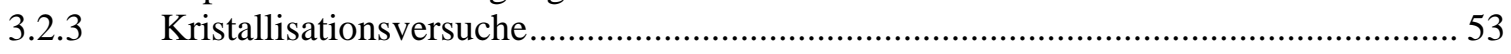

3.3 Struktur und Eigenschaften der Helikasedomäne von hPrp28 ............................................. 54

3.3.1 Expression und Reinigung des DEAD2-Fragments .................................................... 54

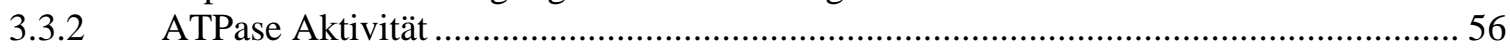

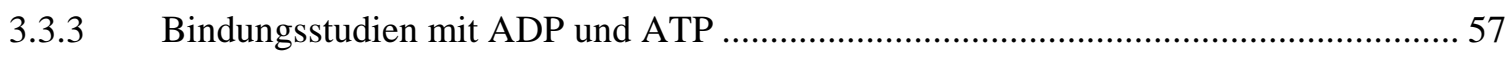

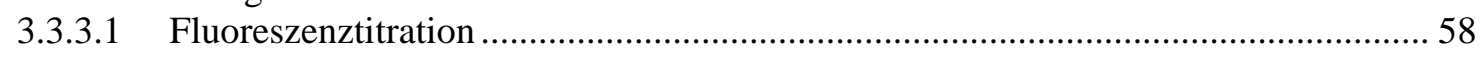

3.3.3.1.1 Bestimmung von Anregungs- und Emissionswellenlänge ................................ 59

3.3.3.1.2 Die Dissoziationskonstante von DEAD2 mit mant-ADP und mant-ATP ........... 59

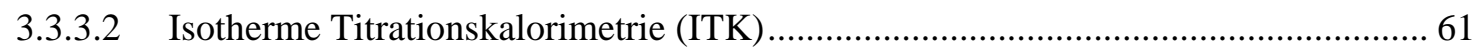

3.3.3.2.1 Die Dissoziationskonstante von DEAD2 mit ADP und ATP............................. 62

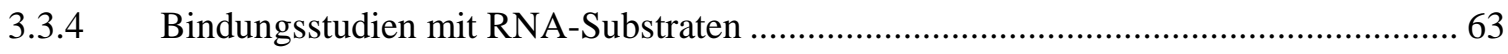

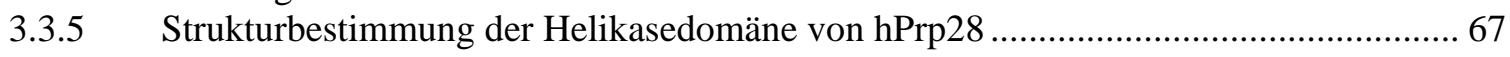

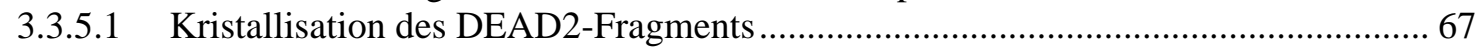

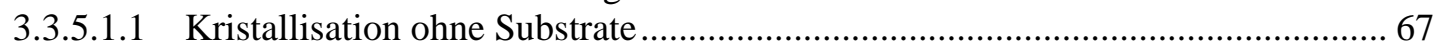

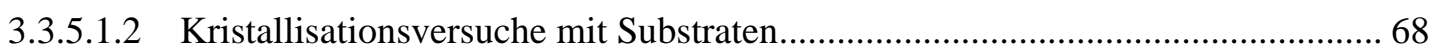

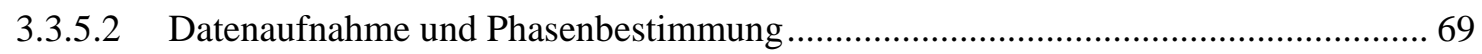

3.3.5.2.1 Versuch der Phasenbestimmung über molekularen Ersatz (MR) ........................ 70

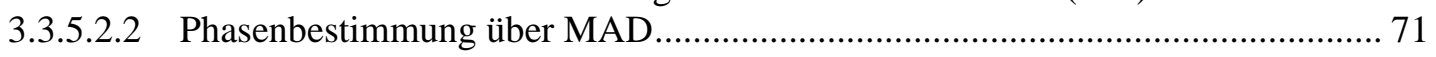




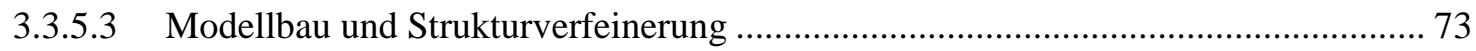

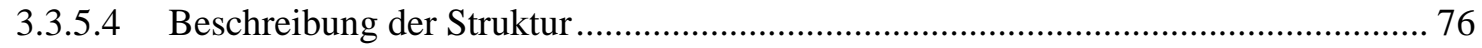

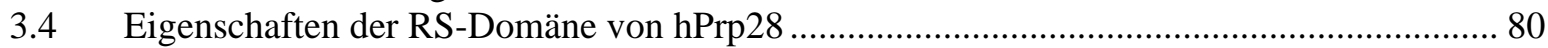

3.4.1 Reinigung und Kristallisationsversuche mit dem RS3-Fragment von hPrp28 …........... 80

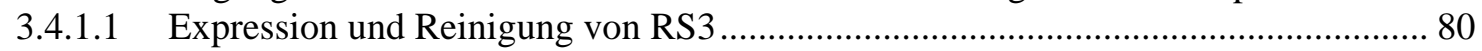

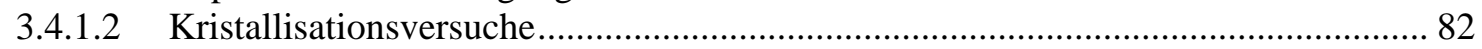

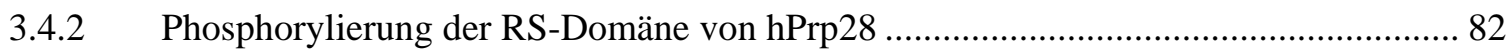

3.4.2.1 Klonierung RS-Domänen spezifischer Kinasen ....................................................... 83

3.4.2.2 Koexpression von RS3 mit RS-Domänen spezifischen Kinasen in E. coli ................ 83

3.4.2.3 In vitro Phosphorylierung der RS-Domäne von hPrp28 ......................................... 85

3.4.2.3.1 Expression und Reinigung der Kinasedomäne von SRPK1 und Clk1 ................ 85

3.4.2.3.2 In vitro Phosphorylierung des RS3-Fragments von hPrp28 ............................... 86

3.4.2.3.2.1 In vitro Phosphorylierung mit SRPK1-Mini ................................................. 86

3.4.2.3.2.2 In vitro Phosphorylierung mit Clk1-Mini .................................................... 88

3.4.2.4 Reinigung und Kristallisationsversuche mit phosphoryliertem RS3-Fragment ........ 89

3.4.2.5 Reinigung und Kristallisationsversuche mit phosphoryliertem hPrp28 .................... 89

3.4.3 Der hydrodynamische Radius des RS3-Fragments von hPrp28 .................................. 90

3.4.4 Untersuchung des RS3-Fragments von hPrp28 über NMR-Spektroskopie ................... 91

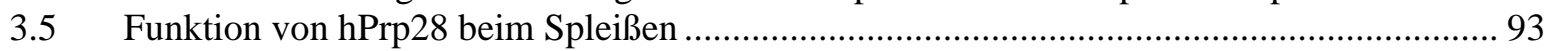

3.5.1 Immunodeletion von hPrp28 und Komplementation mit rekombinantem Protein........ 93

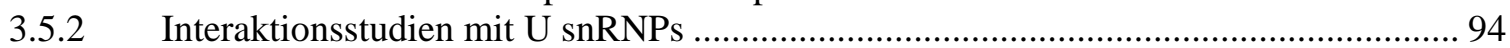

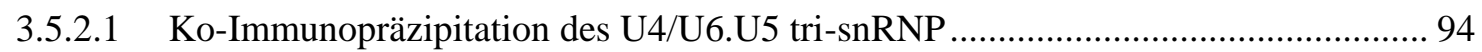

3.5.2.2 Untersuchung der Interaktion von hPrp28 mit dem U1 snRNP ............................ 95

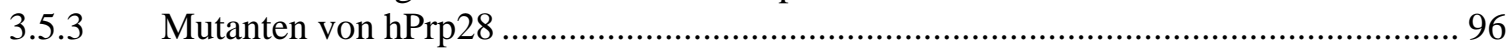

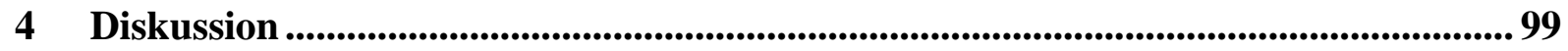

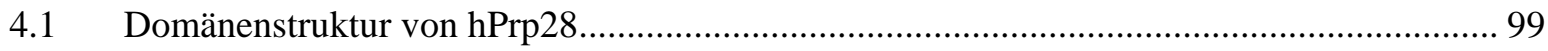

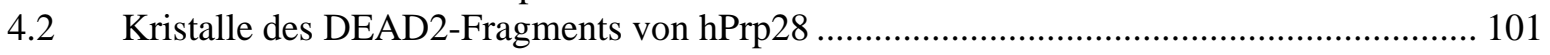

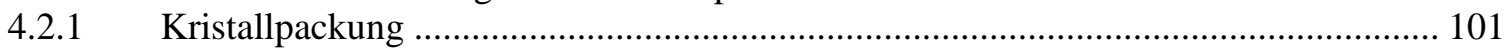

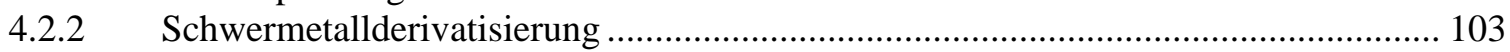

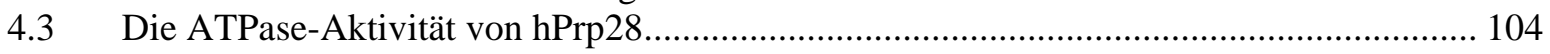

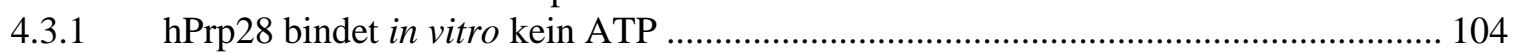

4.3.2 Die Helikasesubdomänen bilden kein katalytisches Zentrum .................................... 107

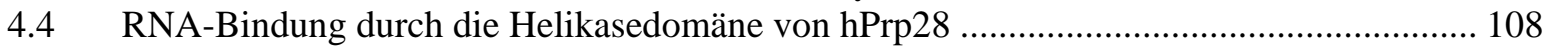

4.5 Die Insertion in der N-terminalen Helikasesubdomäne von hPrp28 …............................... 111

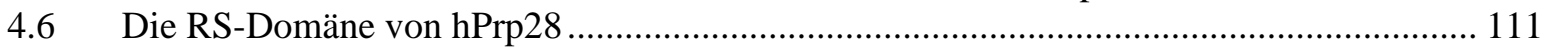

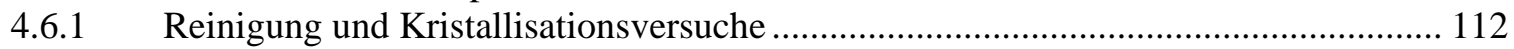

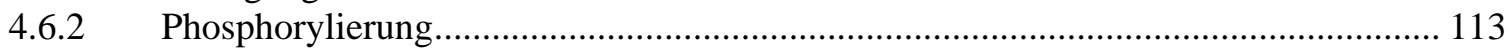

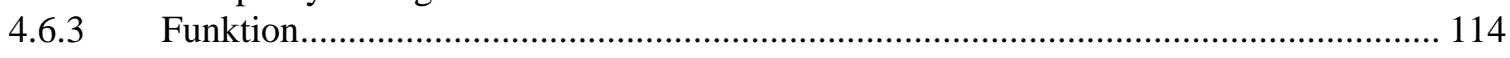

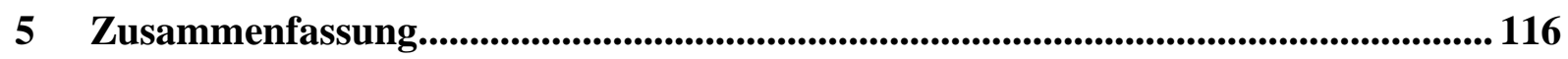

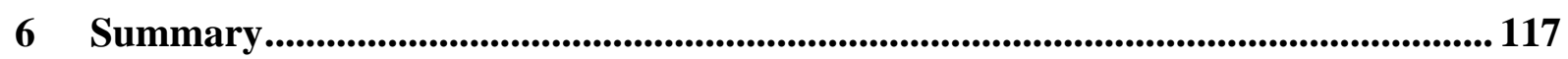

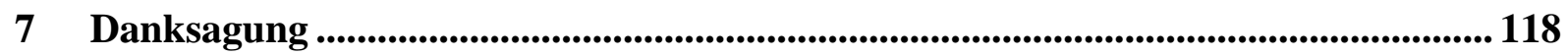

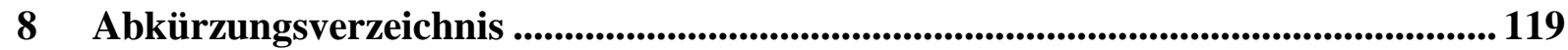

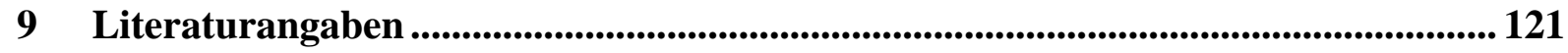

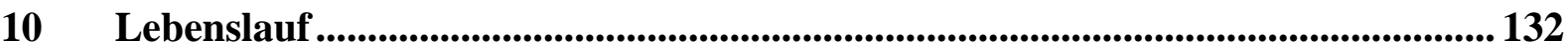




\section{Einleitung}

\subsection{DExD/H-Box Proteine}

In der Zelle findet eine Vielzahl an Prozessen statt, an der RNA-Moleküle beteiligt sind. Dazu gehören die Transkription, das Spleißen, der Kernexport, die Translation und Degradation von mRNA ebenso wie die Biogenese von Ribosomen. An allen diesen Vorgängen sind sogenannte DExD/H-Box Proteine beteiligt. Dabei handelt es um eine weit verbreitete Proteinfamilie, deren Vertreter sowohl in eukaryotischen und prokaryotischen Zellen vorkommen als auch von Viren kodiert werden (Übersicht in Cordin et al. 2005, Linder 2006).

DExD/H-box Proteine gehören zur Superfamilie 2 der Helikasen (SF2). Sie zeigen Ähnlichkeit zu den DNA-Helikasen, die im Allgemeinen der Superfamilie 1 (SF1) zugeordnet werden. Diese Ähnlichkeit betrifft einerseits das Vorkommen bestimmter konservierter Sequenzmotive und andererseits die dreidimensionale Struktur der katalytischen Domäne. Eines dieser konservierten Motive (Motiv II) enthält dabei im Fall der DExD/H-Box Proteine die namensgebende Aminosäuresequenz DExD/H (D: Aspartat, E: Glutamat, H: Histidin, x: beliebige Aminosäure).

Viele DExD/H-Box Proteine zeigen eine RNA-abhängige oder RNA-stimulierte ATPaseAktivität. Für einige dieser Proteine wurde zudem nachgewiesen, dass sie die bei der ATP (oder allgemein NTP)-Hydrolyse freiwerdende Energie dazu nutzen können, RNA-RNADuplexe zu entwinden. Darum werden die DExD/H-Box Proteine auch als „RNA Helikasen“ bezeichnet. Allerdings ist es möglich, dass RNA-RNA-Duplexe nicht das einzige Substrat dieser Proteinfamilie sind. Für zwei DExD/H-Box Proteine wurde gezeigt, dass sie Proteine von einzelsträngigen oder doppelsträngigen RNA-Molekülen entfernen können (Jankowsky et al. 2001, Fairman et al. 2004). DExD/H-Box Proteine könnten folglich auch als RNPasen wirken, also als Proteine, die die Konformationsänderungen in Ribonucleoprotein-Komplexen katalysieren.

\subsubsection{Die konservierten Sequenzmotive der DExD/H-Box Proteine}

Die DExD/H-Box Proteine lassen sich in Abhängigkeit von der genauen Aminosäuresequenz des Motivs II in die Untergruppen der DEAD-, DEAH-, DExD- und DExH-Box Proteine unterteilen. Diese Proteine haben acht konservierte Sequenzmotive gemeinsam (Motiv I, Ia, Ib, II, III, IV, V und VI). Die größte Untergruppe, die DEAD-Box Proteine, enthalten zudem drei zusätzliche Motive (Q, GG und QxxR Motiv). Die konservierten Motive haben funktionelle Bedeutung für die Helikaseaktivität der DExD/H-Box Proteine. Sie sind entsprechend an der Bindung von ATP oder RNA beteiligt oder wichtig für die Kommunikation zwischen den beiden Substratbindestellen. Anhand von Mutationsstudien und Kristallstrukturen diverser Helikasen konnten die einzelnen Motive diesen verschiedenen Funktionen zugeordnet werden (siehe Tabelle 1.1, Übersicht in Cordin et al. 2005, Caruthers und McKay 2002). 
Für die DEAD-Box Proteine besonders aufschlussreich ist die Struktur von Vasa, einem DEAD-Box Protein aus Drosophila melanogaster, das zusammen mit einem ATP-Analogon und einer Substrat ssRNA kristallisiert wurde (Sengoku et al. 2006). Demnach wird das ATP von den Motiven Q, I, II, V und VI gebunden. Dabei interagieren Motiv I, II und VI mit den Phosphaten sowie dem assoziierten $\mathrm{Mg}^{2+}$-Ion. Motiv V bindet dagegen die Ribose, während das Q-Motiv mit dem Adeninanteil interagiert. Dadurch ist das Q Motiv vermutlich dafür verantwortlich, dass DEAD-Box Proteine spezifisch für ATP sind. Diese Spezifität gilt für andere Untergruppen der DExD/H-Box Proteine, denen das Q-Motiv fehlt, nicht. Motiv I und II werden auch als Walker A- und B-Motive bezeichnet, es handelt sich dabei um Elemente, die in vielen NTPasen vorkommen.

Die RNA wird von Motiv Ia, Ib, GG, IV, QxxR und V gebunden. Alle diese Interaktionen betreffen ausschließlich das Ribose-Phosphat-Rückgrat. Damit haben DExD/H-Box Proteine zwar eine Spezifität für RNA (im Gegensatz zu DNA), binden aber unabhängig von der Basensequenz.

Tabelle 1.1: Die konservierten Sequenzmotive der DEAD-Box Proteine. Die Zuordnung der Funktionen basiert insbesondere auf den Kristallstrukturen von Vasa (Sengoku et al. 2006) und eIF4AIII (Bono et al. 2006)

\begin{tabular}{|c|c|c|}
\hline Motiv & Konsensussequenz & Funktion \\
\hline Q & $\mathrm{F}-(\mathrm{x})_{\mathrm{n}}-\mathrm{GxxxPxxxQ}$ & ATP-Bindung: Interaktion mit Adenin \\
\hline $\begin{array}{l}\text { I } \\
\text { (Walker A) }\end{array}$ & AxxGxGKT & ATP-Bindung: Interaktion mit $\beta$ - und $\gamma$-Phosphat $(\mathrm{K})$ und mit $\mathrm{Mg}^{2+}(\mathrm{T})$ \\
\hline Ia & PTRELA & RNA-Bindung \\
\hline GG & GG & RNA-Bindung \\
\hline $\mathrm{Ib}$ & TPGR & RNA-Bindung \\
\hline $\begin{array}{l}\text { II } \\
\text { (Walker B) }\end{array}$ & DEAD & $\begin{array}{l}\text { ATP-Bindung und -Hydrolyse: Interaktion mit } \mathrm{Mg}^{2+} \text { (DEAD) und } \\
\text { aktiviertem Wasser (E) }\end{array}$ \\
\hline III & SAT & Helikase-Aktivität: Interaktion mit Motiv II und VI \\
\hline IV & $(\mathrm{L} / \mathrm{V}) \mathrm{IF}$ & RNA-Bindung \\
\hline QxxR & QxxR & RNA-Bindung \\
\hline $\mathrm{V}$ & TDVxARGID & $\begin{array}{l}\text { Helikase-Aktivität: Interaktion mit Motiv Ia, II und VI } \\
\text { ATP-Bindung: Interaktion mit Ribose } \\
\text { RNA-Bindung }\end{array}$ \\
\hline VI & HRxGRxGR & ATP-Bindung: Interaktion mit $\gamma$-Phosphat \\
\hline
\end{tabular}

Das Motiv III bindet weder ATP noch RNA, während das Motiv V mit beiden Substraten interagiert. Mutationsstudien haben gezeigt, dass diese Motive für die Helikase-Aktivität wichtig sind, sie vermitteln also die Kommunikation zwischen ATP- und RNA-Bindung. In Strukturen von Helikasen wurde entsprechend sichtbar, dass beide Motive mit anderen konservierten Sequenzmotiven interagieren. Diese Interaktionen vermitteln auch eine Verbindung der beiden Subdomänen der Helikaseeinheit (s.u.). 


\subsubsection{Dreidimensionale Struktur von DExD/H-Box Proteinen}

Die konservierten Motive der DExD/H-Box Proteine befinden sich in einem Sequenzabschnitt von 350-400 Aminosäuren. Dieser Sequenzabschnitt bildet die katalytische RNAHelikasedomäne. Die dreidimensionale Struktur dieser Helikasedomäne ist bei mehreren DExD/H-Box Proteinen über Röntgenstrukturanalyse bestimmt worden (Tabelle 1.2).

Strukturell besteht die Helikasedomäne aus zwei einzelnen Subdomänen. Bei beiden Subdomänen handelt es sich um RecA-ähnliche Domänen, d. h. ihre Faltung entspricht im Grundgerüst derjenigen des RecA-Proteins aus E. coli (Story und Steitz 1992). Damit ähneln die DExD/H-Box Proteine strukturell den DNA-Helikasen der Superfamilie I. Eine RecAähnliche Domäne enthält ein zentrales $\beta$-Faltblatt, das von mehreren $\alpha$-Helices umgeben wird. Die konservierten Sequenzmotive der DExD/H-Box Proteine befinden sich fast ausschließlich in Bereichen, die Schleifen zwischen den Sekundärstrukturelementen bilden. Die N-terminale Subdomäne enthält dabei die Motive Q, I, Ia, GG, Ib, II und III. Die Motive IV, QxxR, V und VI dagegen liegen in der C-terminalen Subdomäne (Übersicht in Cordin et al. 2005, Caruthers und McKay 2002).
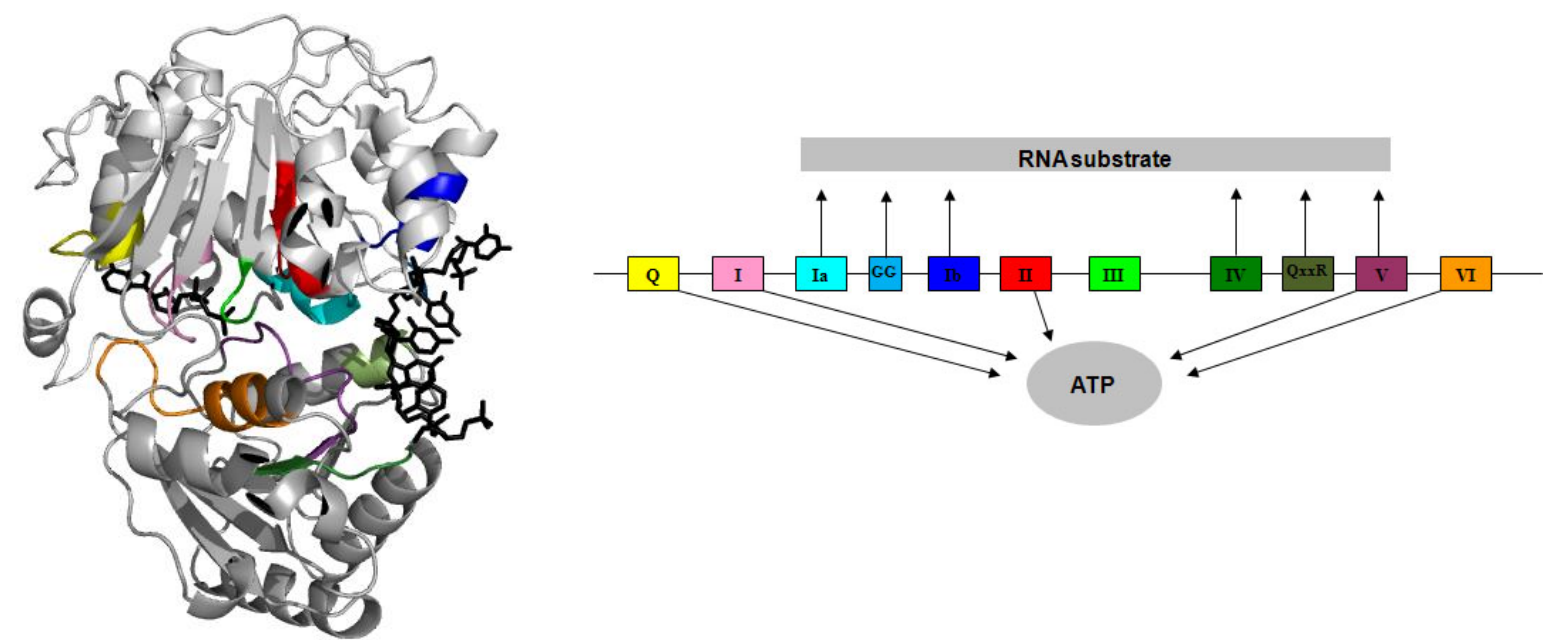

Abb. 1.1: Die dreidimensionale Struktur der Helikasedomäne von Vasa (Sengoku et al. 2006). Die N-terminale Subdomäne ist hellgrau, die C-terminale dunkelgrau, gebundene ADPNP- und RNA-Moleküle in schwarz dargestellt. Die konservierten Sequenzmotive sind dem Schema entsprechend farblich hervorgehoben.

Tabelle 1.2: Proteine der DExD/H-Box Familie, bei denen die vollständige Helikasedomäne kristallisiert wurde. Eventuell kokristallisierte Liganden sind angegeben.

\begin{tabular}{|c|c|c|c|c|c|}
\hline & Motiv II & Liganden & Organismus & PDB-Eintrag & Literatur \\
\hline DDX3x & DEAD & AMP & H. sapiens & $2 \mathrm{i} 4 \mathrm{i}$ & Hogbom et al. 2007 \\
\hline Dhh1p & DEAD & - & S. cerevisiae & $1 \mathrm{~s} 2 \mathrm{~m}$ & Cheng et al. 2005 \\
\hline eIF4AIII & DEAD & ATP, RNA & H. sapiens & $\begin{array}{l}2 \mathrm{jOs} \\
2 \mathrm{HYI}\end{array}$ & $\begin{array}{l}\text { Bono et al. } 2006 \\
\text { Andersen et al. } 2006\end{array}$ \\
\hline eIF4A & DEAD & ADP, ATP & S. cerevisiae & $\begin{array}{l}1 \mathrm{FUU} \\
1 \mathrm{QDE}\end{array}$ & $\begin{array}{l}\text { Caruthers et al.2000 } \\
\text { Benz et al. } 1999\end{array}$ \\
\hline UAP56 & DECD & ADP & H. sapiens & $1 \mathrm{XTJ}$ & Shi et al. 2004 \\
\hline Vasa & DEAD & ADPNP, RNA & D. melanogaster & 2DB3 & Sengoku et al. 2006 \\
\hline MjDEAD & DEAD & - & M. jannaschii & $1 \mathrm{HVs}$ & Story et al. 2001 \\
\hline NS3 & DEAH & ADP & Gelbfibervirus & $1 \mathrm{ymf}$ & Wu et al. 2005 \\
\hline NS3 & $\mathrm{DECH}$ & ssDNA & Hepatitis C Virus & $\begin{array}{l}\text { 1HEI } \\
1 \mathrm{~A} 1 \mathrm{~V}\end{array}$ & $\begin{array}{l}\text { Yao et al. } 1997 \\
\text { Kim et al. } 1998\end{array}$ \\
\hline
\end{tabular}


Die verschiedenen Strukturen der Helikasedomänen von DExD/H-Box Proteinen sind sich zwar in der Faltung der Subdomänen sehr ähnlich, unterscheiden sich aber deutlich in der Orientierung der beiden Subdomänen zueinander. Dies weist darauf hin, dass sie flexibel miteinander verbunden sind und ihre Orientierung in vivo - abhängig von gebundenen Substraten oder Cofaktoren - variabel ist. Die katalytisch aktive Konformation entspricht dabei vermutlich den Strukturen von Vasa (Abb. 1.1) und eIF4AIII. Beide Proteine wurden zusammen mit ATP bzw. ADPNP und RNA kristallisiert. In diesen Strukturen sind die Subdomänen derart orientiert, dass sich die konservierten Sequenzmotive der DExD/H-Box Proteine - die sich auf beide Subdomänen verteilen - in räumlicher Nähe zueinander befinden. Sie formen dadurch in der Spalte zwischen den Subdomänen eine ATPBindetasche. Außerdem bildet sich für RNA-Substrate eine Bindestelle, die sich über beide Subdomänen erstreckt (Sengoku et al. 2006, Bono et al. 2006).

Neben der Helikasedomäne enthalten DExD/H-Box Proteine häufig N- und /oder C-terminal noch weitere Domänen, die charakteristisch für das jeweilige Protein sind. Über diese zusätzlichen Domänen ist strukturell bisher nur wenig bekannt und ihre Funktionen sind unterschiedlich. Da die Helikasedomäne selbst nur unspezifisch an RNA bindet, ist es eine wichtige Aufgabe solcher zusätzlicher Domänen, das Protein zu seiner Substrat-RNA zu bringen. Dabei binden sie entweder direkt spezifisch an die RNA (z.B. DbpA und die 23S rRNA) oder indirekt, indem sie mit anderen Proteinen interagieren und die Helikase dadurch zu einem spezifischen Komplex rekrutieren (Beispiel: Prp22 und das Spleißsom). Eine andere Funktion zusätzlicher Domänen besteht darin, die Helikasedomäne in ihrer Aktivität zu regulieren oder zu unterstützen. Eine Domäne von NS3 (Hepatitis C Virus) erhöht beispielsweise die Affinität für die Substrat-RNA und ist wichtig für die prozessive Entwindung (Übersicht in Tanner und Linder 2001).

\subsubsection{Enzymatische Aktivität der DEAD-Box Proteine}

Die entscheidende Frage, die anhand der Strukturen von Helikasen geklärt werden soll, ist, wie diese Proteine die Hydrolyse von ATP mit der Entwindung einer RNA-Helix bzw. mit der Entfernung eines Proteins von einer RNA verknüpfen.

Für die DNA Helikasen der Superfamilie I geht man davon aus, dass sich die Helikasedomäne wie eine Raupe (englisch: inchworm) auf einem der DNA-Stränge fortbewegt und dabei den anderen Strang verdrängt. Das Modell basiert auf der Beobachtung, dass sich der Abstand zwischen den beiden Subdomänen mit der ATP-Bindung und -Hydrolyse ändert. Da beide Subdomänen das RNA-Substrat binden können, führen Zyklen von ATP-Bindung und -Hydrolyse zur „Kriechbewegung“. Zusätzliche Domänen der DNA-Helikasen unterstützen dabei ähnlich einem Sperrrad die Fixierung der DNA, so dass sich die Helikase nur in eine Richtung fortbewegen kann (Velankar et al. 1999, Lee und Yang 2006, Übersicht in Tanner und Linder 2001).

Dieses Raupen-Modell könnte auch für prozessive RNA Helikasen der DExD/H-Box Proteine gültig sein, wie z.B. das vom Hepatitis C Virus kodierte NS3 (Dumont et al. 2006, Büttner et al. 2007). Für die Untergruppe der DEAD-Box Proteine aber trifft dieses Modell vermutlich 
nicht $\mathrm{zu}$, da sie sich in ihren katalytischen Eigenschaften von den DNA-Helikasen unterscheiden. Zunächst handelt es sich bei den DEAD-Box Proteinen generell um nichtprozessive Helikasen, d.h. sie können nur kurze RNA-Duplexe entwinden. Als weitere Besonderheit wurde bei ihnen beobachtet, dass sie die RNA-Duplexe in beide Richtungen entwinden können, während DNA-Helikasen immer auf eine Richtung festgelegt sind. Diese Eigenschaften entsprechen der Vorstellung, dass es sich bei den Substraten der DEAD-Box Proteine in der Regel um kurze RNA-RNA-Helices oder RNA-Protein-Kontaktstellen handelt (Übersicht in Cordin et al. 2005).

Die dreidimensionale Struktur von Vasa in Komplex mit einem ATP-Analogon und einem kurzen einzelsträngigen RNA-Molekül gab Einblick, wie DEAD-Box Proteine arbeiten könnten. In der Struktur ist sichtbar, dass die $\alpha$-Helix, auf der sich das Motiv Ib befindet, in der RNA eine starke Biegung hervorruft. Diese Biegung führt bei zwei Nukleotiden sogar zur Aufhebung der Basenstapelung zwischen ihnen und ist unvereinbar mit der Bindung einer intakten doppelsträngigen RNA. Die Position dieser $\alpha$-Helix findet sich auch in anderen DEAD-Box Proteinen wieder, nicht aber beispielsweise in NS3 (Hepatitis C Virus). Das Modell für die katalytische Aktivität der DEAD-Box Proteine sieht damit folgendermaßen aus: Die Helikasedomäne bindet ATP und einen RNA-Strang kooperativ. Dadurch wird die RNA gebogen und eine Interaktion mit einem anderen RNA-Strang oder einem assoziierten Protein wird destabilisiert. Die Hydrolyse des ATP verringert dann die Affinität für die RNA und das DEAD-Box Protein löst sich ab. Der letzte Schritt des Modells basiert auf der Beobachtung, dass DEAD-Box Proteine in Gegenwart von ATP gewöhnlich stärker an RNA binden als in Gegenwart von ADP (Sengoku et al. 2006).

In vitro zeigen DEAD-Box Proteine nur selten eine Helikase-Aktivität und auch die ATPase Aktivität ist häufig nur schwach. Es wird darum angenommen, dass sie im Allgemeinen durch das Binden an Cofaktoren aktiviert werden. Assoziierte Proteine könnten beispielsweise die aktive Orientierung der Helikase-Subdomänen zueinander stabilisieren, wie es für eIF4A und seinen Cofaktor eIF4G angenommen wird (Oberer et al. 2005). Neben der Aktivierung der katalytischen Aktivität können assoziierte Proteine außerdem die Substratspezifität der DEAD-Box Proteine vermitteln (Übersicht in Silverman et al. 2003).

\subsection{Das Spleißosom}

Die primären Transkripte der meisten eukaryotischen Gene (prä-mRNA) setzen sich aus kodierenden Sequenzabschnitten, den Exons, und dazwischenliegenden nichtkodierenden Abschnitten, den Introns, zusammen. Vor Beginn der Translation müssen die Introns herausgeschnitten und die Exons zur eigentlichen mRNA zusammengefügt werden. Dieser Vorgang, das Spleißen, wird im Zellkern von einem großen RNA-Proteinkomplex durchgeführt, dem Spleißosom.

Die weitaus meisten Introns des Menschen werden von dem U2-Typ Spleißosom entfernt. Darüber hinaus wurde ein U12-Typ Spleißosom beschrieben, das für eine kleine Gruppe spezieller Introns zuständig ist (Übersicht in Tycowski et al. 2006).

Das U2-Typ Spleißosom wird aus fünf snRNPs (ㅌmall $\underline{\text { nuclear }}$ ribonucleoprotein particles, englisch für kleine nukleare Ribonukleoproteinpartikel), dem U1, U2, U4, U5 und U6 snRNP, 
und einer Vielzahl an Spleißfaktoren aufgebaut. Jedes snRNP enthält eine kleine Uridinreiche RNA (100-200 Nukleotide) und sieben Sm-Proteine (B/B', D1, D2, D3, E, F und G), die vermutlich einen heptameren Ring bilden (Kambach et al. 1999). Ausnahme ist das U6 snRNP, in dem die U6 snRNA in ähnlicher Weise sieben Lsm-Proteine bindet (Lsm 2-8). Zusätzlich enthält jedes snRNP mehrere spezifische Proteine (Übersicht in Will und Lührmann, 2006).

\subsubsection{Der Spleißzyklus}

Eine wichtige Aufgabe des Spleißosoms ist es, ein Intron korrekt zu erkennen. Gekennzeichnet ist ein Intron neben konservierten Nukleotidsequenzen am Anfang (5'Spleißstelle) und Ende (3'-Spleißstelle) durch eine sogenannte Verzweigungsstelle, die ein konserviertes Adenosin enthält und etwa 20-40 Nukleotide 5' von der 3'-Spleißstelle liegt. Bei U2-Typ Introns befindet sich außerdem gewöhnlich eine Polypyrimidin Sequenz vor der 3'-Spleißstelle (Abb. 1.2).

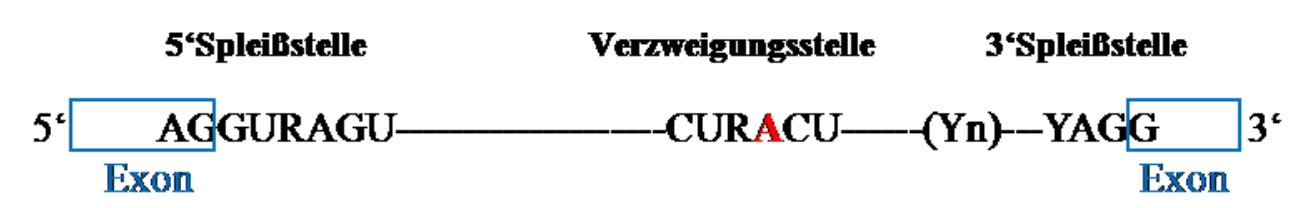

Abb. 1.2: Konsensussequenz des U2-Typ Introns in Säugetieren. $\mathrm{Y}=$ Pyrimidin, $\mathrm{R}=\mathrm{Purin}$. Das zentrale Adenosin der Verzweigungsstelle ist rot markiert.

Das Erkennen der Spleißstellen und die anschließende Entfernung des Introns sind von großen Konformationsänderungen des Spleißosoms begleitet. Entsprechend konnten unterschiedliche Spleißosom-Komplexe isoliert werden. Allgemein wird davon ausgegangen, dass sich das Spleißosom auf der prä-mRNA zunächst schrittweise aus seinen Einzelkomponenten aufbaut und nach der Katalyse wieder zerfällt (Abb. 1.3 A). Dieser Spleißzyklus beginnt damit, dass sich das U1 snRNP an die 5'-Spleißstelle anlagert (EKomplex). Dabei geht die U1 snRNA Basenpaarungen mit der prä-mRNA ein. Es folgt die stabile Bindung des U2 snRNP an die Verzweigungsstelle, die Basenpaarungen zur U2 snRNA ausbildet (Komplex A). Dabei ist das zentrale Adenosin allerdings nicht beteiligt und ragt aus der gebildeten Doppelhelix hervor. Anschließend werden die übrigen snRNPs in Form eines U4/U5/U6 tri-snRNP integriert (Komplex B). Im Folgenden wird durch eine komplexe Konformationsänderung das aktive Zentrum des Spleißosoms gebildet (Komplex $\left.B^{*}\right)$. Dabei werden die Basenpaarungen zwischen der U6 und der U4 snRNA sowie der U1 snRNA und der 5'-Spleißstelle aufgelöst. Die 5'-Spleißstelle geht stattdessen eine Interaktion mit der U6 snRNA ein. Zusätzlich bildet die U6 snRNA Basenpaarungen zur U2 snRNA aus. Das U1 und U4 snRNP verlassen das Spleißsom (Übersicht in Tycowski et al. 2006). 


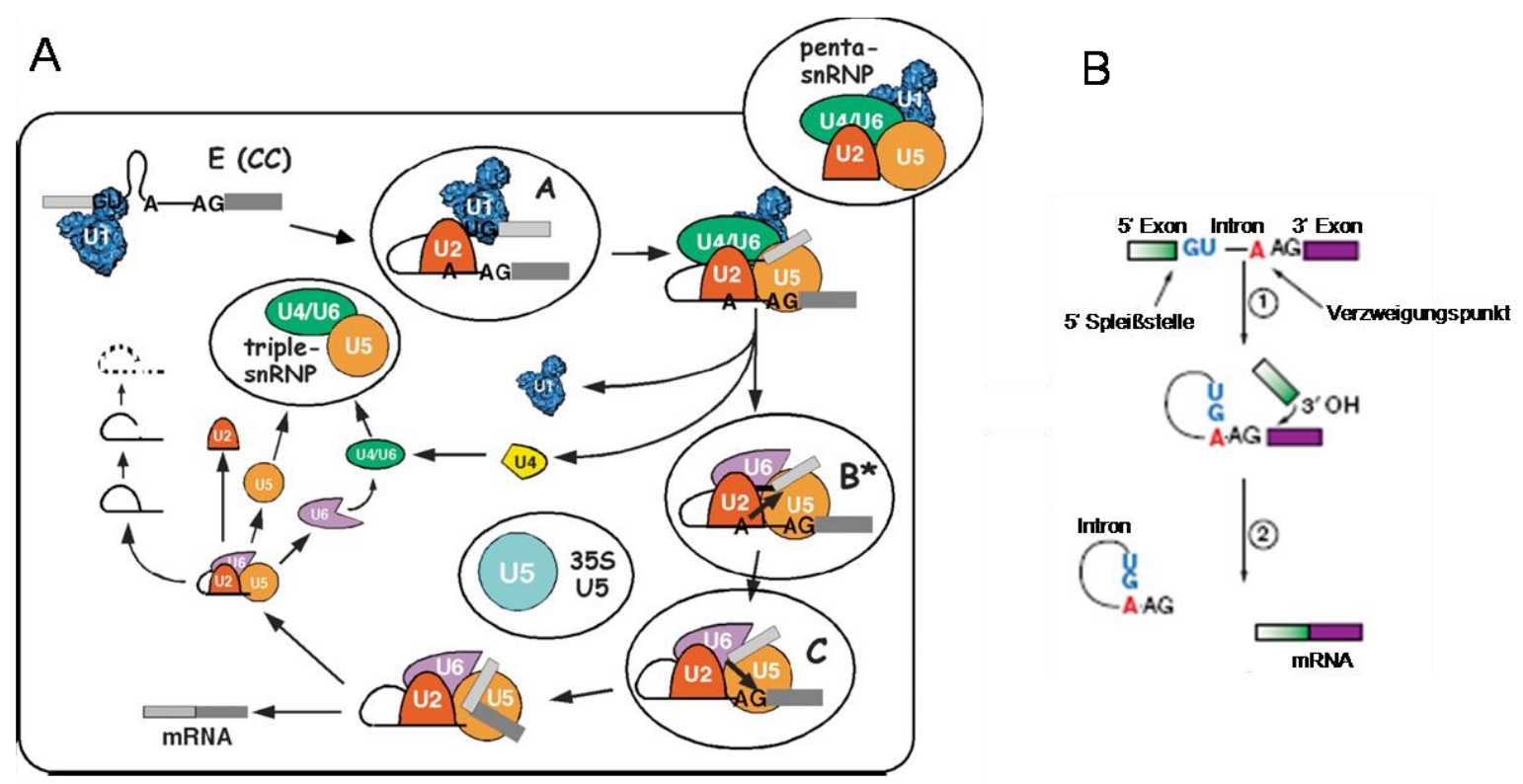

Abb. 1.3: Der Spleißzyklus und die Spleißreaktion. (A) Übersicht über den Spleißzyklus. In klassischer Sichtweise baut sich das Spleißsom schrittweise auf der prä-mRNA auf und zerfällt nach der Spleißreaktion wieder. Alternativ ist ein vollständig assembliertes penta-snRNP gezeigt (Jurica und Moore 2003). (B) Spleißreaktion. Die Spleißreaktion besteht aus zwei Transester-Reaktionen. Das Intron verlässt das Spleißosom in Form einer Lasso-Struktur (Newman 1998).

Die eigentliche Spleißreaktion besteht aus zwei aufeinanderfolgenden Transester-Reaktionen (Abb. 1.3 B). Diese werden vermutlich im Wesentlichen von den RNA-Komponenten des Spleißosoms katalysiert (Valadkhan und Manley 2001). Im ersten Schritt greift das zentrale Adenosin der Verzweigungsstelle als Nukleophil die 5'-Spleißstelle an. Die 3'-5'Phosphodiesterbindung zwischen Exon und Intron wird dabei gespalten und durch eine $2^{6}-5^{6}-$ Phosphodiesterbindung zwischen dem Adenosin und dem Intron ersetzt. Nach dieser Reaktion erfolgen erneut Konformationsänderungen im Spleißosom, es bildet sich der Komplex C. In diesem findet die zweite Transester-Reaktion statt, bei der das freie 5'-Exon die 3'Spleißstelle angreift. Dabei werden die beiden Exons miteinander verknüpft und das Intron in Form einer Lasso-Struktur (englisch: lariat) entfernt. Nach dieser Reaktion wird die mRNA entlassen und das Spleißosom zerfällt in seine Einzelkomponenten, die für einen erneuten Spleißzyklus vorbereitet werden (Übersicht in Will und Lührmann, 2006).

Die Beschreibung des Speißvorgangs als schrittweisen Auf- und Abbau des Spleißosoms auf der prä-mRNA beruht auf der Isolierung der entsprechenden unterschiedlichen Komplexe in Abhängigkeit vom Stadium der Spleißreaktion. Unter Niedrigsalz-Bedingungen und in Abwesenheit von prä-mRNA wurde aus Hefezellen jedoch ein makromolekularer Komplex isoliert, der alle fünf snRNPs enthält (penta-snRNP) (Stevens et al. 2002). Ein analoger Komplex wurde auch in HeLa-Zellen gefunden (Malca et al. 2003). Möglicherweise existiert das Spleißosom daher in der Zelle als ein großer einzelner Komplex. Die unterschiedlichen Stadien im Spleißzyklus reflektierten dann lediglich die darin stattfindenden Konformationsänderungen und damit verbundene wechselnde Interaktionen zwischen prämRNA und snRNPs. 


\subsubsection{DExD/H-box Proteine im Spleißzyklus}

Mit Ausnahme der Anlagerung des U1 snRNPs sind alle Schritte des Spleißzyklus ATPabhängig. Jeder dieser Schritte benötigt außerdem ein oder mehrere Proteine der DExD/HBox Familie (Abb. 1.4). Es wird darum angenommen, dass die DExD/H-Box Proteine das ATP verbrauchen, um RNA-RNA- und RNA-Protein-Interaktionen aufzulösen und dadurch Konformationsänderungen im Spleißosom zu katalysieren (Übersicht in Staley und Guthrie 1998).

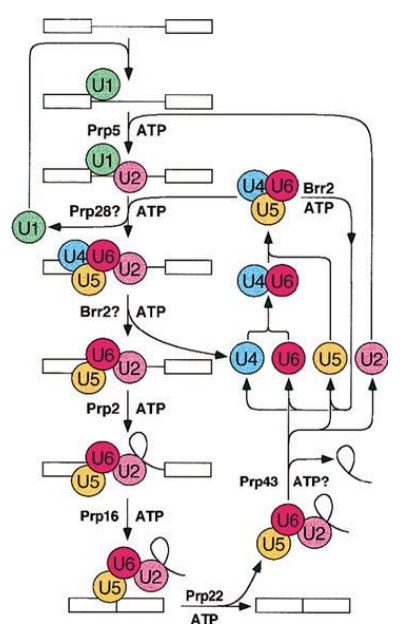

Abb. 1.4: DExD/H-Box Proteine und ATP-verbrauchende Schritte im Spleißzyklus von S. cerevisiae. (Staley und Guthrie 1998)

In der Hefe Saccharomyces cerevisiae sind acht essentielle DExD/H-Box Proteine bekannt, die eine Funktion im Spleißzyklus haben: Prp5, Sub2, Prp28, Brr2, Prp2, Prp16, Prp22 und Prp43. Prp5 und Sub2 sind für die Anlagerung des U2 snRNPs an die Verzweigungsstelle notwendig. Es wird dabei vermutet, dass Sub2 die Verzweigungsstelle der prä-mRNA zugänglich macht, indem es daran gebundene Proteine entfernt. Prp5 dagegen wirkt auf die Konformation der U2 snRNA ein. In die Anlagerung des U4/U6.U5 tri-snRNPs und die damit verbundenen Umlagerungen zum aktiven Spleißosom sind Prp28 und Brr2 involviert. Möglicherweise entwindet dabei Brr2 das U4/U6 snRNA Duplex, während Prp28 den Austausch der U1 gegen die U6 snRNA an der 5'-Spleißstelle bewirkt. Prp2 löst die erste Transester-Reaktion aus. Prp16 ist für die zweite Transester-Reaktion essentiell. Im Anschluss bewirkt Prp22 das Ablösen der mRNA. Prp43 hat eine Funktion in dem abschließenden Zerfall des Spleißosoms (Abb. 1.4, Übersicht in Staley und Guthrie 1998).

$\mathrm{Zu}$ den acht spleißosomalen DExD/H-Box Proteinen der Hefe wurden orthologe Proteine im Menschen gefunden. Neben den beiden Subdomänen der Helikaseeinheit lassen sich bei diesen Proteinen unterschiedliche zusätzliche Domänen identifizieren (Abb. 1.5). Ihre Funktion ist allerdings weitestgehend unklar. Am humanen Spleißvorgang sind möglicherweise noch mehr DExD/H-Box Proteine beteiligt, da in spleißosomalen Komplexen mindestens sieben weitere dieser Proteine gefunden wurden (Übersicht in Jurica und Moore 2003) 


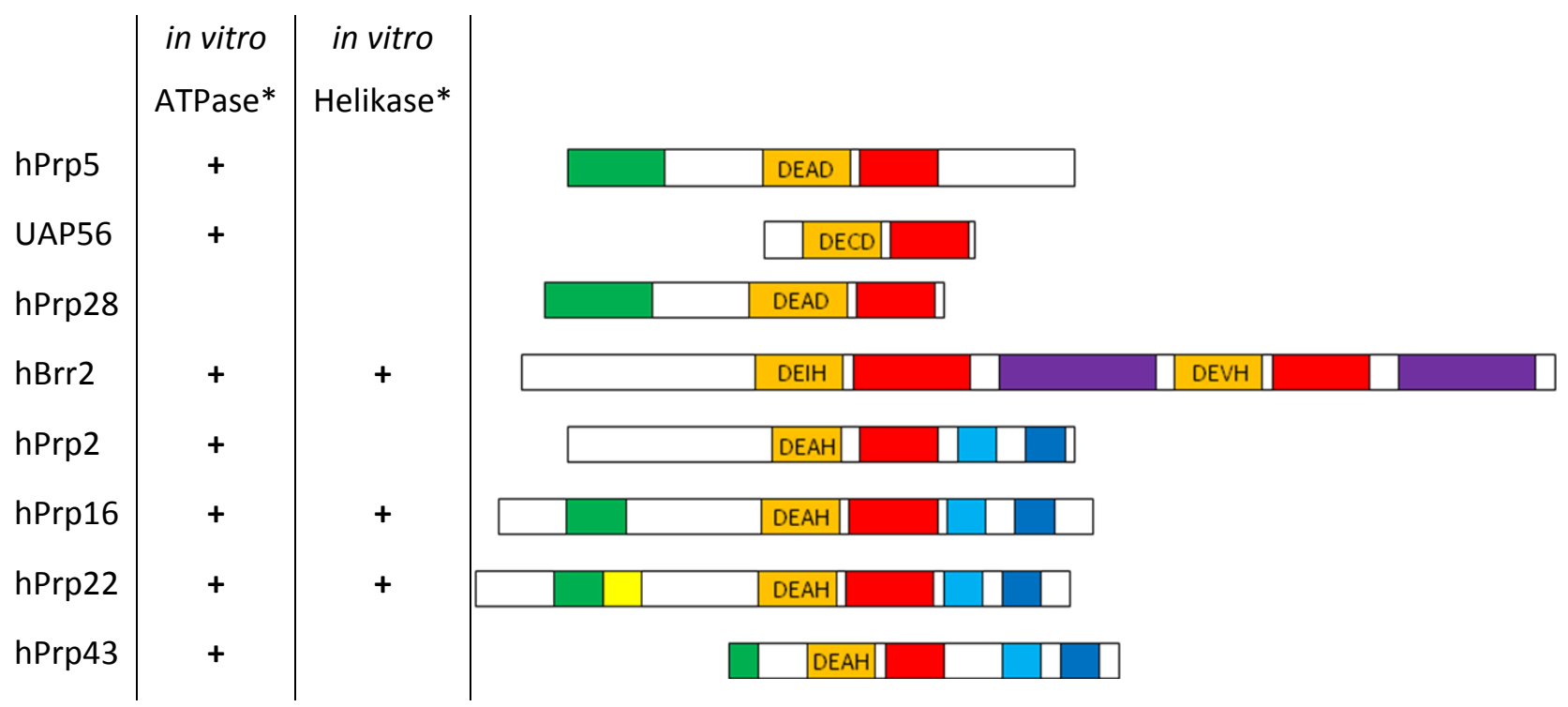

Abb. 1.5: Humane spleißosomale DExD/H-Box Proteine in der Reihenfolge ihrer Funktion im Spleißzyklus. UAP56 ist das Ortholog zu Sub2. Folgende Domänen lassen sich auf der Grundlage der Aminosäuresequenz identifizieren: Grün: RS-ähnliche Domäne; Orange bzw. Rot: N- bzw. C-terminale Domäne der DExD/HBox Proteinfamilie; Violett: SEC63-Domäne; Hellblau: HA2-Domäne; Dunkelblau: DUF1605-Domäne; Gelb: S1-ähnliche RNA-Bindedomäne. * Für mindestens ein Ortholog dieses Proteins nachgewiesene in vitro Aktivität (Wang und Guthrie 1998, Martin et al. 2002, Shi et al. 2004).

\subsubsection{SR Proteine und die RS-Domäne}

SR ( Serin/Arginin-reiche)-Proteine sind essentielle Spleißfaktoren, die in allen Metazoen vorkommen, allerdings in Saccharomyces cerevisiae fehlen (Übersicht in Graveley 2000, Hertel und Graveley 2005). Die am besten untersuchten humanen Vertreter sind ASF/SF2 und SC35. SR-Proteine zeichnen sich dadurch aus, dass sie N-terminal eine oder zwei RNAbindende Domänen (RRM-Domänen) und C-terminal eine RS (Arginin/Serin reiche)-Domäne enthalten. Die RRM-Domäne dient vermutlich dazu, an bestimmte Erkennungssequenzen in der prä-mRNA zu binden. Die RS-Domäne bewirkt dann eine Aktivierung des Spleißvorgangs. RS-Domänen zeichnen sich durch das Auftreten von (RS)-DipeptidWiederholungen in der Aminosäuresequenz aus und variieren stark in ihrer Länge (30-320 Aminosäuren).

SR-Proteine haben essentielle Funktionen für jeden Spleißvorgang. Sie können sowohl die Bindung des U1 snRNP als auch diejenige des U2 snRNP unterstützen und sind notwendig für die Assoziation des U4/U6.U5 tri-snRNP mit dem Spleißosom (Abb. 1.6, Tarn und Steitz 1995, Roscigno und Garcia-Blanco 1995). Außerdem haben SR-Proteine eine Funktion als Regulatoren des alternativen Spleißens: Durch das Binden der RRM-Domäne an bestimmte Erkennungssequenzen im Exon (englisch: exonic splicing enhancer-Sequenzen) können SRProteine das Erkennen einer benachbarten alternativen 5'- oder 3'-Spleißstelle bewirken (Übersicht in Blencowe 2000). Solche alternativen Spleißstellen zeichnen sich oft durch suboptimale Erkennungssequenzen aus und werden darum ohne SR-Protein nur unzureichend vom Spleißosom gebunden. Bei der Regulation des alternativen Spleißens haben die SR Proteine auch Antagonisten: hnRNP A/B Proteine binden ebenfalls an bestimmte 
Erkennungssequenzen (exonic splicing silencer-Sequenzen) und wirken der Spleißaktivierung entgegen. Möglicherweise entscheidet also das relative Verhältnis von speziellen SR- zu hnRNP A/B-Proteinen in einer Zelle, ob eine bestimmte alternative Spleißstelle erkannt wird (Übersicht in Graveley 2000, Hertel und Graveley 2005, Sanford und Caceres 2005).

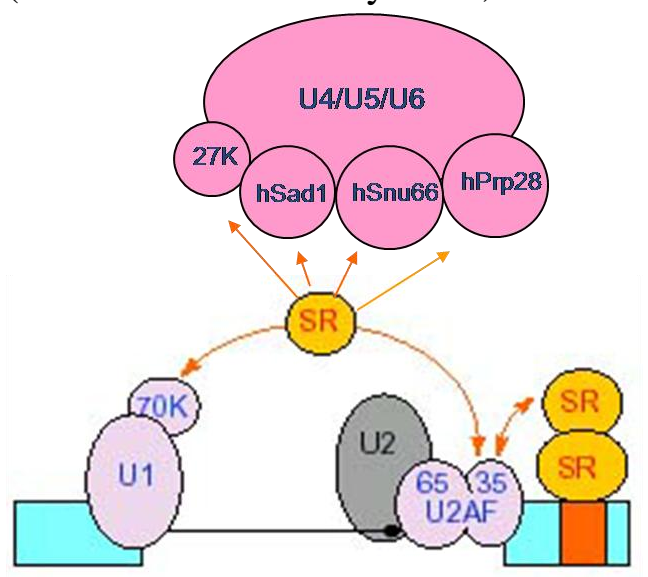

\begin{abstract}
Abb. 1.6: Rekrutierung der U1, U2 und trisnRNPs durch SR Proteine (gelb). Spleißomale Proteine mit RS-Domänen sind mögliche Interaktionspartner und besonders hervorgehoben (nach Blencowe 2000).
\end{abstract}

RS-Domänen kommen nicht nur in SR-Proteinen, sondern auch in den sogenannten SRähnlichen Proteinen vor. Diese Proteine haben zwar alle eine RS-Domäne, unterscheiden sich aber im Hinblick auf das Vorkommen anderer Domänen stark (Abb. 1.7). Darum kann man nicht von einer Proteinfamilie im eigentlichen Sinne sprechen. Viele SR-ähnliche Proteine sind ebenfalls am Spleißprozess beteiligt, es gibt sie aber auch in anderen zellulären Vorgängen (Boucher et al. 2001). Spleißosomale SR-ähnliche Proteine kommen sowohl im U1 snRNP (U1-70K) als auch im U4/U6-U5 tri-snRNP vor (hPrp28, hSnu66, hSad1 und 27K). Außerdem befindet sich in beiden Untereinheiten des U2AF je eine RS-Domäne. Dieser Spleißfaktor ist für die Assoziation des U2 snRNP mit der prä-mRNA wichtig. Weiterhin enthalten neben hPrp28 noch weitere spleißosomale DExD/H-box Proteine RSDomänen.
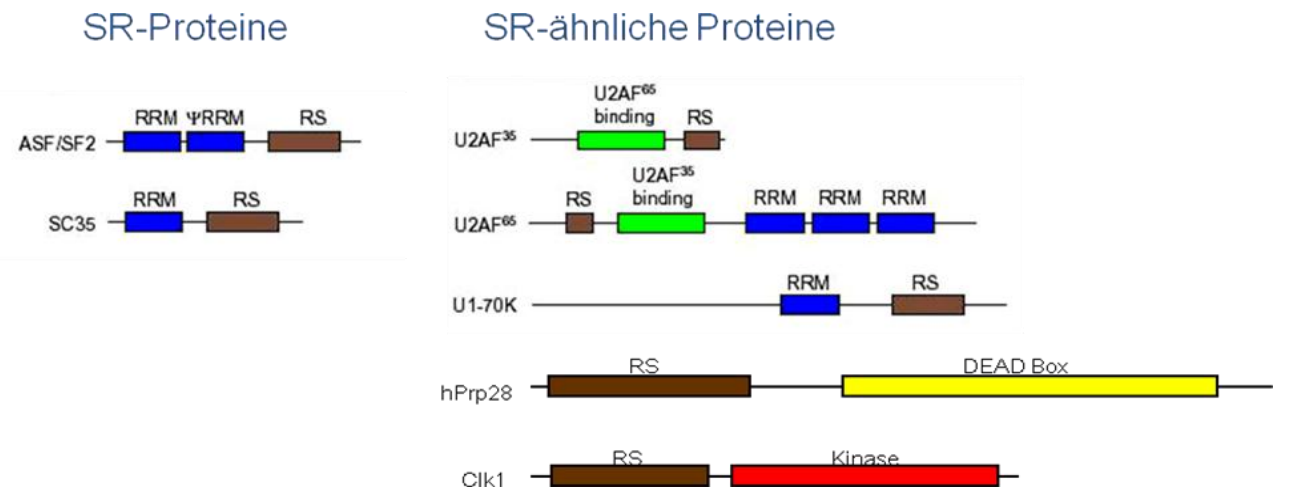

Abb. 1.7: Domänenzusammensetzung einiger humaner SR-Proteine und SR-ähnlicher Proteine. Allen gemeinsam ist die RS-Domäne (braun).

In vitro Experimente haben gezeigt, dass RS-Domänen das Spleißen eines Introns fördern, wenn sie künstlich in dessen Nähe gebracht werden (Graveley und Maniatis 1998, Philipps et al. 2003). Unklar ist aber, wie genau RS-Domänen diese Aktivierung bewirken. Zum einen zeigen in vitro durchgeführte Bindungsstudien, dass RS-Domänen mit anderen RS-Domänen interagieren können. Darum könnten SR-Proteine dadurch wirken, dass sie mit RS-Domänen von Proteinen des Spleißapparates interagieren und dadurch deren Bindung an die prä-mRNA 
stärken. Das U1 snRNP könnte somit über U1-70K und das U2 snRNP über U2AF rekrutiert werden. Das tri-snRNP enthält vier Proteine mit RS-Domäne als mögliche Interaktionspartner (hPrp28, hSnu66, hSad1 und 27K). Übereinstimmend wurde für hSnu66 und hSad1 gezeigt, dass sie essentiell für die Komplex B Bildung sind, also für die Anlagerung des tri-snRNP an das Spleißosom (Makarova et al 2001). Neue Untersuchungen führten allerdings zu einer alternativen Hypothese über die Wirkungsweise von RS-Domänen. Anhand von crosslinkingExperimenten wurde nämlich gezeigt, dass RS-Domänen verschiedener Proteine mit RNA interagieren. Diese Interaktionen hängen vom Stadium im Spleißzyklus ab: Während im EKomplex ein crosslink zwischen der RS-Domäne von U2AF ${ }^{65}$ und der Verzweigungsstelle beobachtet wurde, interagiert im A-Komplex ein SR-Protein mit der Verzweigungsstelle. Im Komplex B wurde ein crosslink zwischen einem (anderen) SR-Protein und der 5'-Spleißstelle detektiert. Die beiden letztgenannten prä-mRNA-Bereiche sind in den entsprechenden Stadien mit einer anderen snRNA gepaart. Darum könnten RS-Domänen auch dadurch die Bindung des Spleißosoms fördern, dass sie sequenzunspezifisch an doppelsträngige RNA binden und die Basenpaarungen zwischen prä-mRNA und U snRNA stabilisieren (Shen und Green 2004, Shen et al. 2004, Shen und Green 2006).

Eine wichtige Eigenschaft der RS-Domänen ist, dass sie in vivo stark phosphoryliert werden. Die Phosphorylierung betrifft dabei insbesondere die Serinreste der (RS)-DipeptidWiederholungen und reguliert sowohl die subzelluläre Lokalisation der SR-Proteine als auch ihre Aktivität beim Spleißen (Übersicht in Graveley 2000). Bei in vitro Bindungsstudien bewirkte die Phosphorylierung eine verstärkte Interaktion zwischen den RS-Domänen von ASF/SF2 und U1-70K (Xiao und Manley 1996). Außerdem ist eine Phosphorylierung offenbar auch für die postulierte Interaktion mit doppelsträngiger RNA notwendig (Shen und Green 2006). Es wurden mehrere Klassen von Kinasen identifiziert, die RS-Domänen phosphorylieren können. Dazu gehören die SRPK-Familie (SRPK1-3) und die Clk-Familie (Clk1-4) sowie DNA Topoisomerase I und hPrp4-Kinase (Colwill et al. 1996, Ngo et al. 2006, Rossi et al. 1996, Kojima et al. 2001).

\subsubsection{Das humane U4/U6/U5 tri-snRNP}

Vor ihrer Assoziation mit dem Komplex A bilden das U4, U6 und U5 snRNP einen stabilen 25 S Komplex, das U4/U6.U5 tri-snRNP. Dieses setzt sich wiederum aus dem U4/U6 und dem U5 snRNP zusammen.

Tabelle 1.3: Übersicht über die snRNP-spezifischen Proteine im humanen U4/U6.U5 tri-snRNP. Ursprünglich wurden die Proteine nach ihrem Molekulargewicht in kDa benannt (in Klammern).

U4/U6 snRNP-spezifisch
hPrp3 (90K)
hPrp31 (61K)
hPrp4 (60K)
CypH $(20 \mathrm{~K})$
hSnu13 $(15,5 \mathrm{~K})$

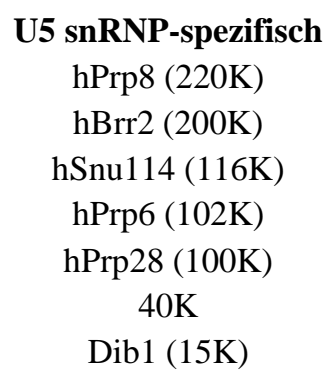

\author{
tri-snRNP-spezifisch \\ hSnu66 (110K) \\ hSad1 (65K) \\ $27 \mathrm{~K}$
}


Im U4/U6 snRNP gehen die U4 und U6 snRNA Basenpaarungen miteinander ein. Sie bilden dabei zwei kurze Doppelstränge (Helix I und II). Zwischen diesen beiden Bereichen faltet sich die U4 snRNA in eine Haarnadelstruktur (5'stem-loop). Die U4/U6 snRNA assoziiert neben den Sm- und Lsm-Proteinen mit fünf U4/U6 snRNP-spezifischen Proteinen: hPrp3 (alternativer Name: 90K), hPrp31 (61K), hPrp4 (60K), CypH (20K) und hSnu13 (15,5K). Dabei bildet hPpr3 zusammen mit hPrp4 und CypH einen stabilen Komplex und bindet diesen durch Interaktionen mit der Helix II an die U4/U6 snRNA. hSnu13 und hPrp31 assoziieren mit der U4 snRNA im Bereich des 5 'stem-loop (Nottrott et al. 2002, Liu et al. 2007).

Der U5 snRNP-Anteil des tri-snRNP enthält neben einem Sm-Heptamer sieben U5 snRNPspezifische Proteine: hPrp8 (220K), hPrp6 (102K), 40K, Dib1 (15K) und die drei NTPasen hBrr2 (200K), hSnu114 (116K) und hPrp28 (100K). Die U5 snRNA bildet eine lange 5'- und eine kurze 3'-Haarnadelstruktur aus (5' stem-loop bzw. 3 'stem-loop). In crosslinking-Studien wurde gezeigt, dass der 5 'stem-loop in räumlicher Nähe zu hPrp8 liegt (Urlaub et al. 2000).

hPrp6 interagiert mit hPrp31 und hPrp3 und verknüpft dadurch das U5 snRNP mit dem U4/U6 snRNP (Makarova et al. 2002, Liu et al. 2006).

Das U5 snRNP enthält drei NTPasen. Die DExH/D-Box Helikase hPrp28 wird in Abschnitt (1.3) ausführlich beschrieben. Die DExD/H-Box Helikase hBrr2 zeigt in vitro eine RNAabhängige ATPase-Aktivität und entwindet doppelsträngige RNA-Moleküle (Laggerbauer et al. 1998). Ein mögliches Substrat ist dabei das U4/U6 snRNA-Duplex, denn Mutationsstudien in der Hefe haben gezeigt, dass Brr2 für die Entwindung der U4/U6 snRNA im Spleißosom essentiell ist (Raghunathan und Guthrie 1998). hBrr2 enthält zwei mögliche Helikasedomänen. Mutationsuntersuchungen in Hefe haben gezeigt, dass nur die N-terminale Domäne ATPase- und Helikase-Aktivität besitzt (Kim und Rossi 1999). Die C-terminale Domäne dagegen wurde vermutlich zu einer Protein-Interaktionsdomäne umfunktioniert (van Nues und Beggs 2001). Die GTPase hSnu114 weist in der Aminosäuresequenz eine hohe Ähnlichkeit zum Elongationsfaktor G (EF-G) auf, einem wichtigen Regulator in der Translation. Mutationsstudien in Hefe zeigten, dass Snu114 für die Entwindung der U4/U6 snRNA wichtig ist (Bartels et al. 2002). Weiterhin waren Mutationen von Snu114 zusammen mit Mutationen von Prp28 oder Brr2 letal (Brenner und Guthrie 2005). Es wird daher vermutet, dass hSnu114 als zentraler Schalthebel im Spleißosom wirkt, der nach GTPBindung oder -Hydrolyse die beiden Helikasen Prp28 und Brr2 aktiviert (Bartels et al. 2003, Small et al. 2006).

hPrp8 ist mit einem Molekulargewicht von $220 \mathrm{kDa}$ das größte und am stärksten konservierte Protein des Spleißosoms. Seine Aminosäuresequenz zeigt jedoch kaum bekannte Motive. Charakterisiert ist lediglich eine C-terminale JAB1/MPN-Domäne, die aber vermutlich zu einer Protein-Interaktionsdomäne umfunktioniert wurde (Pena et al. 2007). Sie interagiert sowohl intramolekular mit dem N-Terminus von hPrp8 als auch intermolekular mit hBrr2 und hSnu114 (Liu et al. 2006). Weiterhin bindet hPrp8 die Proteine hPrp6 und 40K. Diese fünf U5 snRNP spezifischen Proteine bilden auch ohne snRNA einen stabilen Komplex. Insbesondere die Interaktion zwischen hPrp8 und hSnu114 ist äußerst stabil (Achsel et al. 1998). Darüber hinaus zeigten crosslinking-Experimente, dass hPrp8 im tri-snRNP die U5 und U6 snRNA kontaktiert (Urlaub et al. 2000, Vidal et al. 1999) und im Spleißosom dann auch die 5'-Spleißstelle, die Verzweigungsstelle und - nach der ersten Transester-Reaktion - 
die 3'-Spleißstelle der prä-mRNA. Diese Vielzahl an Interaktionen lassen vermuten, dass hPrp8 ein zentraler Regulator des Spleißosoms ist, der sowohl die NTPasen des U5 snRNP als auch die Spleißreaktionen selbst koordiniert (Übersicht in Grainger und Beggs 2005).

Schließlich enthält der $25 \mathrm{~S}$ Komplex noch drei U4/U6.U5 tri-snRNP-spezifische Proteine: hSnu66 (110K), hSad1 (65K) und 27K (Fetzer et al. 1997, Makarova et al. 2001). Alle drei Proteine enthalten eine RS-Domäne (s.u.). hSnu66 und hSad1 sind für die Anlagerung des trisnRNPs an den Komplex A notwendig (Makarova et al. 2001).

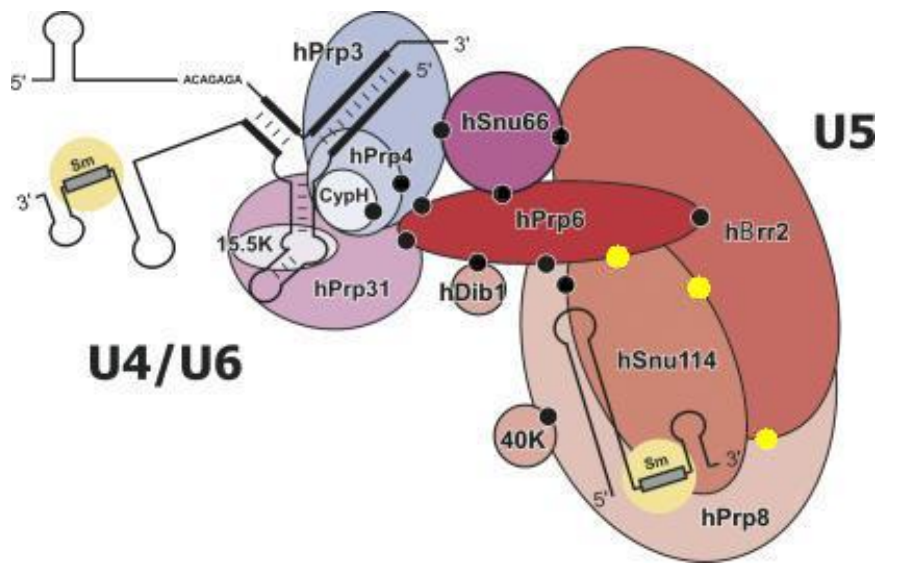

Abb. 1.8: Schematische Darstellung der Protein-Protein-Interaktionen im humanen U4/U6.U5 tri-snRNP. Gelb markierte Interaktionen wurden nur im yeast-two-hybrid System gefunden. Schwarz markierte Interaktionen wurden dagegen durch in vitro Methoden bestätigt. In der Darstellung fehlen hPrp28, hSad1 und 27K, da für diese Proteine keine Interaktionen bekannt sind (nach Liu et al. 2006).

Mit Ausnahme von $\mathrm{CypH}, 40 \mathrm{~K}$ und $27 \mathrm{~K}$ existieren für die beschriebenen Proteine des humanen tri-snRNP Orthologe in der Hefe Saccharomyces cerevisiae.

Informationen über die molekulare Struktur des U4/U6.U5 tri-snRNP beschränken sich bisher auf Kristallstrukturen von zwei humanen Sm-Proteinen (Kambach et al. 1999), hSnu13 im Komplex mit einem U4 snRNA Fragment (Vidovic et al. 2000) sowie im Komplex mit der Nop Domäne von hPrp31 (Liu et al. 2007), CypH im Komplex mit einem Fragment von hPrp4 (Reidt et al. 2000 und 2003), 15K (Reuter et al. 1999, Nielsen et al. 2007) und der JAB1/MPN-Domäne von Prp8 aus Saccharomyces cerevisiae (Pena et al. 2007). Ein Überblick über die Organisation des tri-snRNP wurde durch Cryo-Elektronenmikroskopie erhalten (Abb. 1.9, Sander et al. 2006).

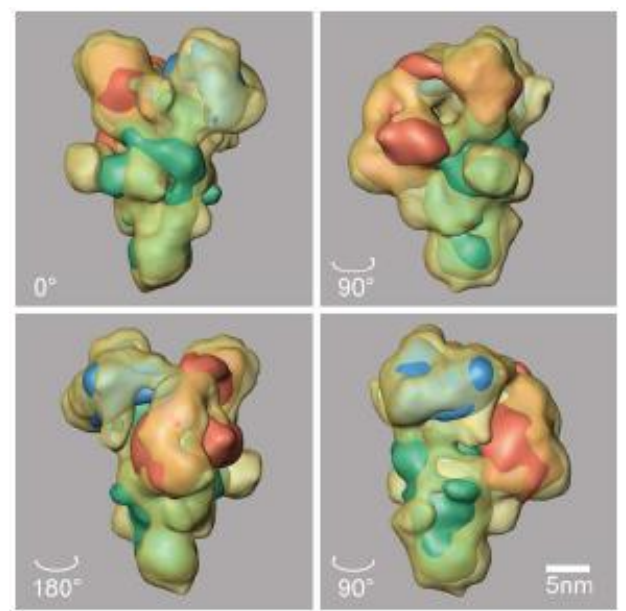

Abb. 1.9: Dreidimensionale Struktur des U4/U6.U5 tri-snRNP berechnet aus cryoelektronenmikroskopischen Aufnahmen. Dargestellt ist das tri-snRNP in vier verschiedenen Orientierungen mit einer Auflösung von ca. $20 \AA$ A. Grün und blau: U5 snRNP. Rot: U4/U6 di-snRNP (Sander et al. 2006). 


\subsubsection{Die Aktivierung des Spleißosoms}

Nach der Anlagerung des U4/U6.U5 tri-snRNP an den Komplex A finden umfangreiche Konformationsänderungen statt, die schließlich zum aktiven Spleißosom (Komplex B*) und zur ersten Transester-Reaktion führen.

Die Analyse der Proteinzusammensetzung unterschiedlicher spleißosomaler Komplexe durch Massenspektrometrie zeigte, dass während der Aktivierung alle U1-snRNP spezifischen Proteine einschließlich der U1 snRNA das Spleißosom verlassen. Dasselbe gilt für alle U4/U6-spezifischen Proteine und die U4 snRNA. Von den tri-snRNP-spezifischen Proteinen ließ sich nur hSnu66 im Komplex B* nachweisen. Weiterhin verlassen möglicherweise auch die U5-spezifischen Proteine hDib1 und hPrp28 das Spleißosom (Makarov et al. 2002). hPrp28 wurde allerdings im Widerspruch dazu in einer Präparation des C-Komplexes detektiert (Jurica et al. 2002). Die übrigen U5-spezifischen Proteine und alle U2-spezifischen Proteine bleiben auch nach der Aktivierung Bestandteile des Spleißosoms. Darüber hinaus unterscheiden sich Komplex $\mathrm{B}$ und $\mathrm{B}^{*}$ in der Assoziation mit einer Vielzahl von Spleißfaktoren. Insbesondere wird während der Aktivierung - vermutlich nach der Ablösung der U4 snRNA (Makarova et al. 2004) - der Prp19/CDC5 Komplex fest integriert, der etwa 30 unterschiedliche Proteine enthält (Makarov et al. 2002, Hartmuth et al. 2002, Makarova et al. 2004, Deckert et al. 2006, Behzadnia et al. 2007).
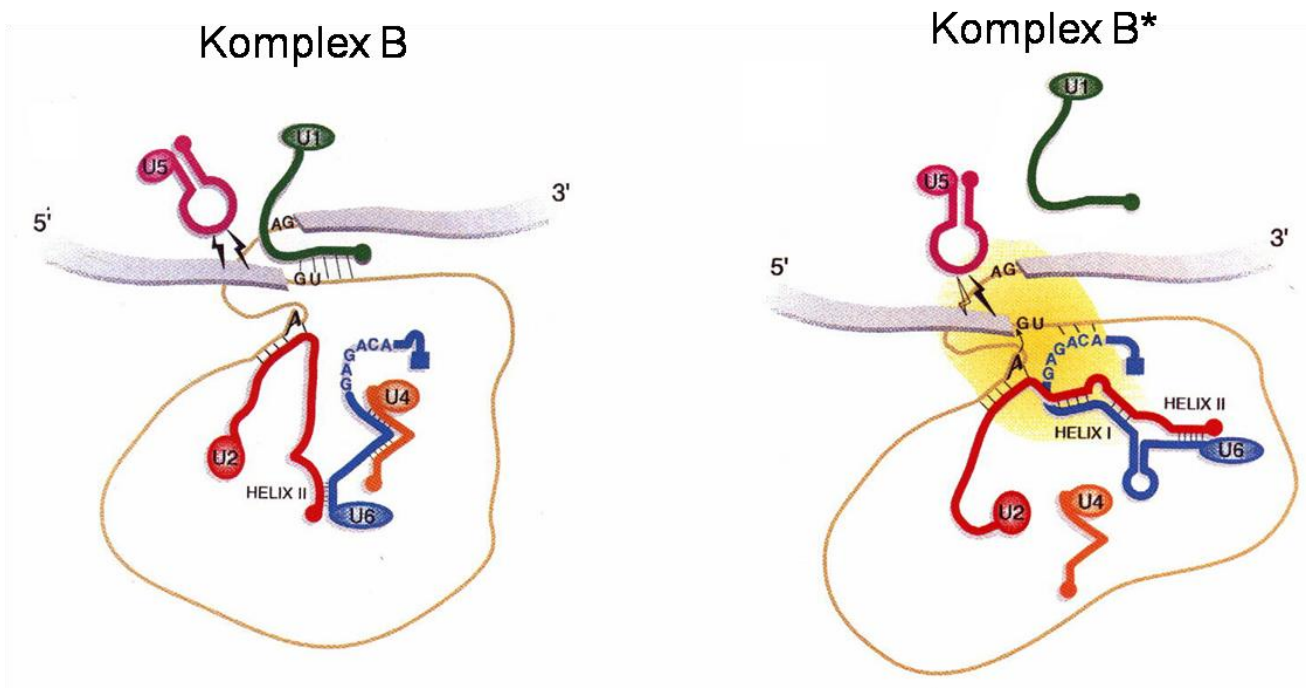

Abb. 1.10: Übersicht über die sich verändernden RNA-RNA-Interaktionen während der Spleißosom Aktivierung. Links vor, rechts nach der Aktivierung. Nähere Erläuterungen im Text (Abbildung von Reinhard Lührmann, Max-Planck-Institut für biophysikalische Chemie, Göttingen).

Diese Veränderungen in der Proteinzusammensetzung während der Aktivierung werden von umfassenden Veränderungen der RNA-RNA Interaktionen begleitet (Abb. 1.10 und 1.11, Übersicht in Staley und Guthrie 1998, Nilsen 1998). Vor der Anlagerung des tri-snRNP gehen die U4 und U6 snRNA über zwei Abschnitte (Helix I und II) Basenpaarungen miteinander ein. Weiterhin paart die prä-mRNA an der 5'-Spleißstelle (Bereich -3 bis +6 relativ zur Exon/Intron Grenze) mit dem 5'-Ende der U1 snRNA und an der Verzweigungsstelle mit der U2 snRNA. Während der Aktivierung wird die U1 snRNA von der prä-mRNA entfernt und die 5'-Spleißstelle (Bereich +5 und +6 ) geht stattdessen eine Interaktion mit der U6 snRNA ein. Außerdem werden U4 und U6 snRNA voneinander getrennt. Die U6 snRNA bildet 
mehrere kurze Helices mit der U2 snRNA aus (Helix Ia, Ib, II und III). Zwischen Helix Ib und II entsteht zudem eine Haarnadelstruktur (U6-ISL, englisch: intramolecular stem loop). Helices Ia und Ib sowie U6-ISL umfassen dabei Regionen der U6 snRNA, die zuvor mit der U4 snRNA gepaart waren. Letztendlich bildet sich auf diese Weise das katalytische Zentrum des Spleißosoms aus, das vermutlich im Wesentlichen aus der U2 und der U6 snRNA besteht (Valadkhan und Manley 2001).

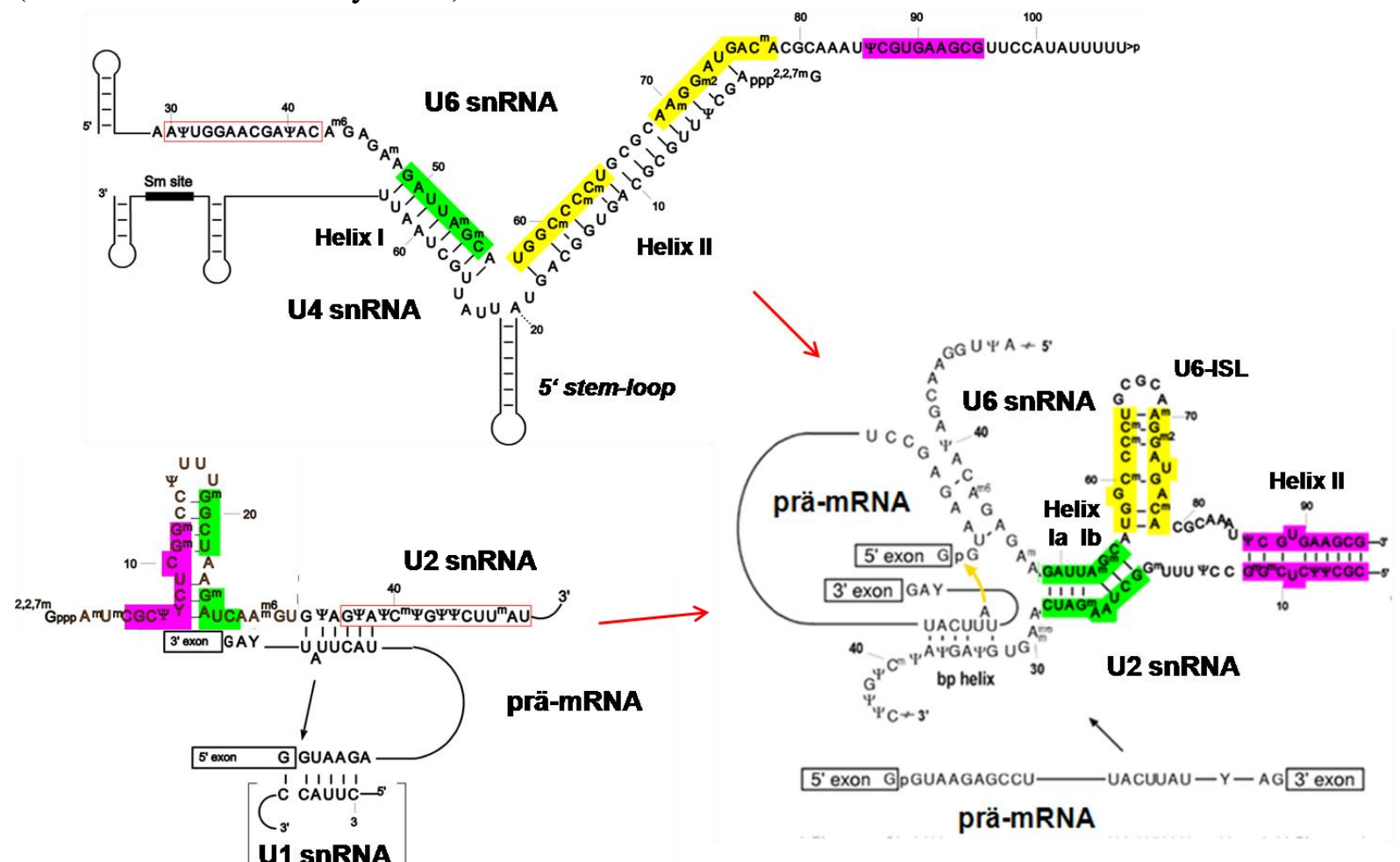

Abb. 1.11: Detailierte Darstellung der sich verändernden RNA-RNA-Interaktionen während der Aktivierung des humanen U2-Typ Spleißosoms. Nicht berücksichtigt ist die U5 snRNA. Vor der Aktivierung sind U4 und U6 snRNA gepaart. Außerdem interagiert die prä-mRNA mit der U1 und U2 snRNA (links). Nach der Aktivierung (rote Pfeile) sind U2 und U6 snRNA gepaart und die U6 snRNA hat die U1 snRNA von der 5'-Spleißstelle der prä-mRNA verdrängt (rechts). (nach Reinhard Lührmann)

Wenngleich auch die RNA-RNA Interaktionen vor und nach der Spleißosom Aktivierung gut charakterisiert sind, so ist die genaue Reihenfolge, in der diese Veränderungen vor sich gehen, noch unklar.

Da die U1 und U6 snRNA mit derselben Region der prä-mRNA interagieren, muss die Entfernung der U1 snRNA ein früher Vorgang sein. Hinweise darauf haben sich aus der Isolation eines humanen spleißosomalen Komplexes ergeben, in dem die U1 snRNA fehlt und die U6 snRNA mit der prä-mRNA interagiert, die U6 und U4 snRNA aber noch gepaart sind (Makarova et al. 2004). Zudem konnten bestimmte prä-mRNA Substrate in HeLa-Zellextrakt gespleißt werden, aus dem die U1 snRNPs entfernt worden waren (Crispino et al. 1996, Konforti und Konarska 1995). Die U6 snRNA kann also auch ohne Hilfe des U1 snRNP die 5'-Spleißstelle binden. In S. cerevisiae wurde außerdem gezeigt, dass die Entfernung der U1 snRNA Voraussetzung für alle weiteren RNA-Umlagerungen während der Aktivierung ist (Staley und Guthrie 1999). Erhöht man nämlich durch Mutationen die Anzahl der Basenpaarungen zwischen der U1 snRNA und der prä-mRNA, so ist die Spleißrate bei tiefen Temperaturen deutlich verringert und es häuft sich in den Zellen ein Komplex an, in dem U4 
und U6 snRNA noch gepaart sind. Dieser Spleißdefekt wird unterdrückt, wenn gleichzeitig die Anzahl der möglichen Basenpaarungen zwischen der U6 snRNA und der 5'-Spleißstelle erhöht wird. Diese Ergebnisse haben gezeigt, dass die Entfernung der U1 snRNA mit der Anlagerung der U6 snRNA gekoppelt ist.

Viele Studien deuten darauf hin, dass die Interaktion der U6 snRNA mit der 5'-Spleißstelle schon vor der Entwindung des U4/U6 snRNA-Duplexes erfolgt. Zum einen ist die hochkonservierte $\mathrm{A}_{41} \mathrm{CAGA}_{45}$ Sequenz der U6 snRNA, die mit der 5'-Spleißstelle interagiert, nicht an der Basenpaarung mit der U4 snRNA beteiligt, sie befindet sich $5^{6}$ von der U4/U6 Helix I. Somit ist eine gleichzeitige Interaktion der U6 snRNA mit der 5'-Spleißstelle und der U4 snRNA im Prinzip möglich. Zum anderen konnte mit speziellen prä-mRNA Substraten gezeigt werden, dass die U6 snRNA auch in Abwesenheit des U2 snRNP an die 5'Spleißstelle binden kann (Konforti und Konarska 1994, Maroney et al. 2000). In diesem Fall sind U4 und U6 snRNA vermutlich noch gepaart. Ein U2/U4/U5/U6-Komplex, der diesem intermediären Zustand entspricht, konnte zudem aus HeLa Zellen isoliert werden (Makarova et al. 2004). Mutationsstudien in S. cerevisiae weisen außerdem darauf hin, dass die Interaktion zwischen der U6 snRNA und der 5'-Spleißstelle sogar notwendig ist, um das U4/U6-Duplex zu entwinden. Erweitert man nämlich die U4/U6 Helix I derart, dass die ACAGA-Sequenz teilweise miteinbezogen und somit maskiert wird, so führt dies zu dem kältesensitiven Phänotyp U4-cs1. In diesen Zellen häufen sich bei tiefen Temperaturen spleißosomale Komplexe an, in denen die U4 und U6 snRNA noch gepaart sind. Zudem enthalten sie auch noch die U1 snRNA. Dies ist ein weiterer Hinweis, dass die U6 snRNAAnlagerung und U1 snRNA-Entfernung gekoppelt sind (Kuhn et al. 1999). Unterdrückt wird der U4-cs1 Phänotyp durch eine Verdopplung der ACAGA-Sequenz (Li und Brow 1996).

Untersuchungen in der Hefe weisen darauf hin, dass die Interaktion der U6 snRNA mit der 5`Spleißstelle möglicherweise in zwei Schritten erfolgt. So wurden bei crosslinkingExperimenten in Hefeextrakt ATP-abhängige Interaktionen zwischen der 5'-Spleißstelle (an Position +2) und sowohl der U6 als auch der U4 snRNA beobachtet. Verknüpft wurde dabei eine ACA-Sequenz in der U6 snRNA, die zwei Nukleotide vor der eigentlichen ACAGASequenz liegt (Johnson und Abelson 2001). Möglicherweise findet also zunächst eine Interaktion der 5'-Spleißstelle mit dieser ACA-Sequenz statt, bevor sie - nach entsprechender Verschiebung der U6 snRNA - an die konservierte ACAGA-Sequenz bindet. Unterstützt wird diese Theorie dadurch, dass Mutationen in der ACA-Sequenz den oben beschriebenen U4-cs1 Phänotyp unterdrücken. Eine mögliche Erklärung für diese Beobachtung ist, dass die U4-cs1 Mutation dazu führt, dass die Spleißosomen im Stadium der frühen U6 snRNA Interaktion an der 5'-Spleißstelle arretieren (Li und Brow 1996).

Auch die Entwindung des U4/U6 snRNA Duplexes könnte in zwei Schritten erfolgen. Hinweise darauf wurden bei crosslinking-Experimenten mit dem U12-Typ Spleißosom gefunden (Frilander und Steitz 2001). Die Maskierung oder Verkürzung des 5'-Exons führte dabei zu einem Zustand, in dem die U6 snRNA einerseits die Helix Ia zur U2 snRNA bereits ausgebildet hatte, aber andererseits gleichzeitig noch über die Helix II mit der U4 snRNA verbunden war. Diese Entwindung der U4/U6 Helix I benötigt offenbar keine vorherige Interaktion der U6 snRNA mit der 5'-Spleißstelle.

Die terminale Schleife der 5'-Haarnadelstruktur der U5 snRNA interagiert im aktiven Spleißosom mit Exonnukleotiden an der 5'-Spleißstelle (insbesondere mit Position -2 und -1). 
Vermutlich positioniert die U5 snRNA auf diese Weise das 5'-Exon für die Spleißreaktion (Wyatt et al. 1992, Alvi et al. 2001). Die Beobachtung von crosslinks zwischen U1 und U5 snRNA in HeLa Extrakt weist darauf hin, dass diese Interaktion der U5 snRNA mit der 5'Spleißstelle schon früh in der Aktivierung stattfindet. Sie ist zudem ATP-abhängig. Möglicherweise hilft die U5 snRNA auch bei der Ablösung der U1 snRNA (Ast und Weiner 1997).

Die Veränderungen in den RNA-RNA-Interaktionen sind von Veränderungen der RNAProtein Kontakte begleitet. Vor der Anlagerung des tri-snRNP wird die 5'-Spleißstelle vom U1 snRNP gebunden. Crosslinking-Experimente in S. cerevisiae weisen insbesondere auf Kontakte mit einigen Sm-Proteinen, U1-70K (im Exonbereich) und U1C (im Bereich +4 und +6 im Intron) hin (Zhang und Rosbash 1999). Für U1C wurde zusätzlich gezeigt, dass es die Interaktion zwischen dem U1 snRNP und der 5'-Spleißstelle stabilisiert (Rossi et al. 1996). Außerdem konnte in humanem HeLa-Zellkernextakt in Komplex A ein ATP-abhängiger crosslink zu der RNA-Helikase p68 detektiert werden (Liu et al. 1998, Liu 2002). Dabei interagiert p68 vermutlich mit dem Duplex aus der U1 snRNA und der 5'-Spleißstelle und hat eine Funktion für dessen Entwindung. Während der Aktivierung werden diese Interaktionen dann durch Interaktionen mit anderen Proteinen ersetzt. Crosslinking-Untersuchungen haben verschiedene Proteine gezeigt, die im Komplex B bzw. B* im Bereich der 5'-Spleißstelle lokalisiert sind (Sha et al. 1998, Ismaili et al. 2001). Identifiziert wurden dabei hPrp8, das mit der hochkonservierten GU-Sequenz am Intronanfang (Position +1 und +2 ) interagiert, sowie hPrp28, das im Bereich +7 des Introns lokalisiert ist. Beide crosslinks traten während der Aktivierung gleichzeitig mit der Interaktion zwischen U6 snRNA und prä-mRNA auf und waren ATP-abhängig (Wyatt et al. 1992, Reyes et al. 1996, Reyes et al. 1999, Maroney et al. 2000, Ismaili et al. 2001).

Es ist unklar, ob die beschriebenen Konformationsänderungen alle gleichzeitig ablaufen oder ob sie sich in mehrere Schritte unterteilen lassen. Ebenso ist noch nicht geklärt, wie viel ATP während der Aktivierung des Spleißosoms insgesamt verbraucht wird. An der Katalyse dieses Vorgangs sind aber mindestens drei DExD/H-Box Proteine beteiligt: p68, hBrr2 und hPrp28.

\section{3 hPrp28}

hPrp28 (alternativer Name: U5-100K) ist ein essentielles DEAD-Box Protein des Menschen, das Bestandteil des U5 snRNP ist. Es umfasst 820 Aminosäuren und hat ein theoretisches Molekulargewicht von 95,6 kDa. Eine Analyse der Aminosäuresequenz zeigt, dass sich die Helikasedomäne mit den konservierten Sequenzmotiven am C-Terminus befindet (Abb. 1.12). Die Domänenzusammensetzung der N-terminalen Hälfte dagegen ist unbekannt. Ein Sequenzabschnitt, der ungefähr die ersten 220 Aminosäuren umfasst, zeichnet sich allerdings durch einen hohen Arginingehalt aus. Insbesondere treten RS- und RD-DipeptidWiederholungen auf. Dieser Bereich wird darum als RS-Domäne bezeichnet. In vivo tritt hPrp28 in verschiedenen Phosphorylierungszuständen auf. Zudem ist es in vitro Substrat der Kinasen Clk1/Sty sowie SRPK1. Die Phosphorylierung betrifft also vermutlich die RSDomäne (Teigelkamp et al. 1997). 


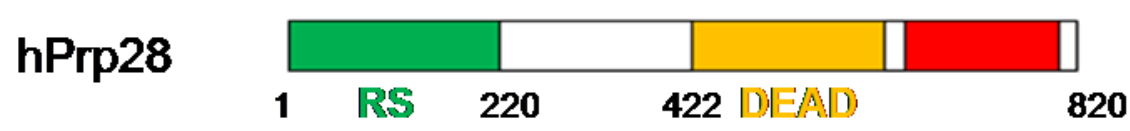

Abb. 1.12: Domänenstruktur von hPrp28. Grün: RS-Domäne, Orange bzw. Rot: N- bzw. C-terminale Domäne der DExD/H-Box Proteine. Die Zahlen geben die Position in der Aminosäuresequenz an.

Hinweise auf die Funktion von hPrp28 ergeben sich vor allem aus Untersuchungen über das orthologe Protein Prp28 aus S. cerevisiae. Demnach hat es eine Funktion beim Austausch der U1 gegen die U6 snRNA an der 5'-Spleißstelle. Prp28 aus S. cerevisiae weist eine $37 \%$ ige Sequenzidentität zum humanen Ortholog hPrp28 auf. Besonders stark konserviert ist dabei die Helikasedomäne. Eine RS-Domäne fehlt dagegen bei Prp28. Entsprechend hat das Protein lediglich ein Molekulargewicht von $67 \mathrm{kDa}$. Im Gegensatz zum humanen Ortholog ist Prp28 in der Hefe außerdem kein fester Bestandteil des U5 snRNP. Obwohl es sich um ein DEADBox Protein handelt, ließ sich in vitro weder eine Helikase- noch eine eindeutige ATPase Aktivität nachweisen (Strauss und Guthrie 1994).

Identifiziert wurde Prp28 durch eine Mutation in der Helikasedomäne (prp28-1: G297 $\rightarrow \mathrm{E}$ ), die zu einem kältesensitiven Phänotyp führt (Strauss und Guthrie 1991). In den Zellen häuft sich dabei ein spleißosomaler Komplex an, in dem die U4 und U6 snRNA noch gepaart sind. Der Spleißzyklus ist somit in einem Schritt vor der U4/U6 Duplex-Entwindung gehemmt. Dieser Phänotyp wird durch eine Schwächung der Interaktion zwischen U1 snRNA und 5'Spleißstelle unterdrückt. Umgekehrt verstärkt die prp28-1 Mutation den Spleißdefekt, der durch Ausdehnung der Anzahl der Basenpaarungen zwischen U1 snRNA und 5'-Spleißstelle entsteht (1.2.5). Eine solche Hyperstabilisierung führt bei niedrigen Temperaturen zu spleißosomalen Komplexen, die alle fünf snRNAs enthalten und in denen U4 und U6 snRNA gepaart sind. Diese Komplexe können in vitro durch Temperaturerhöhung reaktiviert werden, allerdings erfordert dies das Vorhandensein von Prp28 und ATP. Prp28 ist also für die Entfernung der U1 snRNA notwendig (Staley und Guthrie 1999). Unterstützt wird diese Hypothese durch die Beobachtung, dass prp28-1 und U4-cs1 zusammen letal sind (Kuhn et al. 2002). Die U4-cs1 Mutation maskiert teilweise die ACAGA-Sequenz der U6 snRNA und führt dadurch ebenfalls zu einer Blockade der U1 snRNA-Entfernung (Kuhn et al. 1999). Außerdem bewirken einzelne Mutationen der U1 snRNA, welche die Interaktion mit der 5'Spleißstelle schwächen, dass Prp28 nicht mehr essentiell ist (Chen et al. 2001).

Prp28 kann die Entfernung der U1 snRNA auf verschiedenen Wegen bewirken. Einerseits könnte es direkt die Basenpaarung zwischen der U1 snRNA und der 5'-Spleißstelle auflösen. Andererseits könnte es dieses Duplex indirekt schwächen, indem es die Bindung der U6 snRNA erleichtert. Schließlich besteht noch die Möglichkeit, dass Prp28 als RNPase wirkt und ein Protein entfernt, welches das Duplex aus U1 snRNA und 5'-Spleißstelle stabilisiert. Ein solches Protein ist das U1 snRNP-spezifische U1C (Du et al. 2004). Interessanterweise führt eine Mutation der Aminosäure Leucin 13 in U1C dazu, dass Prp28 nicht mehr essentiell ist (Chen et al. 2001).

Die Aktivitäten von Prp28 sowie von Brr2 werden möglicherweise von Prp8 reguliert. Prp8 unterdrückt dabei vermutlich die Helikaseaktivitäten so lange, bis die 5'-Spleißstelle verlässlich erkannt wurde. Hinweise darauf geben verschiedene genetische Interaktionen von Prp8: Eine Mutation von Prp8 wirkt sowohl als Supressor von prp28-1 als auch von brr2-1, einem kaltsensitiven Allel von Brr2. Außerdem unterdrückt eine Prp8-Mutation den U4-cs1 
Phänotyp und wirkt damit den Auswirkungen der Mutationen prp28-1 und brr2-1 entgegen (Strauss und Guthrie 1991, Kuhn et al. 1999 und 2002).

Bisher wurden noch keine Protein-Interaktionspartner von Prp28 bzw. hPrp28 gefunden. Es konnte allerdings ein crosslink zwischen der prä-mRNA und hPrp28 detektiert werden (Ismaili et al. 2001). Dieser crosslink tritt zwischen der Intronposition +7 und einem Aminosäureabschnitt (601-609) von hPrp28 auf, der das konservierte Motiv III enthält. In den Studien wurden verschiedene prä-mRNA Substrate, die eine photoreaktive BenzophenonGruppe an Position +7 enthielten, in HeLa Extrakt inkubiert und zu unterschiedlichen Zeitpunkten mit UV-Licht bestrahlt. Der crosslink zu hPrp28 hängt von der Anwesenheit von hydrolysierbarem ATP ab und tritt gleichzeitig mit Bildung des Komplex B auf. Er überdauert vermutlich die Stadien der Spleißkatalyse. Unter denselben Bedingungen ließ sich auch der crosslink zwischen der 5'-Spleißstelle und hPrp8 detektieren (Maroney et al. 2000). Damit befindet sich hPrp28 zu mindestens in räumlicher Nähe zu hPrp8. Außerdem tritt der crosslink zu hPrp28 zeitgleich mit der Interaktion zwischen prä-mRNA und U6 snRNA auf und ist auch vom Vorhandensein intakter U6 snRNA abhängig. Das 5'-Ende der U1 snRNA, das im frühen Stadium mit der 5'-Spleißstelle interagiert, ist dagegen für den crosslink nicht notwendig. Folglich interagiert hPrp28 möglicherweise mit dem Duplex aus U6 snRNA und 5'-Spleißstelle. Die Loslösung der U1 snRNA wird dann eventuell nur indirekt von ihm katalysiert (Ismaili et al. 2001).

\subsection{Zielsetzung}

Ziel dieser Arbeit war die Aufklärung der molekularen Struktur von hPrp28. Dadurch sollte einerseits Einblick in die strukturelle Organisation des Spleißosoms erhalten werden. Andererseits sollte die Charakterisierung von hPrp28 auch zu neuen Erkenntnissen über die Funktionsweise der Familie der DEAD-Box Proteine führen. Insbesondere sollte geklärt werden, warum hPrp28 im Gegensatz zu anderen DExD/H-Box Proteinen des Spleißzyklus in vitro keine ATPase-Aktivität zeigt, und auf welche Weise es aktiviert werden könnte.

Darüber hinaus wurden Bindungs- und Aktivitätsstudien durchgeführt, um die Funktion von hPrp28 während des Spleißzyklus näher zu charakterisieren. 


\section{Material und Methoden}

\subsection{Material}

\subsubsection{Großgeräte}

ABIPrism 3100 DNA Sequencer

ÄKTA Prime

ÄKTA Purifier

BioPhotometer

Fluorimeter Fluoromax III

Frac900 Fraktionierer

Geldokumentationsgerät GelDoc

MicroCalorimeter VP-ITC

Microfluidizer $110 \mathrm{~S}$

PCR-Cycler

Photometer Ultraspec2100pro

Röntgengenerator Micromax 007

Thermomixer Comfort

Thermostat plus

Tischzentrifuge 5415R

Unitron Schüttelinkubatoren

Zentrifuge Avanti J-20 XPI

Zentrifuge Avanti J-30 I

Zentrifuge Allegra 21R
Applied Biosystems, Darmstadt

GE Healthcare, München

GE Healthcare, München

Eppendorf, Hamburg

Jobin Yvon, Grasbrunn

GE Healthcare, München

BioRad, München

MicroCal, USA

Microfluidics, USA

Biometra, Göttingen

GE Healthcare, München

Rigaku/MSC, Japan

Eppendorf, Hamburg

Eppendorf, Hamburg

Eppendorf, Hamburg

Infors, Einsbach

Beckman Coulter, Krefeld

Beckman Coulter, Krefeld

Beckman Coulter, Krefeld

\subsubsection{Chromatographiesäulen}

GSTrap FF, GSH-Sepharose (5 ml)

HisTrap HP, Ni-NTA-Sepharose $(5 \mathrm{ml})$

HiTrap Desalting, Sephadex G-25 (5ml)

Superdex 75 (26/60), (16/60) oder (10/30)

Superdex 200 (16/60) oder (10/30)

ProntoSIL C18 4/125mm AQ
GE Healthcare, München

GE Healthcare, München

GE Healthcare, München

GE Healthcare, München

GE Healthcare, München

Bischoff Chromatography, Leonberg

Die Säulen werden in 20\% Ethanol gelagert. Ausnahme ist die ProntoSIL-Säule, die in 50\% Acetonitril aufbewahrt wird. 


\subsubsection{Chemikalien}

Alle Chemikalien wurden von den Firmen AppliChem, Fluka, Merck, Roth oder SigmaAldrich bezogen. Sie hatten den Reinheitsgrad pro analysis.

\subsubsection{Enzyme}

Calf Intestinal Phosphatase (CIP)

Pfu DNA Polymerase

Phusion High-Fidelity DNA Polymerase

PreScission Protease

Restriktionsenzyme

(BamHI, DpnI, HindIII, NcoI, SacII, SalI, XhoI)

T4-DNA-Ligase

Taq-DNA-Polymerase
New England Biolabs, Frankfurt

Stratagene, USA

New England Biolabs, Frankfurt

Amersham Pharmacia Biotech, Freiburg

Fermentas, St. Leon-Rot

New England Biolabs, Frankfurt

New England Biolabs, Frankfurt

\subsubsection{DNA Oligonukleotide}

Die DNA Oligonukleotide wurden entweder von MWG Biotech (München) oder Purimex (Grebenstein) bezogen. Oligonukleotide für Mutagenese-Experimente wurden HPLCgereinigt bestellt. In den übrigen Fällen genügte eine Entsalzung.

a) Oligonukleotide für die Klonierung von hPrp28

Restriktionsschnittstellen sind unterstrichen.

\begin{tabular}{|l|l|}
\hline Oligonukleotid & Sequenz $\left(5^{`} \rightarrow 3^{`}\right)$ \\
\hline PQE-80-forward & CG GGA TCC ATG GCA GGA GAG CTG GCT G \\
\hline PQE-80-reverse & CC CAA GCT TCA GGC AAA GAT GGT CTC \\
\hline IBA3-forward & CT CC $\underline{\text { CGC GGT ATG GCA GGA GAG CTG GCT G }}$ \\
\hline IBA3-reverse & CAT GCC ATG GGC AAA GAT GGT CTC TTC C \\
\hline PET21-reverse & CCG $\underline{\text { CTC GAG GGC AAA GAT GGT CTC TTC C }}$ \\
\hline pET21-stop-r & CCG $\underline{\text { CTC GAG TCA GGC AAA GAT GGT CTC TTC CCG }}$ \\
\hline DEAD1-pET21-f & CG GGA TCC ATG GAA GAT CCT CAG GAA CGG G \\
\hline DEAD2-pET21-f & CG GGA TCC ATG GCA AGA CTC CGC AAA CTT CG \\
\hline DEAD3-pGEX-Bam-f & CG GGA TCC AATCCCATCCGATCCTGGAAAG \\
\hline DEAD3-pGEX-Xho-r & CCG CTC GAG TCACAGGATAGCTTGCTTCAGCTCG \\
\hline DEAD4-pGEX-Bam-f & CG GGA TCC GATGATCGTCATTGGTCTCAGAAAAAG \\
\hline DEAD5-pGEX-Bam-f & CG GGA TCC GGCATCAAAAAGCGGCGCCGAAC \\
\hline DEAD6-pGEX-Bam-f & CG GGA TCC GGGCGAGGCTTCATTGCAGGCATTG \\
\hline
\end{tabular}




\begin{tabular}{|c|c|}
\hline Oligonukleotid & Sequenz $\left(5^{\circ} \rightarrow 3^{\circ}\right)$ \\
\hline RS1-pET21-r & CCG CTC GAG CTT AGG CTT CTT ATC ACC \\
\hline RS2-pET21-r & CCG CTC GAG CAA CAT CTT CCT GCC CAA GTC \\
\hline RS3-pET21-r & CCG CTC GAG GCC ACC CAG GTA ACG CTC C \\
\hline RS4-pET21-r & 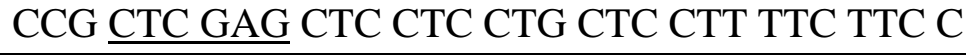 \\
\hline RS5-pET21-r & CCG CTC GAG ACG ATC ATC CCA GCG CTG C \\
\hline
\end{tabular}

b) DNA-Oligonukleotide zur Mutagenese von hPrp28

\begin{tabular}{|c|c|c|}
\hline $\begin{array}{l}\text { Oligo- } \\
\text { nukleotid }\end{array}$ & Sequenz $\left(5^{6} \rightarrow 3^{\circ}\right)$ & \begin{tabular}{|l|}
$\mathrm{T}_{\mathrm{m}}$ \\
{$\left[{ }^{\circ} \mathrm{C}\right]$}
\end{tabular} \\
\hline Motiv1-for & GAGACTGGCAGT GGC GCG ACA GCAGCCTTCCTC & 82,3 \\
\hline Motiv1-rev & GAGGAAGGCTGC TGT CGC GCC ACTGCCAGTCTC & 82,3 \\
\hline Motiv2-for & GTACCTATGTGGTTCTGGCTGCGGCAGATAGGATGATTGAC & 81,2 \\
\hline Motiv2-rev2 & 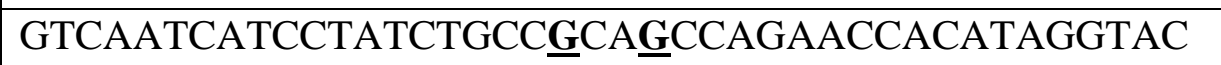 & 81,2 \\
\hline Motiv3-for & 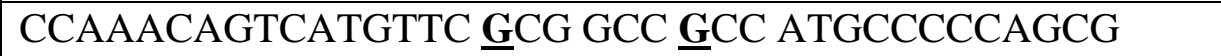 & 85,6 \\
\hline Motiv3-rev & 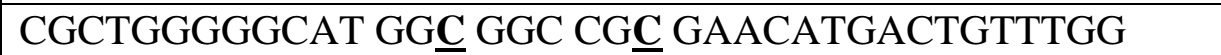 & 85,6 \\
\hline Insert-for & $\begin{array}{l}\text { GAGCACATGCCTGTCAGCAACCAGCGCCAAACAGTCATGTTC } \\
\text { ACGGCCAC }\end{array}$ & 91,8 \\
\hline Insert-rev & $\begin{array}{l}\text { GTGGCCGTGAACATGACTGTTTGGCGCTGGTTGCTGACAGGC } \\
\text { ATGTGCTC }\end{array}$ & 91,8 \\
\hline
\end{tabular}

Die mutierten Nukleotide sind hervorgehoben. Bei den Insert-Oligonukleotiden ist die Deletionsstelle unterstrichen. Die Schmelztemperatur $T_{m}$ wurde nach folgender Formel berechnet:

$$
\begin{array}{r}
\mathrm{T}_{\mathrm{m}} /\left[{ }^{\circ} \mathrm{C}\right]=81,5+0.41 *(\% \mathrm{GC})-675 / \mathrm{N}-(\% \text { Fehlpaarung }) \\
\text { mit } \mathrm{N}=\text { Länge des DNA-Oligonukleotids }
\end{array}
$$

c) DNA-Oligonukleotide für Sequenzierungen

Die Oligonukleotide Prp28-Seq1 bis -Seq5 wurden zur Sequenzierung von hPrp28 verwendet. Die übrigen Oligonukleotide binden Vektorsequenzen und dienten zur Überprüfung der Klonierungsschnittstellen.

\begin{tabular}{|l|l|}
\hline Oligonukleotid & Sequenz $\left(5^{\circ} \rightarrow 3^{\circ}\right)$ \\
\hline Prp28-Seq1 & GGATGAAGAGGATGAACATGG \\
\hline Prp28-Seq2 & GGAGCGTTACCTGGGTGG \\
\hline Prp28-Seq3 & GGCAAGATCCCCAATCCC \\
\hline Prp28-Seq4 & GAAGACCAGGGCTTCAGGC \\
\hline Prp28-Seq5 & GCTGCTGGCAATCTTGGAGC \\
\hline pGEX-for & GCTGGCAAGCCACGTTTGGT \\
\hline pGEX-rev & CGTCTCCGGGAGCTGCATGT \\
\hline T7-for & TAATACGACTCACTATAGGG \\
\hline
\end{tabular}


d) DNA-Oligonukleotide für die Klonierung von Kinasen

Restriktionsschnittstellen sind unterstrichen.

\begin{tabular}{|l|l|}
\hline Oligonukleotid & Sequenz $\left(5^{\circ} \rightarrow 3^{\circ}\right)$ \\
\hline SRPK1Mini-pGEX-Bam-f & CG GGA TCC CCAGAGCAGGAAGAGGAG \\
\hline SRPK1Mini-pGEX-Eco-r & G GAA TTC TTA GGA GTT AAG CCAAGGGTGC \\
\hline Clk1-pGEX-Bam-f & $\begin{array}{l}\text { CG GGA TCC ATG AGA CAC TCA AAG AGA ACT TAC } \\
\text { TGT CC }\end{array}$ \\
\hline Clk1-pGEX-Xho-r & $\begin{array}{l}\text { CCG } \text { CTC GAG TTA CAG ATC TAT ATA CTT TTC TTC } \\
\text { AGA AGG TC }\end{array}$ \\
\hline Clk1Mini-pGEX-Bam-f & CG GGA TCC CAC CTG ATC TGT CAG AGT GGA G \\
\hline
\end{tabular}

\subsubsection{RNA Oligonukleotide}

Die RNA-Oligonukleotide wurden von den Firmen Purimex (Grebenstein) oder IBA (Göttingen) bezogen. RNA-Oligonukleotide für Bindungsstudien wurden HPLC-gereinigt bestellt. Für die Kristallisation war eine PAGE-Reinigung notwendig.

\begin{tabular}{|l|l|}
\hline Oligonukleotid & Sequenz $\left(5^{\circ} \rightarrow 3^{\circ}\right)$ \\
\hline 5 SS RNA & AGGUAAGUAU \\
\hline SS-U1 Hairpin & AGGUAAGUAUGUUUUUCAUACUUACCU \\
\hline SS-U6 Hairpin & AGGUAUGUAUCGUUCUUUUUGAACGAUACAGAG \\
\hline polyU $_{20}$ & UUUUUUUUUUUUUUUUUUUU \\
\hline
\end{tabular}

Für Aktivitätstests wurde außerdem Typ III RNA aus S. cerevisiae (Sigma-Aldrich) verwendet. Dabei handelt es sich um ein RNA-Gemisch, das über Extraktion der gesamten zellulären RNA von Hefe gewonnen wurde.

\subsection{7 cDNA-Bank}

MegaMan Human Transcriptome Library

Stratagene, USA 


\subsubsection{Plasmide}

$\begin{array}{ll}\text { hPrp28-FL-pETM-11 } & \text { Sunbin Liu, MPI Göttingen } \\ \text { hPrp28-FL-pETM-41 } & \text { Sunbin Liu, MPI Göttingen } \\ \text { hPrp28- } \Delta \text { RS } \triangle \text { DEAD-pETM-30 } & \text { Sunbin Liu, MPI Göttingen } \\ \text { hPrp28- } \Delta \text { RS-pETM-11 } & \text { Sunbin Liu, MPI Göttingen } \\ \text { hPrp28- } \triangle \text { RS-pETM-41 } & \text { Sunbin Liu, MPI Göttingen } \\ \text { hPrp28-DEAD-pETM-30 } & \text { Sunbin Liu, MPI Göttingen } \\ \text { SRPK1-pET-24a } & \text { Goran Akusjarvi, BMC, Uppsala } \\ \text { SRPK1 } \Delta \text { NS-pET-15b } & \text { Gourisankar Ghosh, San Diego } \\ \text { pASK-IBA-3 } & \text { IBA,Göttingen } \\ \text { pET-21a } & \text { Novagen, Darmstadt } \\ \text { pET-30a } & \text { Novagen, Darmstadt } \\ \text { pGEX-6P } & \text { GE Healthcare, München } \\ \text { pGEX-TT } & \text { GE Healthcare, München } \\ \text { pMAL-c2x } & \text { New England Biolabs, Frankfurt } \\ \text { pQE-80L } & \text { QIAGEN, Hilden }\end{array}$

\subsubsection{Kit Systeme}

Big Dye Terminator v1.1 Mix

Applied Biosystems, Darmstadt

NucleoSpin Extract II

NucleoSpin Plasmid

Macherey-Nagel, Düren

Plasmid Midi Kit

Macherey-Nagel, Düren

QIAGEN, Hilden

\subsubsection{Verwendete Organismen}

Escherichia coli BL21 STAR (DE3)

Invitrogen, Karlsruhe

E. coli Rosetta 2 (DE3)

Novagen, Darmstadt

E. coli XL1 Blue

Novagen, Darmstadt

\subsubsection{Kristallisationspuffer}

Die Kristallisations-Screens wurden innerhalb der Abteilung angesetzt.

Crystal Screen 1/2/Lite/Cryo/PEGIon

JBScreen 1-10

Magic Screen 1-4

Foorprint Screen 1-3

Structure Screen 1-3
Hampton Research, USA

Jena Bioscience, Jena

Biogenova, Kanada

Stura et al. 1992

Molecular Dimensions, England

Für Schwermetallsalz-Inkubationen wurde verwendet:

JB Screen Heavy

Jena Bioscience, Jena 


\subsubsection{Computerprogramme}

Automar
CCP4 program suite
Coot
Diffraction Anisotropy Server
ESSENS
HKL2000
Mosflm
Origin 7
Procheck
Pymol 0.97
PSIPRED
SHARP/autoSHARP
SigmaPlot 8.0
SWIFT II
Clustal W
ESPript 2.2
XDS

Marresearch GmbH, Norderstedt

Collaborative Computational Project Number 4, 1994

Emsley und Cowtan, 2004

Strong et al. 2006 (www.doembi.ucla.edu/ sawaya/anisoscale)

Uppsala Software Factory (Kleywegt G.A.)

HKL Research, USA

Leslie and Powell, UK

OriginLab Corporation, USA

Laskowski et al., 1993

DeLano Scientific, San Carlos, USA

McGuffin et al. 2000

Global Phasing, Cambridge, UK

SYSTAT Software, Erhrath

Biochrom Ltd., England

EMBL-EBI, Pearson \& Lipman, 1988

Gouet et al., 1999

Kabsch 1993

\subsection{Methoden}

\subsubsection{Mikrobiologische und molekularbiologische Methoden}

\subsubsection{Polymerasekettenreaktion (PCR)}

Die PCR ermöglicht die selektive Vermehrung eines DNA-Abschnitts, der als Matrize bezeichnet wird. Begrenzt wird dieser Abschnitt durch zwei DNA-Oligonukleotide, die komplementär zu den beiden 3'-Enden der Matrizen-DNA-Einzelstränge sind.

Es wird folgender 50 $\mu 1$ Ansatz pipettiert:

a) Mit Pfu-DNA-Polymerase: $\quad$ 50-100 ng Matrizen-DNA

1x Pfu Puffer mit $\mathrm{MgSO}_{4}$

je 50 pmol DNA-Oligonukleotid (Primer)

je $200 \mu \mathrm{M}$ dATP, dGTP, dTTP, dCTP

2,5 U Pfu-DNA-Polymerase

b) Mit Phusion-DNA-Polymerase:

50-100 ng Matrizen-DNA

1x Phusion HF Puffer

je 50 pmol DNA-Oligonukleotid (Primer)

je $200 \mu \mathrm{M}$ dATP, dGTP, dTTP, dCTP

1 U Phusion-DNA-Polymerase 
Es werden in der Regel folgende Temperaturzyklen durchlaufen:

a) Pfu-DNA-Polymerase:

Denaturierung

Denaturierung

Hybridisierung

Elongation

Finale Elongation $95^{\circ} \mathrm{C} \quad 3$,

$95^{\circ} \mathrm{C} \quad 1$,

$52^{\circ} \mathrm{C} \quad 1^{\circ}$

$68^{\circ} \mathrm{C} \quad 2^{\prime}$ pro $\mathrm{kb}$

$68^{\circ} \mathrm{C} 10^{\circ}$ b) Phusion-DNA-Polymerase:

$98^{\circ} \mathrm{C} \quad 1^{\prime}$

$98^{\circ} \mathrm{C} 10^{\prime \prime}$

$52^{\circ} \mathrm{C} \quad 20^{\prime \prime}$

$72^{\circ} \mathrm{C} \quad 30^{\prime \prime}$ pro kb

$72^{\circ} \mathrm{C} \quad 10^{\circ}$

Die Temperatur während der Hybridisierung sollte mindestens $2-3^{\circ} \mathrm{C}$ unterhalb der Schmelztemperatur der Primer liegen. In der Regel konnte die Matrize erfolgreich amplifiziert werden, indem $52^{\circ} \mathrm{C}$ eingesetzt wurden. Abweichungen sind im Ergebnisteil gesondert vermerkt.

Nach der PCR wird das NucleoSpin Extract II Kit von Macherey-Nagel (2.1.9) verwendet, um das PCR-Produkt von Primern und Enzymen zu reinigen. Es wird gemäß den Herstellerangaben vorgegangen und die DNA anschließend in $30 \mu \mathrm{l}$ Wasser aufgenommen.

\title{
2.2.1.2 Präparation von Plasmid-DNA aus Bakterien
}

\author{
LB-Medium: $1 \%(\mathrm{w} / \mathrm{v})$ Trypton \\ $1 \%(\mathrm{w} / \mathrm{v}) \mathrm{NaCl}$ \\ $0,5 \%(w / v)$ Hefeextrakt
}

Die Methoden zur Plasmidpräparation basieren auf der alkalischen Lyse. Abhängig von der Menge der benötigten DNA werden $5 \mathrm{ml}$ (Mini-Präparation) oder $100 \mathrm{ml}$ LB-Medium (MidiPräparation) mit dem entsprechenden Antibiotikum versetzt und mit transformierten E. coli Zellen des Stammes XL1blue angeimpft (2.1.10). Die Inkubation erfolgt unter Schütteln über Nacht bei $37^{\circ} \mathrm{C}$. Die Plasmidpräparation wird mit Kit Systemen von QIAGEN oder Macherey-Nagel nach den Herstellerangaben durchgeführt (2.1.9). Die Plasmid-DNA wird in $50 \mu \mathrm{l}$ (Mini) bzw. $100 \mu \mathrm{l}$ (Midi) Wasser gelöst.

\subsubsection{Bestimmung der DNA-Konzentration}

Die DNA-Konzentrationsbestimmung erfolgt durch Messung der Absorption bei $260 \mathrm{~nm}$. Für doppelsträngige DNA entspricht ein $\mathrm{OD}_{260}$-Wert von 1 einer Konzentration von $50 \mathrm{ng} / \mu \mathrm{l}$.

\subsubsection{DNA Restriktionsverdau}

Restriktionsenzyme (2.1.4) ermöglichen das Schneiden von DNA an einer spezifischen Erkennungssequenz. Der Ansatz erfolgt gemäß den Angaben des Herstellers (Fermentas) und wird für $1-3 \mathrm{~h}$ bei $37^{\circ} \mathrm{C}$ inkubiert. Anschließend wird die DNA auf ein Agarosegel aufgetragen (2.2.1.5) und dadurch der Verdau gestoppt. 


\subsubsection{Agarosegelelektrophorese}

Laufpuffer (1x TBE):

$90 \mathrm{mM}$ Tris

$90 \mathrm{mM}$ Borsäure

$10 \mathrm{mM}$ EDTA

auf $\mathrm{pH} 8,0$ eingestellt 6x DNA-Probenpuffer:

$0,5 \%(\mathrm{w} / \mathrm{v})$ Bromphenolblau

$0,5 \%(\mathrm{w} / \mathrm{v})$ Xylencyanol FF

$60 \%$ Glyzerin

Es werden ausschließlich 1 \%ige Agarosegele verwendet. Die DNA-Probe wird mit DNAProbenpuffer bis zu einer 1x Endkonzentration gemischt. Die Elektrophorese erfolgt für $1 \mathrm{~h}$ bei einer konstanten Spannung von 5-15 V pro cm Agarosegel. Anschließend wird die DNA

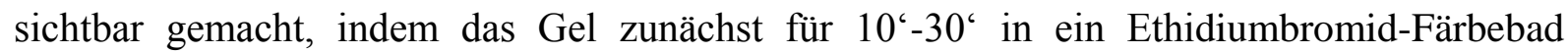
$(1 \mu \mathrm{g} / \mathrm{ml})$ gelegt und anschließend im UV-Durchlicht mit der Wellenlänge $254 \mathrm{~nm}$ oder $365 \mathrm{~nm}$ (bei Gelextraktion) betrachtet wird.

\subsubsection{DNA-Isolierung aus Agarosegelen}

Zur Isolierung von DNA aus Agarosegelen (2.2.1.5) wird das NucleoSpin Extract II Kit von Macherey-Nagel gemäß den Herstellerangaben verwendet (2.1.9). Die DNA wird in $30 \mu 1$ Wasser aufgenommen.

\subsubsection{Transformation}

Bei der Transformation wird Plasmid-DNA in E. coli Bakterien eingebracht, um diese anschließend zu vermehren oder darauf kodierte Gene zur Expression zu bringen. Da E. coli keine natürliche Transformationskompetenz besitzt, werden die Zellen durch Behandlung mit $\mathrm{CaCl}_{2}$ kompetent gemacht (2.2.1.7.1).

Ein $100 \mu \mathrm{l}$ Aliquot der kompetenten Zellen wird vorsichtig auf Eis aufgetaut. In einem Volumen von maximal $10 \mu \mathrm{l}$ werden 100-500 ng der Plasmid-DNA zugegeben und vorsichtig mit den Zellen vermischt. Es folgt für 30‘ eine Inkubation auf Eis. Anschließend werden die Zellen auf dem Heizblock für $1^{\text {' }}$ bei $42^{\circ} \mathrm{C}$ gehalten und danach mindestens $2^{\text {' }}$ auf Eis abgekühlt. Nach Zugabe von $200 \mu \mathrm{LB}-$ Medium wird der Ansatz $45^{\circ}$ bei $37^{\circ} \mathrm{C}$ unter Schütteln inkubiert. In dieser Zeit bilden die Bakterien die durch das Plasmid kodierte Antibiotika-Resistenz aus. Transformierte Bakterien werden durch Ausstreichen auf einer LBAgarplatte mit dem entsprechenden Antibiotikum selektiert. 


\subsection{Herstellung transformationskompetenter Zellen (CaCl2-Methode)}

\author{
LB-Medium: $1 \%(\mathrm{w} / \mathrm{v})$ Trypton \\ $1 \%(\mathrm{w} / \mathrm{v}) \mathrm{NaCl}$ \\ $0,5 \%(\mathrm{w} / \mathrm{v})$ Hefeextrakt \\ $1,5 \%(w / v)$ Agar (nur für Platten)
}

\author{
FB-Puffer: $\quad 100 \mathrm{mM} \mathrm{KCl}$ \\ $50 \mathrm{mM} \mathrm{CaCl}_{2}$ \\ $10 \%(w / v)$ Glyzerin \\ 10 mM K-Acetat, pH 6,4 \\ sterilfiltriert
}

Der E. coli Stamm wird auf einer LB-Agarplatte über Nacht bei $37^{\circ} \mathrm{C}$ angezogen. Eine Kolonie wird in $3 \mathrm{ml}$ LB-Medium überimpft und über Nacht bei $37^{\circ} \mathrm{C}$ unter Schütteln vermehrt. Mit dieser Vorkultur werden $250 \mathrm{ml}$ LB-Medium angeimpft. Es folgt eine Inkubation bei $37^{\circ} \mathrm{C}$ und $220 \mathrm{rpm}$, bis ein $\mathrm{OD}_{600}$-Wert von 0,4-0,6 erreicht ist. Die Zellkultur wird $10^{\circ}-60^{`}$ auf Eis inkubiert und dann zentrifugiert $\left(2250 \mathrm{x} \mathrm{g}, 15^{\circ}, 4^{\circ} \mathrm{C}\right)$, um die Zellen zu pelletieren. Die nachfolgenden Schritte werden auf Eis durchgeführt, um eine möglichst hohe Transformationskometenz zu erreichen. Zunächst wird das Zellpellet in $80 \mathrm{ml}$ vorgekühltem FB-Puffer resuspendiert und auf Eis $10^{\circ}-60^{\circ}$ inkubiert. Nach erneuter Zentrifugation $\left(2250 \mathrm{x} \mathrm{g}, 15^{\circ}, 4^{\circ} \mathrm{C}\right)$ wird das Zellpellet in $10-20 \mathrm{ml}$ vorgekühltem FB-Puffer resuspendiert und in $100 \mu \mathrm{l}$ Aliquots auf Eppendorf-Gefäße verteilt. Die Zellen werden unmittelbar in flüssigem Stickstoff eingefroren und bei $-80^{\circ} \mathrm{C}$ gelagert.

\subsubsection{Klonierung}

Bei einer Klonierung wird ein bestimmtes DNA-Fragment in ein Plasmid eingesetzt. Dadurch kann es in Bakterien anschließend vermehrt oder das von ihm kodierte Protein produziert werden.

Das DNA-Fragment oder Insert wird durch PCR generiert (2.2.1.1) und anschließend an den Enden mit zwei verschiedenen Restriktionsenzymen geschnitten (2.2.1.4). Alternativ kann das Insert auch erhalten werden, indem es aus einem anderen Vektor ausgeschnitten wird.

Die Plasmid-DNA wird über Midi-Präparation aus XL1blue-Zellen isoliert (2.2.1.2) und dann mit den gleichen Restriktionsenzymen wie das Insert verdaut. Die Restriktionsenzyme müssen

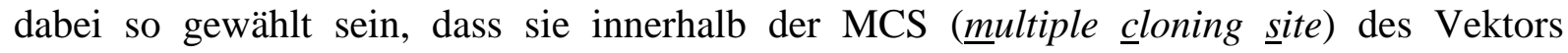
schneiden.

Die geschnittene Insert- und Plasmid-DNA wird über Agarosegelelektrophorese (2.2.1.5) und Extraktion der entsprechenden DNA-Banden (2.2.1.6) gereinigt. Anschließend werden Insertund Plasmid-DNA durch Ligation miteinander verknüpft. Dazu wird ein $10 \mu 1$ Ansatz pipettiert: $\quad 100-200 \mathrm{ng}$

3-10-facher molarer Überschuss $1 \mathrm{x}$ Plasmid-DNA

$2 \mathrm{U}$ Insert-DNA T4-DNA-Ligase-Puffer T4-DNA-Ligase

Der Ligationsansatz wird $2 \mathrm{~h}$ bei $16^{\circ} \mathrm{C}$ oder über Nacht bei $4^{\circ} \mathrm{C}$ inkubiert. Anschließend wird er zur Transformation von XL1blue-Zellen verwendet (2.2.1.7). Klone mit dem gewünschten Insert/Plasmid-Konstrukt werden identifiziert, indem ihre Plasmid-DNA isoliert (Mini- 
Präparation, 2.2.1.2) und ein Aliquot mit den verwendeten Restriktionsenzymen verdaut wird (2.2.1.4). Anschließende Agarose-Gelelektrophorese (2.2.1.5) macht dann sichtbar, ob das Plasmid das Insert enthält. Durch DNA-Sequenzierung wird die korrekte Klonierung im Detail überprüft (2.2.1.9).

\subsubsection{DNA-Sequenzierung}

Bei der DNA-Sequenzierung wird eine PCR mit einem Primer durchgeführt, der etwa zwanzig Nukleotide 5' vor der interessanten DNA-Sequenz bindet. Bei der PCR werden zusätzlich zu den dNTPs auch fluoreszenzmarkierte ddNTPs zugegeben, deren Einbau zum Kettenabbruch führt. Auf diese Weise entstehen unterschiedlich lange DNA-Fragmente, deren endständiges Nukleotid durch die Art der Fluoreszenzmarkierung sichtbar ist.

Es wird folgender $10 \mu \mathrm{l}$ Ansatz pipettiert: $200 \mathrm{ng}$ DNA

8 pmol Primer

$1 \mu 1$ Sequenziermix

$1 \mu 1$ Sequenzierpuffer

ad $10 \mu \mathrm{l}$ Wasser

PCR-Temperaturzyklen:

$\begin{array}{lll}\text { Denaturierung } & 94^{\circ} \mathrm{C} & 2^{\prime} \\ \text { Denaturierung } & 94^{\circ} \mathrm{C} & 30^{\circ}, \\ \text { Hybridisierung } & 50^{\circ} \mathrm{C} & 45^{\prime c} \\ \text { Elongation } & 60^{\circ} \mathrm{C} & 3^{\circ} \\ \text { Finale Elongation } & 60^{\circ} \mathrm{C} & 5^{\circ}\end{array}$ 25x

Das PCR-Produkt wird anschließend über Ethanolfällung gereinigt. Dazu werden $1 \mu$ $125 \mathrm{mM}$ EDTA, $1 \mu \mathrm{l} 3 \mathrm{M}$ Natriumacetat sowie $50 \mu \mathrm{l} 100 \%$ Ethanol zugegeben. Nach vorsichtigem Mischen wird der Ansatz 5' bei Raumtemperatur inkubiert und dann zentrifugiert $\left(16000 \mathrm{x} \mathrm{g}, 4^{\circ} \mathrm{C}, 15^{\circ}\right)$. Das DNA-Pellet wird mit $70 \%$ Ethanol gewaschen, an der Luft getrocknet und in $30 \mu \mathrm{l}$ Wasser aufgenommen.

Die Analyse der Sequenzierung erfolgt in der Abteilung von Prof. Pieler, Universität Göttingen. Die fluoreszenzmarkierten PCR-Fragmente werden auf einem Acrylamidgel aufgetrennt und detektiert. Dazu wird ein ABIPrism 3100 DNA Sequencer verwendet.

\subsubsection{Ortsgerichtete Mutagenese}

Die ortsgerichtete Mutagenese wird nach den Anleitungen des QuickChange Site-Directed Mutagenesis Kit von Stratagene durchgeführt. Dabei werden zwei komplementäre Oligonukleotide verwendet, deren Hybridisierungstemperatur mindestens $78^{\circ} \mathrm{C}$ beträgt und welche die gewünschte Mutation enthalten. In einer PCR-Reaktion wird der Matrizen-Vektor mit diesen Oligonukleotiden vollständig amplifiziert. Der amplifizierte Vektor enthält dann die Mutation. 
Es wird ein $20 \mu l$-Ansatz pipettiert:

\author{
20 ng Matrizen-DNA \\ 1x Phusion HF Puffer \\ $1-2,5 \mathrm{mM} \mathrm{MgCl} 2$ \\ je 4 pmol DNA-Oligonukleotid (Primer) \\ je $80 \mu \mathrm{M}$ dATP, dGTP, dTTP, dCTP \\ 0,4 U Phusion-DNA-Polymerase
}

Die PCR besteht aus folgenden Temperaturzyklen:

$\begin{array}{lll}\text { Denaturierung } & 98^{\circ} \mathrm{C} & 3 \\ \text { Denaturierung } & 98^{\circ} \mathrm{C} & 10^{\prime \prime} \\ \text { Hybridisierung } & \mathrm{x}^{\circ} \mathrm{C} & 30^{\prime \prime} \\ \text { Elongation } & 72^{\circ} \mathrm{C} & 30^{\prime \prime} \text { pro } \mathrm{kb} \\ \text { Finale Elongation } & 72^{\circ} \mathrm{C} & 10^{\prime}\end{array}$ 20x

Die Hybridisierungstemperatur variiert zwischen $55^{\circ} \mathrm{C}$ und $72^{\circ} \mathrm{C}$. Durch Zugabe von $4 \mathrm{U}$ DpnI und Inkubation für $3 \mathrm{~h}$ bei $37^{\circ} \mathrm{C}$ wird die methylierte Matrizen-DNA abgebaut. Es folgt die Transformation von E. coli Zellen des Stammes XL1blue mit $10 \mu 1$ des Amplifikats (2.2.1.7). Positive Klone werden selektiert, indem die Plasmid-DNA isoliert (2.2.1.2) und sequenziert (2.2.1.9) wird.

\title{
2.2.2 Proteinbiochemische Methoden
}

\subsubsection{1 Überexpression rekombinanter Proteine in Bakterien}

Die Überexpression in Bakterien ermöglicht die effiziente Produktion großer Proteinmengen. Dazu wird die kodierende DNA-Sequenz in einen Expressionsvektor kloniert (2.2.1.8) und dann in E. coli Zellen eines Expressionsstammes (BL21 STAR (DE3), Rosetta 2 (DE3)) eingebracht (2.2.1.7). Die Proteinexpression steht bei den meisten Vektoren unter der Kontrolle eines lac-Promotors und wird durch Zugabe von IPTG oder Laktose induziert.

\subsection{Induktion mit IPTG in 2xYT-Medium}

$\begin{array}{ll}\text { 2xYT-Medium: } & 1,6 \%(w / v) \text { Trypton } \\ & 0,5 \%(w / v) \mathrm{NaCl} \\ & 1 \%(w / v) \text { Hefeextrakt }\end{array}$

Ein Liter 2xYT-Medium mit Antibiotika wird mit $30 \mathrm{ml}$ einer Übernachtkultur (2xYT) des den Expressionsvektor tragenden Klons angeimpft und bei $30^{\circ} \mathrm{C}$ und $220 \mathrm{rpm}$ inkubiert. Wenn eine optische Dichte $\mathrm{OD}_{600}=0,3-0,4$ erreicht ist, wird die Expressionskultur bei 16$18^{\circ} \mathrm{C}$ weiterinkubiert. Nachdem das Medium abgekühlt ist, wird bei einem $\mathrm{OD}_{600}$-Wert von 0,4-0,8 die Proteinexpression induziert, indem $0,1 \mathrm{mM}$ bis $0,5 \mathrm{mM}$ IPTG zugegeben werden. Die Kultur wird bei $16-18^{\circ} \mathrm{C}$ weiter inkubiert. Nach $18-24 \mathrm{~h}$ werden die Zellen durch Zentrifugation geerntet $\left(5700 \mathrm{x} \mathrm{g}, 15^{\circ}, 4^{\circ} \mathrm{C}\right)$. Sie werden entweder sofort aufgeschlossen (2.2.2.2) oder in flüssigem Stickstoff tiefgefroren und bei $-80^{\circ} \mathrm{C}$ gelagert. 


\subsection{Autoinduktion}

\begin{tabular}{|c|c|c|c|c|c|}
\hline 1 x ZY: & \multicolumn{2}{|c|}{$\begin{array}{l}1 \%(\mathrm{w} / \mathrm{v}) \text { Trypton } \\
0,5 \%(\mathrm{w} / \mathrm{v}) \text { Hefeextrakt } \\
\text { autoklaviert }\end{array}$} & \multicolumn{3}{|c|}{$\begin{aligned} 1000 \times \mathrm{Mg}^{2+}: & 2 \mathrm{M} \mathrm{MgSO}_{4} \\
& \text { autoklaviert }\end{aligned}$} \\
\hline $50 \times \mathrm{M}:$ & \multicolumn{2}{|c|}{$\begin{array}{l}\text { 1,25 } \mathrm{M} \mathrm{K}_{2} \mathrm{HPO}_{4} \\
1,25 \mathrm{M} \mathrm{NaH}_{2} \mathrm{PO}_{4} \\
\text { 2,5 } \mathrm{M} \mathrm{NH}_{4} \mathrm{Cl} \\
0,25 \mathrm{M} \mathrm{Na}_{2} \mathrm{SO}_{4} \\
\text { autoklaviert }\end{array}$} & $50 \times 5052:$ & \multicolumn{2}{|c|}{$\begin{array}{l}25 \%(\mathrm{v} / \mathrm{v}) \text { Glyzerin } \\
2,5 \%(\mathrm{w} / \mathrm{v}) \text { Glukose } \\
10 \%(\mathrm{w} / \mathrm{v}) \alpha \text {-Laktose } \\
\text { autoklaviert }\end{array}$} \\
\hline \multicolumn{2}{|c|}{5000 x Spurenelemente-1: } & $\begin{array}{l}50 \mathrm{mM} \mathrm{FeCl}_{3} \\
10 \mathrm{mM} \mathrm{ZnSO}_{4} \\
2 \mathrm{mM} \mathrm{NiSO}_{4} \\
2 \mathrm{mM} \mathrm{H}_{3} \mathrm{BO}_{3} \\
\text { sterilfiltriert }\end{array}$ & $\begin{array}{l}20 \mathrm{mM} \mathrm{CaCl}_{2} \\
2 \mathrm{mM} \mathrm{CoCl}_{2} \\
2 \mathrm{mM} \mathrm{Na}_{2} \mathrm{MoC}\end{array}$ & & $\begin{array}{l}10 \mathrm{mM} \mathrm{MnCl}_{2} \\
2 \mathrm{mM} \mathrm{CuCl}_{2} \\
2 \mathrm{mM} \mathrm{Na}_{2} \mathrm{SeO}_{3}\end{array}$ \\
\hline
\end{tabular}

In Autoinduktionsmedium wird die Proteinexpression durch Laktose induziert. Das Medium enthält nur eine begrenzte Menge an Glukose, die in der ersten Wachstumsphase von den Zellen verbraucht wird. Ist die Glukose aufgebraucht, erfolgt die Umstellung des Stoffwechsels auf Laktose und damit auch die Induktion der Expression des rekombinanten Proteins. Ein Vorteil dieses Mediums ist, dass hohe Zelldichten erreicht werden, so dass die Proteinausbeute pro Liter sehr groß ist (Studier 2005).

$10 \mathrm{ml}$ 2xYT-Medium mit Antibiotika werden mit dem transformierten Expressionsstamm angeimpft und über Nacht bei $37^{\circ} \mathrm{C}$ und $220 \mathrm{rpm}$ inkubiert. Am nächsten Tag wird die Kultur in 11 Autoinduktionsmedium ZYM-5052 (1 x ZY, 1 x 5052, 1 x M, 1 x $\mathrm{Mg}^{2+}$, $1 \mathrm{x}$ Spurenelemente-1, Antibiotika) überführt und zunächst bei $30^{\circ} \mathrm{C}$ und $220 \mathrm{rpm}$ inkubiert. Um eine ausreichende Belüftung der Zellen zu gewährleisten, werden dabei maximal $300 \mathrm{ml}$ Medium in einen 21 Erlenmeyer-Kolben gegeben. Sobald ein $\mathrm{OD}_{600}$-Wert von 0,3-0,4 erreicht ist, wird bei $18^{\circ} \mathrm{C}$ weiter inkubiert. Gegebenenfalls wird die Proteinexpression bei einem OD $_{600}$-Wert von 0,4-0,8 durch Zugabe von 0,1-0,3 mM IPTG verstärkt. Nach 48 h Inkubation ist ein $\mathrm{OD}_{600}$-Wert von 10-15 erreicht und die Zellen werden geerntet $\left(5700 \mathrm{x} \mathrm{g}, 15^{\circ}, 4^{\circ} \mathrm{C}\right)$. Sie werden entweder sofort aufgeschlossen (2.2.2.2) oder mit flüssigem Stickstoff tiefgefroren und bei $-80^{\circ} \mathrm{C}$ gelagert.

\subsection{Induktion mit IPTG in Minimalmedium}

Durch Überexpression in Minimalmedium werden Proteinderivate für besondere Anwendungen hergestellt. 


\subsection{Expression von ${ }^{15} \mathrm{~N}$ - und ${ }^{15} \mathrm{~N}-{ }^{13} \mathrm{C}$-markiertem Protein}

\begin{tabular}{|c|c|c|}
\hline 5 x M9-1: & $\begin{array}{l}0,21 \mathrm{M} \mathrm{Na}_{2} \mathrm{HPO}_{4} \\
0,11 \mathrm{M} \mathrm{KH}_{2} \mathrm{PO}_{4} \\
42,8 \mathrm{mM} \mathrm{NaCl} \\
92 \mathrm{mM}^{15} \mathrm{NH}_{4} \mathrm{Cl} \\
\text { pH 7,4, autoklaviert }\end{array}$ & 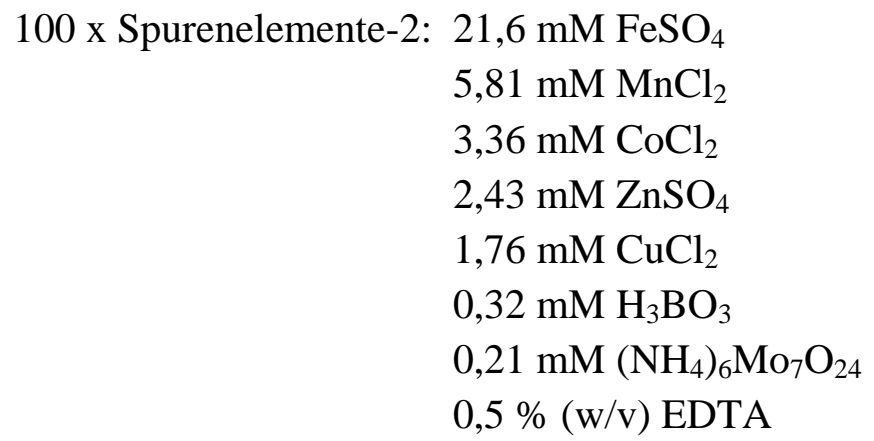 \\
\hline
\end{tabular}

Rühren für mehrere Stunden oder über Nacht, bis Lösung goldbraun (nicht grün). Danach sterilfiltrieren.

Toronto Minimalmedium: 1 x M9-1

$1 \times$ Spurenelemente- 2

$0,4 \%$ Glukose (gegebenenfalls ${ }^{13} \mathrm{C}$-Glukose)

$2 \mathrm{mM} \mathrm{MgSO}_{4}$

$0,1 \mathrm{mM} \mathrm{CaCl}_{2}$

$0,003 \%(\mathrm{w} / \mathrm{v})$ Thiaminhydrochlorid

Antibiotika

Ein Klon des transformierten Expressionsstammes wird in $2 \mathrm{ml} \mathrm{LB}-$ Medium mit Antibiotika für $4 \mathrm{~h}$ bei $37^{\circ} \mathrm{C}$ unter Schütteln $(220 \mathrm{rpm})$ angezogen. Anschließend wird die Kultur in $50 \mathrm{ml}$ Toronto Minimalmedium überführt und über Nacht bei $37^{\circ} \mathrm{C}$ inkubiert. Am nächsten Tag wird die Kultur wiederum in 11 Toronto Minimalmedium verdünnt und bei $18^{\circ} \mathrm{C}$ und 220 rpm gehalten. Bei einem $\mathrm{OD}_{600}$-Wert von 0,5-0,6 wird die Proteinexpression mit 0,3 mM IPTG induziert. Nach 60-70 h Inkubation ist ein $\mathrm{OD}_{600}-$ Wert von 3-4 erreicht. Die Zellen werden geerntet $\left(5700 \times \mathrm{g}, 15^{\circ}, 4^{\circ} \mathrm{C}\right)$, in flüssigem Stickstoff tiefgefroren und bei $-80^{\circ} \mathrm{C}$ gelagert.

\subsection{Expression von Selenomethionin-Protein}

\begin{tabular}{|c|c|c|c|}
\hline 10 x M9-2: & $\begin{array}{l}\text { 0,56 } \mathrm{M} \mathrm{Na}_{2} \mathrm{HPO}_{4} \\
0,29 \mathrm{M} \mathrm{KH}_{2} \mathrm{PO}_{4} \\
85,6 \mathrm{mM} \mathrm{NaCl} \\
\text { 93,5 mM NH} \mathrm{mH}_{4} \mathrm{Cl} \\
\text { autoklaviert }\end{array}$ & 100 x Spurenelemente-3: & $\begin{array}{l}0,5 \%(\mathrm{w} / \mathrm{v}) \mathrm{EDTA}_{(\mathrm{pH} 7,5)} \\
3,1 \mathrm{mM} \mathrm{FeCl}_{3} \\
0,62 \mathrm{mM} \mathrm{ZnCl}_{2} \\
0,076 \mathrm{mM} \mathrm{CuCl}_{2} \\
0,060 \mathrm{mM} \mathrm{CoCl}_{2} \\
0,016 \mathrm{mM} \mathrm{H}_{3} \mathrm{BO}_{3} \\
0,0068 \mathrm{mM} \mathrm{MnCl}_{2} \\
\text { autoklaviert }\end{array}$ \\
\hline
\end{tabular}




$\begin{array}{ll}\text { SeMet-Minimalmedium: } & 1 \times \mathrm{M} 9-2 \\ & 1 \times \text { Spurenelemente-3 } \\ & 1 \mathrm{mM} \mathrm{MgSO}_{4} \\ & 0,3 \mathrm{mM} \mathrm{CaCl}_{2} \\ & 0,4 \% \mathrm{Glukose} \\ & 0,0001 \%(\mathrm{w} / \mathrm{v}) \text { Biotin } \\ & 0,0001 \%(\mathrm{w} / \mathrm{v}) \text { Thiaminhydrochlorid } \\ & (0,005 \%(\mathrm{w} / \mathrm{v}) \text { L-Methionin }) \\ & \text { Antibiotika }\end{array}$

Als Expressionsstamm werden Methionin-auxotrophe B834-(DE3)-Zellen verwendet. $7 \mathrm{ml}$ Minimalmedium mit L-Methionin werden mit einem transformierten Klon angeimpft und über Nacht bei $37^{\circ} \mathrm{C}$ angezogen. Die Vorkultur wird in 11 Minimalmedium mit L-Methionin überführt und bei $30^{\circ} \mathrm{C}$ und $210 \mathrm{rpm}$ inkubiert. Bei einem $\mathrm{OD}_{600}$-Wert von 0,5-0,6 werden die Zellen zentrifugiert $\left(2000 \mathrm{x} \mathrm{g,} 15^{\circ}, 4^{\circ} \mathrm{C}\right)$ und $30^{\circ}$ auf Eis inkubiert. Anschließend werden sie in 11 Minimalmedium ohne Methionin resuspendiert und für $2-3 \mathrm{~h}$ bei $30^{\circ} \mathrm{C}$ und $210 \mathrm{rpm}$ inkubiert. Während dieser Zeit verbrauchen die Zellen noch verbliebenes Methionin (Hungerphase). Sobald der $\mathrm{OD}_{600}$-Wert stagniert, wird 0,005 \% (w/v) Selenomethionin zugegeben und die Kultur nach $18^{\circ} \mathrm{C}$ überführt. Nach $45^{\circ}$ wird die Proteinexpression durch Zugabe von 0,3 mM IPTG induziert. Die Zellernte erfolgt 16-18 h nach der Induktion (5700 x $\mathrm{g}, 20^{\circ}, 4^{\circ} \mathrm{C}$ ). Die Zellen werden in flüssigem Stickstoff tiefgefroren und bei $-80^{\circ} \mathrm{C}$ gelagert.

\subsubsection{Zellaufschluss}

Aufschlusspuffer: $\quad 2 \mathrm{M} \mathrm{LiCl}$

$50 \mathrm{mM}$ Tris- $\mathrm{HCl}, \mathrm{pH} 7,5$

$5 \%(\mathrm{v} / \mathrm{v})$ Glyzerin

$2 \mathrm{mM} \beta$-Mercaptoethanol

Das Zellpellet von 11 Expressionskultur (2.2.2.1) wird in 20-50 ml gekühltem Aufschlusspuffer resuspendiert. Der Zellaufschluss erfolgt unter Kühlung in 3-7 Zyklen bei 80 psi mit einem Microfluidizer. Nach Ultrazentrifugation $\left(20000\right.$ x g, 30*, $\left.4^{\circ} \mathrm{C}\right)$ wird der Überstand zunächst über Affinitätschromatographie gereinigt (2.2.2.3).

\subsubsection{Proteinreinigung}

Alle Proteinreinigungen werden bei $4^{\circ} \mathrm{C}$ an einer ÄKTA Prime Plattform durchgeführt. Eine Ausnahme bildet die analytische Gelfiltration, die bei $20^{\circ} \mathrm{C}$ an einer $\ddot{\mathrm{KKT}}$ A Purifier Plattform erfolgt.

Die Säulen werden in $20 \%$ Ethanol gelagert. Deshalb werden sie vor der Verwendung zunächst mit Wasser gewaschen. 


\subsection{Hexahistidin-Affinitätschromatographie}

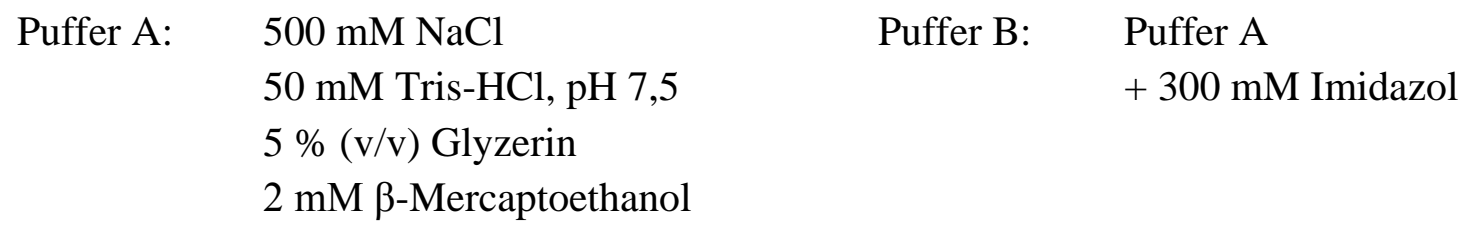

Das Säulenmaterial $\mathrm{Ni}^{2+}$-NTA eignet sich zur spezifischen Reinigung von Hexahistidinmarkierten Proteinen. Es werden Fertigsäulen mit $5 \mathrm{ml}$ Säulenvolumen verwendet (2.1.2). Um eine unspezifische Bindung an die Säule zu unterdrücken, wird die Probe zunächst mit $10 \mathrm{mM}$ Imidazol versetzt und dann auf die mit Puffer A äquilibrierte Säule geladen. Nach Waschen der Säule mit 6 Säulenvolumina 5\% Puffer B (15 mM Imidazol) erfolgt die Elution. Dazu wird ein linearer Gradient von 5-100\% Puffer B über 6-10 Säulenvolumina verwendet. Das Eluat wird in 1 ml-Fraktionen gesammelt.

Zur Reinigung der Säule von restlichen gebundenen Proteinen wird sie mit Wasser äquilibriert und dann mit 1-2 Säulenvolumina $6 \mathrm{M}$ Guanidinhydrochlorid gewaschen.

Für eine besonders gründliche Reinigung und Regeneration der Säule werden die $\mathrm{Ni}^{2+}$-Ionen mit 2 Säulenvolumina 50 mM EDTA entfernt. Nach Waschen mit Wasser wird die Säule mit 1 Säulenvolumen $0,1 \mathrm{M} \mathrm{NiSO}_{4}$ neu beladen. Überschüssige $\mathrm{Ni}^{2+}$-Ionen werden mit jeweils 5 Säulenvolumina Wasser und anschließend Puffer B entfernt.

\subsection{Glutathion-S-Transferase- Affinitätschromatographie}

$\begin{array}{llll}\text { Puffer A: } & 500 \mathrm{mM} \mathrm{NaCl} & \text { Puffer B: } & \text { Puffer A } \\ & 50 \mathrm{mM} \text { Tris-HCl, } \mathrm{pH} \mathrm{7,5} & & +10 \mathrm{mM} \text { reduziertes Glutathion } \\ & 5 \%(\mathrm{v} / \mathrm{v}) \text { Glyzerin } & & \\ & 2 \mathrm{mM} \beta \text {-Mercaptoethanol } & \end{array}$

Zur spezifischen Bindung von Glutathion-S-Transferase (GST)-markierten Proteinen wird GSH-Sepharose verwendet. Es werden Fertigsäulen mit $5 \mathrm{ml}$ Säulenvolumen eingesetzt (2.1.2). Die Säule wird mit Puffer A äquilibriert und mit der Probe beladen. Nach Waschen mit 6 Säulenvolumina Puffer A wird mit 2-4 Säulenvolumina Puffer B eluiert. Das Eluat wird in 1-2 ml Fraktionen gesammelt.

Zur Reinigung wird die Säule mit Wasser äquilibriert und dann mit 1-2 Säulenvolumina 6 M Guanidinhydrochlorid gewaschen.

\subsection{Gelfiltration (Ausschlusschromatographie)}

Bei der Gelfiltration oder Ausschlusschromatographie werden Proteine nach ihrer Größe aufgetrennt. Als Säulenmaterial wird Superdex 75 oder 200 verwendet (2.1.2). Für präparative Gelfiltrationen wird ein Säulenformat von 16/60 oder 26/60 verwendet (d.h. 16 oder 26 mm Durchmesser und $60 \mathrm{~cm}$ Länge) und bei $4^{\circ} \mathrm{C}$ and eine ÄKTA Prime Plattform betrieben. Für 
analytische Gelfiltrationen beträgt das Säulenformat $10 / 30$ und wird bei $20^{\circ} \mathrm{C}$ an einer ÄKTA Purifier Plattform verwendet. Diese Plattform hat den Vorteil, dass die Elution bei verschiedenen UV-Wellenlängen verfolgt werden kann.

Der bei der Gelfiltration verwendete Puffer ist jeweils vom Protein abhängig und wird gesondert im Ergebnisteil beschrieben. Die Säule wird mit dem Puffer äquilibriert. Die Proteinprobe wird auf ein Volumen konzentriert (2.2.2.4), das maximal $2 \%$ des Säulenvolumens beträgt, zentrifugiert $\left(14000 \times \mathrm{g}, 10^{\circ}, 4^{\circ} \mathrm{C}\right)$ und dann auf die Säule aufgetragen. Die Elution erfolgt mit einem Säulenvolumen Puffer.

Zur Reinigung der Säule wird 0,1-0,5 M NaOH verwendet.

\subsection{Entsalzungssäule}

Entsalzungssäulen ermöglichen es, eine Proteinlösung in kurzer Zeit in einen anderen Puffer zu bringen. Es werden Fertigsäulen mit $5 \mathrm{ml}$ Säulenvolumen aus Sephadex G-25 verwendet (2.1.2). Die Säule wird mit dem angestrebten Puffer äquilibriert. Anschließend wird die Proteinprobe in einem Volumen bis zu 1,5 ml aufgetragen und mit 1-2 Säulenvolumina Puffer eluiert. Das Protein durchläuft die Säule schneller als die Salzionen seines Ausgangspuffers.

\subsubsection{Konzentration von Proteinlösungen}

Proteinlösungen werden über Zentrifugation bei $4^{\circ} \mathrm{C}$ konzentriert. Eine Membran mit unterschiedlichen Porengrößen hält dabei das Protein zurück, während die niedermolekularen Pufferbestandteile sie durchwandern können. Es werden VivaSpin-Konzentratoren der Firma Sartorius, Göttingen, verwendet. Die maximale Zentrifugalkraft beträgt 4000 x g.

\subsubsection{Spezifische Proteolyse mit PreScission Protease}

Die GST-Markierung wird nach der GST-Affinitätschromatographie mit PreScission Protease abgespalten. Dazu wird das Fusionsprotein im molaren Verhältnis von 100:1 mit PreScission Protease versetzt und über Nacht bei $4^{\circ} \mathrm{C}$ auf dem Roller inkubiert.

\subsubsection{Phosphorylierung mit SRPK1-Mini}

Um nach der Hexahistidin-Affinitätschromatographie (2.2.2.3.1) die RS-Domäne des gereinigten Proteins zu phosphorylieren, werden zu den vereinigten Fraktionen zunächst $\mathrm{MgCl}_{2}$ und ATP bis zu einer Endkonzentration von $10 \mathrm{mM}$ bzw. $1 \mathrm{mM}$ gegeben. Außerdem wird das Protein mit GST-SRPK1-Mini im molaren Verhältnis von 100:1 versetzt und über Nacht bei $4^{\circ} \mathrm{C}$ auf dem Roller inkubiert. 


\subsubsection{Polyacrylamidgelelektrophorese (PAGE)}

\subsection{SDS-PAGE}

Trenngel: $\quad 10-15 \%(\mathrm{w} / \mathrm{v})$ Acrylamid/Bisacrylamid (37,5:1)

0,376 M Tris- $\mathrm{HCl}, \mathrm{pH} 8,8$

$0,1 \%(\mathrm{w} / \mathrm{v}) \mathrm{SDS}$

$0,08 \%(\mathrm{v} / \mathrm{v})$ TEMED

$0,05 \%(w / v)$ APS

Sammelgel: $\quad 5 \%$ (w/v) Acrylamid/Bisacrylamid (37,5:1)

0,125 M Tris-HCl, $\mathrm{pH} 6,8$

$0,1 \%(\mathrm{w} / \mathrm{v}) \mathrm{SDS}$

$0,15 \%(\mathrm{v} / \mathrm{v})$ TEMED

$0,075 \%(\mathrm{w} / \mathrm{v})$ APS

2 x Laemmli Ladepuffer: $\quad$ 0,125 M Tris-HCl, $\mathrm{pH}$ 6,8

$4 \%(\mathrm{w} / \mathrm{v}) \mathrm{SDS}$

$20 \%(\mathrm{v} / \mathrm{v})$ Glyzerin

$0,2 \mathrm{M}$ DTT

$0,02 \%(\mathrm{w} / \mathrm{v})$ Bromphenolblau

1 x SDS-Laufpuffer: 0,025 M Tris

0,192 M Glycin

$0,1 \%(\mathrm{w} / \mathrm{v}) \mathrm{SDS}$

Bei der SDS-Polyacrylamidgelelektrophorese werden Proteine durch Natriumdodecylsulfat (englisch sodium dodecyl s sulfate, SDS) denaturiert und nach ihrem Molekulargewicht aufgetrennt.

Die Proben werden vor dem Beladen 1:1 mit Laemmli Ladepuffer vermischt und $2^{\circ}$ bei $95^{\circ} \mathrm{C}$ inkubiert. In der Regel werden 12,5 \%ige Gele benutzt. Die Elektrophorese erfolgt bei $25 \mathrm{~mA}$ für 60` bis 90'. Anschließend werden die Proteine durch Coomassie-Färbung sichtbar gemacht (2.2.2.7.3). Eine sensitivere Methode, die zusätzlich auch RNA detektiert, ist die Silberfärbung (2.2.2.7.4).

\subsection{Native PAGE}

Trenngel: $\quad 12,5 \%(\mathrm{w} / \mathrm{v})$ Acrylamid/Bisacrylamid (37,5:1)

0,213 M MOPS, pH 6,8 (mit $50 \mathrm{mM} \mathrm{KOH)}$

$0,08 \%(\mathrm{v} / \mathrm{v})$ TEMED

$0,05 \%$ (w/v) APS 
Sammelgel: $\quad 5 \%(\mathrm{w} / \mathrm{v})$ Acrylamid/Bisacrylamid (37,5:1)

0,063 M MOPS, pH 8,0 (mit $50 \mathrm{mM} \mathrm{KOH}$ )

$20 \%(\mathrm{v} / \mathrm{v})$ Glyzerin

$0,15 \%(\mathrm{v} / \mathrm{v})$ TEMED

$0,075 \%(w / v)$ APS

2 x Ladepuffer: $\quad$ 0,063 M MOPS, pH 8,0 (mit $50 \mathrm{mM} \mathrm{KOH)}$

$20 \%(\mathrm{v} / \mathrm{v})$ Glyzerin

$0,02 \%(\mathrm{w} / \mathrm{v})$ Bromphenolblau

Laufpuffer: $\quad$ 0,022 M MOPS, pH 6,8

$0,10 \mathrm{M}$ Histidin

Bei der nativen Polyacrylamidelektrophorese werden die Proteine nicht denaturiert, sondern entsprechend ihrer nativen Ladung aufgetrennt. Diese Ladung hängt sowohl vom isoelektrischen Punkt des Proteins als auch vom pH-Wert des Puffers ab. Das hier beschriebene Gelsystem eignet sich für Proteine mit einem isoelektrischen Punkt oberhalb von 8,0 (Thomas und Hodes 1981). Im Gegensatz zur SDS-PAGE (2.2.2.7.1) laufen die Proteine während der Elektrophorese in Richtung der Kathode.

Die Proben werden vor dem Beladen 1:1 mit Ladepuffer vermischt und direkt auf das Gel aufgetragen. Das Bromphenolblau im Ladepuffer dient lediglich dazu, die Beladung des Gels zu erleichtern. Um den Verlauf der Elektrophorese beobachten zu können, wird zur Kontrolle Cytochrom $C$ aufgetragen. Dieses Protein hat einen pI-Wert von 9,2 und ist durch seine rote Farbe gut zu verfolgen. Die Elektrophorese erfolgt bei $12 \mathrm{~mA}$ für $3 \mathrm{~h}$. Anschließend werden die Proteine durch Coomassie-Färbung sichtbar gemacht (2.2.2.7.3).

\subsection{Coomassie-Färbung}

Das Polyacrylamidgel wird in $50 \mathrm{ml} 15 \%$ Ethanol und $5 \%$ Essigsäure gelegt, zu dem $200 \mu \mathrm{l}$ 2 \%ige Coomassie-Brilliantblau-Lösung (R250:G250 = 4:1) gegeben werden. Nach 30`-60` sind die Proteine vollständig gefärbt. Das Gel wird anschließend in Wasser entfärbt.

\subsection{Silberfärbung}

Fixierlösung /Stopplösung: $50 \%$ (v/v) Methanol, $12 \%$ (v/v) Essigsäure

Thiosulfatlösung: $\quad 0,8 \mathrm{mM} \mathrm{Na}_{2} \mathrm{~S}_{2} \mathrm{O}_{3}$

Silbernitratlösung: $\quad 12 \mathrm{mM} \mathrm{AgNO}_{3}, 0,026 \%$ (v/v) Formaldehyd

Entwickler: $\quad 0,57 \mathrm{M} \mathrm{Na}_{2} \mathrm{CO}_{3}, 0,0185 \%$ (v/v) Formaldehyd, $16 \mu \mathrm{M} \mathrm{Na}_{2} \mathrm{~S}_{2} \mathrm{O}_{3}$

Für diese Färbung muss unvergälltes Ethanol verwendet werden. Das Polyacrylamidgel wird über Nacht in Fixierlösung gelegt. Anschließend wird es 2 × $20^{\circ}$ in $50 \%$ Ethanol und 1 x 20' in $30 \%$ Ethanol inkubiert. Nach $1^{\prime}$ in Thiosulfatlösung wird das Gel mit Wasser gewaschen 
(3 x 20“) und dann 20` in Silbernitratlösung gelegt. Wieder wird mit Wasser gewaschen (3 x 20“") und dann $2^{6}-10^{\prime}$ im Entwickler inkubiert, bis die gewünschte Färbung erreicht ist. Schließlich wird das Gel mit Wasser gewaschen $\left(2 \times 2^{\circ}\right)$ und die Farbentwicklung durch Inkubation in Stopplösung beendet.

\subsubsection{ATPase Aktivitätstest mittels HPLC}

Die Untersuchung der ATPase Aktivität erfolgt durch direkte Detektion der Umsetzung von ATP zu ADP. Dazu werden ATP und ADP über HPLC mit einer ProntoSIL-Säule (2.1.2) voneinander getrennt und quantifiziert.

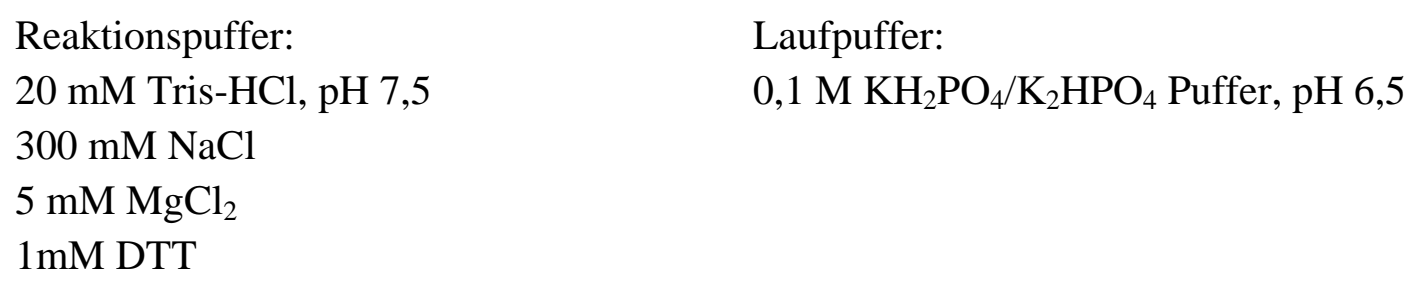

Es werden $1 \mathrm{mg} / \mathrm{ml}$ Protein in Reaktionspuffer eingesetzt. Gegebenenfalls wird außerdem RNA (Typ III aus Hefe) zugegeben. Zur Kontrolle wird jeweils ein identischer Ansatz ohne Protein analysiert. Die Zugabe von 0,5 mM ATP startet die Reaktion. Die Inkubation erfolgt bei $37^{\circ} \mathrm{C}$ für bis zu $9 \mathrm{~h}$. Nach verschiedenen Zeitpunkten werden $20 \mu \mathrm{l}$ Proben entnommen und sofort $2^{\circ}$ bei $85^{\circ} \mathrm{C}$ hitzeinaktiviert. Das denaturierte Protein wird abzentrifugiert (5', $14000 x g, 4^{\circ} \mathrm{C}$ ) und der Überstand über HPLC analysiert.

Die HPLC wird an einer $\ddot{A} K T A$ Purifier Plattform bei $20^{\circ} \mathrm{C}$ durchgeführt. Verwendet wird eine ProntoSIL-Säule (Bettvolumen 1,5 ml, $12 \mathrm{MPa}$ Maximaldruck). Es wird ein Probenvolumen von $10 \mu \mathrm{l}$ aufgetragen. Die HPLC erfolgt mit einer Flussrate von $1 \mathrm{ml} / \mathrm{min}$ mit dem oben angegebenen Laufpuffer. Die Detektion von ATP und ADP erfolgt über UVAbsorption bei $280 \mathrm{~nm}$ und $254 \mathrm{~nm}$. ATP verlässt die Säule etwas früher als ADP. Die Berechnung des Verhältnisses zwischen ATP und ADP erfolgt über Integration und Vergleich der Flächen unterhalb der 254 nm-UV-Absorptionsmaxima. Es gilt:

$$
\text { hydrolysiertes ATP in }[\%]=100 \% * \text { Fläche }_{\mathrm{ADP}} /\left(\text { Fläche }_{\mathrm{ATP}}+\text { Fläche }_{\mathrm{ADP}}\right)
$$

Von jedem Wert wird noch der entsprechende Wert der Kontrollreaktion abgezogen.

\subsubsection{Bestimmung der Proteinkonzentration}

\subsection{Bradford-Test}

Diese Methode beruht auf der Absorptionsänderung des Farbstoffs Coomassie Brilliantblau G-250 bei Bindung an Protein (Bradford 1976). Es wird das Protein Assay FarbstoffKonzentrat von der Firma Bio-Rad verwendet. Dieses wird zunächst mit 4 Teilen Wasser 
verdünnt. Davon werden $980 \mu 1$ mit $20 \mu 1$ der Proteinprobe gemischt. Nach 3`Inkubation bei Raumtemperatur wird die Absorption bei $595 \mathrm{~nm}$ gemessen. Der $\mathrm{OD}_{595}$-Wert entspricht ungefähr der Proteinkonzentration in $\mathrm{mg} / \mathrm{ml}$ in der Probe.

\subsection{UV-Absorptionsmessung}

Diese Methode beruht auf der Absorption von Proteinen bei $280 \mathrm{~nm}$ aufgrund ihres Gehalts an Tryptophan und Tyrosin. Enthält ein Protein $\mathrm{x}$ Tryptophanreste und y Tyrosinreste, errechnet sich der theoretische molare Extinktionskoeffizient nach folgender Formel:

$$
\varepsilon_{280 \text { (denat) }}=\mathrm{x}(\mathrm{Tyr}) * 1280 \mathrm{M}^{-1} \mathrm{~cm}^{-1}+\mathrm{y}(\mathrm{Trp}) * 5690 \mathrm{M}^{-1} \mathrm{~cm}^{-1}
$$

Dieser Wert gilt jedoch nur für ein entfaltetes Protein. Der molare Extinktionskoeffizient eines nativen Proteins wird nach der Methode von Gill und Hippel (1989) bestimmt.

Puffer A:

6 M Guanidiniumchlorid

20 mM Kaliumphosphatpuffer, pH 6,5
Puffer B:

$150 \mathrm{mM} \mathrm{NaCl}$

10 mM Tris* $\mathrm{HCl}, \mathrm{pH} 7,5$

$10 \mathrm{mM} \mathrm{MgCl} 2$

$1 \mathrm{mM}$ DTT

Es werden identische Proteinmengen in Puffer A und Puffer B überführt (Endkonzentration etwa $0,5 \mathrm{mg} / \mathrm{ml}$ ). Die Ansätze werden für $2 \mathrm{~h}$ bei $37^{\circ} \mathrm{C}$ inkubiert. Puffer A führt dabei zu einer Denaturierung des Proteins, während Puffer B das native Protein enthält. Nach Äquilibrierung der Proben auf $20^{\circ} \mathrm{C}$ wird die UV-Absorption bei $280 \mathrm{~nm}$ gemessen. Für den nativen Extinktionskoeffizienten gilt:

$$
\varepsilon_{280(\text { nativ })}=\varepsilon_{280(\text { denat })} * \mathrm{OD}_{280(\text { Puffer B })} / \mathrm{OD}_{280(\text { Puffer A) }}
$$

\subsubsection{Bestimmung von Bindungskonstanten}

Die Stärke der Bindung zwischen einem Protein und seinem Liganden kann mit der Dissoziationskonstanten $K_{D}$ beschrieben werden. Es gilt:

$$
\begin{array}{ll}
K_{D}=\frac{[P]^{*}[L]}{[P L]} & \\
& {[\mathrm{P}]: \text { Konzentration des freien Proteins }} \\
& {[\mathrm{L}]: \text { Konzentration des freien Liganden }} \\
& {[\mathrm{PL}]: \text { Konzentration des Protein-Ligand-Komplexes }}
\end{array}
$$

Zur Bestimmung der Dissoziationskonstanten für die Interaktion von hPrp28 mit ATP und ADP wurden zwei verschiedene Methoden verwendet: Fluoreszenztitration (2.2.2.10.1) und isotherme Titrationskalorimetrie (ITK, 2.2.2.10.2). In beiden Fällen wurde der $\mathrm{K}_{\mathrm{D}}$-Wert bei $25^{\circ} \mathrm{C}$ in Bindungspuffer ermittelt. 
Bindungspuffer:

$10 \mathrm{mM}$ Hepes/NaOH, pH 7,5

$150 \mathrm{mM} \mathrm{NaCl}$

$10 \mathrm{mM} \mathrm{MgCl}_{2}$

$1 \mathrm{mM}$ DTT

\subsection{Fluoreszenztitration}

Die Bestimmung des $\mathrm{K}_{\mathrm{D}}$-Wertes erfolgt über die Messung der Abnahme der TryptophanFluoreszenz des Proteins mit zunehmender Ligandenkonzentration. Als Ligand werden mantADP und mant-ATP (Jena Bioscience, Jena) verwendet. Die mant-Gruppe ist ein Fluorophor, das bei $355 \mathrm{~nm}$ maximal angeregt wird und bei $448 \mathrm{~nm}$ maximal fluoresziert. Da sich die Anregungswellenlänge mit der Tryptophan-Fluoreszenz von Proteinen überschneidet, kommt es bei Bindung des mant-Nukleotids zu einem Energietransfer zwischen der TryptophanFluoreszenz des Proteins und der mant-Gruppe (FRET-Effekt). Dadurch nimmt die Tryptophan-Fluoreszenz ab.

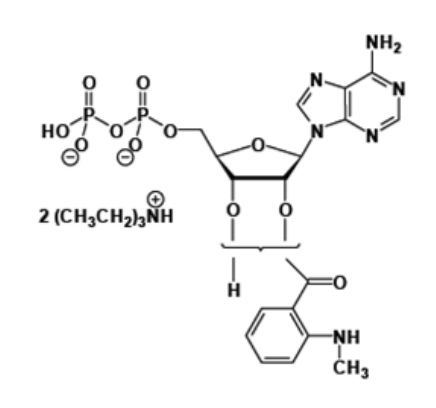

Abb. 2.1: mant-ADP

\subsection{Datenaufnahme}

Für mant-ATP und mant-ADP wird jeweils eine Ausgangslösung hergestellt, deren Konzentrationen über UV-Absorption bei $255 \mathrm{~nm}$ genau bestimmt werden. Gemäß den Herstellerangaben wird als Extinktionskoeffizient $\varepsilon_{255 \mathrm{~nm}}=23300 \mathrm{M}^{-1} \mathrm{~cm}^{-1}$ verwendet.

Es werden jeweils $140 \mu$ l Proben in Bindungspuffer vorbereitet. Sie enthalten $4 \mu \mathrm{M}$ Protein und unterschiedliche Konzentrationen des Liganden. Jede Probe wird dreimal unabhängig voneinander angesetzt. Nach dem Mischen werden sie $30^{\circ}-60^{\circ}$ bei $25^{\circ} \mathrm{C}$ inkubiert, damit sich das Bindungsgleichgewicht einstellt.

Die Fluoreszenzmessungen werden mit einem Spektrofluorimeter Fluoromax III (2.1.1) bei $25^{\circ} \mathrm{C}$ durchgeführt. Es werden $0,2 \times 1 \mathrm{~cm}^{2}$ Küvetten verwendet. Jede Probe wird für $5^{\circ} \mathrm{im}$ Küvettenhalter vorinkubiert. Gemessen wird das Fluoreszenzsignal (S/R, in der Einheit cps counts per second) bei $330 \mathrm{~nm}$ nach Anregung bei $295 \mathrm{~nm}$. Der Öffnungsschlitz für die Anregung ist $2 \mathrm{~nm}$ breit, derjenige für die Detektion $5 \mathrm{~nm}$. Die Detektion erfolgt während 1' 
mit einer Integrationszeit von $0,5^{\prime}$ “. Für jede Probe wird der Mittelwert berechnet und um den Beitrag des Puffers korrigiert.

Für einzelne Proben wird außerdem ein Fluoreszenzspektrum aufgenommen. Dabei wird mit $295 \mathrm{~nm}$ angeregt und das Fluoreszenzsignal (S/R) von $300 \mathrm{~nm}$ bis zu $470 \mathrm{~nm}$ gemessen (Schrittweite 0,5 nm).

\subsection{Korrekturfaktoren}

Die mant-Gruppe absorbiert einen kleinen Anteil der Anregungs- und Fluoreszenzstrahlung. Dieser Anteil wird mit zunehmender Ligandenkonzentration größer und verringert das beobachtete Fluoreszenzsignal (S/R). Durch Multiplikation mit Korrekturfaktoren wird dieser inner filter effect ausgeglichen (Birdsall et al. 1983).

Die Korrekturfaktoren basieren auf dem Lambert-Beer-Gesetz. Es wird dabei vereinfacht angenommen, dass das gemessene Fluoreszenzsignal im Küvettenmittelpunkt entsteht. Dann muss bezogen auf $0,2 \times 1 \mathrm{~cm}^{2}$ Küvetten die Anregungsstrahlung eine Weglänge von $0,5 \mathrm{~cm}$ und die Fluoreszenzstrahlung eine Strecke von $0,1 \mathrm{~cm}$ zurücklegen. Mit den molaren Extinktionskoffizienten $\varepsilon_{295 \mathrm{~nm}}$ (mant) und $\varepsilon_{330 \mathrm{~nm}}$ (mant) ergibt sich:

$$
(S / R)_{k o r r}=(S / R)_{\text {gemessen }} * 10^{\varepsilon_{295 n m}(\operatorname{mant})^{*}[L] * 0,5 \mathrm{~cm}} * 10^{\varepsilon_{330 \mathrm{~nm}}(\operatorname{mant})^{*}[L] * 0,1 \mathrm{~cm}}
$$

[L]: mant-ATP- oder -ADP-Konzentration

Der erste Exponentialterm korrigiert die Absorption der Anregungsstrahlung, der zweite Term die Absorption der Fluoreszenzstrahlung.

\subsection{Datenauswertung}

Die Gesamtkonzentration $[\mathrm{P}]_{0}$ des Proteins setzt sich aus der Konzentration des freien Proteins $[\mathrm{P}]$ und des Protein-Ligand-Komplexes $[\mathrm{PL}]$ zusammen: $[\mathrm{P}]_{0}=[\mathrm{P}]+[\mathrm{PL}]$. Damit lässt sich die Gleichung für den $\mathrm{K}_{\mathrm{D}}$-Wert (2.2.2.10) umformen zu:

$$
[P L]=\frac{[P]_{0}[L]}{[L]+K_{D}}
$$

[L]: Konzentration des freien Liganden

Diese Gleichung hat dieselbe Form wie die Michaelis-Menten Gleichung. Bei der Messung ist [PL] proportional zu der Abnahme der Tryptophan-Fluoreszenz $\Delta \mathrm{F}$. Maximal kann [PL] den Wert von $[\mathrm{P}]_{0}$ erreichen. Darum gilt:

$$
\Delta F=\frac{\Delta F_{\max }[L]}{[L]+K_{D}}
$$

Setzt man vereinfachend [L] gleich der zugegebenen Gesamtkonzentration des Liganden, so lässt sich mit dieser Formel $\mathrm{K}_{\mathrm{D}}$ aus den Typtophan-Fluoreszenzmessungen berechnen. Es wird das korrigierte Fluoreszenzsignal (S/R) gegen [L] aufgetragen und an folgende Gleichung angepasst: 


$$
\begin{aligned}
&(S / R)_{\text {korr }}=F_{\max }-\frac{\Delta F_{\max }[L]}{[L]+K_{D}} \\
& \\
& \mathrm{~F}_{\max }=\text { maximales (S/R)-Signal } \\
& \Delta \mathrm{F}_{\max }=\text { maximale Abnahme des (S/R)-Signals }
\end{aligned}
$$

Anpassungsparameter sind $\mathrm{F}_{\max }, \Delta \mathrm{F}_{\max }$ und $\mathrm{K}_{\mathrm{D}}$. Der Kurvenangleich wird mit dem Programm SigmaPlot durchgeführt.

Da die oben angegebene Gleichung dieselbe Form wie die Michaelis-Menten Gleichung hat, gilt in analoger Weise außerdem der Eadie-Hofstee-Plot:

$$
\Delta F=\Delta F_{\max }-K_{D} \frac{\Delta F}{[L]}
$$

Trägt man also $\Delta \mathrm{F}$ gegen $\Delta \mathrm{F} /[\mathrm{L}]$ auf, so ergibt sich eine Gerade, aus deren Steigung $\mathrm{K}_{\mathrm{D}}$ abgelesen werden kann. Dies ist eine alternative Möglichkeit, den $\mathrm{K}_{\mathrm{D}}$-Wert aus den Meßergebnissen zu bestimmen.

\subsection{Isotherme Tirationskalorimetrie (ITK)}

Bei der ITK wird die bei der Bindung umgesetzte Wärme gemessen. Dabei wird eine Proteinlösung vorgelegt und der Ligand in kleinen Volumina zugegeben. Nach jeder Zugabe wird die Wärmeauf- oder -abnahme durch Vergleich mit einer Referenzzelle bestimmt. Die umgesetzte Wärme nimmt mit steigender Ligandenkonzentration $a b$, da das Protein zunehmend gesättigt vorliegt. Aus dem Kurvenverlauf dieser Abnahme lassen sich der $\mathrm{K}_{\mathrm{D}^{-}}$ Wert, die Anzahl der Bindungsstellen $\mathrm{n}$ auf dem Protein und die molare Bindungsenthalpie $\Delta \mathrm{H}$ bestimmen. Außerdem folgen aus diesen Werten die Änderungen der freien Enthalpie $\Delta \mathrm{G}$ und der Entropie $\Delta \mathrm{S}$.

Ligand und Protein werden in Bindungspuffer gelöst bzw. überführt. Von der Proteinlösung werden 1,6 ml benötigt. Die Konzentration des Proteins sollte idealerweise 10-100-fach höher sein als der $\mathrm{K}_{\mathrm{D}}$-Wert. Von der Ligandenlösung werden $500 \mu \mathrm{l}$ angesetzt. Die Konzentration des Liganden wird etwa 14-fach höher angesetzt als die Proteinkonzentration. Die Konzentrationen von Ligand und Protein werden photometrisch genau ermittelt. Für die Liganden ATP und ADP wird dabei der molare Extinktionskoeffizient $\varepsilon_{259 \mathrm{~nm}}=15400 \mathrm{M}^{-1} \mathrm{~cm}^{-1}$ verwendet (Talavera und Cruz 2005). Für das Protein wird der molare Extiktionskoeffizient nach der Methode von Gill und Hippel bestimmt (2.2.2.9.2).

Die Protein- und Ligandenlösung werden auf $23^{\circ} \mathrm{C}$ temperiert und entgast. Die Referenzzelle wird mit Wasser, die Probenzelle mit der Proteinlösung gefüllt. Der Ligand wird in 28 Injektionsschritten zugegeben $(0,5 \mu \mathrm{l}$ pro sec). Das erste Injektionsvolumen beträgt $3 \mu 1$ und wird später nicht in die Berechnung mit einbezogen. Die übrigen 27 Injektionsvolumina betragen $10 \mu 1$. Nach jeder Injektion wird 210“ gewartet. Die Rührgeschwindigkeit beträgt $308 \mathrm{rpm}$ und die Temperatur $25^{\circ} \mathrm{C}$. Der Offset-Wert der Referenzzelle wird auf $15 \mu \mathrm{Cal} / \mathrm{sec}$ eingestellt.

Als Kontrolle wird ein analoges Experiment durchgeführt, bei der der Ligand in eine Pufferlösung ohne das Protein titriert wird. Dadurch wird die Verdünnungswärme detektiert, die bei der Zugabe des Liganden auftritt. Diese Verdünnungswärme muss von den 
Bindungsdaten subtrahiert werden, um nur die durch die Bindung umgesetzte Wärme zu erhalten.

Die Auswertung erfolgt mit dem Computerprogramm Origin. Der Wärmeumsatz jeder Injektion wird integriert und durch die Änderung der Ligandenkonzentration in der Probenzelle bei der jeweiligen Injektion geteilt. Die Verdünnungswärme wird abgezogen. Die erhaltenen Werte $[\mathrm{kcal} / \mathrm{mol}]$ werden gegen das molare Verhältnis zwischen Protein und Ligand anfgetragen. Durch nichtlineare Regression wird dann ein Kurvenangleich durchgeführt, aus dem die Werte für $\mathrm{n}, \Delta \mathrm{H}, \Delta \mathrm{S}$ und $\mathrm{K}_{\mathrm{D}}$ folgen.

\subsubsection{Röntgenkristallographische Methoden}

\subsubsection{Bestimmung der Molekularstruktur eines Protein über Kristallographie}

Mittels Röntgenkristallographie ist es möglich, die molekulare Struktur großer Makromoleküle wie Proteine aufzuklären. Notwendig dafür sind geeignete Kristalle des entsprechenden Proteins. Der Kristall wird dann mit einem Röntgenstrahl definierter Wellenlänge bestrahlt. Trifft dieser auf den Proteinkristall, so wird er gestreut und das Streuungsmuster wird detektiert. Da das Streuverhalten von der Orientierung des Kristalls abhängt, wird er während der Messung gedreht, um möglichst alle Streu-Reflexe zu erfassen. Aus dem allgemeinen Streuungsmuster lassen sich zunächst die Raumgruppe und die Dimensionen der Einheitszelle des Kristalls ermitteln. Die Intensität und Phase der einzelnen Reflexe schließlich liefern die Informationen, die zur Bestimmung der molekularen Struktur des Proteins führen. Dazu wird zunächst die Elektronendichte $\rho$ an jedem Punkt x, y, z in der Einheitszelle über Fouriertransformation berechnet:

$$
\begin{array}{r}
\rho(x y z)=\frac{1}{V} \sum_{h k l}|F(h k l)| \cdot e^{-i 2 \pi(h x+k y+l z)+i \alpha(h k l)} \\
\text { V: Volumen der Einheitszelle } \\
\text { h,k,l: Millersche Indizes des Reflexes } \\
\text { F: Strukturfaktor des Reflexes } \\
\alpha: \text { Phasendifferenz des Reflexes }
\end{array}
$$

Der Strukturfaktor F(hkl) beschreibt die Wellenfunktion des jeweiligen Streu-Reflexes. Seine Amplitude $|\mathrm{F}(\mathrm{hkl})|$ ergibt sich aus der bei der Datenaufnahme gemessenen Intensität des Reflexes. Seine Phasendifferenz $\alpha(\mathrm{hkl})$ ist dagegen nicht direkt meßbar. Um dieses Phasenproblem der Kristallographie zu lösen, sind für Proteine mehrere Methoden entwickelt worden. Prinzipiell lassen sich dabei MR ( molecular replacement, englisch für molekularen

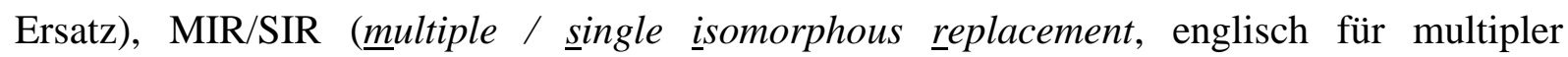
isomorpher Ersatz) und MAD/SAD ( multiple / single wavelength anomalous dispersion, englisch für anomale Streuung bei multiplen Wellenlängen) unterscheiden.

MR setzt voraus, dass die molekulare Struktur eines ähnlichen Proteins bereits bekannt ist. Die Sequenzidentität sollte mindestens $30 \%$ betragen. Die Struktur des bekannten Proteins wird zunächst derart innerhalb der Einheitszelle des neuen Kristalls plaziert, dass es der 
Position und Orientierung der unbekannten Struktur entspricht. Auf dieser Grundlage werden erste Annäherungen für die Phasen der Struktur des kristallisierten Proteins errechnet.

Für die Phasenbestimmung über SIR oder MIR werden neben dem nativen Proteinkristall ein (SIR) bzw. mehrere (MIR) derivatisierte Kristalle benötigt, die außer dem Protein auch damit assoziierte Schwermetallatome enthalten. Da Schwermetalle die Röntgenstrahlung viel effektiver streuen als das Protein, genügt oft ein einziges Schweratom, um deutliche Intensitätsunterschiede im Streuungsmuster des nativen und derivatisierten Kristalls zu detektieren. Diese Unterschiede werden genutzt, um zunächst die Schweratome in der Einheitszelle zu lokalisieren und dann daraus erste Phasen für das Protein abzuschätzen. Voraussetzung für SIR/MIR ist, dass die Schweratome die Einheitszelldimensionen des Kristalls nicht verändern, so dass nativer und derivatisierter Kristall isomorph sind.

Für die Phasenbestimmung über SAD oder MAD ist in der Regel ebenfalls ein derivatisierter Proteinkristall notwendig. Häufig handelt es sich um ein Schwermetallatom-Derivat, geeignet sind aber auch beispielsweise Selen, Brom oder Iod. Die entscheidende Eigenschaft dieser Elemente ist, dass sie ein Absorptionsmaximum im Röntgenbereich haben. Durch diese Absorption bewirken sie, dass das Friedel Gesetz nicht mehr gilt, so dass sich bestimmte Symmetrie-äquivalente Reflexe, die Friedelpaare, in ihrer Intensität unterscheiden. Diesen Effekt bezeichnet man als anomale Streuung. Der Intensitätsunterschied zwischen den Reflexen der Friedelpaare lässt sich analog zu SIR/MIR dazu nutzen, die anomal streuenden Atome zu lokalisieren und dann daraus erste Phasen für das Protein abzuschätzen. Bei starker anomaler Streuung kann ein Datensatz ausreichen, um die Phasen zu bestimmen (SAD). Eine bessere Phasenabschätzung erreicht man jedoch oft, wenn man von demselben Kristall Datensätze bei mehreren bestimmten Wellenlängen aufnimmt (MAD). Diese Methode beruht darauf, dass sich die anomale Streuung mit der Wellenlänge ändert. Denn der erzeugte Unterschied zwischen den Strukturfaktoren der Friedelpaare besteht aus einem realen $\left(f^{\star}\right)$ und einem imaginären $\left(f^{*}\right)$ Anteil. Während $f^{*}$ seinen größten Wert beim Absorptionsmaximum des anomal streuenden Atoms hat (peak Wellenlänge), zeigt $\mathrm{f}^{\prime}$ ein Minimum bei einer geringfügig größeren Wellenlänge (inflection point). Datensätze, die bei der peak- und inflection point- Wellenlänge aufgenommen wurden, zeigen dadurch maximale Unterschiede in der anomalen Streuung und ergänzen sich in ihrem Informationsgehalt. Zusätzlich wird häufig außerdem ein Datensatz bei einer deutlich kleineren (high remote) oder größeren (low remote) Wellenlänge aufgenommen.

Ist ein Proteinkristall mit einem Schwermetallatom derivatisiert, das anomale Streuung zeigt, lassen sich auch Kombinationen aus SIR/MIR und SAD/MAD anwenden, die als SIRAS bzw. MIRAS bezeichnet werden.

\subsubsection{Kristallisation von Proteinen}

Zur Kristallisation von Proteinen werden sitting drop-Kristallisationsplatten (Cryschem, Hampton) verwendet. Dabei werden $500 \mu \mathrm{l}$ des Kristallisationspuffers in das Reservoir pipettiert. Getrennt davon wird auf einer kleinen Erhöhung über dem Reservoir $1 \mu 1$ der Proteinlösung mit $1 \mu \mathrm{l}$ des Kristallisationspuffers gemischt. Die Proteinlösung und das Reservoir sind durch Dampfdiffusion miteinander verbunden. Mit durchsichtigem Klebeband 
werden die Ansätze luftdicht abgedeckt und bei $4^{\circ} \mathrm{C}$ oder $20^{\circ} \mathrm{C}$ inkubiert. Während dieser Inkubation diffundiert Wasser aus der Proteinlösung zum Reservoir. Dadurch werden die Präzipitantien und das Protein langsam konzentriert und das Protein bildet unter geeigneten Bedingungen Kristalle.

Bei Kristallisationsversuchen, die von der HT-X-facility in Hamburg durchgeführt werden, wird ebenfalls die sitting drop-Methode verwendet. Es werden aber für jeden Ansatz nur $300 \mathrm{nl}$ Proteinlösung mit $300 \mathrm{nl}$ Kristallisationspuffer gemischt und bei $19^{\circ} \mathrm{C}$ inkubiert.

\subsubsection{Schwermetallderivatisierung}

Für die Phasenbestimmung über MAD (2.2.3.1) müssen Proteinkristall-Derivate hergestellt werden, die in das Kristallgitter eingefügte Schwermetallatome enthalten. Die Einführung der Schwermetalle erfolgt durch Soaking. Es werden sitting drop-Kristallisationsplatten (Cryschem, Hampton) verwendet. In das Reservoir wird der Kristallisationspuffer vorgelegt. Außerdem wird ein $5 \mu$ großer Topfen Kristallisationspuffer pipettiert, zu dem das Schwermetallsalz in einer Endkonzentration von $5 \mathrm{mM}$ zugegeben wird. In den Tropfen werden native Proteinkristalle überführt und für 2-7 Tage bei $20^{\circ} \mathrm{C}$ inkubiert.

Vor der Datensammlung wird der derivatisierte Proteinkristall in einen Tropfen Kristallisationspuffer ohne Schwermetallsalz transferiert und 1 ' -5 ' inkubiert (,Backsoaking “), um nichtgebundene Schwermetallionen zu entfernen.

Folgende Schwermetallsalze wurden für eine Derivatisierung der Proteinkristalle getestet: $\mathrm{Na}_{2} \mathbf{W O}_{4}, \quad \mathrm{~K}_{2} \mathbf{P d C l}{ }_{2}, \quad \mathbf{A g N O}_{3}, \quad \mathrm{~K}_{2} \mathbf{I r C l}_{6}, \quad \mathbf{S m C l}_{3}, \mathbf{H o}\left(\mathrm{NO}_{3}\right)_{3}, \quad \mathrm{~K}_{2} \mathbf{P t C l} \mathbf{H}_{4}, \mathbf{H g C l}_{2}, \mathbf{C}(\mathbf{H g A c})_{4}$, $\mathrm{AcHgC}_{6} \mathrm{H}_{5}$ und $\mathbf{H g}(\mathrm{Ac})_{2}$.

\subsubsection{Datensammlung}

Vor der Datensammlung wird der Kristall in flüssigem Stickstoff eingefroren und dann auf einem Goniometerkopf im Schnittpunkt des Röntgenstrahls mit der Rotationsachse montiert. In dieser Position wird der Kristall durch einen mit flüssigem Stickstoff gekühlten Cryostrom auf einer Temperatur von $100 \mathrm{~K}$ gehalten. Die Datensammlung bei tiefen Temperaturen verringert die Schädigung des Kristalls durch die Strahlung und ermöglicht dadurch häufig die Aufnahme mehrerer Datensätze von einem einzigen Kristall.

Verschiedene Datensätze nativer und derivatisierter DEAD2-Kristallen werden an dem 14.1bzw. 14.2-Strahl des Berliner Elektronensynchrotrons (BESSY, Freie Universität Berlin) und dem BW7a- bzw. X12-Strahl des Deutschen Elektronen Synchrotrons (DESY, Hamburg) aufgenommen.

Für die Aufnahme eines MAD-Datensatzes von einem mit Phenylquecksilberacetat derivatisierten Kristall wird der 14.1 Strahl am BESSY verwendet. Es wird zunächst ein Fluoreszenzscan durchgeführt, um die Absorptionseigenschaften des Kristalls zu untersuchen, und damit die optimalen Wellenlängen für die Messung zu ermitteln. Anschließend werden die einzelnen Datensätze in folgender Reihenfolge aufgenommen: peak (1,00858 $)$, inflection point $(1,00957 \AA)$, high remote $(0,93222 \AA)$ und low remote $(1,00940 \AA)$. Pro 
Aufnahme wird der Kristall um $1^{\circ}$ gedreht. Um Strahlenschäden gering zu halten, wird jeder Datensatz nur über $120^{\circ}$ aufgenommen, und es wird die kleinstmögliche Belichtungszeit $\left(3,2^{\prime c}\right)$ verwendet. Die Detektion der gestreuten Röntgenstrahlung erfolgt mit einem MAR225-MOSAIC-Detektor (mar research, Hamburg). Der Detektorabstand beträgt $20 \mathrm{~cm}$.

Zur Indizierung, Integration und Datenreduktion wird das XDS- oder das HKL2000Programmpaket verwendet.

\subsubsection{Phasenbestimmung und Berechnung der Elektronendichteverteilung}

Zur Phasenberechnung (2.2.3.1) über molekularen Ersatz (MR) wird das Programm Molrep aus dem CCP4-Paket verwendet.

Die Bestimmung der Position von Schwermetallatomen in derivatisierten Proteinkristallen und die Ableitung der Phaseninformation über SAD/MAD (2.2.3.1) werden mit dem Programm autoSHARP durchgeführt. Daraus erhält man erste Informationen über die Elektronendichteverteilung im Kristall. Im Anschluss wird diese erste Elektronendichteverteilung mit SHARP über das Programm DM (density modification) des CCP4-Paketes verbessert, indem bekannte Eigenschaften von Lösungsmittel- und Proteinelektronendichten einfliessen. Dabei wird der Raum in Lösungsmittel- und Proteindichte unterteilt (eingestellter Lösungsmittelgehalt: 50\%) und die Dichte außerhalb des Proteins korrigiert (solvent flattening).

\subsubsection{Modellbau und Strukturverfeinerung}

In die Elektronendichtekarte (2.2.3.5) wird die Aminosäuresequenz des DEAD2-Fragments von hPrp28 eingepasst. Dazu wird das Graphikprogramm Coot verwendet. Die Verfeinerung erfolgt mit Refmac5 (CCP4 Programmpaket).

Zunächst werden die bekannten Strukturen der Helikase-Subdomänen von Vasa getrennt voneinander mit ESSENS in die Elektronendichte eingepasst und dann in die Aminosäuresequenz von hPrp28 umgebaut. Strukturbereiche von hPrp28, die in Vasa fehlen, werden gebaut, indem zunächst ein $\mathrm{C}_{\alpha}$-Gerüst in die Elektronendichte eingefügt und dieses dann in die entsprechenden Aminosäuren umgewandelt wird.

Modellbau und Verfeinerung wechseln einander ab. Während der Verfeinerung wird das Modell über Fourier Transformation in Strukturfaktoren umgerechnet und ihre Intensitäten $\left|F_{c}\right|$ werden mit den gemessenen Intensitäten $\left|F_{o}\right|$ verglichen. Auf dieser Grundlage wird das Modell rechnerisch so verändert, dass es den experimentellen Daten besser entspricht. Dabei werden bekannte Werte für Bindungswinkel und -längen in Proteinmolekülen ebenso beachtet wie interatomare Wechselwirkungen und Temperaturfaktoren einzelner Atome $\left(\mathrm{B}_{\mathrm{j}}\right)$. Die Qualität des Modells lässt sich durch den R-Faktor ausdrücken:

$$
R=\frac{\sum \| F_{o}|-| F_{c}||}{\sum\left|F_{o}\right|}
$$


Je kleiner der R-Faktor ist, desto besser entsprechen die aus dem Modell berechneten Amplituden der Strukturfaktoren $\left|F_{c}\right|$ den experimentell gemessenen $\left|F_{o}\right|$.

Man unterscheidet dabei zwischen dem kristallographischen $\left(\mathrm{R}_{\text {cryst }}\right)$ und dem freien $\left(\mathrm{R}_{\text {free }}\right) \mathrm{R}$ Faktor. Während sich $\mathrm{R}_{\text {cryst }}$ aus der Gesamtheit der gemessenen Reflexe berechnet, wird für die Ermittlung des $\mathrm{R}_{\text {free }}$ nur ein kleiner Anteil (5\%) davon verwendet. Diese Reflexe werden nicht in die Verfeinerung einbezogen, sie dienen ausschließlich der Bewertung des Modells.

Bei der Verfeinerung mit Refmac5 wird schließlich das Modell verwendet, um verbesserte Phasenabschätzungen der Strukturfaktoren und damit eine verbesserte Elektronendichtekarte $\mathrm{zu}$ berechnen. Auf dieser Grundlage wird dann das Modell wiederum manuell im Graphikprogramm Coot bearbeitet. Dabei werden die $2 F_{0}-F_{c}$ und $F_{o}-F_{c^{-}}$ Elektronendichtekarten verwendet, die noch vorhandene Fehler des Modells besonders betonen.

Während der fortlaufenden Zyklen aus Modellbau und Verfeinerung sollten sich die Werte für $\mathrm{R}_{\text {cryst }}$ und $\mathrm{R}_{\text {free }}$ einander annähern und im Idealfall jeweils unterhalb von $20 \%$ liegen. 


\section{Ergebnisse}

In dieser Arbeit wurde das humane DEAD-Box Protein hPrp28 strukturell und funktionell charakterisiert. Das Protein ist ein integraler Bestandteil des U5 snRNP des Spleißosoms. Die Struktur der Helikasedomäne von hPrp28 gab Einblick in den molekularen Aufbau eines Teils dieses mehrere Megadalton großen RNA-Protein-Komplexes. Bindungs- und Aktivitätsstudien führten zudem zu neuen Erkenntnissen über die Funktionsweise von hPrp28 während des Spleißzyklus.

\subsection{Klonierung, Reinigung und Kristallisationsversuche mit hPrp28}

Um hPrp28 strukturell zu charakterisieren, wurde zunächst versucht, es als Volllängenprotein zu kristallisieren.

Die Kristallisation eines Proteins für eine Strukturbestimmung setzt voraus, dass man dieses Protein in großer Menge und mit hoher Reinheit herstellen kann. Zu diesem Zweck wurde hPrp28 in mehrere Vektoren kloniert.

\subsubsection{Klonierung von hPrp28}

Die Tabelle 3.1 zeigt im Überblick alle Vektoren, in die hPrp28 kloniert wurde (2.2.1.8). Die Klonierungen in pETM-11 und pETM-41 wurden von Sunbin Liu (Max-Plack-Institut für biophysikalische Chemie, Göttingen, AG Reinhard Lührmann) durchgeführt. Bei den übrigen Klonierungen erfolgte die PCR mit Pfu-Polymerase und dem Vektor hPrp28-FL-pETM-11 als Matrize.

Die Konstrukte wurden in mehrere verschiedene Expressionsstämme von E. coli eingebracht (2.2.1.7). Mit dem Vektor hPrp28-FL-pASK-IBA-3 wurde keine detektierbare Expression von hPrp28 erreicht und mit den übrigen Vektoren war die Expression sehr schwach (ohne Darstellung). Nur der Vektor hPrp28-FL-pET-21a führte zu einer deutlichen Expression.

Nachteil des hPrp28-FL-pET-21a-Vektors ist, dass das Protein sowohl mit einer carboxyterminalen Hexahistidin- als auch einer aminoterminalen T7-Markierung exprimiert wird. Die Entfernung dieser Markierungen über eine Proteaseschnittstelle ist nicht möglich. Es wurde versucht, ein Fusionsprotein ohne T7-Markierung zu erhalten, indem die entsprechende kodierende Sequenz aus dem Vektor entfernt wurde. Dies führte jedoch zu einer deutlichen Abnahme der Expression (ohne Darstellung). Darum wurde für die Reinigung von hPrp28 der ursprüngliche hPrp28-FL-pET-21a Vektor verwendet. 
Tabelle 3.1: Übersicht über die Klonierung von hPrp28 (in Volllänge) in verschiedene Vektoren. Die verwendeten Oligonukleotide und Restriktionsschnittstellen des Vektors sind angegeben. Die Vektoren vermitteln die Expression mit verschiedenen Fusionspartnern, um eine Reinigung über Affinitätschromatographie zu ermöglichen. N: aminoterminal. C: carboxyterminal. Die erhaltenen Konstukte wurden folgendermaßen benannt: hPrp28-FL-[Vektorname], mit FL für full-length = Volllänge (englisch).

\begin{tabular}{l|l|l|l} 
Vektor & Fusionspartner & Oligonukleotid & Restriktionsschnittstellen \\
\hline pETM-11 & Hexahistidin (N) & [von Sunbin Liu] & NcoI, KpnI \\
\hline pETM-41 & $\begin{array}{l}\text { Maltose-bindendes } \\
\text { Protein (N) }\end{array}$ & [von Sunbin Liu] & NcoI, KpnI \\
\hline pMAL-c2x & $\begin{array}{l}\text { Maltose-bindendes } \\
\text { Protein (N) }\end{array}$ & $\begin{array}{l}\text { PQE-80-forward } \\
\text { PQE-80-reverse }\end{array}$ & BamHI, HindIII \\
\hline pQE-80L & Hexahistidin (N) & $\begin{array}{l}\text { PQE-80-forward } \\
\text { PQE-80-reverse }\end{array}$ & BamHI, HindIII \\
\hline pASK-IBA-3 & $\begin{array}{l}\text { Strep-tag (Streptavidin } \\
\text { bindendes Peptid) (C) }\end{array}$ & $\begin{array}{l}\text { IBA3-forward } \\
\text { IBA3-reverse }\end{array}$ & SacII, NcoI \\
\hline pGEX-6P-3 & $\begin{array}{l}\text { Glutathion-S-Transferase } \\
\text { (N) }\end{array}$ & $\begin{array}{l}\text { PQE-80-forward } \\
\text { PET21-reverse }\end{array}$ & BamHI, SalI \\
\hline pET-21a & Hexahistidin (C) & $\begin{array}{l}\text { PQE-80-forward } \\
\text { PET21-reverse }\end{array}$ & BamHI, XhoI \\
\hline
\end{tabular}

\subsubsection{Expression und Reinigung von hPrp28}

Für die Expression von hPrp28 wurde der Vektor hPrp28-FL-pET-21a in E. coli-Zellen des Stammes Rosetta 2 (DE3) eingebracht (2.2.1.7). Die Zellen wurden kultiviert und über Autoinduktion und $0,3 \mathrm{mM}$ IPTG induziert (2.2.2.1.2). Ein Liter Autoinduktionsmedium ergab dabei 2-3 mg gereinigtes hPrp28. Nach dem Aufschluss (2.2.2.2) wurde es im ersten Schritt über eine Hexahistidin-Affinitätschromatographie (Ni-NTA-Sepharose) gereinigt (2.2.2.3.1, Abb. 3.1). Analyse fraktionierter Proben über SDS-Gelelektrophorese zeigte, dass der Großteil anderer Proteine im Zelllysat dadurch abgetrennt wurde (2.2.2.7.1). 
A

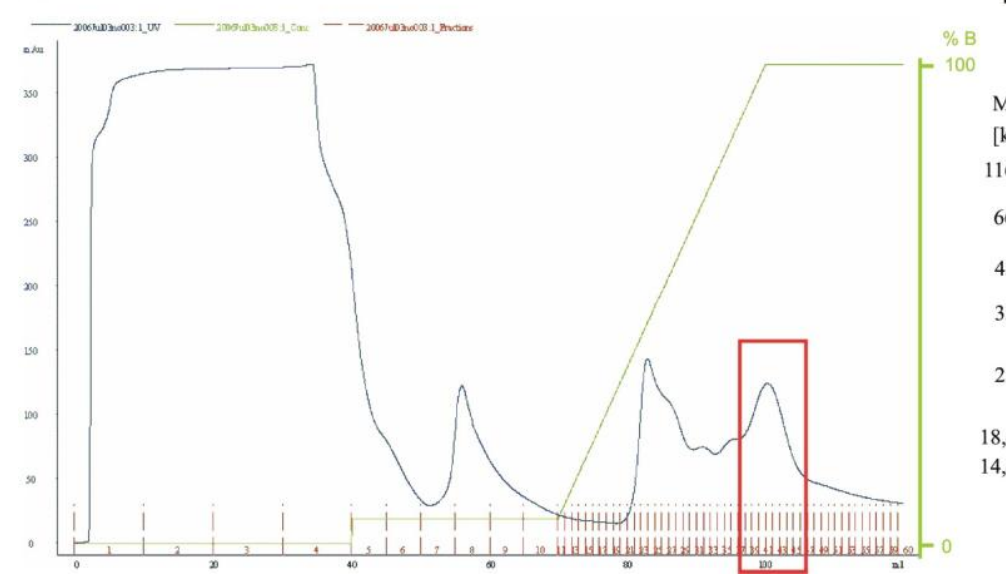

B

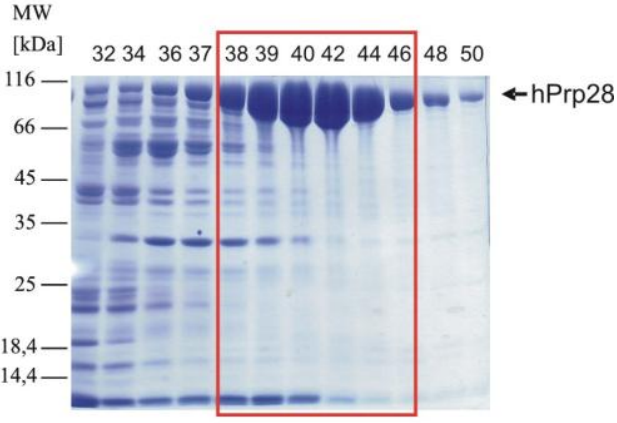

Abb. 3.1: Erster Reinigungsschritt: Hexahistidin-Affinitätschromatographie. (A) Elutionsprofil der Ni-NTASepharose-Säule. Auf der X-Achse ist das Volumen in [ml], auf der Y-Achse links die UV-Absorption bei $280 \mathrm{~nm}$ in [mAU] (blauer Graph) aufgetragen. Die Y-Achse rechts zeigt den Anteil an Puffer B in \% (grüner Graph). Gesammelte Fraktionen sind angegeben. (B) Analyse einzelner Fraktionen über SDS-PAGE. Die Fraktionsnummern sind oberhalb des Gels angegeben. hPrp28 eluiert erst bei relativ hohen ImidazolKonzentrationen, es befindet sich in den Fraktionen 38-46 unterhalb des letzten UV-Absorptionsmaximums (rot gekennzeichnet).

Die Fraktionen, die hPrp28 enthielten, wurden vereinigt und auf etwa $10 \mathrm{mg} / \mathrm{ml}$ konzentriert (2.2.2.4). Es folgte ein zweiter Reinigungsschritt über Gelfiltration (Superdex 200, 2.2.2.3.3). Dafür war ein Puffer mit hohem Salzgehalt notwendig, da hPrp28 ansonsten auf der Säule aggregierte $(500 \mathrm{mM} \mathrm{NaCl}, 10 \mathrm{mM}$ Tris-HCl, $\mathrm{pH} 7,5,5 \%$ Glyzerin, $2 \mathrm{mM} \beta-$ Mercaptoethanol). Durch die Gelfiltration wurden weitere Verunreinigungen abgetrennt. Außerdem zeigte das Elutionsvolumen von $61 \mathrm{ml}$ (entspricht $\sim 100 \mathrm{kDa}$ ), dass hPrp28 als Monomer vorlag (Abb. 3.2). Anschließend wurde hPrp28 konzentriert (2.2.2.4) und für Kristallisationsansätze eingesetzt.

A

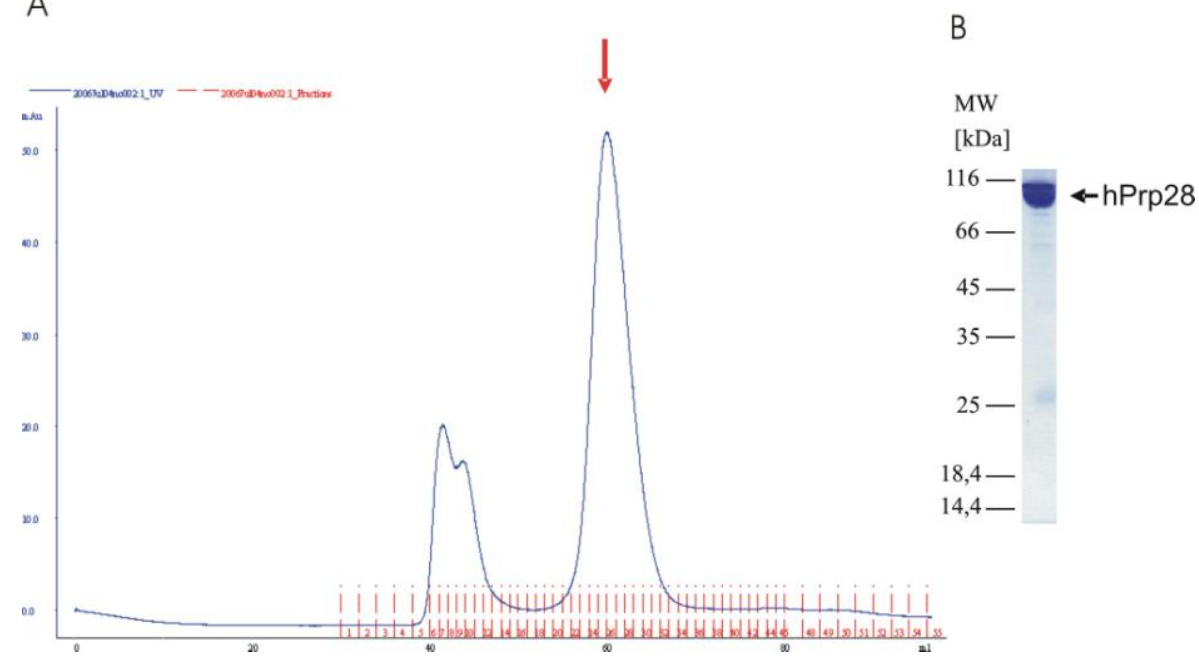

Abb. 3.2: Zweiter Reinigungsschritt: Gelfiltration. (A) Elutionsprofil der Superdex 200-Säule (16/60). Auf der X-Achse ist das Volumen in [ml], auf der Y-Achse die UV-Absorption bei $280 \mathrm{~nm}$ in [mAU] (blauer Graph) aufgetragen. Gesammelte Fraktionen sind angegeben. hPrp28 befand sich in den Fraktionen unterhalb des zweiten UV-Absorptionsmaximums (roter Pfeil) (B) Analyse des gereinigten hPrp28 über SDS-PAGE. Nach der Gelfiltration wurden die Fraktionen, die hPrp28 enthielten, vereinigt und konzentriert. Das Gel zeigt ein Aliquot nach der Konzentration. Es sind nur minimale Mengen kontaminierender Proteine vorhanden. 


\subsubsection{Kristallisationsversuche}

Das gereinigte hPrp28 wurde in einer Konzentration zwischen $4 \mathrm{mg} / \mathrm{ml}$ und $8 \mathrm{mg} / \mathrm{ml}$ eingesetzt (2.2.3.2). Es wurden alle verfügbaren Kristallisationsscreens verwendet (2.1.11). Die Ansätze wurden bei $20^{\circ} \mathrm{C}$ oder $4^{\circ} \mathrm{C}$ inkubiert. Bis heute wurden keine Kristalle von hPrp28 als Volllängenprotein erhalten.

\subsection{Klonierung und Reinigung von Fragmenten von hPrp28 (Überblick)}

Das Volllängenprotein bildete unter keiner der getesteten Bedingungen Kristalle. Dies weist darauf hin, dass die Gesamtstruktur von hPrp28 möglicherweise zu flexibel ist, um eine Kristallisation zu erlauben. Aus diesem Grund wurden verschiedene Fragmente von hPrp28 in Expressionsvektoren kloniert und gereinigt. Auf diese Weise sollte versucht werden, zu mindestens Teilbereiche von hPrp28 zu kristallisieren.

\subsubsection{Klonierung}

Die Fragmente wurden mit zwei Ausnahmen so gewählt, dass sie entweder mit dem NTerminus von hPrp28 begannen (,RS“-Fragmente) oder mit dem C-Terminus von hPrp28 endeten („DEAD“-Fragmente). Als Expressionsvektor wurde in den meisten Fällen pET-21a oder pGEX-6P-3 verwendet. Der Vektor pET-21a bewirkt die Expression mit einer aminoterminalen T7- und einer carboxyterminalen Hexahistidin-Markierung. Der Vektor pGEX-6P-3 dagegen führt zu einer Expression mit einer aminoterminalen Glutathion-STransferase (GST)-Markierung. Der Vorteil dieses Vektors ist, dass sich die GST-Markierung mit einer spezifischen Protease entfernen lässt.

Die Tabelle 3.2 zeigt im Überblick alle klonierten Fragmente und ihre Eigenschaften hinsichtlich Expression und Reinigung. Die Abbildung 3.3 gibt einen schematischen Überblick über die enthaltenen Domänen. Die Klonierungen der Fragmente $\triangle \mathrm{RS} \triangle \mathrm{DEAD}$, $\triangle \mathrm{RS}$ und DEAD wurden von Sunbin Liu (Max-Plack-Institut für biophysikalische Chemie, AG Reinhard Lührmann) durchgeführt. Dazu wurden die NcoI- und KpnI-Schnittstelle des jeweiligen Vektors genutzt. Alle übrigen Klonierungen erfolgten über die BamHI- und XhoISchnittstelle des pET-21a- bzw. pGEX-6P-3-Vektors. Ausnahme ist die Klonierung des RS5Fragments in pGEX-6P-3, für die anstelle der XhoI- die SalI-Schnittstelle des Vektors verwendet wurde (2.2.1.8). 
Tabelle 3.2: Übersicht über die Klonierung von hPrp28-Fragmenten in verschiedene Vektoren. Die verwendeten Oligonukleotide sind angegeben. Zusätzlich gibt die Tabelle einen Überblick über die Löslichkeit des Fragments: - unlöslich. + löslich. (+) nur sehr geringe Ausbeute $(<10 \%)$ an löslichem Protein. Die vorletzte Spalte zeigt, ob ein Reinigungsprotokoll etabliert worden ist und die letzte, ob Kristallisationsversuche unternommen wurden: + umfassende Kristallisationsversuche. (+): nur eine Auswahl an Kristallisationsscreens getestet. Die erhaltenen Konstrukte wurden folgendermaßen benannt: hPrp28-[Bezeichnung]-[Vektorname].

\begin{tabular}{|c|c|c|c|c|c|c|}
\hline Bezeichnung & Aminosäuren & Vektor(en) & Oligonukleotide & löslich & $\begin{array}{l}\text { Reinigung } \\
\text { etabliert }\end{array}$ & $\begin{array}{l}\text { Kristallisations- } \\
\text { ansätze }\end{array}$ \\
\hline$\Delta \mathrm{RS} \triangle \mathrm{DEAD}$ & $221-405$ & pETM-30 & [Sunbin Liu] & - & - & - \\
\hline \multirow{2}{*}{$\Delta \mathrm{RS}$} & \multirow{2}{*}{$221-820$} & \multirow{2}{*}{$\begin{array}{l}\text { pETM-11 } \\
\text { pETM-41 }\end{array}$} & \multirow{2}{*}{ [Sunbin Liu] } & + & + & + \\
\hline & & & & + & - & - \\
\hline DEAD & $405-820$ & pETM-30 & [Sunbin Liu] & - & - & - \\
\hline DEAD1 & $207-820$ & pET-21a & $\begin{array}{l}\text { DEAD1-pET21-f } \\
\text { PET21-reverse }\end{array}$ & + & + & $(+)$ \\
\hline \multirow{2}{*}{ DEAD2 } & \multirow{2}{*}{$338-820$} & pET-21a & $\begin{array}{l}\text { DEAD2-pET21-f } \\
\text { PET21-reverse }\end{array}$ & + & + & + \\
\hline & & pGEX-6P-3 & $\begin{array}{l}\text { DEAD2-pET21-f } \\
\text { pET21-stop-r }\end{array}$ & + & + & + \\
\hline DEAD3 & $388-784$ & pGEX-6P-3 & $\begin{array}{l}\text { DEAD3-pGEX-Bam-f } \\
\text { DEAD3-pGEX-Xho-r }\end{array}$ & $(+)$ & - & - \\
\hline DEAD4 & $353-820$ & pGEX-6P-3 & $\begin{array}{l}\text { DEAD4-pGEX-Bam-f } \\
\text { pET21-stop-r }\end{array}$ & + & + & $(+)$ \\
\hline \multirow{2}{*}{ DEAD5 } & \multirow{2}{*}{$257-820$} & pET-21a & $\begin{array}{l}\text { DEAD5-pGEX-Bam-f } \\
\text { PET21-reverse }\end{array}$ & + & + & - \\
\hline & & pGEX-6P-3 & $\begin{array}{l}\text { DEAD5-pGEX-Bam-f } \\
\text { pET21-stop-r }\end{array}$ & - & - & - \\
\hline \multirow{2}{*}{ DEAD6 } & \multirow{2}{*}{$300-820$} & pET-21a & $\begin{array}{l}\text { DEAD6-pGEX-Bam-f } \\
\text { PET21-reverse }\end{array}$ & + & + & - \\
\hline & & pGEX-6P-3 & $\begin{array}{l}\text { DEAD6-pGEX-Bam-f } \\
\text { pET21-stop-r }\end{array}$ & + & + & + \\
\hline RS1 & $1-138$ & pET-21a & $\begin{array}{l}\text { PQE-80-forward } \\
\text { RS1-pET21-r }\end{array}$ & + & + & $(+)$ \\
\hline $\mathrm{RS} 2$ & $1-206$ & pET-21a & $\begin{array}{l}\text { PQE-80-forward } \\
\text { RS2-pET21-r }\end{array}$ & + & + & $(+)$ \\
\hline RS3 & $1-257$ & pET-21a & $\begin{array}{l}\text { PQE-80-forward } \\
\text { RS3-pET21-r }\end{array}$ & + & + & + \\
\hline RS4 & $1-337$ & pET-21a & $\begin{array}{l}\text { PQE-80-forward } \\
\text { RS4-pET21-r }\end{array}$ & + & + & - \\
\hline \multirow{2}{*}{ RS5 } & \multirow{2}{*}{$1-355$} & pET21a & $\begin{array}{l}\text { PQE-80-forward } \\
\text { RS5-pET21-r }\end{array}$ & + & + & - \\
\hline & & pGEX-6P-3 & $\begin{array}{l}\text { PQE-80-forward } \\
\text { RS5-pET21-r }\end{array}$ & $(+)$ & - & - \\
\hline
\end{tabular}




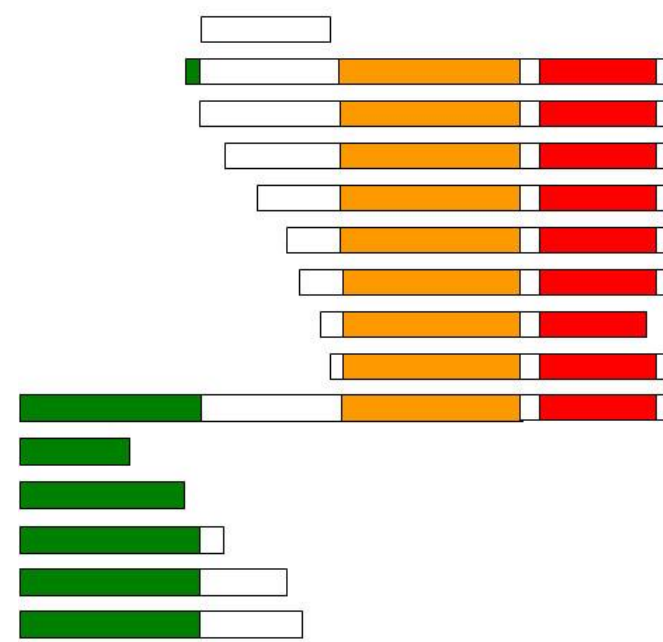

\author{
$\triangle \mathrm{RS} \triangle \mathrm{DEAD}(221-405)$ \\ DEAD1-Fragment (207-820) \\ $\triangle R S(221-820)$ \\ DEAD5-Fragment (257-820) \\ DEAD6-Fragment (300-820) \\ DEAD2-Fragment (338-820) \\ DEAD4-Fragment (353-820) \\ DEAD3-Fragment (388-784) \\ DEAD-Fragment (405-820) \\ hPrp28 \\ RS1-Fragment (1-138) \\ RS2-Fragment (1-206) \\ RS3-Fragment (1-257) \\ RS4-Fragment (1-337) \\ RS5-Fragment (1-355)
}

Abb. 3.3: Schematische Übersicht über die konstruierten Fragmente von hPrp28. Grün: RS-Domäne, orange bzw. rot: N-terminale bzw. C-terminale Domäne des DEAD-Box Proteins. In Klammern ist angegeben, welche der 820 Aminosäuren von hPrp28 das Fragment umfasst.

\title{
3.2.2 Expression und Reinigung
}

Die Expression der hPpr28-Fragmente erfolgte in E. coli Zellen des Stammes Rosetta 2 (DE3). Die Stärke der Expression nahm dabei generell mit der Länge des Fragmentes ab. Die Tabelle 3.2 gibt eine Übersicht über die Löslichkeit der Proteine und darüber, ob eine Reinigung etabliert werden konnte. Die Expression und Reinigung unter Verwendung des hPrp28-DEAD2-pGEX-6P-3 Vektors wird im Abschnitt (3.3.1) beschrieben. Genaue Angaben zur Expression und Reinigung des RS3-Fragments finden sich im Abschnitt (3.4.1.1). Die übrigen Reinigungen wurden generell - abhängig davon, ob eine Hexahistidinoder GST-Markierung vorlag - analog zu den Reinigungen des DEAD2- bzw. RS3-Fragments durchgeführt. Es gab lediglich geringe Unterschiede in der Glyzerin- und NatriumchloridKonzentration im Puffer für die Gelfiltration.

\subsubsection{Kristallisationsversuche}

Gereinigtes Protein wurde für Kristallisationsansätze verwendet (2.2.3.2). Die Tabelle 3.2 gibt einen Überblick. Die Kristallisationsversuche mit dem DEAD2- und RS3-Fragment werden in den folgenden Abschnitten näher beschrieben. Erfolgreich waren diese Versuche nur mit dem DEAD2-Fragment auf der Grundlage des hPrp28-DEAD2-pGEX-6P-3 Konstrukts (Abschnitt $(3.3 .5))$. 


\subsection{Struktur und Eigenschaften der Helikasedomäne von hPrp28}

Das DEAD2-Fragment von hPrp28 umfasst die Aminosäuren 338-820 (Abb. 3.4). Es enthält alle konservierten Sequenzmotive der DEAD-Box-Proteinfamilie und damit die gesamte Helikasedomäne von hPrp28. Dies ist der funktionelle Abschnitt des Proteins und hat in vivo die Aufgabe, ATP sowie ein RNA-Substrat zu binden und dann dieses RNA-Substrat zu entwinden oder daran bindende Proteine zu entfernen.

Die in vitro Eigenschaften und die Struktur des DEAD2-Fragments von hPrp28 werden in den nachfolgenden Abschnitten näher beschrieben.

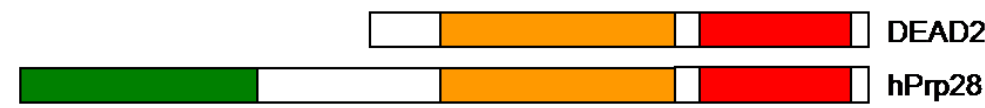

Abb. 3.4: Schematische Übersicht über das DEAD2-Fragment von hPrp28. Grün: RS-Domäne, orange bzw. rot: N-terminale bzw. C-terminale Domäne des DEAD-Box Proteins.

\subsubsection{Expression und Reinigung des DEAD2-Fragments}

Für die Expression des DEAD2-Fragments von hPrp28 wurde der Vektor hPrp28-DEAD2pGEX-6P-3 in E. coli Zellen des Stammes Rosetta 2 (DE3) oder BL21 STAR (DE3) eingebracht (2.2.1.7). Die Expression des GST-DEAD2-Fusionsproteins wurde über Autoinduktion mit zusätzlicher Zugabe von $0,1 \mathrm{mM}$ IPTG durchgeführt (2.2.2.1.2). Aus einem Liter Autoinduktionskultur wurden 20-30 mg reines DEAD2-Protein erhalten. Nach dem Aufschluss (2.2.2.2) bestand der erste Reinigungsschritt in einer GSTAffinitätschromatographie (GSH-Sepharose, 2.2.2.3.2). Dadurch wurde der Großteil kontaminierender Proteine abgetrennt (Abb. 3.5).

A

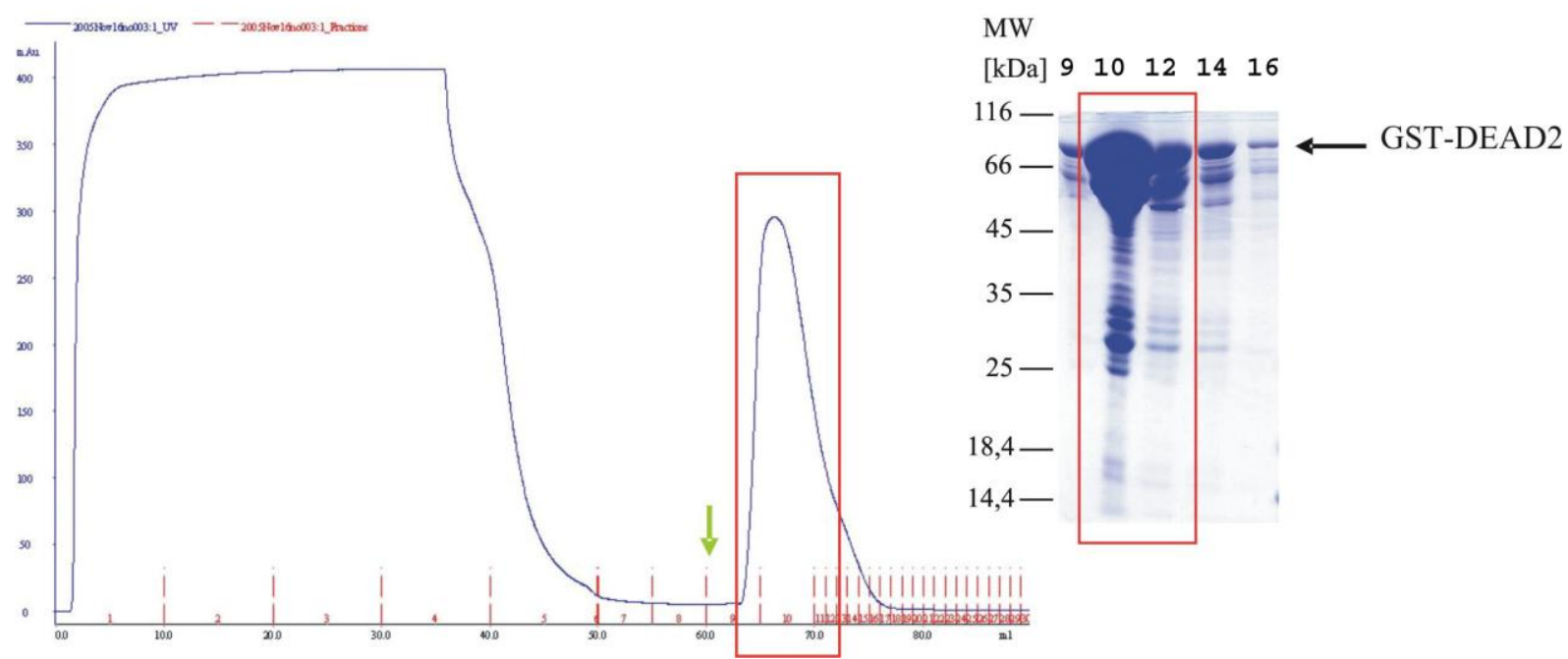

Abb. 3.5: Erster Reinigungsschritt: GST-Affinitätschromatographie. (A) Elutionsprofil der GSH-Säule. Auf der X-Achse ist das Volumen in [ml], auf der Y-Achse die UV-Absorption bei $280 \mathrm{~nm}$ in [mAU] aufgetragen. In Rot sind gesammelte Fraktionen angegeben. Der grüne Pfeil markiert den Beginn der Elution mit $10 \mathrm{mM}$ reduziertem Glutathion. (B) Analyse einzelner Fraktionen über SDS-PAGE. Die Fraktionsnummern sind oberhalb des Gels angegeben. Das GST-DEAD2-Fusionsprotein bindet an die Säule und verlässt sie erst mit der Elution (rot markiert). 
Die Fraktionen, die das DEAD2-Fragment enthielten, wurden vereinigt und über Nacht mit PreScission Protease inkubiert (2.2.2.5). Dadurch wurde die GST-Markierung vom DEAD2Fragment abgeschnitten. Anschließend wurde das Protein auf etwa $10 \mathrm{mg} / \mathrm{ml} \mathrm{konzentriert}$ (2.2.2.4). Danach folgte als zweiter Reinigungsschritt eine Gelfiltration (2.2.2.3.3, Superdex 75, Puffer: $150 \mathrm{mM} \mathrm{NaCl}, 10 \mathrm{mM}$ Tris-HCl, pH 7,5, $2 \mathrm{mM} \beta$-Mercaptoethanol). Wie die Analyse einzelner Fraktionen auf einem SDS-Acrylamidgel zeigte, wurde dadurch ein $45 \mathrm{kDa}$ Protein sowie ein Großteil des abgeschnittenen GST abgetrennt (2.2.2.7.1). Außerdem wurde durch die Gelfiltration das reduzierte Glutathion, das im ersten Reinigungsschritt zur Elution zugegeben worden war, entfernt. Das Elutionsvolumen von $57 \mathrm{ml}$ (entspricht 55 kDa) zeigt, dass DEAD2 als Monomer vorliegt (Abb. 3.6).

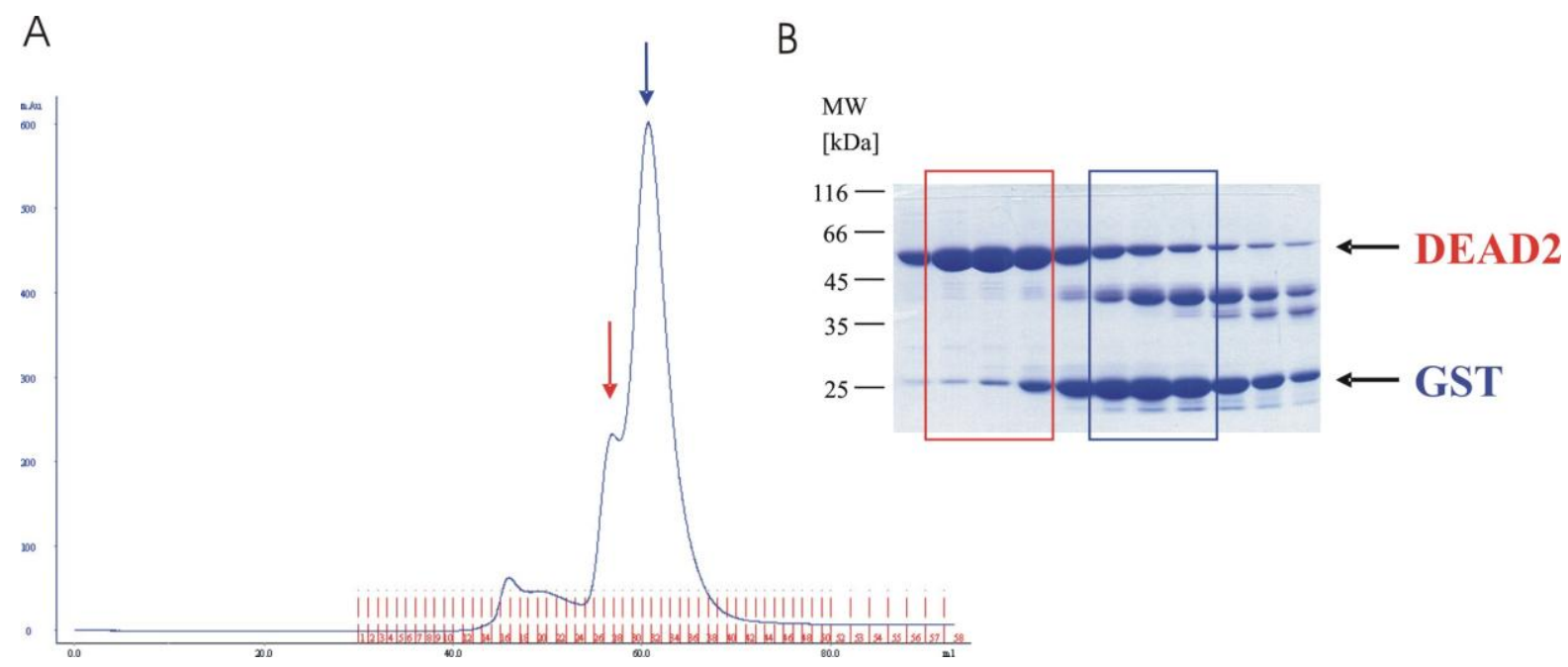

Abb. 3.6: Zweiter Reinigungsschritt: Gelfiltration. (A) Elutionsprofil der Superdex 75-Säule (16/60). Auf der XAchse ist das Volumen in [ml], auf der Y-Achse die UV-Absorption bei $280 \mathrm{~nm}$ in [mAU] aufgetragen. In Rot sind gesammelte Fraktionen angegeben. (B) Analyse der Fraktionen 25-36 über SDS-PAGE. Fraktionen unter dem ersten Absorptionsmaximum im Elutionsprofil (roter Pfeil) enthalten DEAD2-Protein, während Fraktionen unter dem zweiten Absorptionsmaximum (blauer Pfeil) GST und ein 45 kDa Protein enthalten.

Fraktionen, die das DEAD2-Fragment enthielten, wurden vereinigt und nochmals über eine GST-Affinitätschromatographie-Säule (GSH-Sepharose, 2.2.2.3.2) geleitet. Dabei wurde derselbe Puffer wie bei der Gelfiltration verwendet. In diesem letzten Reinigungsschritt wurde das restliche GST entfernt. Gereinigtes DEAD2-Protein befand sich beim Beladen der Säule im Durchfluss (Abb. 3.7). Die entsprechenden Fraktionen wurden vereinigt und auf etwa $10 \mathrm{mg} / \mathrm{ml}$ (laut Bradford) konzentriert (2.2.2.4). 
A

B

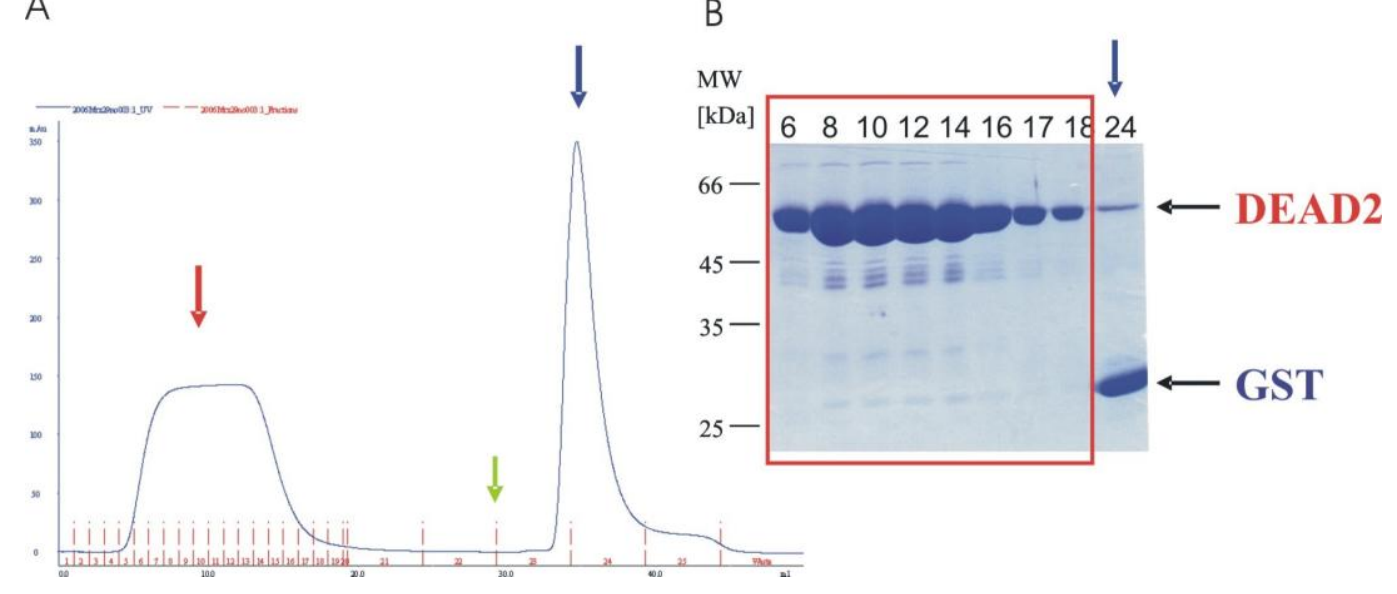

Abb. 3.7: Dritter Reinigungsschritt: GST-Affinitätschromatographie. (A) Elutionsprofil der GSH-SepharoseSäule. Auf der X-Achse ist das Volumen in [ml], auf der Y-Achse die UV-Absorption bei $280 \mathrm{~nm}$ in [mAU] aufgetragen. Der grüne Pfeil kennzeichnet des Beginn der Elution. In Rot sind gesammelte Fraktionen angegeben. (B) Analyse gesammelter Fraktionen über SDS-PAGE. DEAD2-Protein befindet sich im Durchfluss beim Beladen der Säule (roter Pfeil). Das GST bindet dagegen an die Säule und verlässt sie erst bei Elution mit reduziertem Glutathion (blauer Pfeil).

\subsubsection{ATPase Aktivität}

Voraussetzung für die RNPase- oder RNA-Helikaseaktivität von DEAD-Box Proteinen ist die Hydrolyse von ATP. Viele dieser Proteine zeigen entsprechend in vitro eine RNA-stimulierte oder -abhängige ATPase-Aktivität. Es sollte überprüft werden, ob sich diese Aktivität auch bei der Helikasedomäne von hPrp28 nachweisen lässt. Dazu wurde die Umsetzung von ATP zu ADP durch das DEAD2-Protein anhand von HPLC analysiert (2.2.2.8).

Referenzläufe mit einer ATP- bzw. ADP-Lösung zeigten, dass das Elutionsvolumen von ATP 4,0 $\mathrm{ml}$ und von ADP 4,7 ml beträgt.

Die Abb. 3.8 zeigt das Elutionsprofil einer Probe, die nach 9 h Inkubation mit DEAD2Protein genommen wurde. Zum Vergleich ist das Elutionsprofil eines Kontrollansatzes ohne Protein dargestellt. Man erkennt, dass in Gegenwart von DEAD2-Protein mehr ADP gebildet wird als in der Kontrolle. Jedoch wurde das ATP nach dieser langen Zeit - nach Abzug der proteinunabhängigen ATP-Hydrolyse - nur zu etwa $11 \%$ zu ADP umgesetzt. Aus dem molaren Verhältnis von 1:28 $(18 \mu \mathrm{M}: 500 \mu \mathrm{M})$ zwischen DEAD2 und ATP ergibt sich damit eine Umsatzrate von etwa 0,3 ATP pro DEAD2-Protein pro Stunde. Die ATPase-Aktivität ist somit sehr niedrig. 


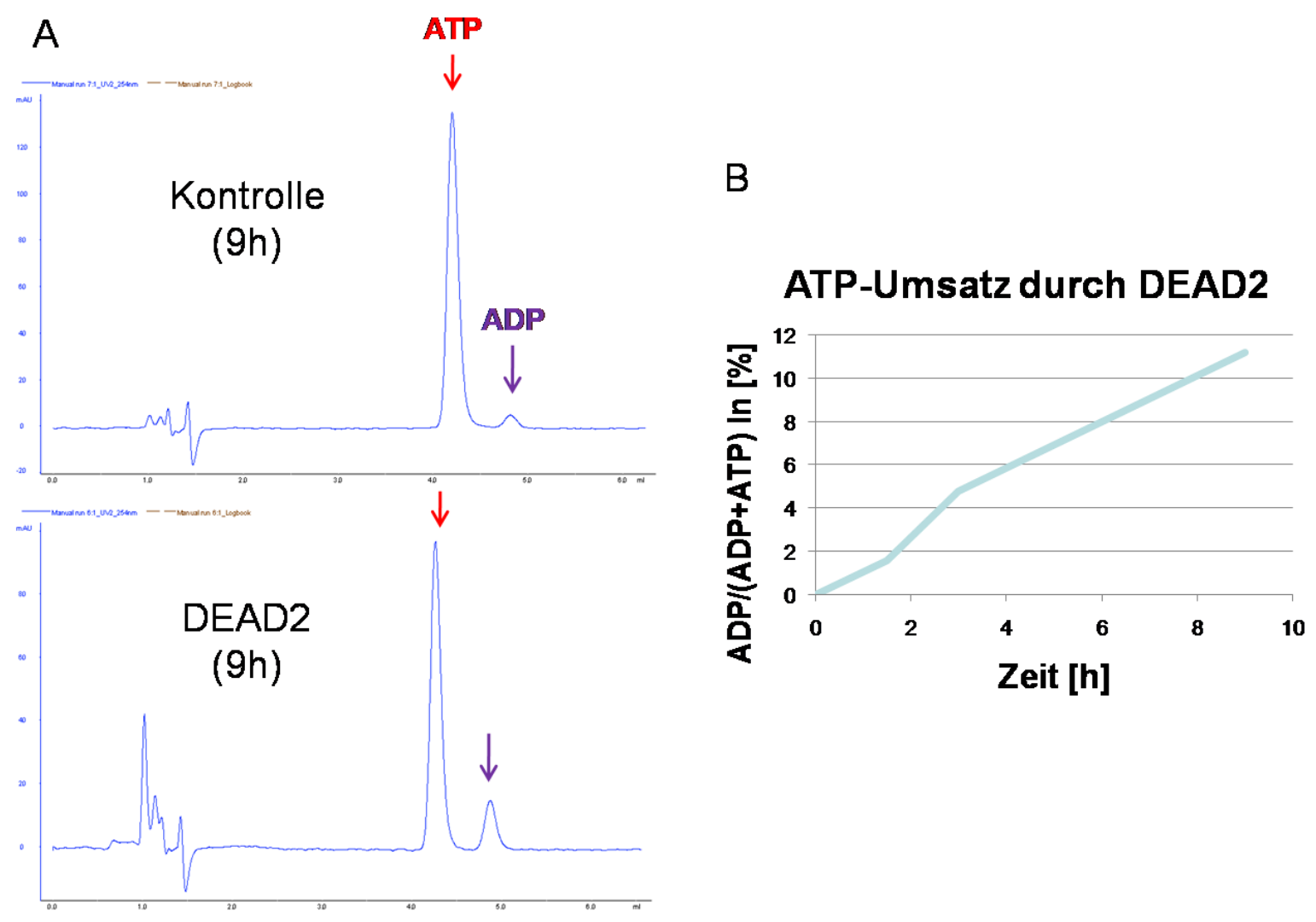

Abb. 3.8: ATPase Aktivität des DEAD2-Proteins. (A) Elutionsprofil der HPLC für Proben nach 9h Inkubation bei $37^{\circ} \mathrm{C}$. Oben Kontrolle ohne Protein, unten mit $18 \mu \mathrm{M}$ DEAD2 $(1 \mathrm{mg} / \mathrm{ml})$. Auf der X-Achse ist das Volumen in [ml], auf der Y-Achse die UV-Absorption bei $256 \mathrm{~nm}$ in [mAU] aufgetragen. ATP (roter Pfeil) verlässt die Säule vor ADP (violett). (B) Prozentualer Anteil des ADP im Reaktionsansatz in Abhängigkeit von der Inkubationszeit mit DEAD2 bei $37^{\circ} \mathrm{C}$. Die Kontrollwerte wurden jeweils abgezogen.

In Gegenwart verschiedener Konzentrationen (zwischen 0,25 $\mu \mathrm{g} / \mu \mathrm{l}$ und $5 \mu \mathrm{g} / \mu \mathrm{l}$ ) von Typ III RNA aus Hefe (2.1.6) wurde ein vergleichbar niedriger ATP Umsatz beobachtet. Die ATPase-Aktivität wird also nicht durch RNA stimuliert. Vermutlich ist der beobachtete kleine ATP-Umsatz auf minimale Verunreinigungen der DEAD2-Präparation mit ATPasen aus $E$. coli zurückzuführen. Zusammengefasst ließ sich also unter den getesteten Bedingungen keine in vitro ATPase Aktivität des DEAD2-Proteins nachweisen.

Analoge Experimente mit hPrp28 als Volllängenprotein führten zu denselben Ergebnissen. Auch nach Phosphorylierung der RS-Domäne (s.u.) zeigte hPrp28 in vitro keine ATPaseAktivität.

\subsubsection{Bindungsstudien mit ADP und ATP}

Die Ursache für die fehlende in vitro ATPase Aktivität könnte darin liegen, dass das isolierte DEAD2 in einer Konformation vorliegt, die keine ATP-Bindung zulässt. Zur Klärung dieser Frage wurden die Dissoziationskonstanten $\left(\mathrm{K}_{\mathrm{D}}\right)$ für die Interaktionen zwischen DEAD2 und ATP bzw. ADP bestimmt. Dabei wurden zwei verschiedene Methoden verwendet: Zum einen fluorimetrische Messungen und zum anderen isotherme Titrationskalorimetrie (ITK). 


\subsubsection{Fluoreszenztitration}

Die fluorimetrische Bestimmung der $\mathrm{K}_{\mathrm{D}}$-Werte erfolgte über die Abnahme der TryptophanFluoreszenz von DEAD2 durch die Ligandenbindung (2.2.2.10.1).

Die Bindung eines Liganden führt häufig zu einer Änderung der Tryptophan-Fluoreszenz eines Proteins, da sie die chemische Umgebung beeinflusst. Zunächst wurden darum Bindungsstudien mit (unmodifiziertem) ATP und ADP durchgeführt. Jedoch zeigte sich im Fall von DEAD2, dass sich die Tryptophan-Fluoreszenz nur sehr geringfügig in der Gegenwart von ATP oder ADP verändert (Abb. 3.9). Das machte eine $\mathrm{K}_{\mathrm{D}}$-Wert Bestimmung mit diesen Liganden problematisch.
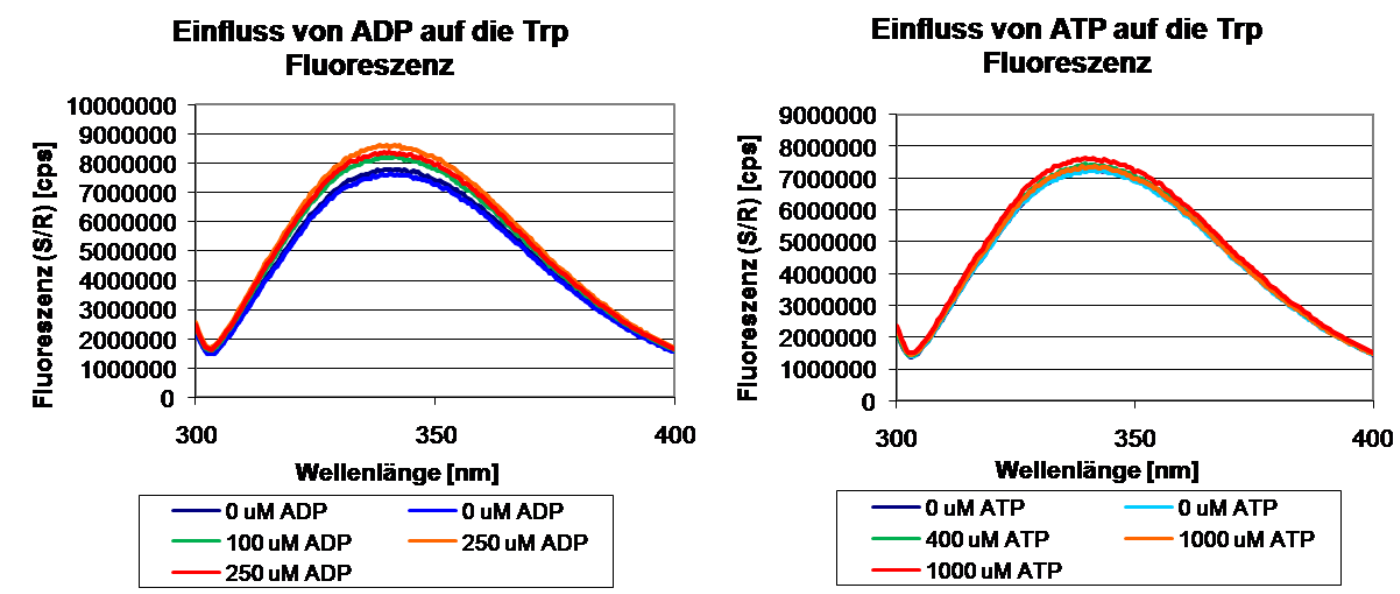

Abb. 3.9: Fluoreszenzspektrum von DEAD2 in Gegenwart verschiedener Konzentrationen an ADP oder ATP (Anregungswellenlänge $295 \mathrm{~nm}$ ). Die Anwesenheit von ADP bzw. ATP hat nur einen sehr kleinen Effekt auf die Tryptophan-Fluoreszenz. Proben für $0 \mu \mathrm{M}$ ADP/ATP (blau) und für $250 \mu \mathrm{M}$ ADP / $1000 \mu \mathrm{M}$ ATP (rot) wurden zweimal separat angesetzt.

In einem zweiten Ansatz wurden mant-modifizierte Nukleotide verwendet. Die mant-Gruppe ist ein Fluorophor, dessen Anregungsspektrum sich mit der Tryptophan-Fluoreszenz von Proteinen überschneidet. Bei Bindung an ein mant-Nukleotid kommt es darum zu einem Energietransfer (FRET-Effekt) und zur Abnahme der Tryptophan-Fluoreszenz (Abb. 3.10).
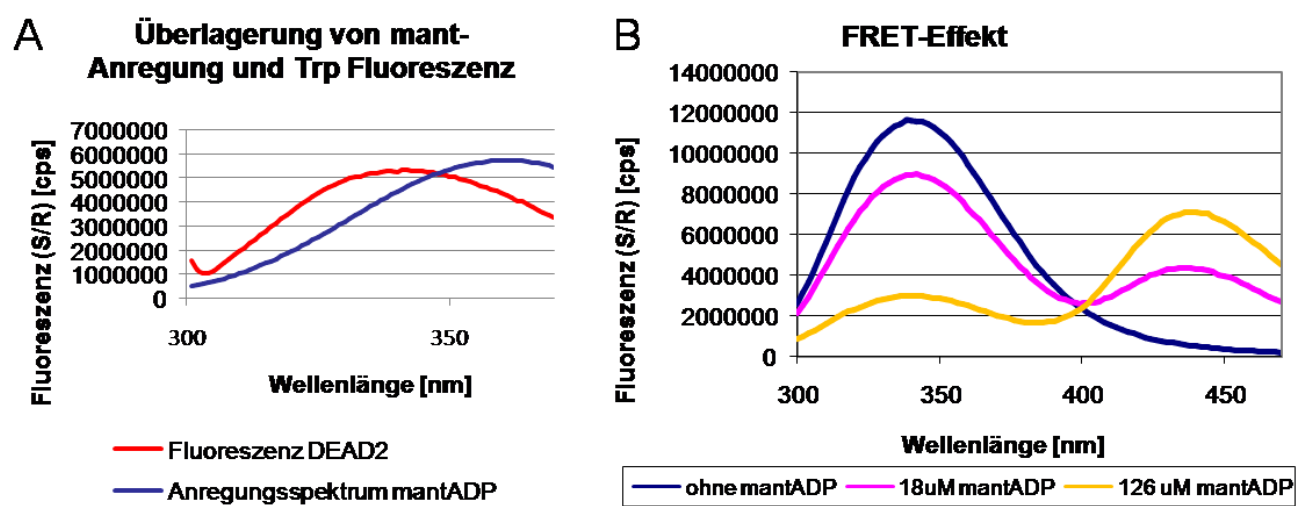

Abb. 3.10: Die mant-Gruppe wird durch die Tryptophan-Fluoreszenz angeregt. (A) Überlagerung des Fluoreszenz-spektrums von DEAD2 (rot, Anregungswellenlänge $295 \mathrm{~nm}$ ) mit dem Anregungsspektrum von mant-ADP (blau, Messung der mant-Fluoreszenz bei $440 \mathrm{~nm}$ ). (B) FRET-Effekt. Dargestellt sind Fluoreszenzspektren von drei Proben mit konstanter DEAD2-Konzentration und unterschiedlichen mant-ADP Konzentrationen. Mit zunehmender mant-ADP Konzentration nimmt die Tryptophan-Fluoreszenz von DEAD2 ab und die mant-Fluoreszenz zu. Die Anregungswellenlänge betrug $285 \mathrm{~nm}$, um die Eigenfluoreszenz der mantGruppe zu unterdrücken. 


\subsection{Bestimmung von Anregungs- und Emissionswellenlänge}

Zunächst mussten geeignete Wellenlängen für die Anregung und Emissionsmessung ermittelt werden. Dazu wurden ein Fluoreszenzspektrum von DEAD2 und ein UVAbsorptionsspektrum von mant-ADP aufgenommen (Abb. 3.11).
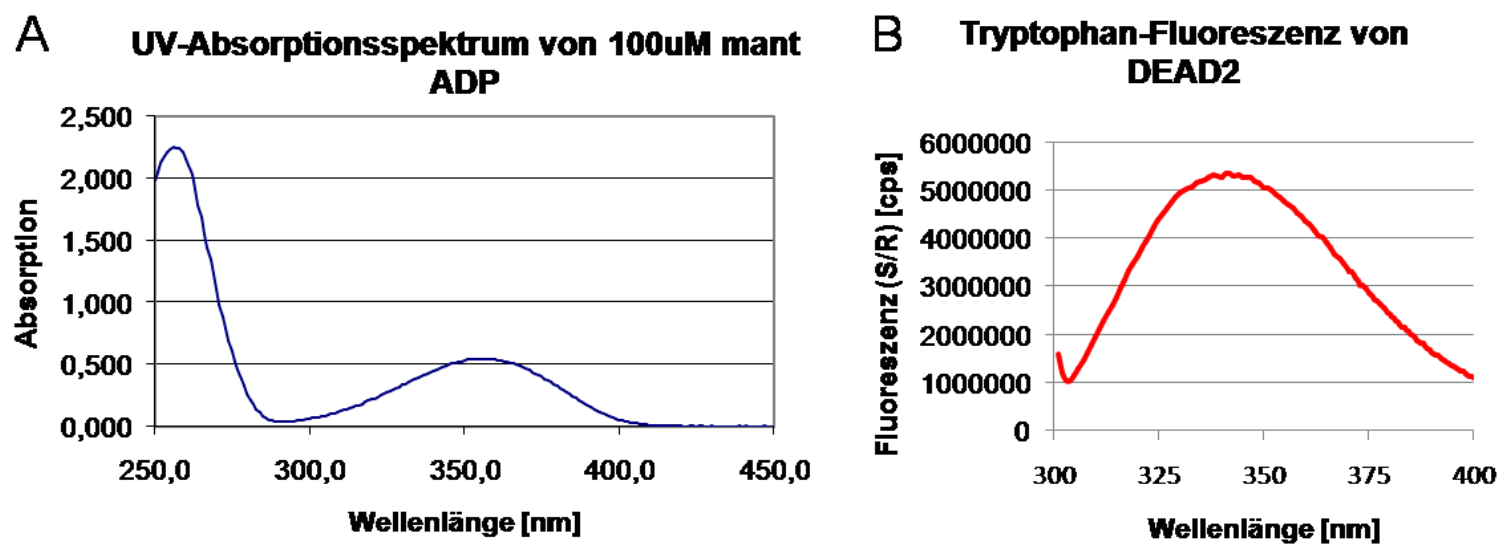

Abb. 3.11: (A) UV-Absorptionsspektrum von mant-ADP bei einer Konzentration von $100 \mu$ M. Bei $292 \mathrm{~nm}$ befindet sich ein lokales Minimum. (B) Fluoreszenzspektrum des DEAD2-Fragments bei Anregung mit $295 \mathrm{~nm}$. Bei $340 \mathrm{~nm}$ ist die Tryptophan-Fluoreszenz maximal.

DEAD2 enthält fünf Tryptophane und zwölf Tyrosine. Um selektiv nur die Tryptophanfluoreszenz zu detektieren, sollte die Anregungswellenlänge $\geq 295 \mathrm{~nm}$ sein, da unterhalb von $295 \mathrm{~nm}$ zusätzlich auch die Tyrosine angeregt werden. Außerdem sollte die Anregungswellenlänge so gewählt werden, dass die Strahlung möglichst wenig von dem Liganden absorbiert wird, um einen inner filter effect zu unterdrücken (2.2.2.10.1.2). Das UVAbsorptionsspektrum zeigt, dass mant-ADP ein Absorptionsminimum bei $292 \mathrm{~nm}$ hat (Abb. 3.11A). Das gleiche trifft für mant-ATP zu. Darum wurde zur Anregung der Tryptophane die kleinstmögliche selektive Wellenlänge von $295 \mathrm{~nm}$ gewählt.

Die Messung der Tryptophanfluoreszenz sollte bei einer Wellenlänge erfolgen, bei der einerseits die Fluoreszenz stark ist, bei der aber andererseits wiederum eine geringe Absorption durch den Liganden auftritt. Das Fluoreszenzspektrum von DEAD2 (bei Anregung mit $295 \mathrm{~nm}$ ) hat ein Maximum bei $340 \mathrm{~nm}$ (Abb. 3.11B). Bei dieser Wellenlänge tritt jedoch auch eine starke Absorption durch die mant-Gruppe auf, deren UVAbsorptionsspektrum ein lokales Maximum bei $355 \mathrm{~nm}$ zeigt. Bei $330 \mathrm{~nm}$ absorbiert die mant-Gruppe dagegen deutlich weniger stark, während die Tryptophan-Fluoreszenz nur etwas schwächer ist. Als Wellenlänge für die Emissionsmessung wurde darum $330 \mathrm{~nm}$ gewählt.

\subsection{Die Dissoziationskonstante von DEAD2 mit mant-ADP und mant-ATP}

Zur Bestimmung des $\mathrm{K}_{\mathrm{D}}$-Wertes bei $25{ }^{\circ} \mathrm{C}$ wurden Proben mit $4 \mu \mathrm{M}$ DEAD2 und mit unterschiedlichen Ligandenkonzentrationen angesetzt $(0-200 \mu \mathrm{M}$ mant-ADP, 0-400 $\mu \mathrm{M}$ mant-ATP). Dann wurde jede Probe mit $295 \mathrm{~nm}$ angeregt und das Fluoreszenzsignal (S/R in cps) bei $330 \mathrm{~nm}$ detektiert (2.2.2.10.1.1). 
Aufgrund der ziemlich hohen Ligandenkonzentrationen, die für die Messung eingesetzt wurden, war ein inner filter effect nicht $\mathrm{zu}$ vermeiden. Darum mussten die gemessenen Fluoreszenzsignale noch entsprechend korrigiert werden (2.2.2.10.1.2). Zur Berechnung der Korrekturfaktoren wurden die molaren Extinktionskoeffizienten von mant-ADP bzw. -ATP bei $295 \mathrm{~nm}$ und $330 \mathrm{~nm}$ benötigt. Sie wurden aus dem UV-Absorptionsspektrum abgelesen (Abb. 3.11A). Es ergaben sich $\varepsilon_{295 \mathrm{~nm}}=469 \mathrm{M}^{-1} \mathrm{~cm}^{-1}$ und $\varepsilon_{330 \mathrm{~nm}}=3570 \mathrm{M}^{-1} \mathrm{~cm}^{-1}$.

Die Datenauswertung (2.2.2.10.1.3) erfolgte gemäß dem Eadie-Hofstee Plot:

$$
\begin{aligned}
& \Delta F=\Delta F_{\max }-K_{D} \frac{\Delta F}{[L]} \\
& \Delta \mathrm{F}=\text { Abnahme des }(\mathrm{S} / \mathrm{R})_{\mathrm{korr}}-\text { Signals } \\
& \Delta \mathrm{F}_{\max }=\text { maximale Abnahme des }(\mathrm{S} / \mathrm{R})_{\text {korr }} \text {-Signals } \\
& {[\mathrm{L}]=\text { Konzentration von mant-ADP/-ATP } } \\
& \mathrm{K}_{\mathrm{D}}=\text { Dissoziationskonstante }
\end{aligned}
$$

mant-ADP

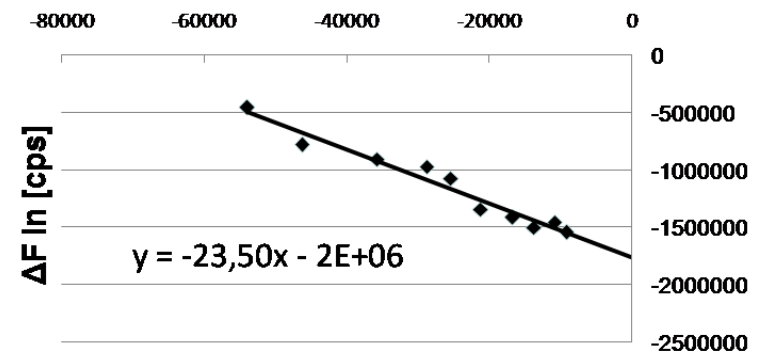

$\Delta \mathbf{F} / \mathrm{L}]$ in $[\mathrm{cps} / \mathrm{\mu M}]$
mant-ATP

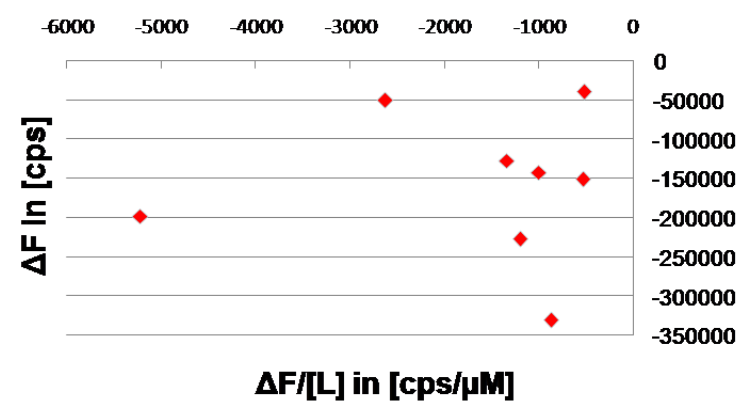

Abb. 3.12: Eadie-Hofstee Plot. Aufgetragen ist die Fluoreszenzabnahme $\Delta \mathrm{F}$ auf der Y-Achse gegen die Fluoreszenzabnahme $\Delta \mathrm{F}$ geteilt durch die mant-ADP bzw. -ATP Konzentration [L] auf der X-Achse. Bei mantADP ergibt sich eine Gerade mit der Steigung -23,5 $\mu$ M. Bei mant-ATP ist keine Auswertung möglich.

Für mant-ADP liegen die Messwerte wie erwartet auf einer Geraden. Aus ihrer Steigung ergibt sich als $\mathrm{K}_{\mathrm{D}}$-Wert 23,5 $\mu \mathrm{M}$. Die Werte für mant-ATP liegen dagegen breit gestreut vor. Eine Gerade konnte nicht eingepasst werden. Dies weist auf einen sehr hohen $\mathrm{K}_{\mathrm{D}^{-}}$Wert und entsprechend auf eine schwache Interaktion zwischen DEAD2 und mant-ATP hin (Abb. 3.12).

Zusätzlich erfolgte die Datenauswertung durch direkte Anpassung der Messwerte an folgende Formel (Berechnung mit SigmaPlot):

$$
\begin{aligned}
(S / R)_{\text {korr }}=F_{\text {max }}-\frac{\Delta F_{\text {max }}[L]}{[L]+K_{D}} & \\
& \mathrm{~F}_{\max }=\operatorname{maximales}(\mathrm{S} / \mathrm{R})_{\text {korr }} \text {-Signal }
\end{aligned}
$$

Für mant-ADP ergab sich als $\mathrm{K}_{D^{-}}$Wert $24,5 \pm 1,9 \mu \mathrm{M}$. Dies stimmt gut mit dem Wert gemäß dem Eadie-Hofstee Plot überein. Für mant-ATP ist die Kurve äußerst flach, es handelt sich nahezu um eine waagerechte Gerade. Rechnerisch ergibt sich als $\mathrm{K}_{\mathrm{D}}$-Wert $6258 \pm 18 \mu \mathrm{M}$. Allerdings streuen die Messwerte sehr stark um die entsprechende Kurve, so dass dieser $\mathrm{K}_{\mathrm{D}^{-}}$ Wert ungenau ist (Abb. 3.13). 

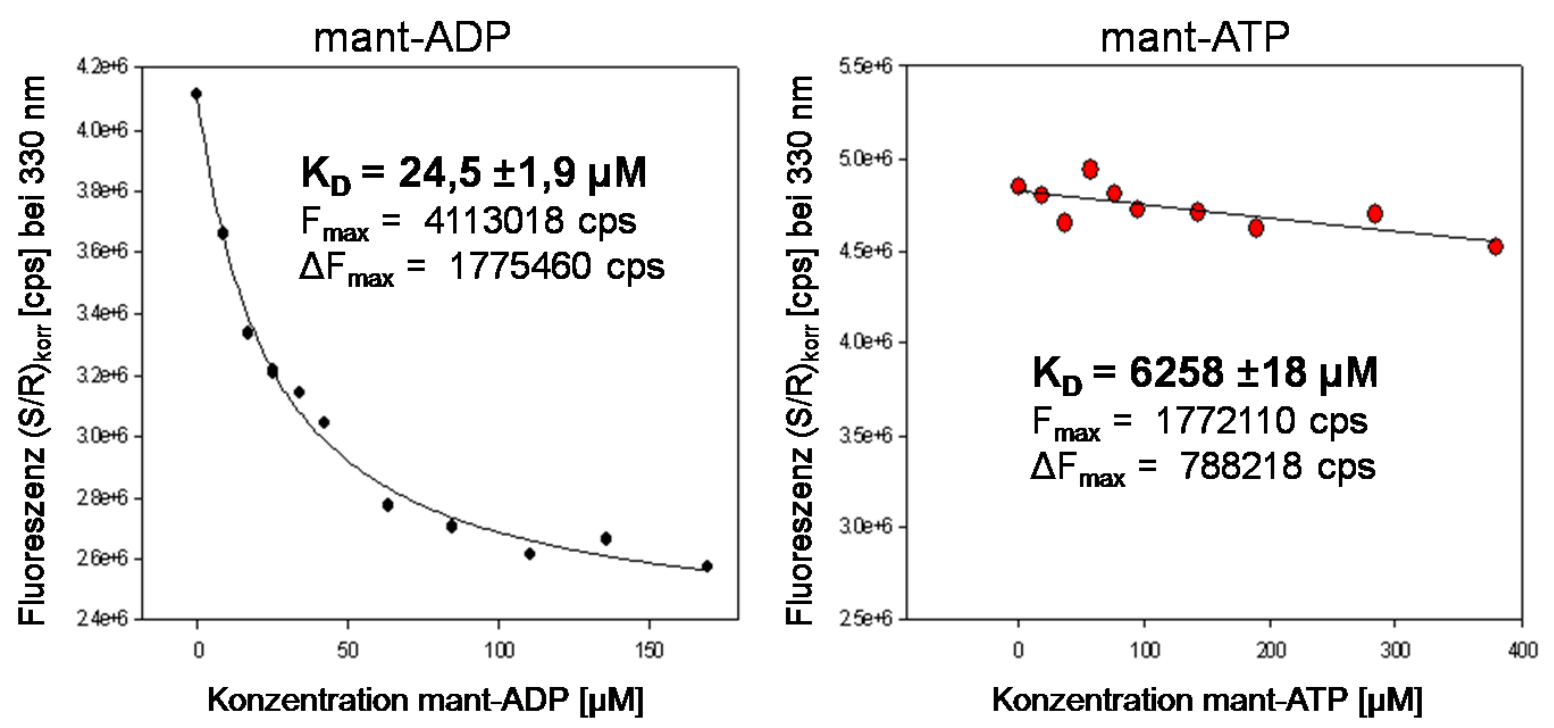

Abb. 3.13: Kurvenanpassung mit SigmaPlot. Für mant-ADP ergibt sich ein $K_{D}$-Wert von $24,5 \pm 1,9 \mu M$, für mantATP von $6258 \pm 18 \mu \mathrm{M}$. Außerdem sind die erhaltenen Werte für die Anpassungsparameter $\mathrm{F}_{\max }$ und $\Delta \mathrm{F}_{\max }$ angegeben.

Im Durchschnitt ergab sich für die Interaktion von DEAD2 mit mant-ADP ein $\mathrm{K}_{\mathrm{D}^{-}}$Wert von 24 $\pm 2,5 \mu \mathrm{M}$. Die Interaktion mit mant-ATP ist deutlich schwächer. Eine genaue Bestimmung des $\mathrm{K}_{\mathrm{D}}$-Wertes war nicht möglich $\left(\mathrm{K}_{\mathrm{D}}>1000 \mu \mathrm{M}\right)$.

Es wurden analoge Experimente auch in Gegenwart von 0,5 $\mu \mathrm{g} / \mu 1$ RNA (Typ III aus Hefe) durchgeführt. Die RNA führte jedoch zu keiner wesentlichen Veränderung der gemessenen $\mathrm{K}_{\mathrm{D}}$-Werte für mant-ADP und mant-ATP.

\subsubsection{Isotherme Titrationskalorimetrie (ITK)}

Bei der ITK wird der $K_{D^{-}}$Wert über die Messung der molaren Bindungswärme in Abhängigkeit von der Ligandenkonzentration bestimmt (2.2.2.10.2). Das DEAD2-Protein wurde in der Probenzelle vorgelegt und mit ATP oder ADP titriert.

Die genaue Kenntnis der Konzentrationen der Bindungspartner ist für die Auswertung notwendig. Darum wurde zunächst der molare Extinktionskoeffizient für DEAD2 zu $\varepsilon_{280 \mathrm{~nm}}=41000 \mathrm{M}^{-1} \mathrm{~cm}^{-1}$ nach der Methode von Gill und Hippel ermittelt (2.2.2.9.2). Die Konzentration der Ligandenlösung (ATP bzw. ADP) wurde ebenfalls über die UV-Absorption bestimmt.

Bei der ITK sollte darauf geachtet werden, dass die Verdünnungswärme bei der Ligandentitration möglichst gering ist. Das Gegen-Ion kann darauf einen Einfluss haben. Darum wurden zunächst Kontrollversuche mit unterschiedlichen ATP- und ADP-Salzen durchgeführt. Natrium-ADP zeigte eine sehr geringe Verdünnungswärme. Bei $\mathrm{Na}_{2}$-ATP war die Verdünnungswärme dagegen sehr hoch. Deutlich kleinere Werte wurden mit Tris-ATP beobachtet (Abb. 3.14). Darum wurden Na-ADP und Tris-ATP für die ITK-Experimente verwendet. 


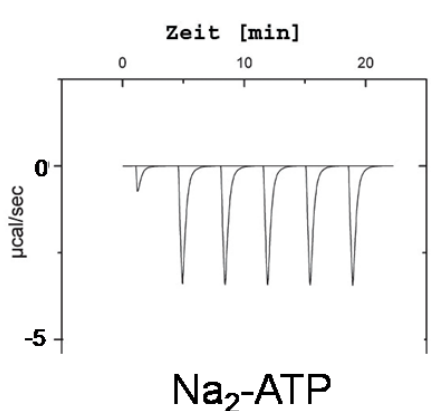

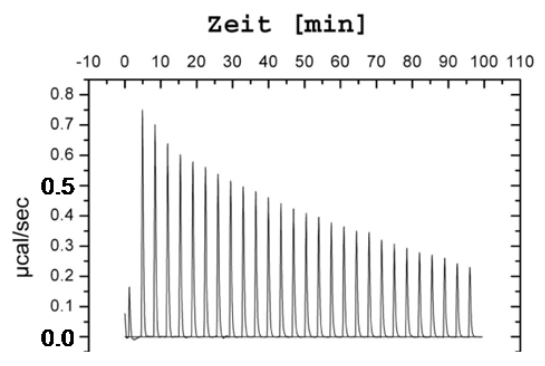

Tris-ATP

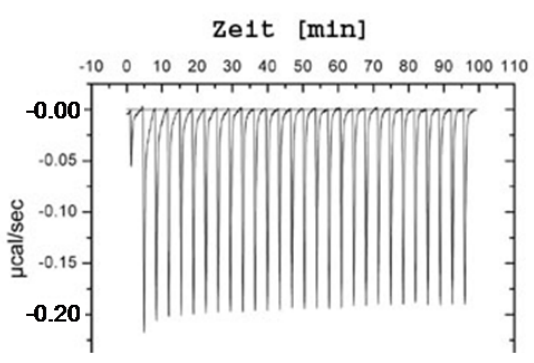

Na-ADP

Abb. 3.14: ITK-Rohdaten für die Verdünnungswärmen verschiedener Liganden. Dargestellt ist die entstehende Wärmeenergie pro Zeit gegen die Zeit. Die Liganden wurden in Bindungspuffer titriert. Bei $\mathrm{Na}_{2}$-ATP entstand viel Verdünnungswärme, bei Tris-ATP und Na-ADP waren die Werte relativ gering.

\subsection{Die Dissoziationskonstante von DEAD2 mit ADP und ATP}

DEAD2-Protein lag in einer Konzentration zwischen $120 \mu \mathrm{M}$ und $210 \mu \mathrm{M}$ vor und wurde in der Probenzelle vorgelegt. Die Konzentration der Ligandenlösung (ATP oder ADP) betrug zwischen 2,0 und 2,5 $\mu \mathrm{M}$. Sie wurde bei $25^{\circ} \mathrm{C}$ in einzelnen Injektionen mit dem Protein vermischt und die Bindungswärme bestimmt.
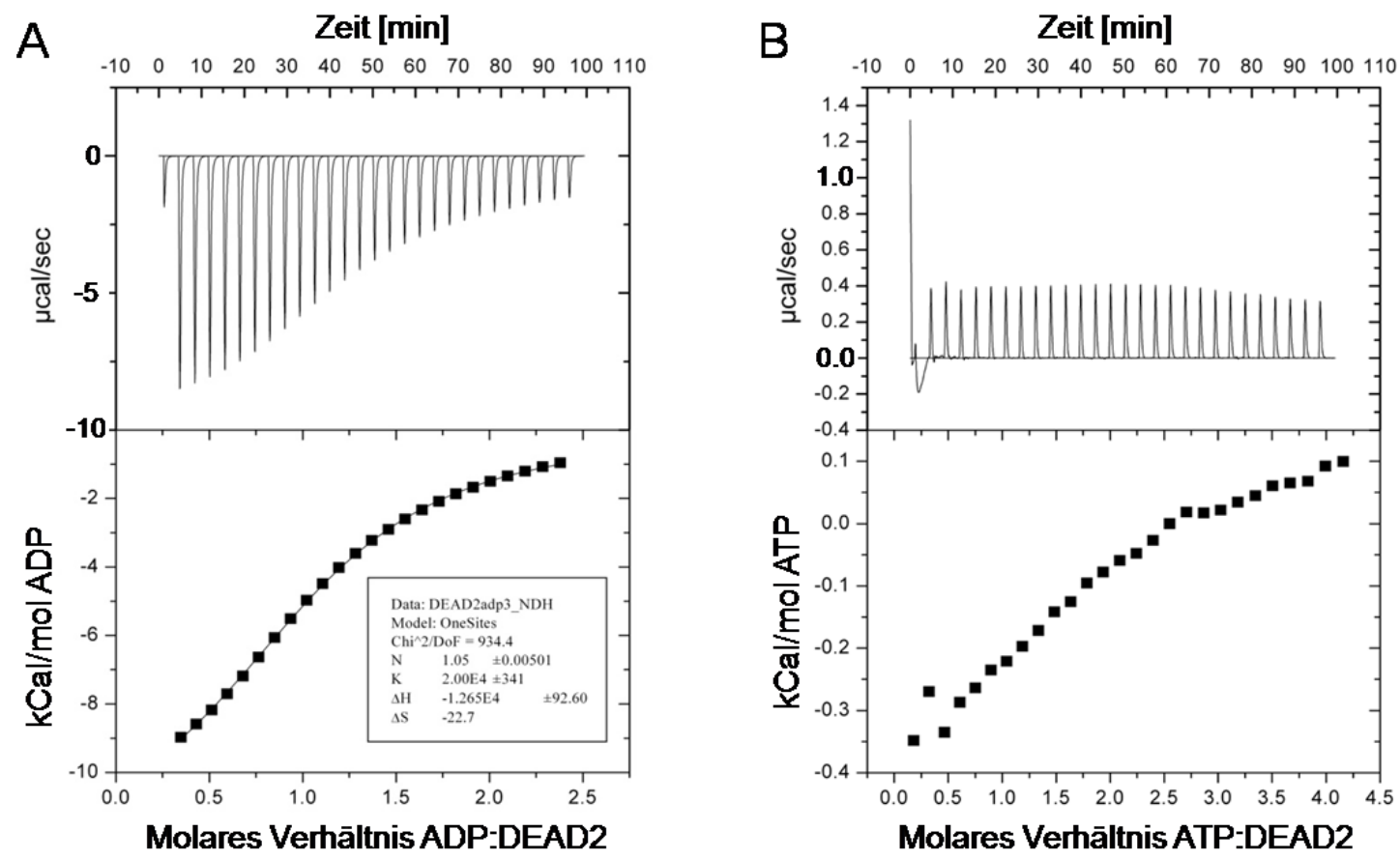

Abb. 3.15: ITK-Rohdaten (oben) und differentieller Auftrag der Bindewärme pro mol Ligand gegen das molare Verhältnis von Ligand zu DEAD2 (unten, nach Abzug der Verdünnungswärmen). (A) ADP zeigte deutlich die Entwicklung von Bindungswärme, der $\mathrm{K}_{\mathrm{D}}$-Wert betrug 50-70 $\mu \mathrm{M}$. (B) Bei ATP war keine Bindungswärme detektierbar.

Für die Interaktion von DEAD2 mit ADP ergab sich in verschiedenen Messungen ein $\mathrm{K}_{\mathrm{D}^{-}}$ Wert zwischen $50 \mu \mathrm{M}$ und $70 \mu \mathrm{M}$. Diese Werte sind etwas höher als bei der Fluoreszenztitration $(24 \pm 2,5 \mu \mathrm{M})$. Die molare Bindungsenthalpie $\Delta \mathrm{H}$ lag zwischen -12 und $-16 \mathrm{kCal} / \mathrm{mol}$. Für die Entropieänderung $\Delta \mathrm{S}$ ergaben sich -23 bis $-35 \mathrm{Cal} /\left(\mathrm{mol}^{*} \mathrm{~K}\right)$, die 
Entropie nimmt also ab. Die Anzahl der Bindestellen $n$ für ADP auf DEAD2 betrug erwartungsgemäß eins (Abb. 3.15).

Bei der Titration mit ATP wurden nur sehr kleine Wärmeumwandlungen beobachtet, die sich kaum mit der Ligandenkonzentration änderten. Ihre Größe war mit der bei der Kontrolltitration gemessenen Verdünnungswärme vergleichbar. Dies könnte bedeuten, dass bei der Bindung von ATP an DEAD2 keine Bindungswärme entsteht und sie somit nicht detektierbar ist. Wahrscheinlicher ist es aber, dass die Bindung gar nicht stattfindet. Dies würde dem Ergebnis aus der Fluoreszenztitration entsprechen.

\subsubsection{Bindungsstudien mit RNA-Substraten}

Neben einem ATP/ADP-Molekül binden DEAD-Box Proteine auch RNA. Dabei wird hauptsächlich das Zucker-Phosphat-Rückgrat gebunden, d.h. die Interaktion erfolgt in der Regel sequenzunspezifisch.

Um die RNA-Bindung des DEAD2-Fragments zu untersuchen, wurden Interaktionsstudien durchgeführt. Dazu wurden die folgenden drei RNA-Moleküle verwendet, die jeweils mögliche in vivo Substrate von hPrp28 repräsentieren (Abb. 3.16):

\section{5'SS RNA (10 nt): AGGUAAGUAU}

\section{5'SS-U1 (25 nt): AGGUAAGUAUGUUUUUCAUACUUACCU}

prä-mRNA

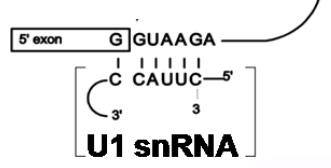

\section{5'SS-U6 (33 nt):} AGgUAUGUAUCGUUCUUUUUGAACGAUACAGAG

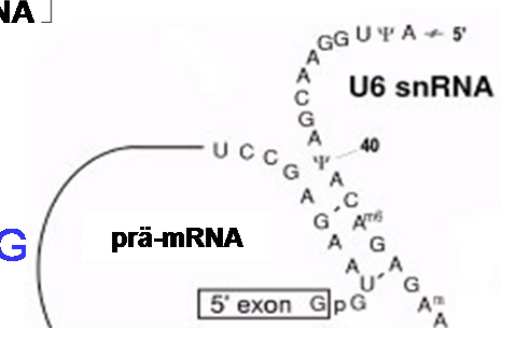

Abb. 3.16: Für Interaktionsstudien verwendete RNA-Moleküle. Die Sequenzen der RNAs sind an mögliche in vivo Substrate (rechts) von hPrp28 angelehnt. Schwarz: Sequenz der humanen 5'-Spleißstelle (teilweise modifiziert). Unterstrichen: polyU Schleife. Rot: Komplementäre Sequenz humaner U1 snRNA. Blau: Komplementäre Sequenz humaner U6 snRNA. Die zwei unteren RNA-Moleküle bilden Haarnadelstrukturen aus.

Die 5'SS RNA umfasst 10 Nukleotide, welche die Sequenz der humanen 5'-Spleißstelle enthalten. Die 5'SS-U1 RNA ist 25 Nukleotide lang und enthält zusätzlich die zur 5'Spleißstelle komplementäre Sequenz der humanen U1 snRNA. Dazwischen befinden sich fünf Uridine. Die RNA bildet eine Haarnadelstruktur aus, in der diese Uridine die Schleife bilden. Es werden dabei 11 Basenpaarungen ausgebildet und die theoretische Schmelztemperatur beträgt $26^{\circ} \mathrm{C}$. Analog dazu ist auch die dritte RNA aufgebaut, die 33 Nukleotide lang ist. Anstelle der U1 enthält sie die U6 snRNA Sequenz, die mit der 5'Spleißstelle paart. Um die Anzahl der Basenpaarungen zu erhöhen, wurde die Sequenz der 5'Spleißstelle etwas modifiziert. Dies erfolgte in Anlehnung an das RNA-Substrat in Experimenten von Ismaili et al. 2001. Es ergeben sich dadurch ebenfalls 11 Basenpaarungen und eine theoretische Schmelztemperatur von $30^{\circ} \mathrm{C}$. 
Zusätzlich wurden Interaktionsstudien mit einer RNA aus 20 Uridinen ( $\mathrm{U}_{20}$-RNA) sowie mit einem RNA-Gemisch aus Hefe (Typ III RNA) durchgeführt (2.1.6).

Die Interaktion zwischen DEAD2 und RNA-Substraten wurde über analytische Gelfiltration (Superdex 75) untersucht (2.2.2.3.3). Bei Interaktion durchlaufen Protein und RNA dabei gemeinsam die Säule und der Komplex hat ein in der Regel kleineres Elutionsvolumen als die Einzelkomponenten.

In einem Volumen von $300 \mu \mathrm{l}$ wurden 15 nmol DEAD2 mit 6 nmol der RNA vermischt (Puffer: $120 \mathrm{mM} \mathrm{NaCl}, 10 \mathrm{mM}$ Tris-HCl, pH 7,5, $2 \mathrm{mM} \beta$-Mercaptoethanol). Der Ansatz wurde $10^{\circ}$ bei $37^{\circ} \mathrm{C}$ inkubiert, um RNA-Sekundärstrukturen aufzulösen. Dann folgten $30^{\circ}$ auf Eis. Die Gelfiltration wurde bei $20^{\circ} \mathrm{C}$ durchgeführt und die UV-Absorption bei $280 \mathrm{~nm}$, $254 \mathrm{~nm}$ und $220 \mathrm{~nm}$ detektiert. Im Elutionsprofil der Säule ließen sich auf diese Weise Protein- und RNA-Komponenten identifizieren: Bei Proteinen ist die UV-Absorption bei $280 \mathrm{~nm}$ doppelt so hoch wie bei $254 \mathrm{~nm}$. Deutlich dominierend ist jedoch die Absorption bei $220 \mathrm{~nm}$. Bei RNA hingegen tritt die höchste UV-Absorption bei $254 \mathrm{~nm}$ auf und ist etwa doppelt so hoch wie bei $280 \mathrm{~nm}$. Die UV-Absorption bei $220 \mathrm{~nm}$ liegt in ihrer Stärke dazwischen.

Das DEAD2-Protein hatte in Abwesenheit von RNA ein Elutionsvolumen von 10,5 ml auf der Gelfiltrationsäule (Superdex 75 (10/30)). Das UV-Absorptionsprofil entsprach demjenigen eines Proteins: Dominierend war die Absorption bei $220 \mathrm{~nm}$, gefolgt von $280 \mathrm{~nm}$ und $254 \mathrm{~nm}$. In Gegenwart von RNA waren in den Elutionsprofilen jeweils zwei UV-Absorptionsmaxima zu erkennen (Abb. 3.17). Das zweite Maximum repräsentierte dabei vermutlich ungebundene RNA, da seine Lage von dem jeweiligen Substrat abhing. Außerdem entsprach sein UVAbsorptionsprofil demjenigen von RNA: Am stärksten war die Absorption bei $254 \mathrm{~nm}$, gefolgt von $220 \mathrm{~nm}$ und $280 \mathrm{~nm}$. Das erste UV-Maximum im Elutionsprofil repräsentierte dagegen DEAD2. Dies war an dem dominierenden Beitrag der $220 \mathrm{~nm}$-Absorption zu erkennen und wurde durch Analyse der entsprechenden Fraktionen über SDS-PAGE bestätigt (2.2.2.7.1).

In Gegenwart der 5'SS- bzw. U 20 -RNA war das Elutionsvolumen von DEAD2 nur minimal kleiner und sein UV-Absorptionsprofil im Wesentlichen unverändert. Darum kann davon ausgegangen werden, dass in diesen Fällen kein stabiler DEAD2-RNA-Komplex gebildet wurde.

In Gegenwart der 5'SS-U1 RNA war das Elutionsvolumen von DEAD2 auf $10 \mathrm{ml}$ gesunken. Außerdem zeigte das UV-Absorptionsprofil, dass die Absorption bei $254 \mathrm{~nm}$ fast so stark wie bei $280 \mathrm{~nm}$ war (Verhältnis 2:3). Dies könnte auf eine schwache Komplexbildung zwischen DEAD2 und der 5'SS-U1 RNA hinweisen.

Eindeutiger war das Ergebnis mit der 5'SS-U6 RNA. In diesem Fall betrug das Elutionsvolumen von DEAD2 nur 9,5 ml. Zudem zeigte das UV-Absorptionsprofil, dass die Absorption bei $254 \mathrm{~nm}$ höher war als bei $280 \mathrm{~nm}$ (Verhältnis 3:2). Dies weist deutlich auf die Bildung eines Protein-RNA-Komplexes hin.

Die Analyse der Gelfiltrations-Fraktionen über SDS-PAGE (2.2.2.7.1) und anschließende Silberfärbung (2.2.2.7.4) bestätigte die Interaktion zwischen DEAD2 und 5'SS-U6 RNA, da beide in einer Fraktion detektiert wurden (Abb. 3.18). Die anderen drei RNA-Substrate konnten dagegen nicht auf dem Gel sichtbar gemacht werden, auch nicht in den Fraktionen unterhalb des zweiten UV-Absorptionsmaximums. Möglicherweise wurden sie vor oder 
während der SDS-PAGE degradiert. Entsprechend war nicht abschließend zu klären, inwieweit DEAD2 und die 5'SS-U1 RNA miteinander interagieren.
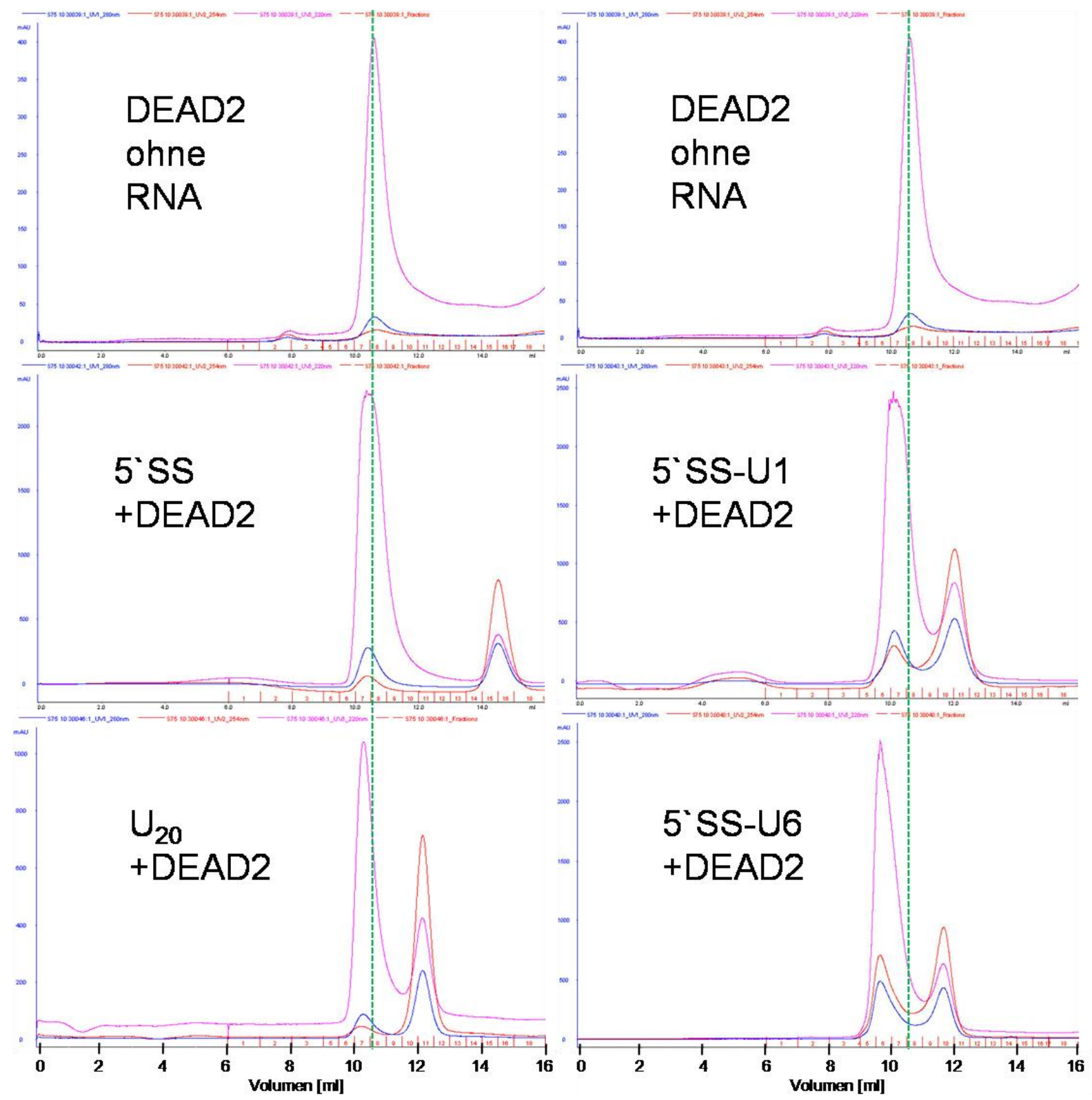

Abb. 3.17: Elutionsprofile der Gelfiltrationen (Superdex 75 (10/30)) zur Detektion von Komplexen zwischen DEAD2 und verschiedenen RNA-Substraten. Aufgetragen ist die UV-Absorption [mAU] gegen das Elutionsvolumen [ml]. Die UV-Absorption wurde bei drei verschiedenen Wellenlängen detektiert: Violett: 220 $\mathrm{nm}$, rot: $254 \mathrm{~nm}$, blau: $280 \mathrm{~nm}$. Oben ist zum Vergleich jeweils das Elutionsprofil von DEAD2 ohne RNA abgebildet. DEAD2 alleine hat ein Elutionsvolumen von 10,5 $\mathrm{ml}$ (grüne Linie). In der Mitte und unten repräsentiert das erste UV-Absorptionsmaximum DEAD2 bzw. einen DEAD2-RNA Komplex, das zweite ungebundene RNA. Für die 5'SS-U6 RNA ist eine Interaktion deutlich erkennbar. 


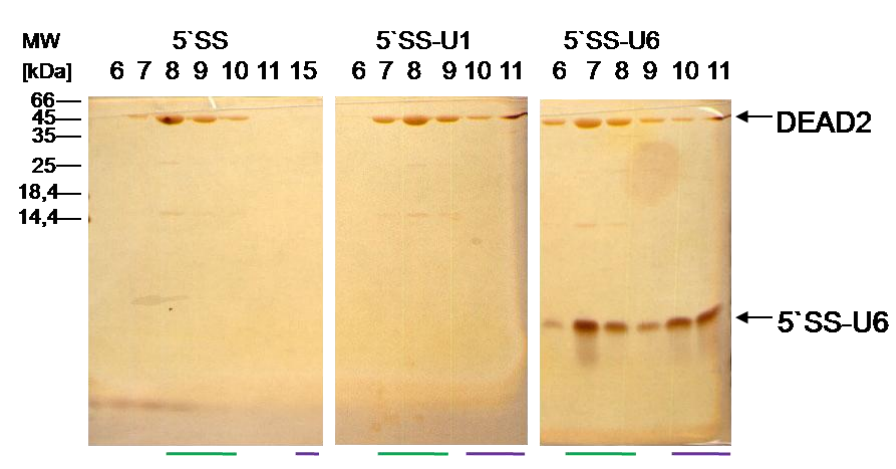

Abb. 3.18: Analyse einzelner Fraktionen aus den Gelfiltrations-Läufen (Abb. 3.17) über SDS-PAGE. Die Fraktionsnummern sind angegeben. Unter den Gelen ist gekennzeichnet, ob die Fraktionen zum jeweils ersten (grün) oder zweiten (violett) UV-Absorptionsmaximum gehören. Die Gele sind silbergefärbt. Im Fall der 5'SS-, 5'SS-U1- und $\mathrm{U}_{20}$-RNA (Gel für $\mathrm{U}_{20}$-RNA nicht abgebildet) befand sich das DEAD2-Protein hauptsächlich in Fraktion 8. Die RNA-Moleküle waren nicht detektierbar. Im Fall der 5'SS-U6-RNA befand sich DEAD2 hauptsächlich in Fraktion 7. Die RNA ließ sich sowohl zusammen mit DEAD2 als auch alleine in den Fraktionen unterhalb des zweiten UV-Absorptionsmaximums nachweisen.

Die bisherigen Ergebnisse mit definierten RNA-Molekülen könnten zu der Schlussfolgerung führen, dass DEAD2 sequenzspezifisch das Duplex aus der 5'-Spleißstelle und der U6 snRNA erkennt und bindet. Um eine solche mögliche Spezifität näher zu untersuchen, wurde eine zusätzliche Interaktionsstudie mit einem RNA-Gesamtzellextrakt aus Hefezellen (Typ III RNA) durchgeführt.

In einem Volumen von $200 \mu 1$ wurden 10 nmol DEAD2 und $250 \mu \mathrm{g}$ Typ III RNA vermischt. Es wurde genauso vorgegangen, wie für die anderen RNA-Substrate beschrieben.

Führte man die Gelfiltration mit Typ III RNA alleine aus, so wurde ein prominentes UVAbsorptionsmaximum bei $10 \mathrm{ml}$ Elutionsvolumen beobachtet (Abb. 3.19). Im Elutionsprofil zusammen mit DEAD2 wurde dieses UV-Absorptionsmaximum bei $10 \mathrm{ml}$ ebenfalls beobachtet und entsprach der ungebundenen Typ III RNA. Seine Höhe war allerdings verglichen mit dem Lauf mit Typ III RNA alleine um ein Drittel reduziert. Dies zeigte, dass ein großer Anteil der RNA die Säule im Komplex mit DEAD2 durchlief. Dieser Komplex wurde durch das erste UV-Absorptionsmaximum repräsentiert und hatte ein Elutionsvolumen von nur $9 \mathrm{ml}$. Die UV-Absorption bei $254 \mathrm{~nm}$ war nahezu doppelt so hoch wie bei $280 \mathrm{~nm}$ und damit typisch für RNA. Die Analyse über SDS-PAGE bestätigte, dass sich in den entsprechenden Fraktionen DEAD2 zusammen mit Typ III RNA befand.

Da ein großer Anteil der Typ III RNA offenbar mit DEAD2 interagieren kann, ist eine sequenzspezifische Bindung von RNA durch DEAD2 unwahrscheinlich. 


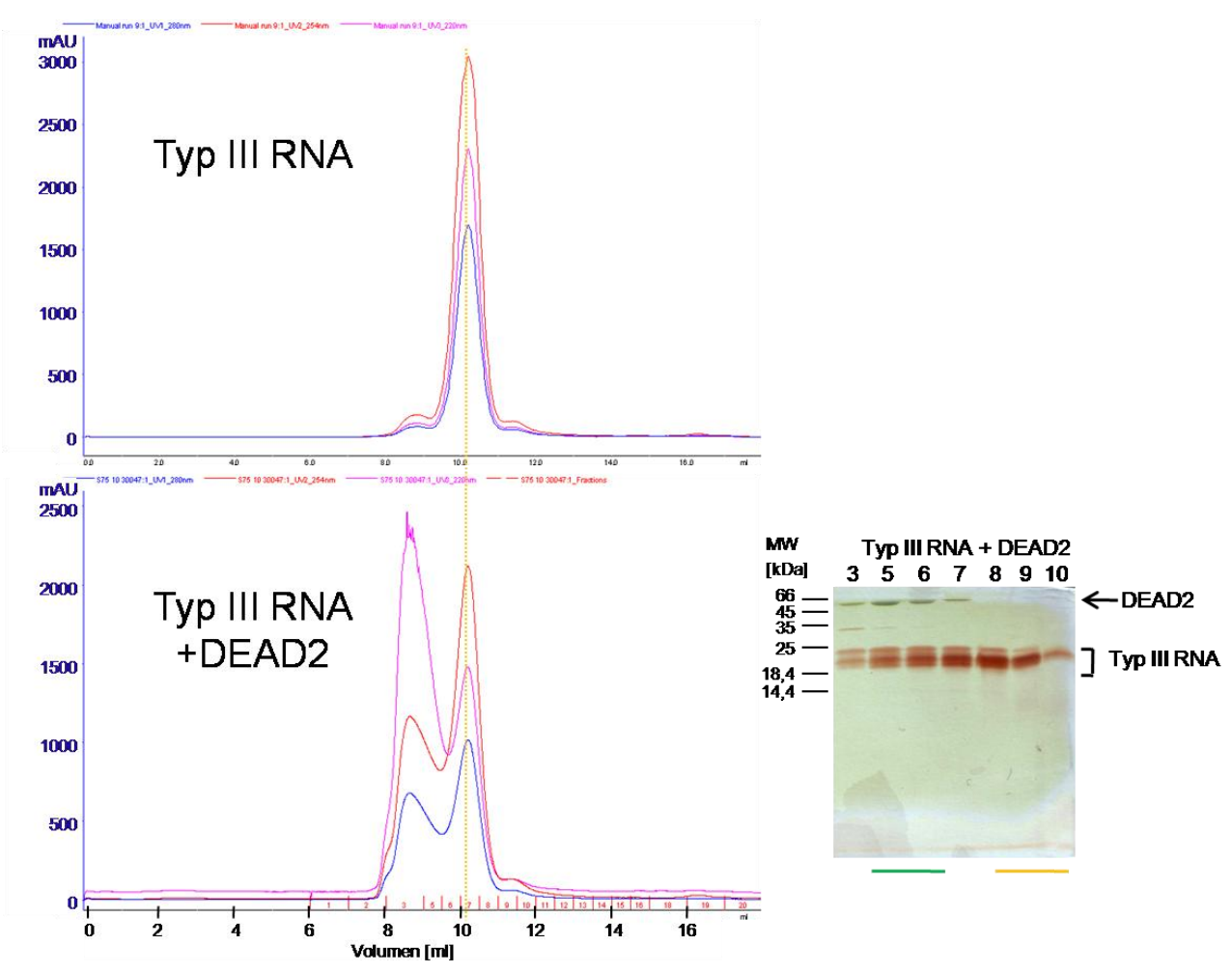

Abb. 3.19: Elutionsprofile der Gelfiltrationen (Superdex 75) zur Detektion von Komplexen zwischen DEAD2 und Typ III RNA. Aufgetragen ist die UV-Absorption [mAU] gegen das Elutionsvolumen [ml]. Die UVAbsorption wurde bei drei verschiedenen Wellenlängen detektiert: Violett: $220 \mathrm{~nm}$, Rot: $254 \mathrm{~nm}$, Blau: $280 \mathrm{~nm}$. Oben ist das Elutionsprofil der reinen Typ III RNA dargestellt. Ihr Elutionsvolumen beträgt $10 \mathrm{ml}$ (orange Linie). Zusammen mit DEAD2 tritt ein zusätzliches UV-Absorptionsmaximum auf, das einen Komplex aus DEAD2 und Typ III RNA repräsentiert. Dies wird durch Analyse einzelner Fraktionen über SDS-PAGE bestätigt. Das Gel wurde sowohl Coomassie- als auch Silber-gefärbt. Fraktionsnummern stehen über dem Gel. Die Zugehörigkeit zum ersten (grün) oder zweiten (orange) UV-Absorptionsmaximum ist unterhalb des Gels gekennzeichnet.

\subsubsection{Strukturbestimmung der Helikasedomäne von hPrp28}

Im Gegensatz zu hPrp28 binden andere DEAD-Box Helikasen wie beispielsweise Vasa und eIF4A ATP und zeigen zumindestens eine schwache ATPase-Aktivität. Die Struktur des DEAD2-Fragments gab Einblick in die molekularen Ursachen für diesen Unterschied.

\subsubsection{Kristallisation des DEAD2-Fragments}

Von der Vielzahl an Fragmenten, die von hPrp28 konstruiert wurden (3.2), war DEAD2 das einzige, von dem Kristalle für eine Strukturbestimmung erhalten wurden.

\subsection{Kristallisation ohne Substrate}

Für Kristallisationsansätze (2.2.3.2) wurde das gereinigte DEAD2-Protein auf $10 \mathrm{mg} / \mathrm{ml}$ konzentriert (2.2.2.4). Mit Ausnahme der JB-screens wurden alle verfügbaren Kristallisationsscreens verwendet (2.1.11) und bei $20^{\circ} \mathrm{C}$ inkubiert. Die Magic Screen 
Bedingung $62\left(2 \mathrm{M}\left(\mathrm{NH}_{4}\right)_{2} \mathrm{SO}_{4}, 0,2 \mathrm{M} \mathrm{Li}_{2} \mathrm{SO}_{4}, 0,1 \mathrm{M}\right.$ CAPS, pH 10,5) war die einzige von allen getesteten Bedingungen, in der Kristalle erhalten wurden.

Die ersten Kristalle waren relativ klein. Um größere Kristalle zu erhalten, wurde zunächst der pH-Wert optimiert. Die Kristallform zeigte eine starke pH-Abhängigkeit: Bei hohem pH-Wert $(10,5)$ waren die Kristalle sehr lang und zerbrechlich, während sie bei niedrigeren $\mathrm{pH}-$ Werten gleichmäßig in alle drei Raumrichtungen wuchsen (Abb. 3.20A). Der optimale pH-Wert lag bei 9,0 .

A

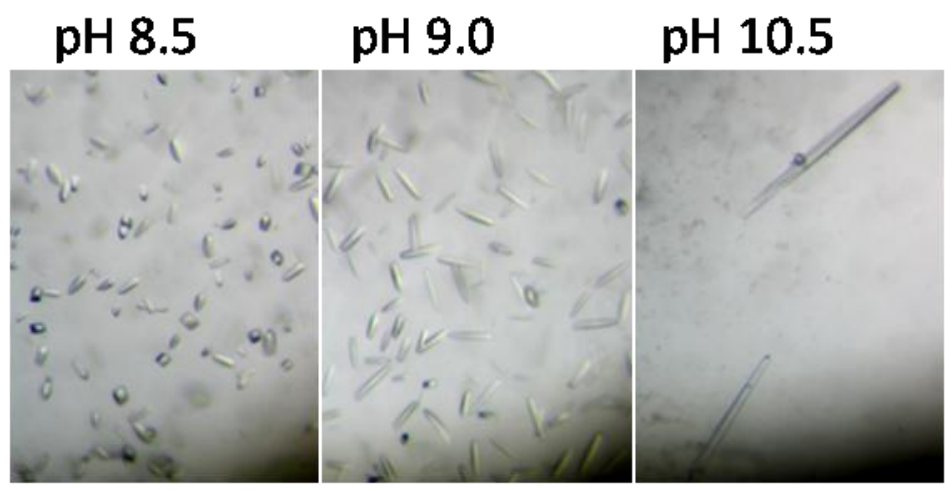

B

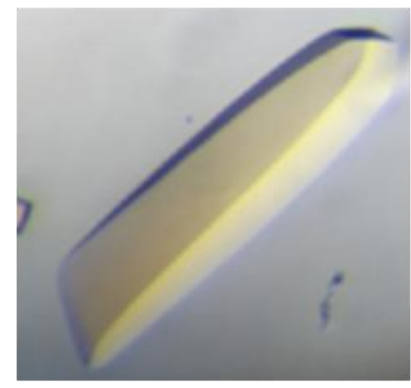

- $0,1 \mathrm{~mm}$

Abb. 3.20: Kristalle von DEAD2. (A) Die Form der Kristalle in Abhängigkeit vom pH-Wert. Kristallisationsbedingung: $2 \mathrm{M}\left(\mathrm{NH}_{4}\right)_{2} \mathrm{SO}_{4}, 0,2 \mathrm{M} \mathrm{Li}_{2} \mathrm{SO}_{4}, 0,1 \mathrm{M}$ CAPS. Der pH-Wert wurde durch Tritration mit $\mathrm{NaOH}$ variiert. (B) Kristall in optimierter Kristallisationsbedingung (2,2 $\mathrm{M}\left(\mathrm{NH}_{4}\right)_{2} \mathrm{SO}_{4}, 20 \%$ (v/v) Glyzerin, 0,1 M CAPS, pH 9,0).

Weitere Kristallisationsexperimente zeigten, dass Lithiumsulfat nicht notwendig war und durch Ammoniumsulfat ersetzt werden konnte. Außerdem konnten auch Kristalle erhalten werden, wenn der Kristallisationspuffer mit $20 \%$ (v/v) Glyzerin versetzt worden war. Dieser Glyzeringehalt ermöglichte das direkte Einfrieren der Kristalle ohne Bildung von Eiskristallen (Cryobedingung) und damit die Datenaufnahme bei tiefen Temperaturen (100 K).

Die Größe der Kristalle wurde optimiert, indem die Protein- und AmmoniumsulfatKonzentration variiert wurden. Mit $15 \mathrm{mg} / \mathrm{ml}$ Proteinkonzentration und 2,2 M Ammoniumsulfat (mit $20 \%$ (v/v) Glyzerin, 0,1 M CAPS, pH 9,0) wurden Kristalle von $0,2 \mathrm{~mm} \times 0,2 \mathrm{~mm} \times 0,5 \mathrm{~mm}$ Größe erhalten (Abb. 3.20B). Diese wurden für die Datenaufnahme und Strukturlösung verwendet.

\subsection{Kristallisationsversuche mit Substraten}

Besonders interessant ist eine Proteinstruktur im Komplex mit einem Substrat. Darum wurden Kokristallisationsversuche von DEAD2 mit RNA, ADP und dem nichthydrolysierbaren ATPAnalogon ADPNP unternommen.

Dazu wurde zunächst die etablierte Cryo-Bedingung, die zur Kristallisation des apo-Proteins geführt hatte (3.3.5.1.1), getestet. $1 \mathrm{mM} \mathrm{MgCl} 2$ und a) $1 \mathrm{mM} \mathrm{ADP,} \mathrm{b)} 1 \mathrm{mM}$ ADPNP oder c) $1 \mathrm{mM}$ ADPNP und 0,2 mM 5'SS-U6-RNA (3.3.4) wurden zur Lösung zugefügt. Entweder wurden die Kristalle unter diesen Bedingungen wachsen gelassen oder es wurden Kristalle, die in Lösung ohne Ligand gewachsen waren, in den Puffer transferiert und 2-4 Tage 
inkubiert. Anschließende Datenaufnahmen und Auswertung der Elektronendichten zeigten aber, dass unter diesen Bedingungen keines der Substrate an DEAD2 gebunden hatte.

Die Ursache für die fehlende Substratbindung in der Cryobedingung für das apo-Protein ist vermutlich der hohe Salzgehalt des Puffers, der die Interaktion mit dem Protein schwächt. Darum wurde für die Kokristallisation nach einer Bedingung mit niedriger Ionenstärke gesucht. Dazu wurde gereinigtes DEAD2-Protein in der Konzentration $10 \mathrm{mg} / \mathrm{ml} \mathrm{mit} 2 \mathrm{mM}$ $\mathrm{MgCl}_{2}, 2 \mathrm{mM}$ ADPNP und 5'SS-U6-RNA im 2-fachen molaren Überschuss gemischt und für Kristallisationsversuche verwendet. Die Kristallisationsexperimente wurden von der $H T$-Xfacility in Hamburg durchgeführt und umfassten die Kristallisationsscreens Emerald Cryo, HR Natrix, JCS 6 und Jena 1-4. Es wurden jedoch keine Kristalle erhalten.

\subsubsection{Datenaufnahme und Phasenbestimmung}

Die Kristalle des DEAD2-Proteins zeigten ein relativ einheitliches Streuverhalten. Mit Synchrotron-Strahlung (BESSY, Berlin oder DESY, Hamburg) ergab sich eine Auflösung zwischen 2,4 $\AA$ und 2,6 ̊. Die Kristalle zeigten dabei ein anisotropes Streuverhalten (Abb. 3.21). In einigen Raumrichtungen wurden Reflexe bis $2,2 \AA$ beobachtet, in anderen Raumrichtungen aber nur bis 2,6 ̊́. Um eine Vollständigkeit der Daten von mindestens 90\% zu erreichen, wurden die Daten nur bis zu einer Auflösung von 2,4 Å prozessiert (2.2.3.4).

Die Indizierung ergab für das Kristallgitter zunächst die orthorhombische Raumgruppe C222. Das systematische Fehlen bestimmter Reflexe zeigte darüber hinaus das Vorhandensein einer Schraubenachse an, so dass sich schließlich als Raumgruppe C222 $2_{1}$ ergab. Analyse mit dem Diffraction Anisotropy Server von Michael R. Sawaya (UCLA-Department, Strong et al. 2006) zeigte, dass die Auflösung in Richtung der a-Achse nur 2,6 , in Richtung der b- und c-Achse aber 2,2 Å betrug.

Die Einheitszelle der Raumgruppe C222 enthält aufgrund der vorhandenen acht Symmetrieoperatoren acht asymmetrische Einheiten. Um $\mathrm{zu}$ bestimmen, wieviele Proteinmoleküle sich in einer asymmetrischen Einheit befinden, wird der Matthews Koeffizient berechnet (Matthews 1968). Dazu wird das Volumen der asymmetrischen Einheit durch das Molekulargewicht des DEAD2-Fragments (54,9 kDa) geteilt. Der Matthews Koeffizient liegt bei Proteinen zwischen 1,7-3,0 $\AA^{3} / \mathrm{Da}$. Ein Wert in diesem Bereich $\left(2,83 \AA^{3} / \mathrm{Da}\right)$ ergibt sich ausschließlich mit einem einzigen DEAD2-Protein pro asymmetrischer Einheit. Damit beträgt der Lösungsmittelgehalt der Kristalle 56,5 \%. 
A

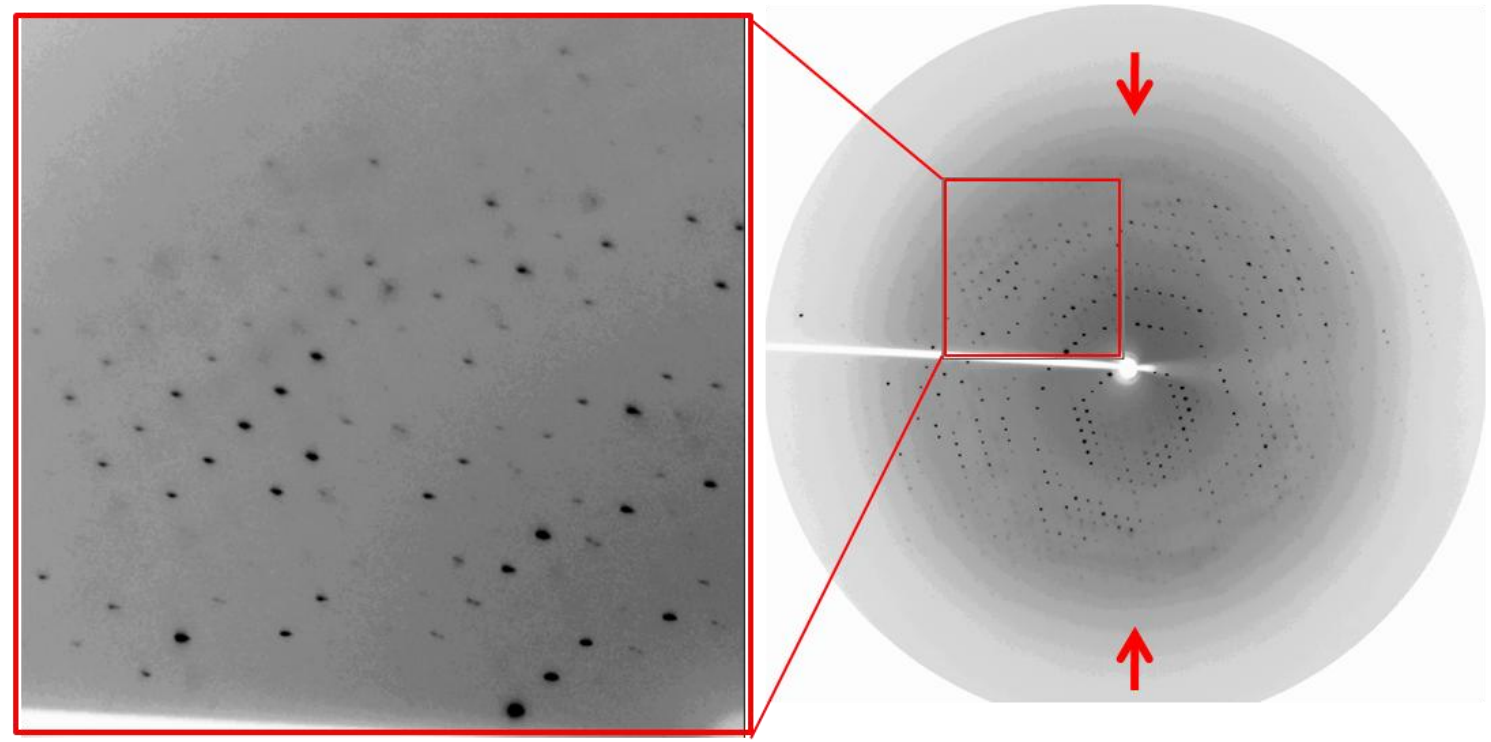

B

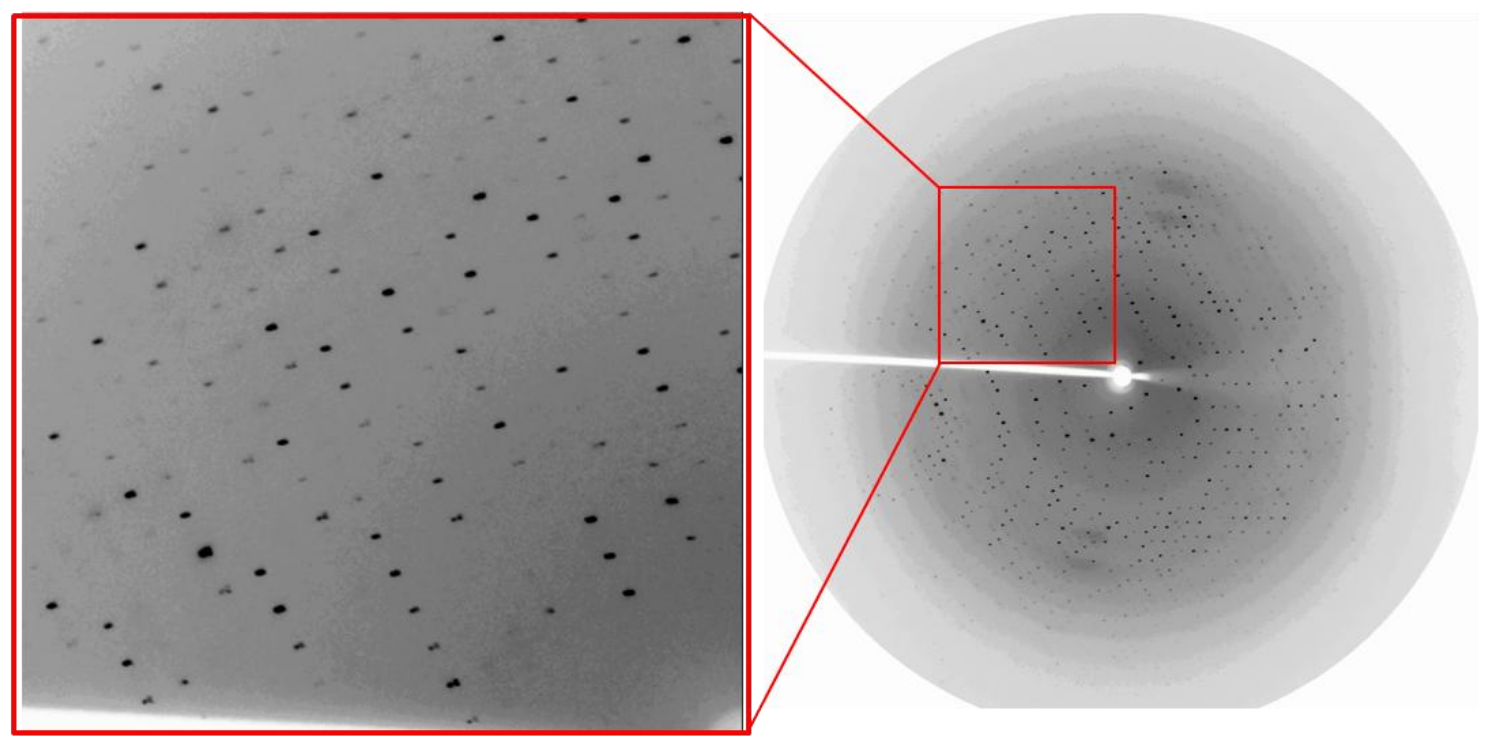

Abb. 3.21: Anisotropes Streuverhalten der DEAD2-Kristalle. Dargestellt sind die Röntgenbeugungsbilder bei zwei verschiedenen Orientierungen des Kristalls. Links ist jeweils ein identischer Bereich vergrößert abgebildet. Der helle Punkt im Zentrum der Beugungsbilder zeigt die Position des ungebeugten Röntgenstrahls. Je weiter entfernt ein Streu-Reflex von diesem Zentrum ist, desto höher ist die repräsentierte Auflösung. Zwischen den beiden Aufnahmen (A) und (B) wurde der Kristall um $90^{\circ}$ gedreht. In (B) streut der Kristall gleichmäßig bis zu einer Auflösung von 2,2 ̊. In (A) dagegen fehlen in zwei Sektoren des Bildes (rote Pfeile) hochauflösende Reflexe.

\subsection{Versuch der Phasenbestimmung über molekularen Ersatz (MR)}

Die Strukturen von mehreren DExD/H-Box-Helikasedomänen sind bereits bekannt (Tabelle 1.2). Darum wurde zunächst versucht, die Phasendifferenzen für die DEAD2-Strukturfaktoren über molekularen Ersatz (MR, 2.2.3.1) zu bestimmen.

Die größte Aminosäuresequenzidentität zum DEAD2-Fragment haben die Helikasedomänen der Proteine Vasa, DDX3x (beide $38 \%$ ) und MjDEAD (33\%). Darüber hinaus wurden auch Dhh1 (Sequenzidentität $30 \%)$, eIF4A (30\%) und UAP56 (28\%) als Suchmodelle für die MR-Berechnung verwendet. Mit keinem dieser Proteine wurde eine eindeutige Lösung 
gefunden. Die Ursache dafür war vermutlich, dass sich die Helikasedomänen in der relativen Orientierung ihrer Subdomänen unterscheiden. Diese Orientierung ist bei DEAD2 offensichtlich anders als in jedem der Suchmodelle.

Es wurde auch versucht, nur die N-terminale Subdomäne von Vasa oder MjDEAD als Suchmodell zu verwenden. Dieser Teil umfasst $61 \%$ bzw. $55 \%$ der Gesamtstruktur. Doch auch damit wurde keine eindeutige MR-Lösung gefunden.

\subsection{Phasenbestimmung über MAD}

Für eine experimentelle Phasenbestimmung wurde zunächst ein derivatisierter Proteinkristall benötigt. Dazu wurden DEAD2-Kristalle in Kristallisationspuffer inkubiert, dem verschiedene Schwermetallsalze zugefügt worden waren (2.2.3.3).

Der Kristallisationspuffer von DEAD2 enthält eine hohe Ammoniumsulfat-Konzentration und zudem einen hohen $\mathrm{pH}-$ Wert. Dies sind ungünstige Voraussetzungen für eine Schwermetallderivatisierung (Sigler und Blow 1965). Um einen Hinweis zu erhalten, welche Substanzen unter diesen Bedingungen dennoch mit dem Protein reagieren, wurde DEAD2 in Kristallisationspuffer gelöst, das jeweils $10 \mathrm{mM}$ eines Schwermetallsalzes enthielt. Nach Inkubation über Nacht wurde eine native Gelelektrophorese durchgeführt (2.2.2.7.2, Abb. 3.22). Falls das Schwermetall mit DEAD2 interagiert, sollte dies in einer Verschiebung der Bande auf dem Gel sichtbar werden (Boggon und Shapiro 2000).

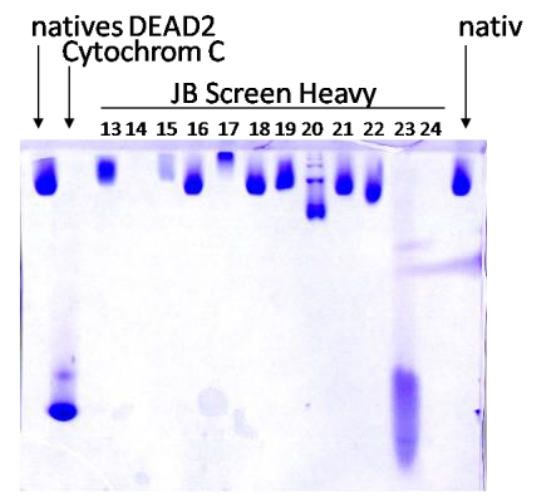

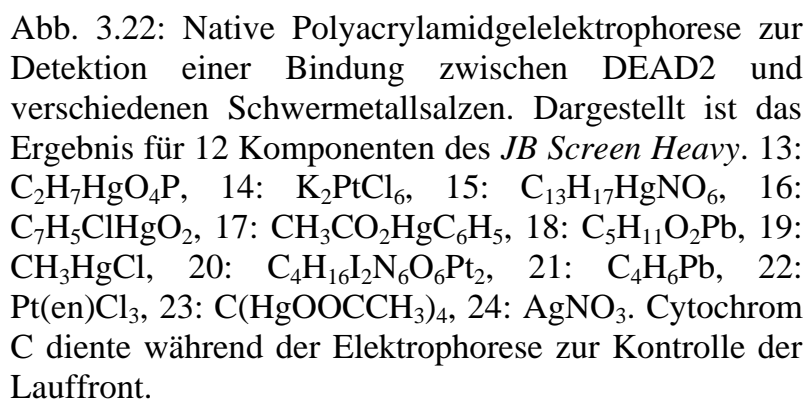

Eines der Schwermetallsalze, die auf dem nativen Gel zu einer Verschiebung der Bande des DEAD2-Fragments geführt hatten, war Phenylquecksilberacetat (Komponente Nr. 17 des $J B$ Screen Heavy, Jena Bioscience). Proteinkristalle, die damit inkubiert wurden, zeigten bei der Datensammlung eine relativ starke anomale Streuung. Das bedeutete, dass diese Substanz auch innerhalb des Kristalls spezifisch an DEAD2 gebunden hatte. Von einem entsprechend derivatisierten Kristall wurde ein MAD-Datensatz aufgenommen (2.2.3.4, Tab. 3.3). Anhand eines Fluoreszenzscans wurden die optimalen Wellenlängen für die Messung ausgewählt (Abb. 3.23). 


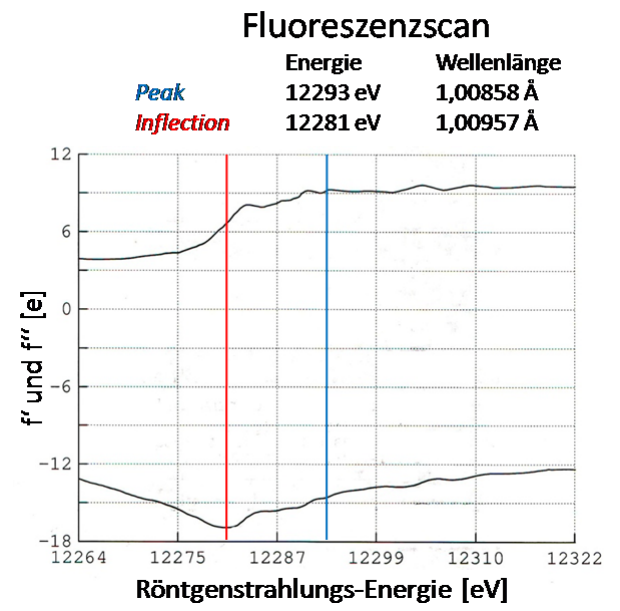

Abb. 3.23: Fluoreszenzscan mit einem Phenylquecksilberacetat-derivatisierten DEAD2Kristall. Der obere Graph gibt den imaginären Anteil ( $f^{\star}$ ), der untere Graph den realen Anteil ( $\left.f^{\star}\right)$ der anomalen Streuung an. Das Spektrum wurde zwischen $12264 \mathrm{eV}$ und $12322 \mathrm{eV}$ Photonenenergie aufgenommen (X-Achse). Über dem Spektrum ist angegeben, welche Wellenlängen für den peak- (maximales $\mathrm{f}^{\prime \prime}$ ) und inflection point- (minimales $\mathrm{f}^{\prime}$ ) Datensatz verwendet wurden.

Tabelle 3.3: Statistik der Datenaufnahme für den MAD-Datensatz mit einem Phenylquecksilberacetatderivatisierten DEAD2-Kristall. Werte in Klammern beziehen sich auf die höchste Auflösungsschale.

\begin{tabular}{|l|l|l|l|l|}
\hline Datensatz & peak & inflection point & high remote & low remote \\
\hline Wellenlänge $[\AA]$ & 1,00858 & 1,00957 & 0,93222 & 1,01212 \\
\hline Auflösung $[\AA]$ & \multicolumn{4}{|c|}{$30-2,4(2,49-2,40)$} \\
\hline Raumgruppe & \multicolumn{4}{|c|}{$\mathrm{C} 222,1$} \\
\hline Zellkonstanten $[\AA]$ & $\begin{array}{l}\mathrm{a}=125,344 \\
\mathrm{~b}=136,614 \\
\mathrm{c}=73,134 \\
\alpha=\beta=\gamma=90^{\circ}\end{array}$ & $\begin{array}{l}\mathrm{a}=125,372 \\
\mathrm{~b}=136,660 \\
\mathrm{c}=73,155 \\
\alpha=\beta=\gamma=90^{\circ}\end{array}$ & $\begin{array}{l}\mathrm{a}=125,374 \\
\mathrm{~b}=136,682 \\
\mathrm{c}=73,162 \\
\alpha=\beta=\gamma=90^{\circ}\end{array}$ & $\begin{array}{l}\mathrm{a}=125,412 \\
\mathrm{~b}=136,747 \\
\mathrm{c}=73,185 \\
\alpha=\beta=\gamma=90^{\circ}\end{array}$ \\
\hline beobachtete Reflexe & 241172 & 241335 & 243686 & 239968 \\
\hline einmalige Reflexe & 24997 & 25012 & 25119 & 24992 \\
\hline $\begin{array}{l}\text { Vollständigkeit der } \\
\text { Reflexe }[\%]\end{array}$ & $96,7(82,4)$ & $96,9(83,0)$ & $96,2(80,4)$ & $96,5(81,7)$ \\
\hline $\begin{array}{l}\text { Redundanz } \\
{[-f a c h]}\end{array}$ & $2,6(2,6)$ & $2,6(2,5)$ & $2,6(2,5)$ & $2,6(2,6)$ \\
\hline $\begin{array}{l}\text { Signal/Rauschen } \\
(\mathrm{I} / \sigma(\mathrm{I}))\end{array}$ & $24,8(6,8)$ & $25,6(7,2)$ & $23,4(5,5)$ & $24,9(6,9)$ \\
\hline $\mathrm{R}_{\text {sym }}{ }^{*}$ & $3,3(13,0)$ & $3,2(12,5)$ & $3,6(15,9)$ & $3,3(12,7)$ \\
\hline $\begin{array}{l}\text { phasing power } \\
(\text { nach AutoSHARP) }\end{array}$ & 0,702 & 0,465 & 0,544 & - \\
\hline
\end{tabular}

${ }^{*}$ Wenn $\mathrm{I}_{\mathrm{hkl}}^{\mathrm{i}}$ die i-te Messung und $<\mathrm{I}_{\mathrm{hkl}}>$ die durchschnittliche Intensität des Reflexes hkl ist, dann:

$$
R_{s y m}=100 \cdot \sum_{h k l i}\left|I_{h k l}^{i}-\left\langle I_{h k l}\right\rangle\right| / \sum_{h k l i}\left\langle I_{h k l}^{i}\right\rangle
$$

Das anomale Signal erwies sich als ausreichend, um die Schweratome zu lokalisieren (Abb. 3.24, Tab. 3.4). Dabei hatte nur ein Quecksilberatom pro DEAD2-Protein gebunden. Dies genügte jedoch, um eine erste Elektronendichtekarte zu berechnen (2.2.3.5). 

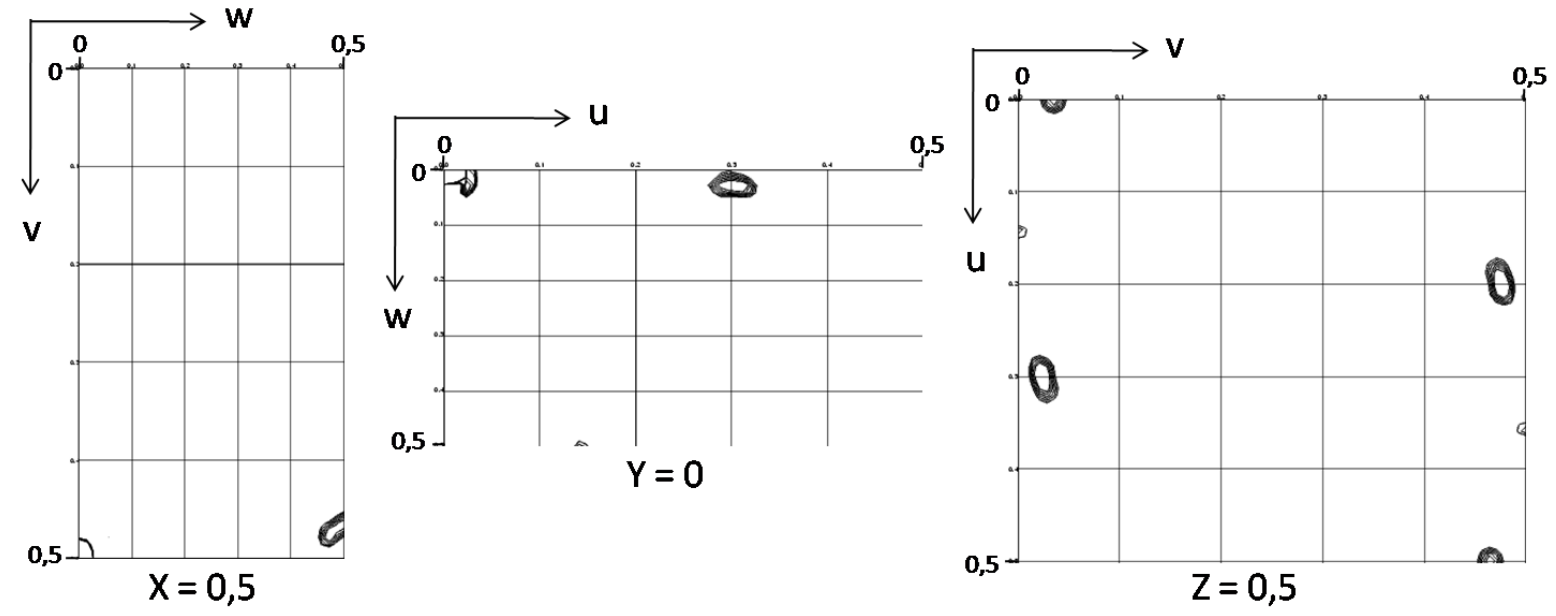

Abb. 3.24: Darstellung von drei Harker-Sektionen ( $\mathrm{x}=0,5, \mathrm{y}=0$ und $\mathrm{z}=0,5)$ im Patterson-Raum, der anhand der anomalen Differenzen des peak-Datensatzes berechnet wurde (Mapmask aus dem CCP4 Programmpaket). Die deutlich erkennbaren Maxima zeigen, dass die Quecksilberatome spezifisch im Protein-Kristall gebunden wurden. Aus der Lage der Maxima im Patterson Raum lässt sich die Anzahl und Position der Schweratome innerhalb der Einheitszelle ableiten.

Tabelle 3.4: Schwermetallpositionen aus AutoSHARP. In der ersten Zeile (CRYST1) sind die Einheitszellkonstanten und die Raumgruppe aufgeführt. Die zweite bis vierte Zeile (SCALE1-3) stellt die angewandte Rotationsmatrix dar. Anschließend folgt die Beschreibung der gefundenen Quecksilberatome (Hg). Angegeben ist die Position innerhalb der Einheitszelle (Koordinaten $\mathrm{x}$, y und z) sowie die Belegung der Schwermetallposition und ihr B-Faktor (Temperaturfaktor) in $\left[\AA^{3}\right]$. Obwohl die asymmetrische Einheit nur ein Quecksilberatom enthält, kann dieses zwei alternative, nahe beieinander liegende Positionen einnehmen.

CRYST1 $125.400136 .700 \quad 73.20090 .0090 .0090 .00$ C2221

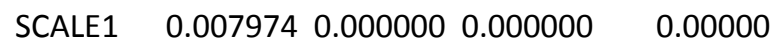

$\begin{array}{lllll}\text { SCALE2 } & 0.000000 & 0.007315 & 0.000000 & 0.00000\end{array}$

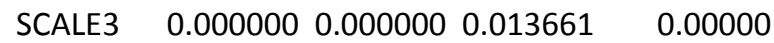

$\begin{array}{lllllll} & \text { Atomtyp } & \mathrm{x} & \mathrm{y} & \mathrm{z} & \text { Belegung } & \text { B-Faktor }[\AA] \\ \text { ATOM } & 1 \mathrm{HG} & 18.502 & 1.597 & 17.376 & 0.72 & 73.29 \\ \text { ATOM } & 2 \mathrm{HG} & 21.387 & 2.347 & 16.659 & 0.13 & 19.02\end{array}$

\subsubsection{Modellbau und Strukturverfeinerung}

Die anfängliche Elektronendichtekarte, die nach Phasenberechnung durch MAD erhalten worden war, zeigte insbesondere für die N-terminale Helikasesubdomäne bereits viele strukturelle Details (Abb. 3.25). Dies ermöglichte den Einbau großer Bereiche der Aminosäurekette des DEAD2-Fragments (2.2.3.6). Als Orientierung diente dabei die Struktur von Vasa (Sengoku et al. 2006).

Andere Bereiche der Elektronendichtekarte waren deutlich unklarer in der Interpretation und insbesondere in der C-terminalen Helikasesubdomäne ließen sich einzelne Abschnitte der Aminosäurekette nicht einbauen. Über Strukturverfeinerungen konnte gerade in diesen schlecht definierten Bereichen keine Verbesserung erreicht werden. Dies weist darauf hin, dass die DEAD2-Proteine im Kristall in einigen Regionen flexibel sind und dadurch kein geordnetes Gitter bilden. 


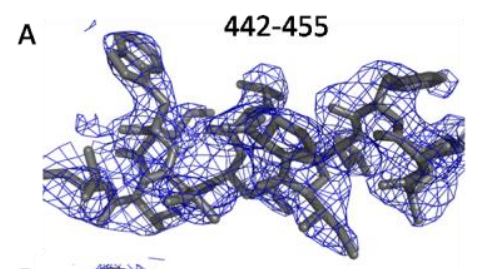

B

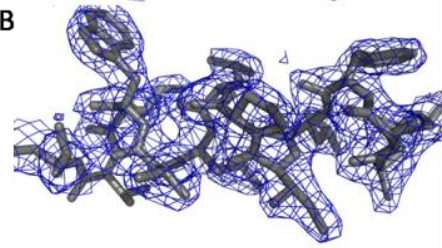

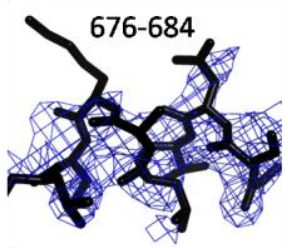

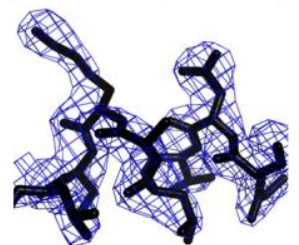

Abb. 3.25: Zwei Ausschnitte aus der Elektronendichtekarte für DEAD2. (A) Vor der Verfeinerung. (B) Nach der Verfeinerung. Die Aminosäuren 442-455 sind bereits vor der Verfeinerung gut sichtbar. Für Aminosäure 676-684 zeigt die Elektronendichtekarte zwar den Verlauf des Peptidrückgrats, die Konformation der Seitenketten ist aber nicht eindeutig.

Aufgrund dieser Probleme ist die Strukturverfeinerung noch nicht abgeschlossen. Das bisher erhaltene molekulare Modell von DEAD2 enthält noch etwa 50 Aminosäuren, deren Geometrie nicht innerhalb erlaubter Bereiche des Ramachandran Plots liegen (Abb. 3.26). Außerdem sind die Standardabweichungen der Bindungswinkel und -längen vom Idealwert noch relativ hoch (Tab. 3.5).

Tab. 3.5: Verfeinerungsstatistik. Verwendet wurde der low remote Datensatz des PhenylquecksilberacetatDerivats von DEAD2. Angegeben sind die statistischen Werte nach einer Verfeinerung mit Refmac mit drei verschiedenen Gewichtungsfaktoren (weight factor). Je höher dieser Wert ist, desto mehr werden bei der Berechnung die experimentellen Daten berücksichtigt. Dies führt allerdings zu größeren Standardabweichungen der Bindungslängen und -winkel. FOM: figure of merit (Bewertungsfaktor für die Qualität der Phasen mit dem Idealwert 1). B-Faktor: Temperaturfaktor, der die Schwingung der Atome um ihre Mittellage beschreibt.

\begin{tabular}{|l|c|c|c|}
\hline weight factor (Refmac) & 0,01 & 0.05 & 0,10 \\
\hline $\mathrm{R}_{\text {cryst }}$ & 33,8 & 28,3 & 25,9 \\
\hline $\mathrm{R}_{\text {free }}$ & 38,1 & 34,3 & 32,8 \\
\hline FOM & 0,673 & 0,721 & 0,731 \\
\hline Standardabweichung (Bindungslängen) $[\AA]$ & 0,010 & 0,017 & 0,023 \\
\hline Standardabweichung (Bindungswinkel) $\left[{ }^{\circ}\right]$ & 2,267 & 3,082 & 3,409 \\
\hline allgemeiner B-Faktor $\left[\AA^{2}\right]$ & \multicolumn{3}{|l}{} \\
\hline
\end{tabular}

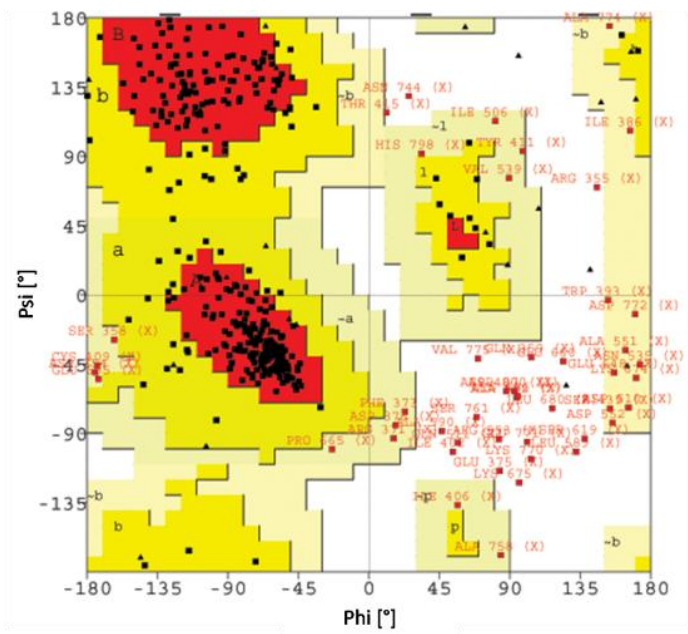

Ramachandran Plot

Anteil der Aminosäurereste in

- bevorzugten Regionen (rot): $\quad 71,8 \%$

- erlaubten Regionen (gelb): $\quad 14,9 \%$

- bedingt erlaubten Regionen (beige): $\quad 6,9 \%$

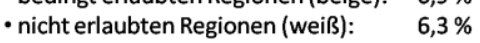

Abb. 3.26: Ramachandran Plot für das vorläufige Modell des DEAD2-Fragments von hPrp28 (erstellt mit Procheck). Gegeneinander aufgetragen sind die Rotationswinkel psi und phi. Schwarze Quadrate kennzeichnen Aminosäurereste in bevorzugten (rot) und erlaubten (gelb) Regionen. Rote Quadrate kennzeichnen Reste in nicht erlaubten (weiß) oder nur bedingt erlaubten Regionen (beige). Dreiecke symbolisieren Glycine. 
Das vorläufige Modell enthält die Reste 353-457, 468-689, 716-722 und 730-802 von hPrp28 und damit insgesamt 407 Aminosäuren. Die nicht eingebauten Sequenzbereiche des DEAD2Fragments (grau in Abb. 3.27 und 3.28) umfassen neben Resten am N- und C-Terminus zwei Schleifenregionen sowie eine vorhergesagte $\alpha$-Helix und einen $\beta$-Faltblatt-Strang (PSIPRED). Für den $\beta$-Faltblatt-Strang (Sequenzbereich 690-695) ist zwar Elektronendichte für das Protein-Rückgrat erkennbar, jedoch ermöglicht die schlechte Qualität keine Zuordnung der Aminosäuren. Für die aus Sequenzvergleichen vorhergesagte $\alpha$-Helix (Bereich 700-710) fehlt hingegen die Elektronendichte vollständig.

Weiterhin gibt es mehrere Sequenzbereiche in dem Modell, für die zwar der Verlauf des Proteinrückgrats in der Elektronendichte erkennbar, die genaue Konformation der Aminosäureseitenketten aber unsicher ist. Diese Bereiche sind in der Abb. 3.27 und 3.28 rot gekennzeichnet.

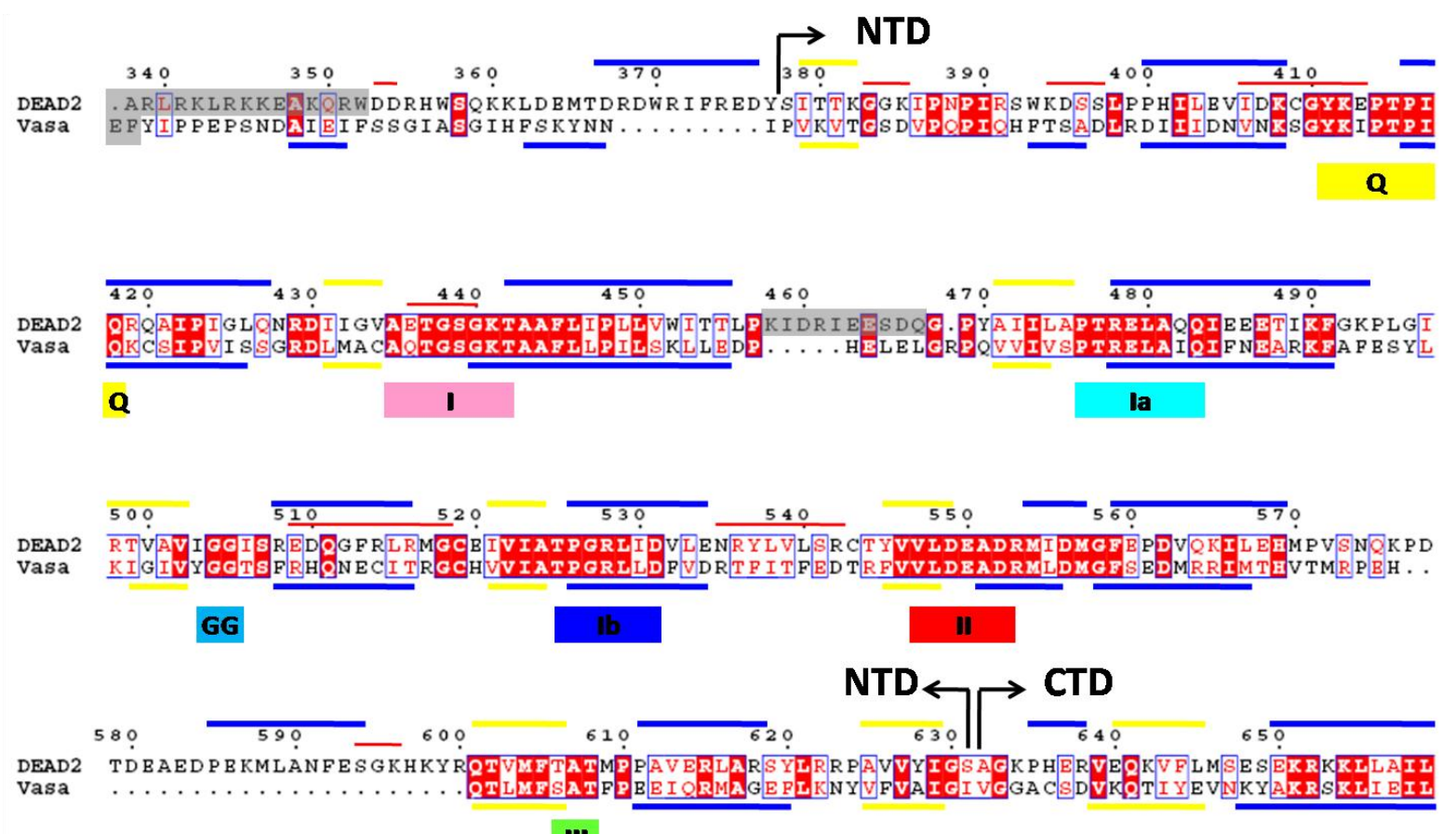

III

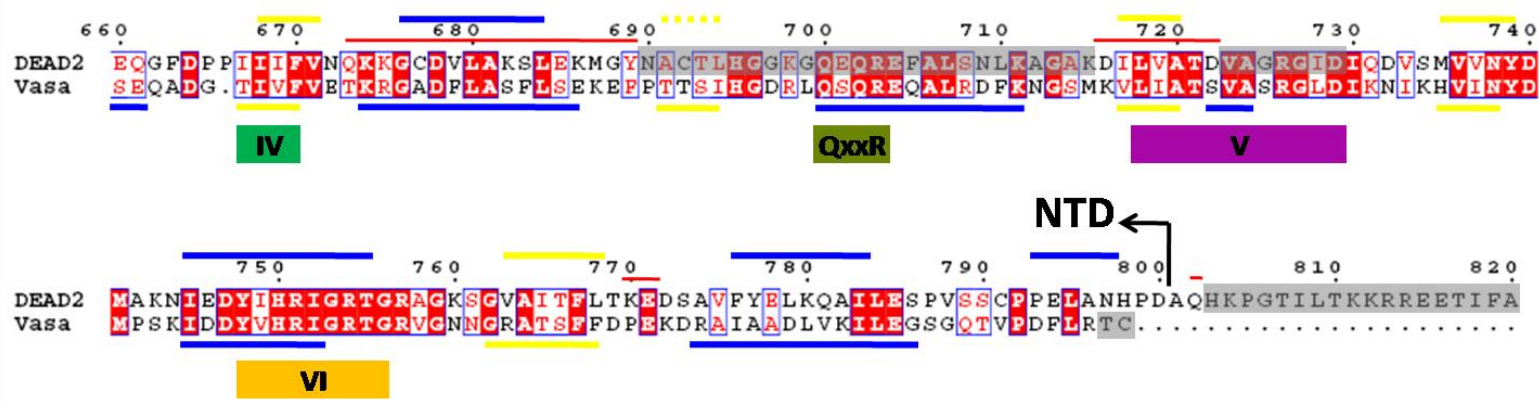

Abb. 3.27: Sequenzalignment (Clustal W) zwischen dem DEAD2-Fragment und der Helikasedomäne von Vasa (Sengoku et al. 2006). Die beiden Aminosäuresequenzen sind zu $38 \%$ identisch (rot hinterlegt). In den Strukturen fehlende Sequenzbereiche sind grau hinterlegt. Rote Balken kennzeichnen Aminosäuren des DEAD2Strukturmodells, deren Seitenkettenkonformation unsicher ist. Gelbe ( $\beta$-Faltblatt) und blaue $(\alpha-H e l i x)$ Balken zeigen die jeweilige Lokalisation von Sekundärstrukturelementen in den Proteinen. Weiterhin sind die konservierten Sequenzmotive der DEAD-Box Proteinfamilie und die Grenzen der N-terminalen und Cterminalen Helikasesubdomäne gekennzeichnet (NTD bzw. CTD). Zahlen geben die Aminosäuresequenz von hPrp28 an. 


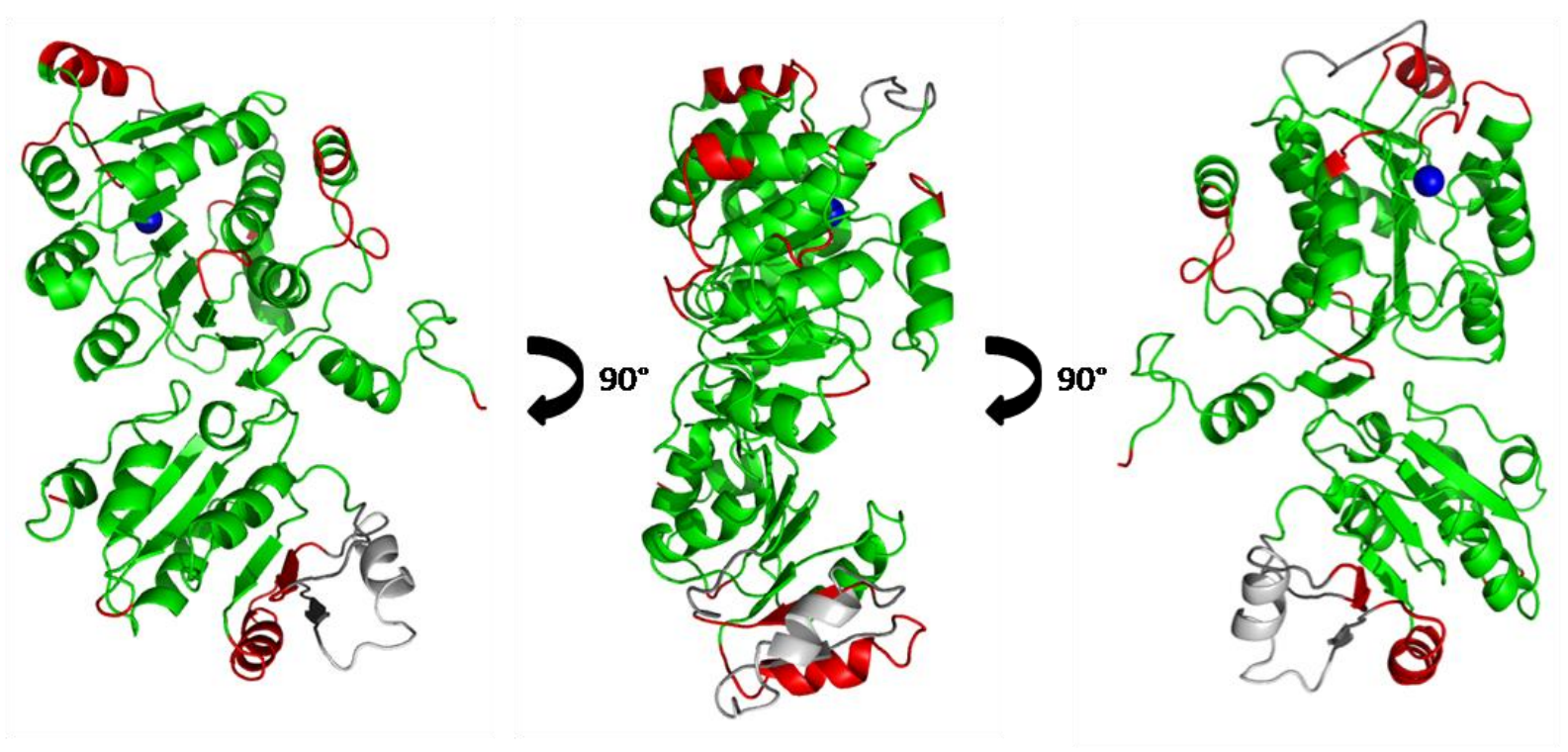

Abb. 3.28: Vorläufiges Strukturmodell des DEAD2-Fragments von hPrp28 in drei verschiedenen Orientierungen. Die Lage des zur Phasenberechnung verwendeten Quecksilberatoms ist angegeben (blau). Rot gekennzeichnet sind Bereiche, in denen die Konformation der Aminosäureseitenketten unsicher ist. Graue Bereiche fehlen in dem Strukturmodell. Zur Vollständigkeit ist ihre aus dem Vergleich mit Vasa (Sengoku et al. 2006) zu erwartende Struktur gezeigt.

\subsubsection{Beschreibung der Struktur}

Da die Verfeinerung des Modells von DEAD2 noch nicht abgeschlossen ist, wird die Struktur nicht im molekularen Detail beschrieben.

Die Helikasedomäne von hPrp28 besteht wie bei anderen DExD/H-Box Proteinen aus zwei Subdomänen mit einer RecA-ähnlichen Struktur (1.1.2). Die N-terminale Subdomäne (NTD) enthält ein zentrales achtgliedriges $\beta$-Faltblatt, das von zehn $\alpha$-Helices umgeben ist. Die Cterminale Subdomäne (CTD) ist ähnlich aufgebaut, aber insgesamt kleiner. Sie besteht aus einem sechsgliedrigen zentralen $\beta$-Faltblatt, das von vermutlich sieben $\alpha$-Helices umgeben wird (Abb. 3.29B).

Das Quecksilberatom, das zur Phasenberechnung in das Protein eingefügt worden war (3.3.5.2.2), ist eine kovalente Bindung mit Cystein 543 eingegangen. Es befindet sich damit im Inneren der NTD.

Die Helikasedomäne von hPrp28 enthält eine Besonderheit, die sie von anderen DExD/H-Box Helikasen unterscheidet. Dabei handelt es sich um eine Insertion von 24 Aminosäuren in der N-terminalen Subdomäne (Aminosäuren 576-599, Abb. 3.27). Diese Insertion findet sich auch bei den orthologen Proteinen von Drosophila melanogaster oder Caenorhabditis elegans wieder, aber nicht in Prp28 aus Saccharomyces cerevisiae. Strukturell bildet der Sequenzabschnitt eine kleine Kappe über der N-terminalen Subdomäne, die aus einer $\alpha$-Helix und einer Schleifenregion besteht (Abb. 3.29C). Diese Kappe befindet sich auf der NTD auf der entgegengesetzten Seite wie die konservierten Sequenzmotive (Abb. 3.30).

Die Struktur von DEAD2 zeigt neben der Helikasedomäne auch etwa 20 Aminosäuren der Nterminal anschließenden Sequenz. Dieser Abschnitt bildet eine $\alpha$-Helix aus, zeigt aber ansonsten keine Sekundärstrukturelemente (Abb. 3.29C). Es handelt sich hierbei vermutlich 
um einen kleinen Teil der N-terminal angrenzenden Domäne. Für eine korrekte Faltung wird wahrscheinlich die vollständige Domäne benötigt, so dass die Struktur dieses Sequenzabschnitts im DEAD2-Fragment vermutlich nicht der Struktur in hPrp28 entspricht.

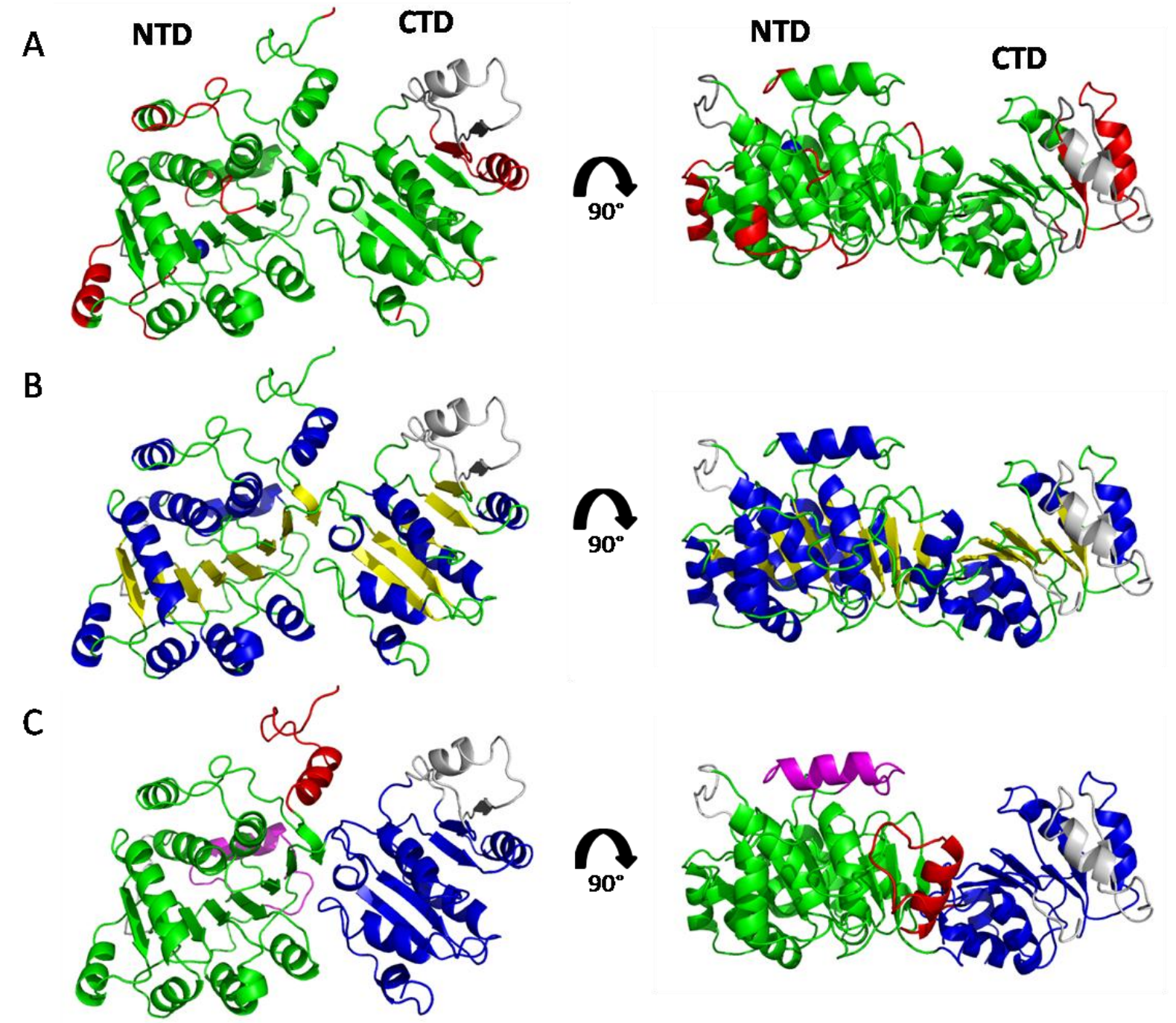

Abb. 3.29: Struktur des DEAD2-Fragments von hPrp28 in jeweils zwei verschiedenen Orientierungen. Die Lage der in der Elektronendichte fehlenden Bereiche ist in grau angedeutet. (A) Fehlende bzw. problematische Sequenzbereiche des Modells. Erläuterungen siehe Abb. 3.28 (B) Sekundärstrukturelemente. Gelb: $\beta$-Faltblatt. Blau: $\alpha$-Helix. Grün: ohne Sekundärstruktur. (C) Domänenaufbau. Grün und blau: N-terminale bzw. C-terminale Helikasesubdomäne (NTD bzw. CTD). Rot: N-terminal angrenzender Sequenzabschnitt. Violett: Insertion in der NTD als Besonderheit von hPrp28.

Die Strukturen der NTD und CTD von DEAD2 sind sehr ähnlich zu denen anderer DExD/HBox Proteine wie beispielsweise Vasa. Sie unterscheiden sich aber in ihrer relativen Lage zueinander. Verglichen mit der kompakten Struktur von Vasa (Abb. 1.1, Sengoku et al. 2006) hat DEAD2 eine sehr offene Konformation. Dabei sind die konservierten Sequenzmotive (Tab. 1.1) auf der NTD und der CTD weit voneinander entfernt und bilden folglich in der Kristallform kein funktionelles aktives Zentrum (Abb. 3.30). Diese offene Orientierung der Subdomänen könnte erklären, warum hPrp28 in vitro keine ATPase-Aktivität zeigt. 

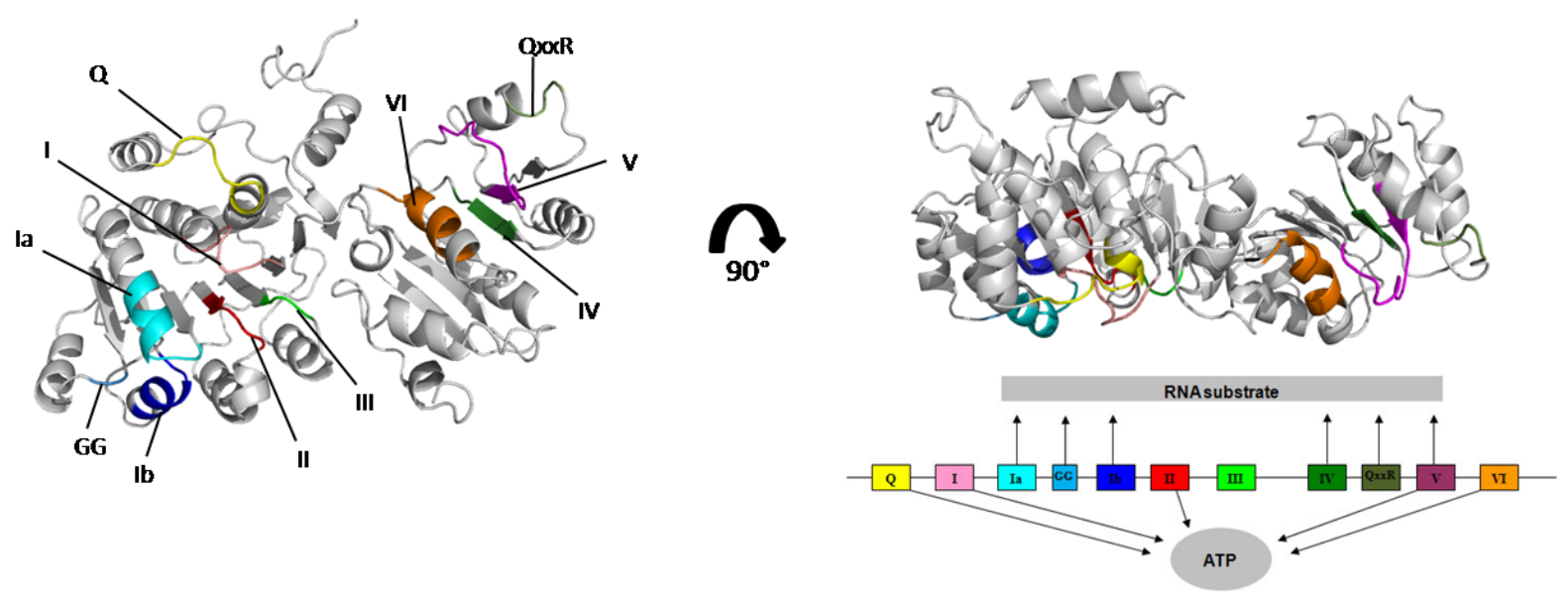

Abb. 3.30: Struktur des DEAD2-Fragments von hPrp28 in jeweils zwei verschiedenen Orientierungen. Farblich hervorgehoben ist die Lage der konservierten Sequenzmotive der DExD/H-Box Proteine. Die Farbkodierung ist schematisch dargestellt und entspricht derjenigen in Abb. 1.1.

Einen weiteren Hinweis auf die Ursache der fehlenden ATPase-Aktivität liefert die Konformation der ATP-Bindestelle, die von den Motiven Q, I und II der NTD sowie V und VI der CTD gebildet wird (1.1.2). Die Hauptaffinität liegt dabei auf der NTD. Um zu überprüfen, ob eine ATP-Bindung möglich ist, wurde die Struktur von DEAD2 mit der von Vasa verglichen. Das DEAD-Box Protein Vasa wurde zusammen mit einem ATP-Analogon $\left(\mathrm{Mg}^{2+}\right.$-ADPNP) kristallisiert und weist darum eine funktionelle ATP-Bindestelle auf (1.1.2, Sengoku et al. 2006). Durch Überlagerung beider Strukturen wurde das ATP-Analogon in die potentielle Bindetasche von DEAD2 moduliert (Abb. 3.31). Dabei ergibt sich, dass das $\mathrm{Mg}^{2+}-$ Ion, das Adenin, die Ribose und die erste Phosphatgruppe gut in das Modell eingepasst werden können. Die zweite und insbesondere die dritte Phosphatgruppe kollidieren dagegen mit Aminosäurereste, die zu dem konservierten Motiv I gehören. Die Ursache dafür ist die Konformation der sogenannten P-Schleife, die von diesen Aminosäuren gebildet wird. Dieser Sequenzabschnitt unterscheidet sich am stärksten zwischen den Strukturen von DEAD2 und Vasa. In Vasa ist die Lage der P-Schleife seitlich verlagert, so dass ein ATP ohne Kollision binden kann. Aus dem Vergleich lässt sich ableiten, dass das DEAD2-Fragment in der Lage sein sollte, ADP zu binden, nicht aber ATP. Dies stimmt mit den Ergebnissen aus den Interaktionsstudien überein (3.3.3). 
A
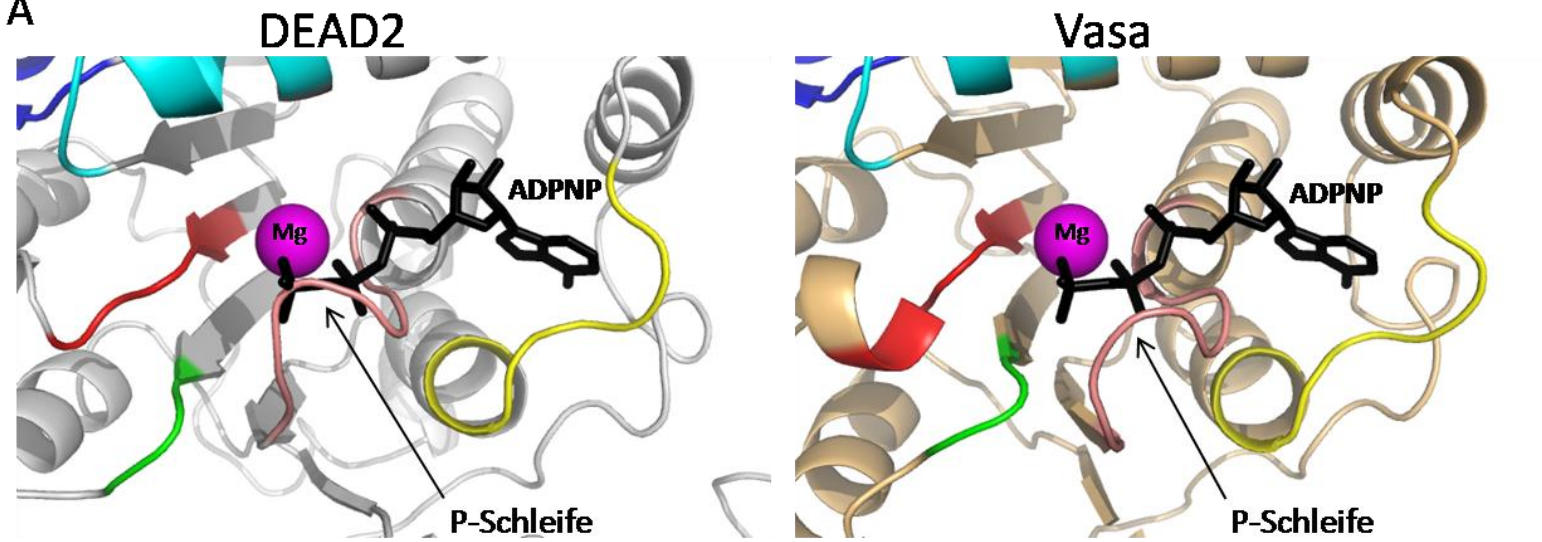

B

DEAD2

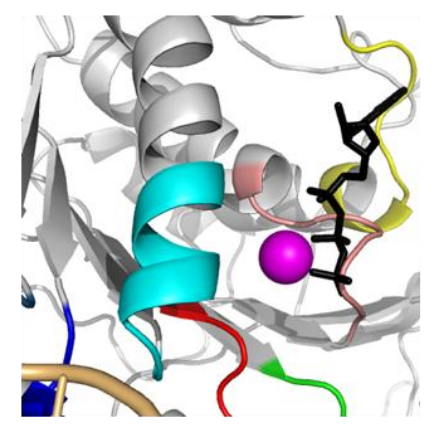

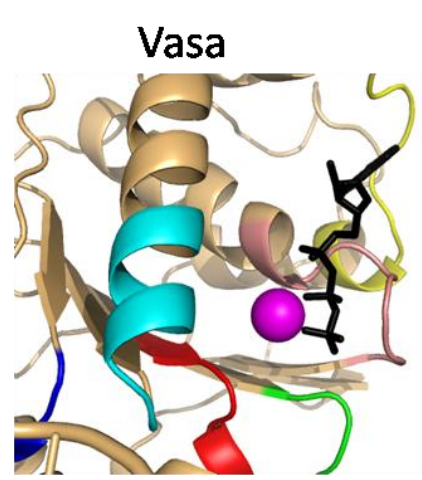

C

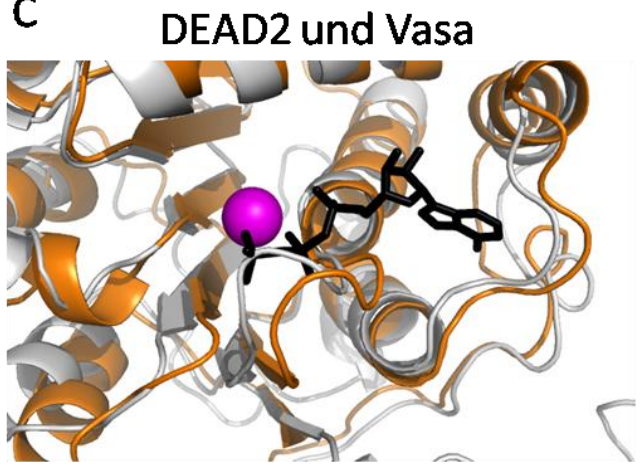

Abb. 3.31: Vergleich der ATP-Bindestelle auf den N-terminalen Helikasesubdomänen von DEAD2 und Vasa. Die Position des $\mathrm{Mg}^{2+}$-Ions (violett) und des ATP-Analogons (schwarz) basiert auf der Kristallstruktur von Vasa (Sengoku et al. 2006). Die konservierten Sequenzmotive der DEAD-Box Proteinfamilie sind analog zu Abb. 3.30 farblich hervorgehoben. Die ATP-Bindestelle wird von den Motiven Q (gelb), I (rosa) und II (rot) gebildet. (A) Die ATP-Bindestelle von DEAD2 (links, grau) und Vasa (rechts, orange) in derselben Orientierung. Der größte Unterschied liegt in der Konformation der P-Schleife, die von Resten des Motivs I gebildet wird. Bei DEAD2 kollidiert die P-Schleife mit der dritten Phosphatgruppe des modulierten ATP-Analogons. (B) wie (A) aber in anderer Orientierung. (C) Überlagerung der Struktur von DEAD2 (grau) und Vasa (orange). Die Orientierung entspricht derjenigen in $(\mathrm{A})$. 


\subsection{Eigenschaften der RS-Domäne von hPrp28}

DEAD-Box Proteine besitzen neben der Helikasedomäne oft noch weitere Domänen. Diese Domänen vermitteln häufig die Substratspezifität des Proteins, indem sie zum Beispiel Interaktionen mit bestimmten Komplexen eingehen. Andererseits können zusätzliche Domänen auch direkt als Regulator der Helikaseaktivität wirken.

Die Helikasedomäne von hPrp28 wird N-terminal von einem Sequenzabschnitt aus etwa 350 Aminosäuren flankiert. Die genaue Domänenzusammensetzung und Funktion dieses Bereichs sind unklar. Die ersten 220 Aminosäuren werden als RS-Domäne bezeichnet. Über RSDomänen fehlen bisher strukturelle Informationen. Darum war dieser Bereich für eine Strukturanalyse besonders interessant.

\subsubsection{Reinigung und Kristallisationsversuche mit dem RS3-Fragment von hPrp28}

Das RS3-Fragment umfasst die Aminosäuren 1-257 von hPrp28 und enthält damit die vollständige postulierte RS-Domäne (Abb. 3.32). Dieses Fragment ließ sich sehr gut reinigen und hatte verglichen zu den größeren RS4- und RS5-Fragmenten eine deutlich höhere Expressionsrate in Bakterien. Darum lag der Schwerpunkt der Experimente mit den Nterminalen Fragmenten von hPrp28 auf RS3.

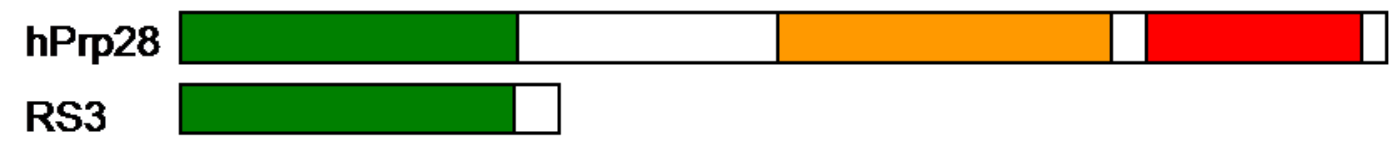

Abb 3.32: Schematische Übersicht über das RS3-Fragment von hPrp28. Grün: RS-Domäne, orange bzw. rot: Nterminale bzw. C-terminale Domäne des DEAD-Box Proteins.

\subsubsection{Expression und Reinigung von RS3}

Für die Expression des RS3-Fragments von hPrp28 wurde der Vektor hPrp28-RS3-pET-21a in E. coli Zellen des Stammes Rosetta 2 (DE3) eingebracht (2.2.1.7). Die Zellen wurden kultiviert und die Expression über Autoinduktion angeregt (2.2.2.1.2). Die Expression des GST-DEAD2-Fusionsproteins wurde über Autoinduktion mit zusätzlicher Zugabe von 0,1 mM IPTG durchgeführt. Aus einem Liter Autoinduktionskultur wurden 20-30 mg RS3Protein erhalten. Als erster Reinigungsschritt wurde nach dem Aufschluss (2.2.2.2) eine Hexahistidin-Affinitätschromatographie (Ni-NTA-Sepharose) durchgeführt (2.2.2.3.1). Dabei wurde RS3 erst bei relativ hohen Imidazol-Konzentrationen eluiert. Wie die Analyse fraktionierter Proben über SDS-Gelelektrophorese zeigte (2.2.2.7.1), ermöglichte dies eine sehr effektive Abtrennung anderer Proteine (Abb. 3.33). 
A

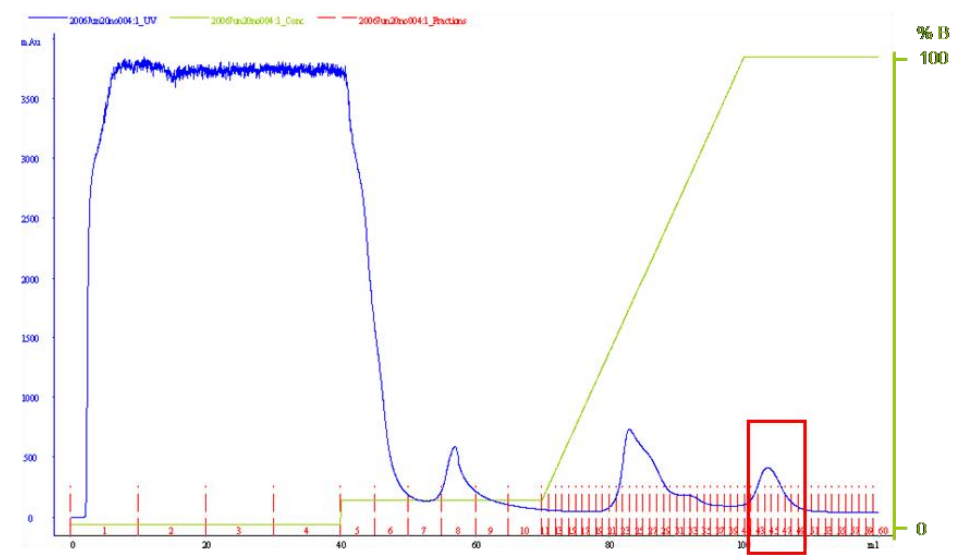

B

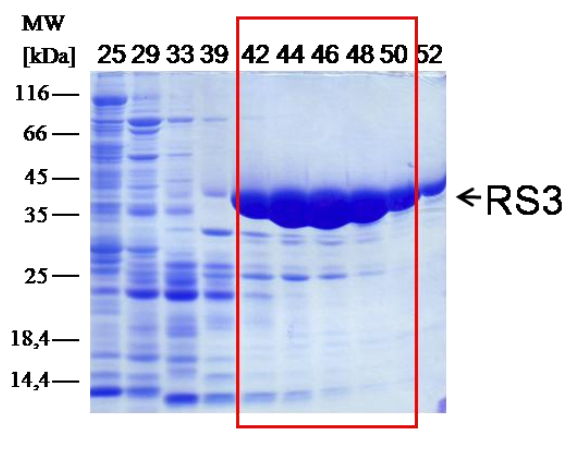

Abb. 3.33: Erster Reinigungsschritt: Hexahistidin-Affinitätschromatographie. (A) Elutionsprofil der Ni-NTASepharose-Säule. Auf der X-Achse ist das Volumen in [ml], auf der Y-Achse links die UV-Absorption bei $280 \mathrm{~nm}$ in [mAU] (blauer Graph) aufgetragen. Die Y-Achse rechts zeigt den Anteil an Puffer B in \% (grüner Graph). Gesammelte Fraktionen sind angegeben. (B) Analyse einzelner Fraktionen über SDS-PAGE. Die Fraktionsnummern sind oberhalb des Gels angegeben. RS3 eluiert erst bei hohen Imidazol-Konzentrationen, es befindet sich in den Fraktionen unterhalb des letzten UV-Absorptionsmaximums (rot gekennzeichnet).

Fraktionen, die RS3 enthielten, wurden vereinigt und auf etwa $10 \mathrm{mg} / \mathrm{ml}$ konzentriert (2.2.2.4). Es folgte ein weiterer Reinigungsschritt über Gelfiltration (2.2.2.3.3, Superdex 200). Dafür war ein Puffer mit hohem Salzgehalt notwendig (500mM NaCl, $10 \mathrm{mM}$ Tris-HCl, pH 7,5, 5\% Glyzerin), da das RS3-Protein sonst auf der Säule aggregierte.

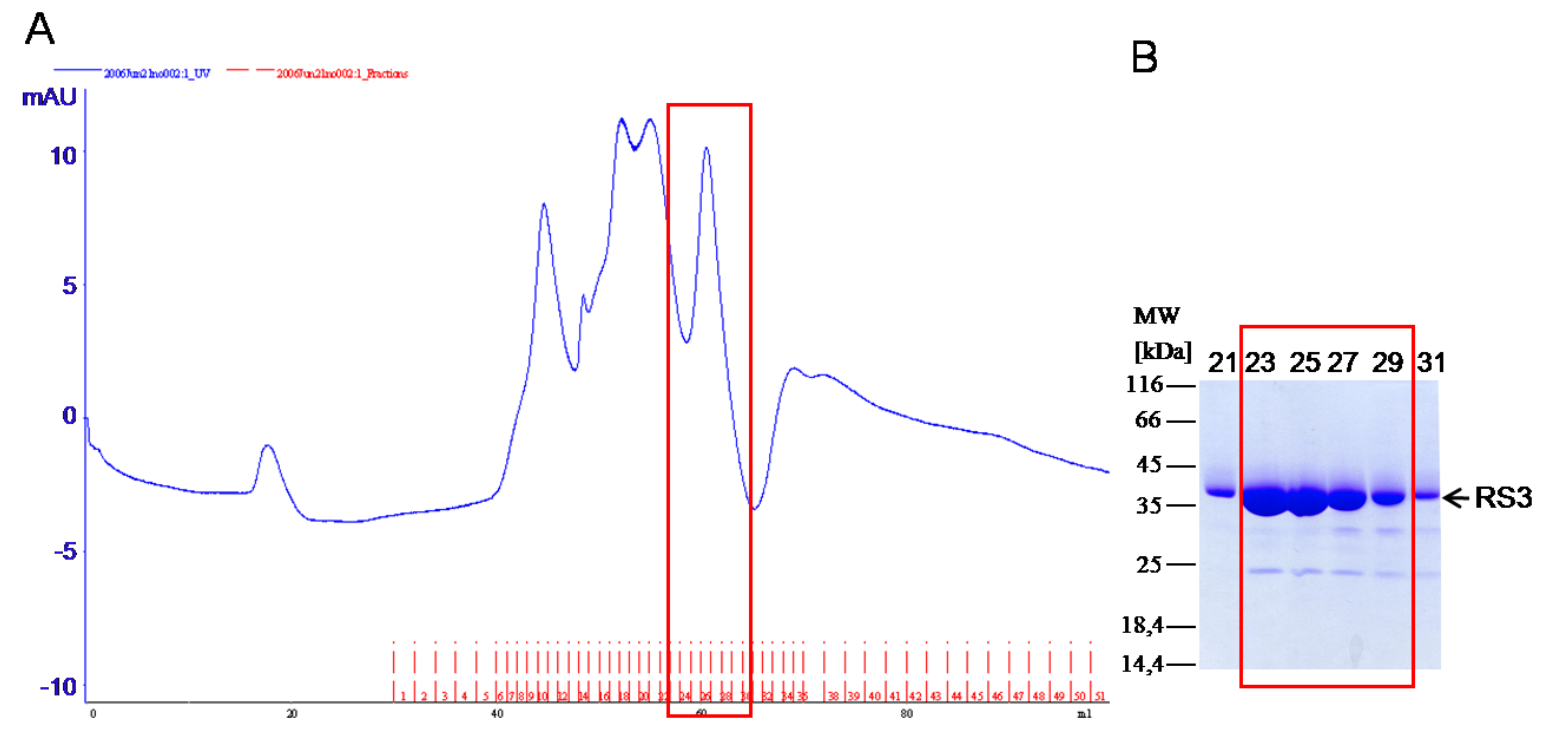

Abb. 3.34: Zweiter Reinigungsschritt: Gelfiltration. (A) Elutionsprofil der Superdex 200 Säule (16/60). Auf der $\mathrm{X}$-Achse ist das Volumen in [ml], auf der Y-Achse die UV-Absorption bei $280 \mathrm{~nm}$ in [mAU] (blauer Graph) aufgetragen. Gesammelte Fraktionen sind angegeben. Die detektierte UV-Absorption ist sehr gering. RS3 (rot gekennzeichnet) ließ sich anhand der Absorption bei $280 \mathrm{~nm}$ nicht lokalisieren. Dies ermöglichte erst die (B) Analyse einzelner Fraktionen über SDS-PAGE. Die Fraktionsnummern sind oberhalb des Gels angegeben. RS3 hat ein scheinbares Molekulargewicht von $40 \mathrm{kDa}$.

Das RS3-Fragment zeigt mehrere Besonderheiten (Abb. 3.34). Zunächst enthält dieses Protein kein Typtophan, nur ein Tyrosin sowie drei Phenylalanine. Dadurch ist seine UV-Absorption bei $280 \mathrm{~nm}$ sehr gering und entsprechend wird seine Lage auf einem bei dieser Wellenlänge 
aufgenommenem Elutionsprofil häufig von geringen Verunreinigungen, die stärker absorbieren, überdeckt. Erst die Detektion bei $220 \mathrm{~nm}$ während einer analytischen Gelfiltration (Superdex 200 (10/30)) machte das Laufverhalten von RS3 deutlich. Das Elutionsvolumen von $13 \mathrm{ml}$ entspricht dem eines Proteins mit einem Molekulargewicht von $80 \mathrm{kDa}$. Da das theoretische Molekulargewicht von RS3 nur $31 \mathrm{kDa}$ beträgt, könnte dies auf eine Dimer- oder Trimerbildung hinweisen. Jedoch zeigte das RS3-Protein auch bei der SDSGelelektrophorese (2.2.2.7.1) ein abweichendes Molekulargewicht von etwa $40 \mathrm{kDa}$. Es muss davon ausgegangen werden, dass das RS3-Fragment aufgrund seines hohen Arginingehalts auch bei der Gelfiltration kein Standardverhalten zeigt (Abb. 3.35).

A

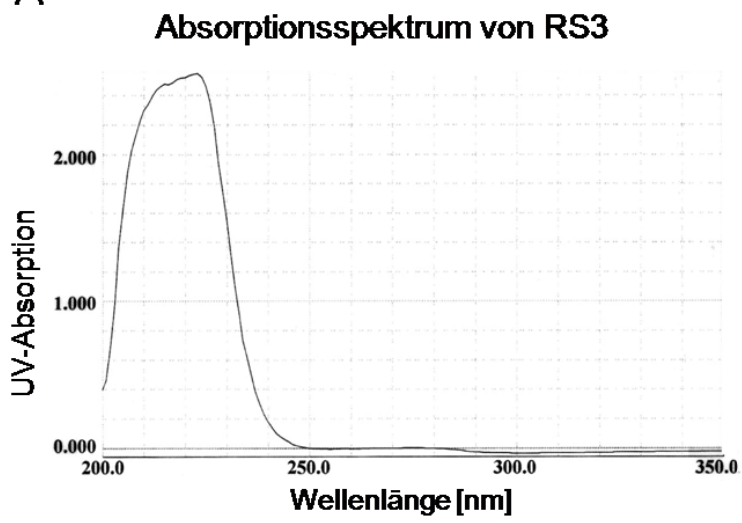

$\mathrm{B}$

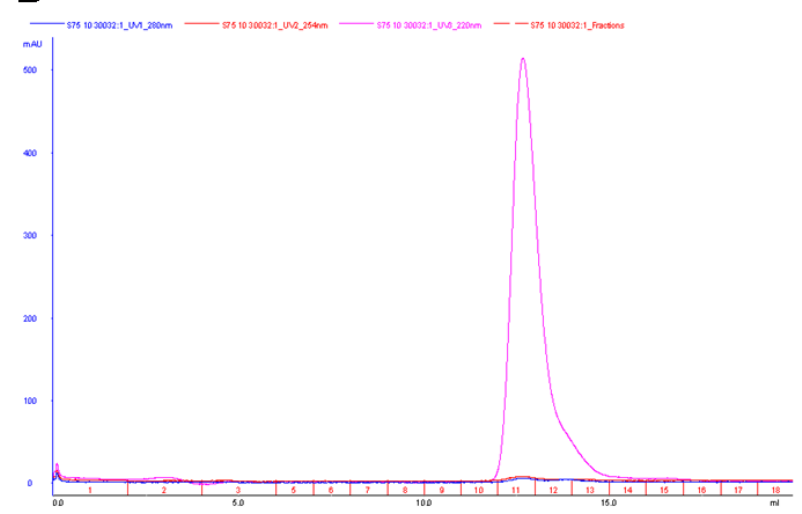

Abb. 3.35: Besonderheiten in der UV-Absorption von RS3. (A) UV-Absorptionsspektrum einer Lösung mit 2 $\mathrm{mg} / \mathrm{ml}$ RS3-Protein. Das Fehlen von Tryptophan führt zu der sehr schwachen Absorption bei $280 \mathrm{~nm}$. Die Absorption bei $220 \mathrm{~nm}$ durch die Peptidbindungen ist dagegen deutlich ausgeprägt. (B) Analytische Gelfiltration mit RS3 (Superdex 200 (10/30)). Auf der X-Achse ist das Volumen in [ml], auf der Y-Achse die UVAbsorption in [mAU] aufgetragen. Blau: $280 \mathrm{~nm}$. Rot: $260 \mathrm{~nm}$. Violett: $220 \mathrm{~nm}$. Nur die UV-Absorption bei $220 \mathrm{~nm}$ macht die Position von RS3 sichtbar. Das Laufverhalten entsprach einem Molekulargewicht von $80 \mathrm{kDa}$.

Nach der Reinigung über Gelfiltration wurde das RS3-Fragment auf 15-30 mg/ml konzentriert (2.2.2.4) und für Kristallisationsversuche verwendet (2.2.3.2).

\subsubsection{Kristallisationsversuche}

Für Kristallisationsansätze wurde das gereinigte RS3-Fragment in einer Konzentration von $15 \mathrm{mg} / \mathrm{ml}$ oder $30 \mathrm{mg} / \mathrm{ml}$ eingesetzt. Es wurden alle verfügbaren Kristallisationsscreens verwendet und die Ansätze bei $20^{\circ} \mathrm{C}$ oder $4^{\circ} \mathrm{C}$ inkubiert. Bis heute wurden keine Kristalle erhalten.

\subsubsection{Phosphorylierung der RS-Domäne von hPrp28}

Die RS-Domäne von hPrp28 liegt in humanen Zellen stark phosphoryliert vor (1.3). Da die Phosphorylierung einen Teil der positiven Ladung der RS-Domäne neutralisiert, könnte sie die Kristallisation des RS3-Fragments begünstigen. Das bakterielle Expressionssystem enthält jedoch keine entsprechenden Kinasen. Darum wurden zunächst zwei RS-Domänenspezifische Kinasen in Expressionsvektoren kloniert. 


\subsubsection{Klonierung RS-Domänen spezifischer Kinasen}

Es wurden mehrere Klassen von humanen Kinasen identifiziert, die RS-Domänen phosphorylieren können (1.2.3). Am besten charakterisiert sind SRPK1 und Clk1 (alternativer Name: Clk/Sty). Die Abb. 3.36 gibt einen Überblick über ihre Domänenstruktur.

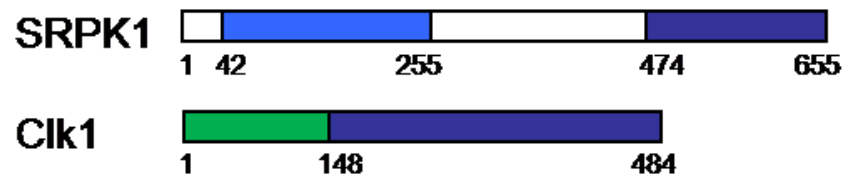

Abb. 3.36: Übersicht über die Domänenstruktur von SRPK1 und Clk1. Grün: RS-Domäne. Blau: Kinasedomäne. Die Kinasedomäne von SRPK1 wird aus zwei getrennten Sequenzabschnitten gebildet. Die Zahlen geben die Position in der Aminosäuresequenz an.

Diese beiden Proteine wurden einerseits in Volllänge und andererseits reduziert auf ihre Kinasedomäne (SRPK1-Mini und Clk1-Mini) in die Expressionsvektoren pGEX-TT oder pGEX-6P kloniert (2.2.1.8). Beide Vektoren führten $\mathrm{zu}$ einer Expression mit einer $\mathrm{N}$ terminalen GST-Markierung. Die Tabelle 3.2 zeigt die Klonierungen im Überblick.

Tabelle 3.2: Übersicht über die Klonierung RS-Domänen spezfischer Kinasen in Expressionsvektoren. Verwendete Oligonukleotide und Restriktionsschnittstellen des Vektors sind angegeben. SRPK1-Mini und Clk1Mini sind auf die Kinasedomänen der jeweiligen Proteine reduziert.

\begin{tabular}{|l|l|l|l|l|}
\hline Bezeichnung & Aminosäuren & Vektor & Oligonukleotide & Restriktionsschnittstellen \\
\hline SRPK1 & $1-655$ & pGEX-TT & [Jana Schmitzova] & Bam HI, Eco RI \\
\hline SRPK1-Mini & $\begin{array}{l}42-255 \text { und } \\
474-655\end{array}$ & pGEX-6P & $\begin{array}{l}\text { SRPK1Mini-pGEX-Bam-f } \\
\text { SRPK1Mini-pGEX-Eco-r }\end{array}$ & Bam HI, Eco RI \\
\hline Clk1 & $1-484$ & pGEX-6P & $\begin{array}{l}\text { Clk1-pGEX-Bam-f } \\
\text { Clk1-pGEX-Xho-r }\end{array}$ & Bam HI, SalI \\
\hline Clk1-Mini & $148-484$ & pGEX-6P & $\begin{array}{l}\text { Clk1Mini-pGEX-Bam-f } \\
\text { Clk1-pGEX-Xho-r }\end{array}$ & Bam HI, XhoI \\
\hline
\end{tabular}

Für die PCR wurde Phusion-DNA-Polymerase verwendet (2.2.1.1). Die Klonierung von SRPK1 in den pGEX-TT Vektor wurde von Eike Schulz und Jana Schmitzova (Universität Göttingen, Abteilung Prof. Ralf Ficner) durchgeführt. Als Matrize für SRPK1 diente der Vektor SRPK1-pET-24a (von Dr. Goran Akusjarvi (Yue et al. 2000)), für SRPK1-Mini dagegen der Vektor SRPK1 $\mathrm{NS1-pET-15b}$ (von Dr. Gourisankar Ghosh (Ngo et al. 2005)). Zur Amplifikation von Clk1 wurde eine humane cDNA-Bank (MEGAMAN) als Matrize verwendet (2.1.7).

\subsubsection{Koexpression von RS3 mit RS-Domänen spezifischen Kinasen in E. coli}

Der einfachste Weg, um phosphoryliertes Protein herzustellen, besteht darin, es zusammen mit der entsprechenden Kinase in Bakterienzellen zu exprimieren. Da die Bakterien hierzu 
zwei unterschiedliche Expressionsvektoren gleichzeitig enthalten, müssen sich die Vektoren in der vermittelten Antibiotika-Resistenz unterscheiden. Da sowohl die pGEX-Vektoren als auch das pET-21-Plasmid eine Ampicillin-Resistenz vermitteln, wurde zunächst das RS3Fragment in den Expressionsvektor pET-30a transferiert, der über eine Kanamycin-Resistenz selektiert wird (2.2.1.8). Diese Klonierung wurde von Eike Schulz und Jana Schmitzova (Universität Göttingen, Abteilung Prof. Ralf Ficner) durchgeführt. Es wurden die Restiktionsschnittstellen BamHI und XhoI verwendet. Der resultierende hPrp28-RS3-pET30a-Vektor bewirkte die Expression von RS3 mit einer N- und C-terminalen HexahistidinMarkierung sowie einer N-terminalen S-Tag-Markierung.

E. coli Zellen des Stammes Rosetta 2 (DE3) wurden mit hPrp28-RS3-pET-30a und einem der vier Kinase-Expressionsvektoren transformiert (2.2.1.7). Die Induktion erfolgte mit $0,3 \mathrm{mM}$ IPTG bei $37^{\circ} \mathrm{C}$ für $4-8 \mathrm{~h}$ (2.2.2.1.1). Anschließend wurden die Zellen aufgeschlossen (2.2.2.2) und eine Hexahistidin-Affinitätschromatographie durchgeführt, um RS3 zu reinigen (2.2.2.3.1, Abb. 3.37A).
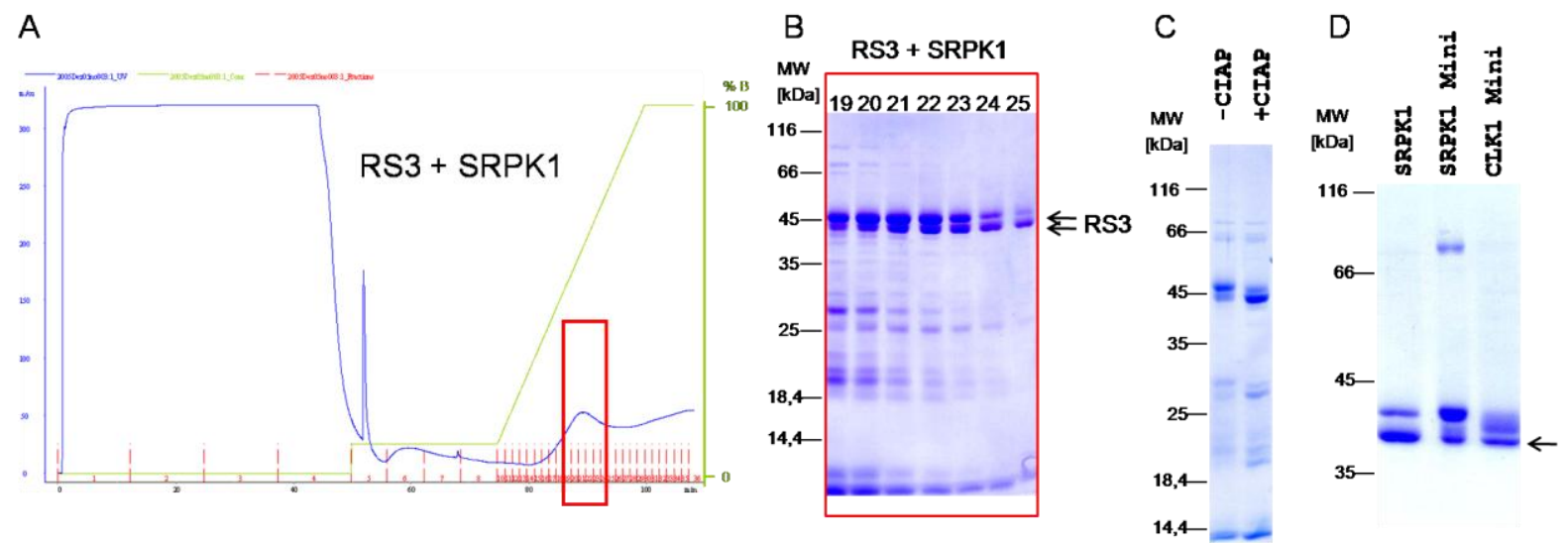

Abb. 3.37: Koexpression von RS3 mit RS-Domänen spezifischen Kinasen. (A) Elutionsprofil der HexahistidinAffinitätschromatographie nach Koexpression von RS3 mit SRPK1. Auf der X-Achse ist das Volumen [ml], auf der Y-Achse links die UV-Absorption bei $280 \mathrm{~nm}$ [mAU] (blauer Graph) aufgetragen. Die Y-Achse rechts zeigt den Anteil an Puffer B in [\%] (grüner Graph). Gesammelte Fraktionen sind angegeben. (B) - (D) SDS-PAGE. (B) Analyse fraktionierter Proben aus (A) über SDS-PAGE (rot gekennzeichnet). Fraktionsnummern sind über dem Gel angegeben. In den Elutionsfraktionen wurden zwei verschiedene RS3-Spezien beobachtet. (C) Die Inkubation mit CIAP zeigt, dass es sich bei der langsamer wandernden Spezies um ein phosphoryliertes Protein handelt. (D) Koexpression von RS3 mit SRPK1-Mini führt wie bei SRPK1 zu einer definierten phosphorylierten Spezies. Koexpression mit Clk1-Mini erzeugt ein Spektrum unterschiedlich stark phosphorylierter RS3-Proteine. Der Pfeil gibt die Lage des unphosphorylierten RS3 an. Diese Koexpression wurde mit einem hPrp28-RS3-pET30a-Vektor durchgeführt, bei dem die für den S-Tag kodierende Sequenz enzymatisch entfernt worden war. Deshalb ist das Molekulargewicht geringer.

Die gemeinsame Expression von RS3 mit SRPK1 oder SRPK1-Mini führte zu zwei verschiedenen RS3-Spezies, die sich in ihrem Laufverhalten bei der SDS-Gelelektrophorese unterschieden (Abb. 3.37B). Die Inkubation mit einer Phosphatase (CIAP) führte zur Abnahme der langsamer wandernden RS3-Spezies (Abb. 3.37C). Bei dieser handelte es sich folglich um phosphoryliertes Protein. Damit war gezeigt, dass sowohl SRPK1 in Volllänge als auch SRPK1-Mini in der Lage sind, die RS-Domäne von hPrp28 zu phosphorylieren. Die beiden RS3-Spezies waren durch weitere Reinigungsschritte jedoch nicht voneinander zu trennen.

Die Koexpression von RS3 mit der Kinase Clk1 führte zu keiner erkennbaren Phosphorylierung (ohne Abbildung). Die Ursache dafür ist vermutlich die sehr geringe 
Expressionsrate von Clk1 in E. coli (ohne Abbildung). Zusammen mit Clk1-Mini wurde dagegen zwar phosphoryliertes RS3-Protein beobachtet, es handelte sich dabei aber im Gegensatz zur Koexpression mit SRPK1 nicht um eine definierte Spezies, sondern um ein Spektrum unterschiedlich stark phosphorylierter Proteine (Abb. 3.37D). Dennoch folgt, dass auch Clk1 die RS-Domäne von hPrp28 phosphorylieren kann.

\subsubsection{In vitro Phosphorylierung der RS-Domäne von hPrp28}

Bei Kristallisationsversuchen ist es vorteilhaft, wenn eine homogene Proteinlösung verwendet wird. Darum sollte das RS3-Fragment in nur einem einzigen Phosphorylierungszustand vorliegen. Die Koexpressionsversuche hatten aber nur zu Gemischen mit unterschiedlichem Phosphorylierungsgrad geführt. Deshalb wurde eine Strategie zur in vitro Phosphorylierung entwickelt. Dazu mussten zunächst RS-Domänen-spezifische Kinasen gereinigt werden.

\subsection{Expression und Reinigung der Kinasedomäne von SRPK1 und Clk1}

Die pGEX-Expressionsvektoren für die verschiedenen Kinasen wurden in E. coli Zellen des Stammes Rosetta 2 (DE3) eingebracht (2.2.1.7). Die Zellen wurden kultiviert und mit 0,3 mM IPTG induziert (2.2.2.1.1).

Die Expressionsrate für SRPK1 und Clk1 als Volllängenprotein war nur sehr gering (ohne Abbildung), während SRPK1-Mini und Clk1-Mini, die nur die Kinasedomäne des jeweiligen Proteins enthalten, gute Ausbeuten ergaben. Darum wurden für in vitro Phosphorylierungen nur diese beiden Kinasefragmente gereinigt. Die Koexpressions-Versuche hatten gezeigt, dass sowohl SRPK1-Mini als auch Clk1-Mini katalytisch aktiv sind und die RS-Domäne von hPrp28 phosphorylieren können (3.4.2.2).

Clk1-Mini und SRPK1-Mini wurden mit einer N-terminalen GST-Markierung exprimiert. Entsprechend erfolgte ihre Reinigung anhand von GST-Affinitätschromatographie (2.2.2.3.2, Abb. 3.38). Fraktionen, die das GST-SRPK1-Mini bzw. das GST-Clk1-Mini Protein enthielten, wurden vereinigt, auf eine Konzentration von etwa $15 \mathrm{mg} / \mathrm{ml}$ gebracht (2.2.2.4) und für in vitro Phosphorylierungen eingesetzt.

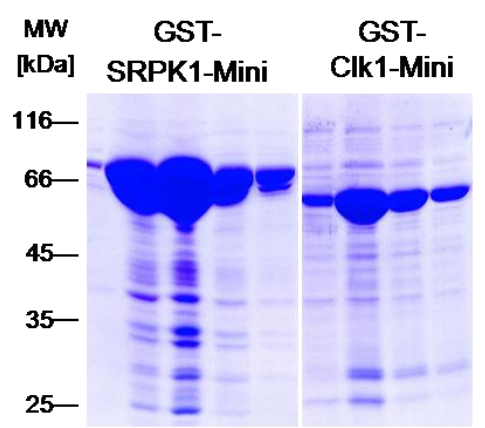

Abb. 3.38: Reinigung des GST-SRPK1-Mini und des GST-Clk1-Mini Fusionsproteins über GSTAffinitätschromatographie. Dargestellt ist die Analyse von Proben der Elutionsfraktionen durch SDS-PAGE. GST-SRPK1-Mini hat ein Molekulargewicht von etwa 75 kDa, GST-Clk1-Mini von etwa 65 kDa. Diese Proteine wurden als Enzyme für in vitro Phosphorylierungen eingesetzt. 


\subsection{In vitro Phosphorylierung des RS3-Fragments von hPrp28}

Um die in vitro Phosphorylierung zu untersuchen, wurde das gereinigte RS3-Protein im molaren Verhältnis 10:1 mit GST-SRPK1-Mini oder GST-Clk1-Mini vermischt und bei $37^{\circ} \mathrm{C}$ inkubiert. Für diese Experimente wurden zwei Puffer mit unterschiedlichen Salzkonzentrationen verwendet (Puffer A: $50 \mathrm{mM}$ Tris HCl, pH 7,5, $10 \mathrm{mM} \mathrm{MgCl}$, Puffer B: Puffer A mit $500 \mathrm{mM} \mathrm{NaCl}$ ). Die Phosphorylierung wurde durch Zugabe von $1 \mathrm{mM}$ ATP gestartet. Nach verschiedenen Zeitpunkten wurde eine Probe entnommen und über SDSPAGE analysiert (2.2.2.7.1). Phosphorylierung bewirkte eine verlangsamte Wanderung und damit eine Verschiebung der Proteinbande zu höherem scheinbarem Molekulargewicht. Es wurde bei allen Proben zu jedem Zeitpunkt eine einzelne definierte Proteinbande beobachtet (Abb. 3.39A). Die in vitro Phosphorylierung führte damit im Gegensatz zur Koexpression in Bakterien nicht zu einem Gemisch aus unterschiedlichen Phosphorylierungszuständen.

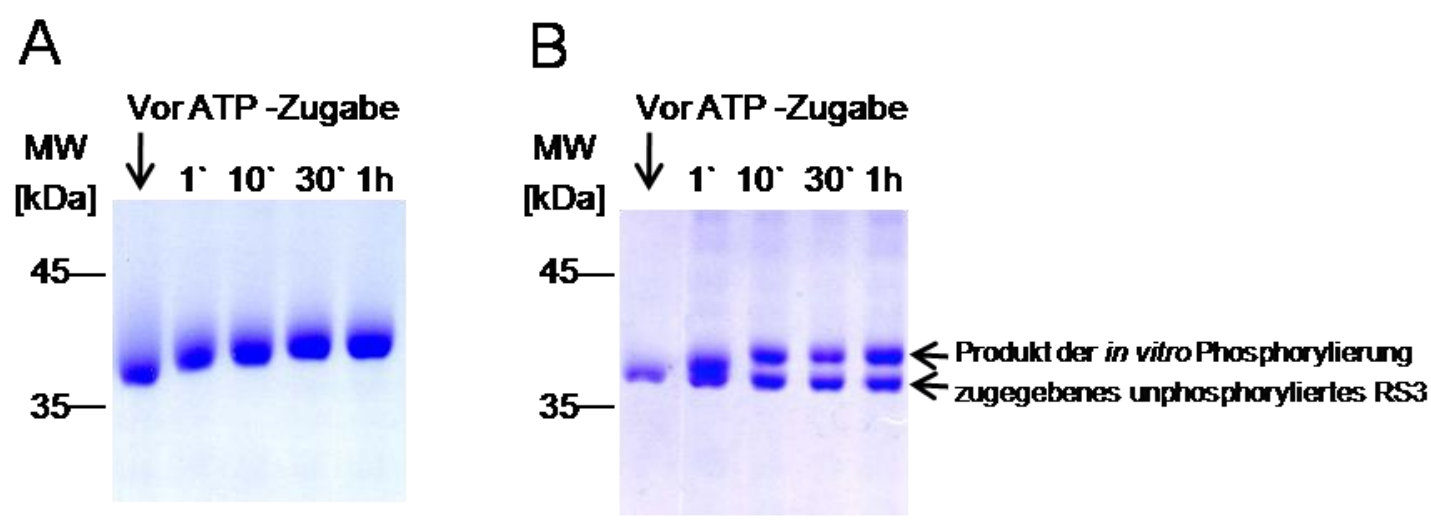

Abb. 3.39: In vitro Phosphorylierung von RS3 mit SRPK1-Mini. Proben wurden nach unterschiedlich langen Inkubationszeiten genommen und über SDS-PAGE analysiert. (A) Die Proteinbande verschob sich nach oben.

(B) Zugabe von unphosphoryliertem RS3 vor Beladen des Gels verdeutlichte die Größe der Verschiebung.

Um die Stärke der Phosphorylierung besser sichtbar zu machen, wurden die Proben vor dem Auftrag auf das SDS-Gel mit unphosphoryliertem RS3 vermischt (Abb. 3.39B).

\subsection{In vitro Phosphorylierung mit SRPK1-Mini}

SRPK1-Mini phosphorylierte das RS3-Protein in beiden verwendeten Puffern. Allerdings wurde im Niedrigsalzpuffer ein höherer Phosphorylierungsgrad erreicht als im Hochsalzpuffer (Abb. 3.40A). Möglicherweise schwächte der Salzgehalt die Interaktion zwischen SRPK1und RS3, so dass nur hochaffine Erkennungssequenzen phosphoryliert wurden.

Ein Vergleich mit der Verschiebung der Proteinbande bei der Koexpression mit SRPK1 oder SRPK1-Mini zeigte, dass der erreichte Phosphorylierungsgrad demjenigen in Niedrigsalzpuffer ähnelte (Abb 3.40B). 

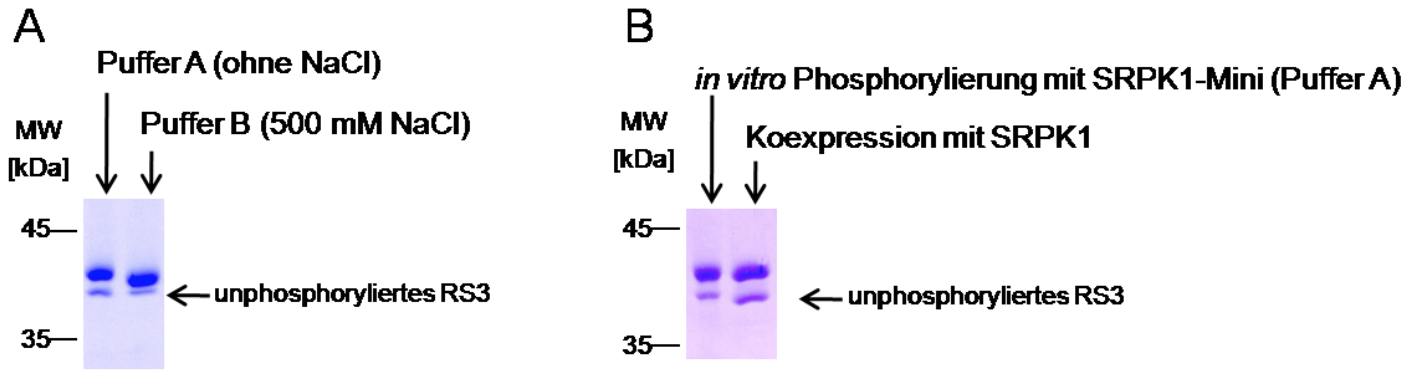

Abb. 3.40: In vitro Phosphorylierung von RS3 mit SRPK1-Mini. Die Proben wurden mindestens $1 \mathrm{~h}$ bei $37^{\circ} \mathrm{C}$ inkubiert. Direkt vor der Analyse über SDS-PAGE wurde unphosphoryliertes RS3 zugegeben. (A) In Niedrigsalzpuffer (Puffer A) ist die Verschiebung der Proteinbande aufgrund der Phosphorylierung stärker als in Hochsalzpuffer (Puffer B). (B) Der Phosphorylierungsgrad bei Inkubation in Niedrigsalzpuffer ist vergleichbar mit demjenigen, der bei der Koexpression erreicht wurde. Die Koexpression wurde mit einem hPrp28-RS3pET30a-Vektor durchgeführt, bei dem die für den S-Tag kodierende Sequenz enzymatisch entfernt worden war. Dadurch sind die Molekulargewichte der unphosphorylierten RS3-Proteine vergleichbar.

Um die Anzahl der Phosphorylierungsstellen abzuschätzen, wurden Proben mittels MALDITOF-MS analysiert. Diese Analyse wurde von Nicole Eiselt im Labor von Bernhard Schmidt durchgeführt (Max-Planck-Institut für experimentelle Medizin, Göttingen). Dabei sollte der genaue Massenunterschied zwischen phosphoryliertem und unphosphoryliertem RS3 bestimmt werden. Für RS3, das im Niedrigsalzpuffer phosphoryliert worden war, wurde kein Ergebnis erhalten. Die Massendifferenz zwischen unphosphoryliertem RS3 und RS3-Protein, das im Hochsalzpuffer phosphoryliert worden war, betrug etwa 865 g/mol (Abb. 3.41). Dies entspricht der Masse von 11 Phosphatgruppen (jeweils $79 \mathrm{~g} / \mathrm{mol}$ ). Das bedeutet, dass fast $50 \%$ der insgesamt 23 Serine des RS3-Proteins im Hochsalzpuffer phosphoryliert wurden. Da die Verschiebung der Proteinbande auf dem SDS-Gel nach Phosphorylierung in Niedrigsalzpuffer etwa doppelt so hoch war wie in Hochsalzpuffer, liegt RS3 darin möglicherweise zu $100 \%$ phosphoryliert vor.

MALDI-TOF

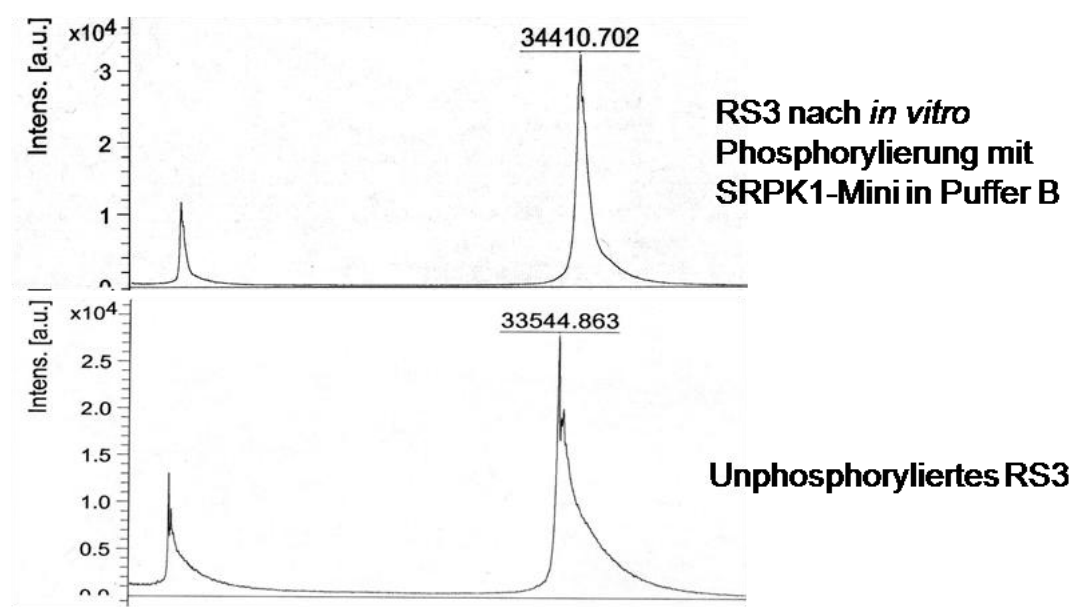

Abb. 3.41: Massenbestimmung durch MALDI-TOF. Aufgetragen ist die Signalintensität gegen die Flugzeit. Analyse von unphosphoryliertem RS3 sowie von RS3, das in Niedrigsalzpuffer bei $4^{\circ} \mathrm{C}$ über Nacht von SRPK1Mini in vitro phosphoryliert wurde. Die Massendifferenz beträgt etwa $865 \mathrm{Da}$. Die Analyse wurde von Nicole Eiselt und Bernhard Schmidt (MPI, Göttingen) durchgeführt.

Die Lokalisation der Phosphorylierungsstellen wurde durch Verdau mit GluC oder Trypsin und anschließender Massenspektrometrie eingeschränkt. Diese Analyse wurde von Henning 
Urlaub durchgeführt (Max-Planck-Institut für biophysikalische Chemie, Göttingen). Im RS3Fragment wurden 9 Phosphorylierungsstellen gefunden (Abb. 3.42). Davon befinden sich 8 innerhalb der ersten 120 Aminosäuren von hPrp28 und damit in einem Bereich, den bereits das RS1-Fragment von hPrp28 vollständig umfasst.

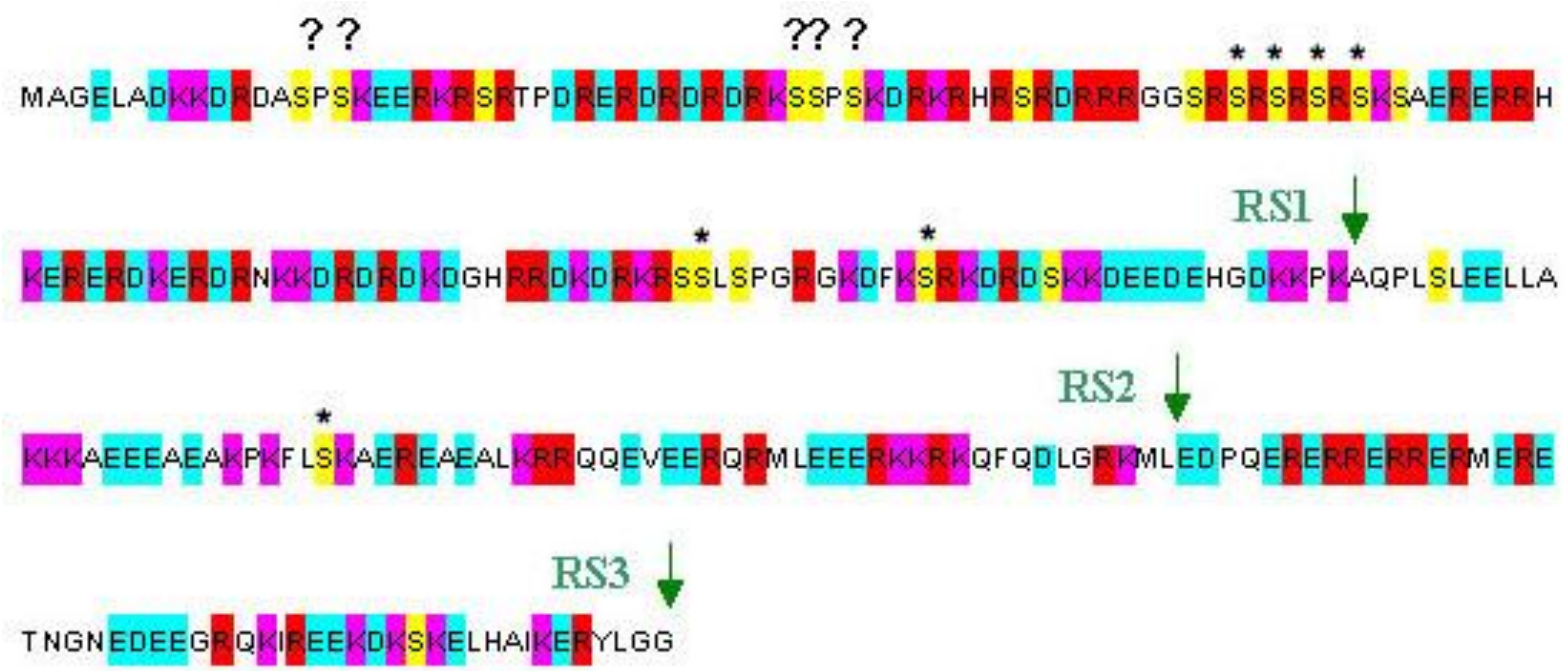

Abb. 3.42: Identifizierung von neun Phosphorylierungsstellen durch Massenspektrometrie. Die Phosphorylierung war in vitro durch SRPK1-Mini in Puffer B erfolgt. Dargestellt ist die Aminosäuresequenz des RS3-Fragments von hPrp28. Die C-Termini des RS1- und RS2-Fragments sind angegeben. Häufig auftretende Aminosäuren sind farblich hervorgehoben: Gelb: Serin. Rot: Arginin. Violett: Lysin. Blau: Aspartat oder Glutamat. * lokalisierte Phosphorylierungsstelle. ? Phosphorylierungsstelle vorhanden, aber genaue Lokalisation unklar. Die Analyse wurde von Henning Urlaub (MPI, Göttingen) durchgeführt.

\subsection{In vitro Phosphorylierung mit Clk1-Mini}

Clk1-Mini phosphorylierte das RS3-Protein nur im Niedrigsalzpuffer (Abb. 3.43A). Die Phosphorylierung war nicht so stark wie mit SRPK1-Mini in diesem Puffer (Abb. 3.43B). Die Verschiebung der Proteinbande auf dem SDS-Gel war ungefähr vergleichbar mit der Phosphorylierung durch GST-SRPK1-Mini im Hochsalzpuffer. Dies entsprach einem Phosphorylierungsgrad von etwa $50 \%$. Genauere Analysen wurden nicht durchgeführt.

A

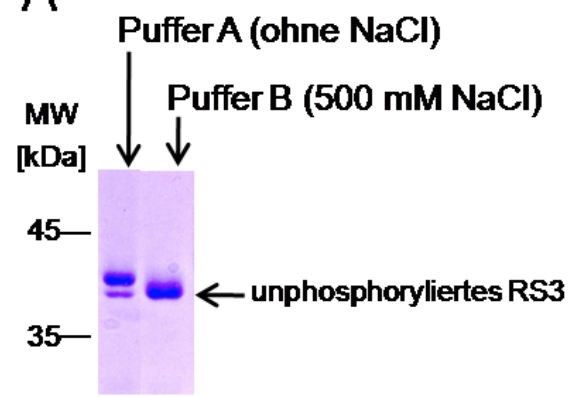

B

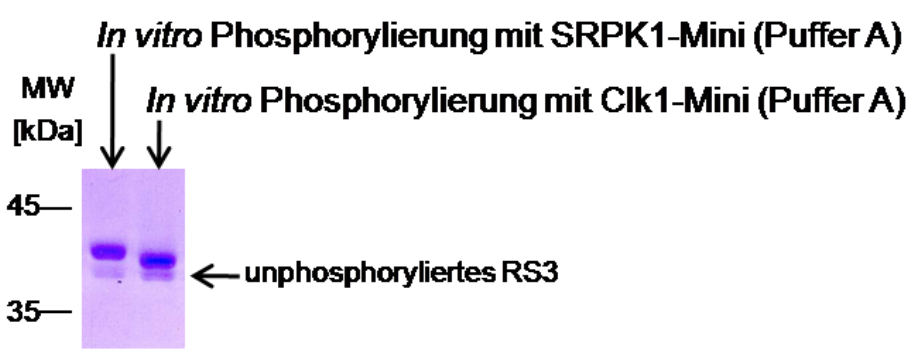

Abb. 3.43: In vitro Phosphorylierung von RS3 mit Clk1-Mini. Die Proben wurden mindestens $1 \mathrm{~h}$ bei $37^{\circ} \mathrm{C}$ inkubiert. Direkt vor der Analyse über SDS-PAGE wurde unphosphoryliertes RS3 zugegeben. (A) Eine Phosphorylierung durch Clk1 ist nur in Niedrigsalzpuffer (Puffer A) erkennbar. (B) Die Inkubation in Niedrigsalzpuffer führt mit SRPK1-Mini zu einem höheren Phosphorylierungsgrad als mit Clk1-Mini. 


\subsubsection{Reinigung und Kristallisationsversuche mit phosphoryliertem RS3-Fragment}

Die in vitro Phosphorylierung des RS3-Proteins mit SRPK1-Mini führt offensichtlich zu einem einheitlichen Phosphorylierungszustand. Dies wurde durch die MALDI-TOF-Analyse insbesondere für die Phosphorylierung im Hochsalzpuffer bestätigt, da nur eine einzelne Protein-Spezies detektiert wurde (Abb 3.41). Die Homogenität war eine gute Voraussetzung für Kristallisationsversuche. Darum wurde entsprechend phosphoryliertes RS3-Protein in großem Maßstab gereinigt.

Zunächst wurde RS3 wie beschrieben exprimiert und im ersten Schritt über HexahistidinAffintätschromatographie gereinigt (3.4.1.1). Anschließend wurde das Protein über Nacht mit GST-SRPK1-Mini bei $4^{\circ} \mathrm{C}$ inkubiert (2.2.2.6). Analyse auf dem SDS-Gel ergab dieselbe Verschiebung der Proteinbande wie im Kapitel (3.4.2.3.2.1) für den Hochsalzpuffer bei $37^{\circ} \mathrm{C}$ beschrieben (ohne Abbildung). Als zweiter Reinigungsschritt wurde eine Gelfiltration durchgeführt (Superdex 200, Puffer: $200 \mathrm{mM} \mathrm{NaCl}, 10 \mathrm{mM}$ Tris-HCl, pH 7,5, 5\% Glyzerin) (2.2.2.3.3). Die Phosphorylierung von RS3 bewirkte dabei, dass ein Puffer mit nur $200 \mathrm{mM}$ $\mathrm{NaCl}$ verwendet werden konnte, ohne dass RS3 auf der Säule aggregierte. Bei einer analytischen Gelfiltration (Superdex 200 (10/30)) hatte das phosphorylierte RS3 dasselbe Elutionsvolumen wie unphosphoryliertes RS3 (Abb. 3.44).

Fraktionen, die das phosphorylierte RS3 enthielten, wurden vereinigt, auf $30 \mathrm{mg} / \mathrm{ml}$ konzentriert (2.2.2.4) und für Kristallisationsansätze verwendet (2.2.3.2). Bis heute wurden jedoch keine Kristalle erhalten.
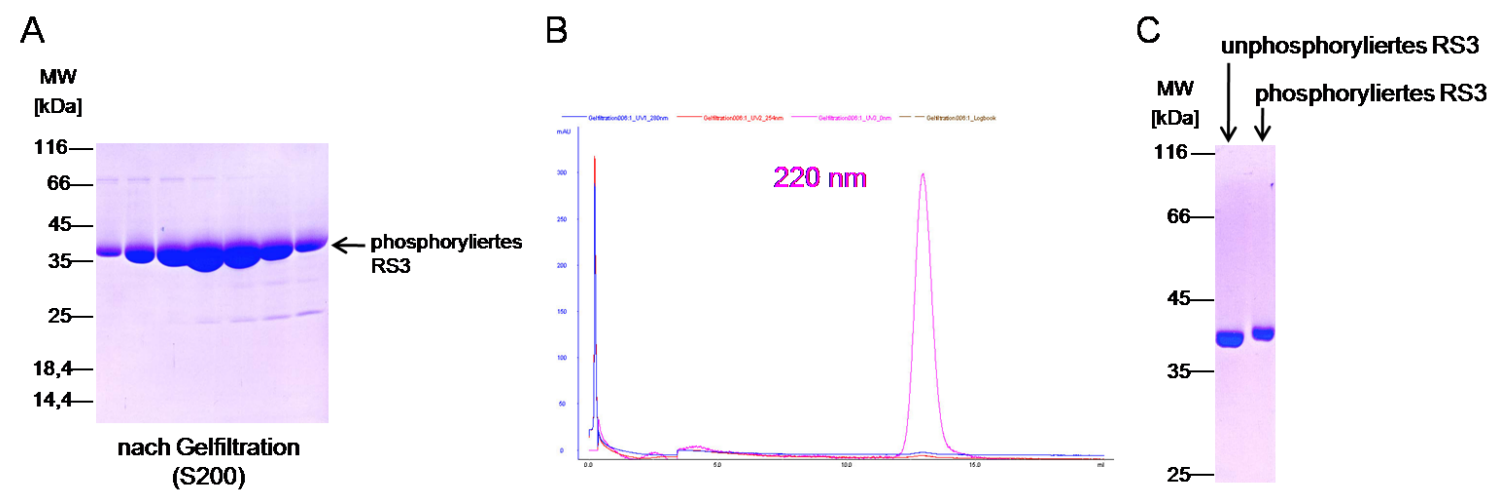

Abb. 3.44: Reinigung von phosphoryliertem RS3. (A) Analyse fraktionierter Proben über SDS-PAGE nach der Gelfiltration (Superdex 200). (B) Analytische Gelfiltration mit phosphoryliertem RS3 (Superdex 200 (10/30)). Auf der X-Achse ist das Volumen in [ml], auf der Y-Achse die UV-Absorption in [mAU] aufgetragen. Blau: $280 \mathrm{~nm}$. Rot: $260 \mathrm{~nm}$. Violett: $220 \mathrm{~nm}$. Nur die UV-Absorption bei $220 \mathrm{~nm}$ macht die Position von RS3 sichtbar. Das Laufverhalten entspricht einem Molekulargewicht von $80 \mathrm{kDa}$. (C) SDS-PAGE zeigt, dass das gereinigte RS3-Protein phosphoryliert ist, da es im SDS-Gel langsamer läuft als unphosphoryliertes RS3.

\subsubsection{Reinigung und Kristallisationsversuche mit phosphoryliertem hPrp28}

Analog zum phosphorylierten RS3-Fragment (3.4.2.4) wurde auch phosphoryliertes hPrp28 gereinigt. Für die Gelfiltration (Superdex 200, Puffer: $300 \mathrm{mM} \mathrm{NaCl}, 10 \mathrm{mM}$ Tris-HCl, pH 7,5, 5\% Glyzerin, $2 \mathrm{mM} \beta$-Mercaptoethanol) konnte durch die Phosphorylierung auch beim Volllängenprotein die NaCl-Konzentration im Puffer gesenkt werden. Dies ist ein Hinweis, dass hPrp28 tatsächlich phosphoryliert vorliegt. Eine Verschiebung der Proteinbande bei der 
SDS-PAGE gegenüber unphosphoryliertem hPrp28 konnte beim Volllängenprotein nicht beobachtet werden (Abb. 3.45).

A

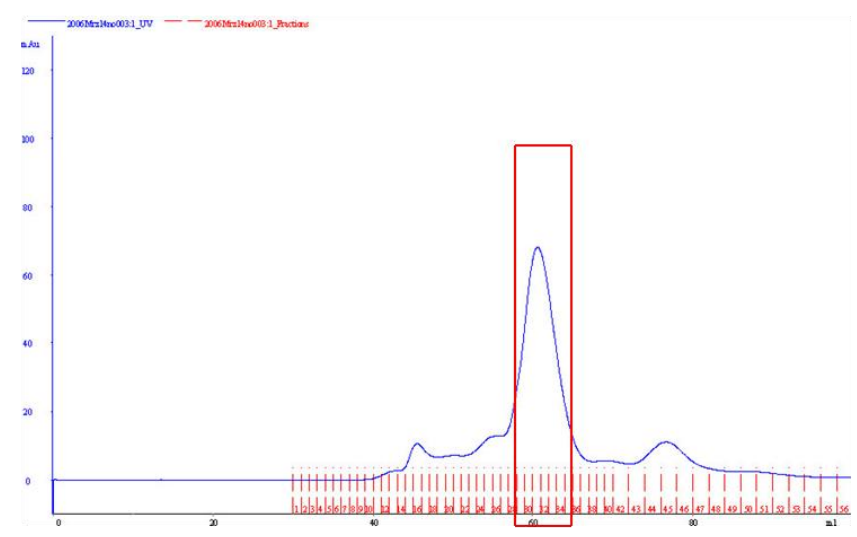

B

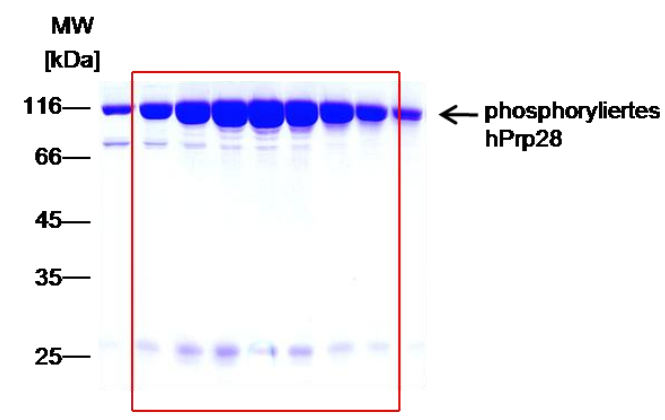

Abb. 3.45: Reinigung von phosphoryliertem hPrp28. Zweiter Reinigungsschritt: Gelfiltration. (A) Elutionsprofil der Superdex 200 Säule (16/60). Auf der X-Achse ist das Volumen in [ml], auf der Y-Achse die UV-Absorption bei $280 \mathrm{~nm}$ in [mAU] (blauer Graph) aufgetragen. Gesammelte Fraktionen sind angegeben. (B) Analyse einzelner Fraktionen über SDS-PAGE. Phosphoryliertes hPrp28 befindet sich in den Fraktionen unterhalb des UV-Absorptionsmaximums (rot gekennzeichnet).

Fraktionen, die das phosphorylierte hPrp28 enthielten, wurden vereinigt. Das Protein wurde auf $6-8 \mathrm{mg} / \mathrm{ml}$ konzentriert (2.2.2.4) und für Kristallisationsversuche verwendet (2.2.3.2). Bis heute wurden keine Kristalle erhalten.

\subsubsection{Der hydrodynamische Radius des RS3-Fragments von hPrp28}

Einen ersten Hinweis, ob die Phosphorylierung der RS-Domäne von hPrp28 ihre Faltungsstruktur verändert, kann durch die Messung der globulären Molekülgröße des RS3Fragments erhalten werden. Ein Maß für die globuläre Molekülgröße ist der hydrodynamische Radius. Dieser kann einerseits über PFG-Diffusions-NMR-Spektroskopie (PFG: pulsed field gradients, englisch für gepulste Feldgradienten) bestimmt werden (Wilkins et al. 1999). Andererseits lässt sich der hydrodynamische Radius auch über die Messung der Lichtstreuung berechnen (DLS: $\underline{\text { dynamic }}$ light scattering, englisch für dynamische Lichtstreuung).

Sowohl PFG-Diffusions-NMR-Spektroskopie als auch DLS wurden zur Bestimmung der hydrodynamischen Radii von phosphoryliertem und unphosphoryliertem RS3 angewendet. Diese Messungen wurden von Hai-Young Kim durchgeführt (Max-Planck-Institut für biophysikalische Chemie, Göttingen, Abteilung Prof. C. Griesinger, AG M. Zweckstätter).

Die PFG-Diffusions-NMR-Spektroskopie ergab für unphosphoryliertes RS3 einen hydrodynamischen Radius von 3,0 nm und für phosphoryliertes RS3 von 4,4 nm (ohne Abbildung). Diese Werte zeigten sich im Bereich von $1 \mathrm{mg} / \mathrm{ml}$ bis $20 \mathrm{mg} / \mathrm{ml}$ unabhängig von der Konzentration des Proteins. Gemessen wurde bei $25^{\circ} \mathrm{C}$ in folgendem Puffer: $500 \mathrm{mM}$ $\mathrm{NaCl}, 10 \mathrm{mM}$ Natriumphosphatpuffer, pH 6,3.

Ein Protein mit dem Molekulargewicht des RS3-Fragments (31 kDa) hat rechnerisch im Durchschnitt einen hydrodynamischen Radius von $2,5 \mathrm{~nm}$ im nativen Zustand und von 5,5 $\mathrm{nm}$, wenn es denaturiert ist. Daraus folgt, dass sich unphosphoryliertes RS3 wie ein gefaltenes 
Protein verhält. Das phosphorylierte RS3 ist im Vergleich dazu zwar weniger kompakt, liegt allerdings auch nicht vollständig entfaltet vor.

Die DLS-Messungen führten zu ähnlichen Ergebnissen. Für unphosphoryliertes RS3 ergab sich ein hydrodynamischer Radius von 3,5 nm, für phosphoryliertes RS3 von im Durchschnitt 4,5 nm (Abb. 3.46). Auch bei diesen Messungen hingen die Werte nicht von der Proteinkonzentration ab. Gemessen wurde in folgendem Puffer: $250 \mathrm{mM} \mathrm{NaCl}, 10 \mathrm{mM}$ Natriumphosphatpuffer, pH 6,3.
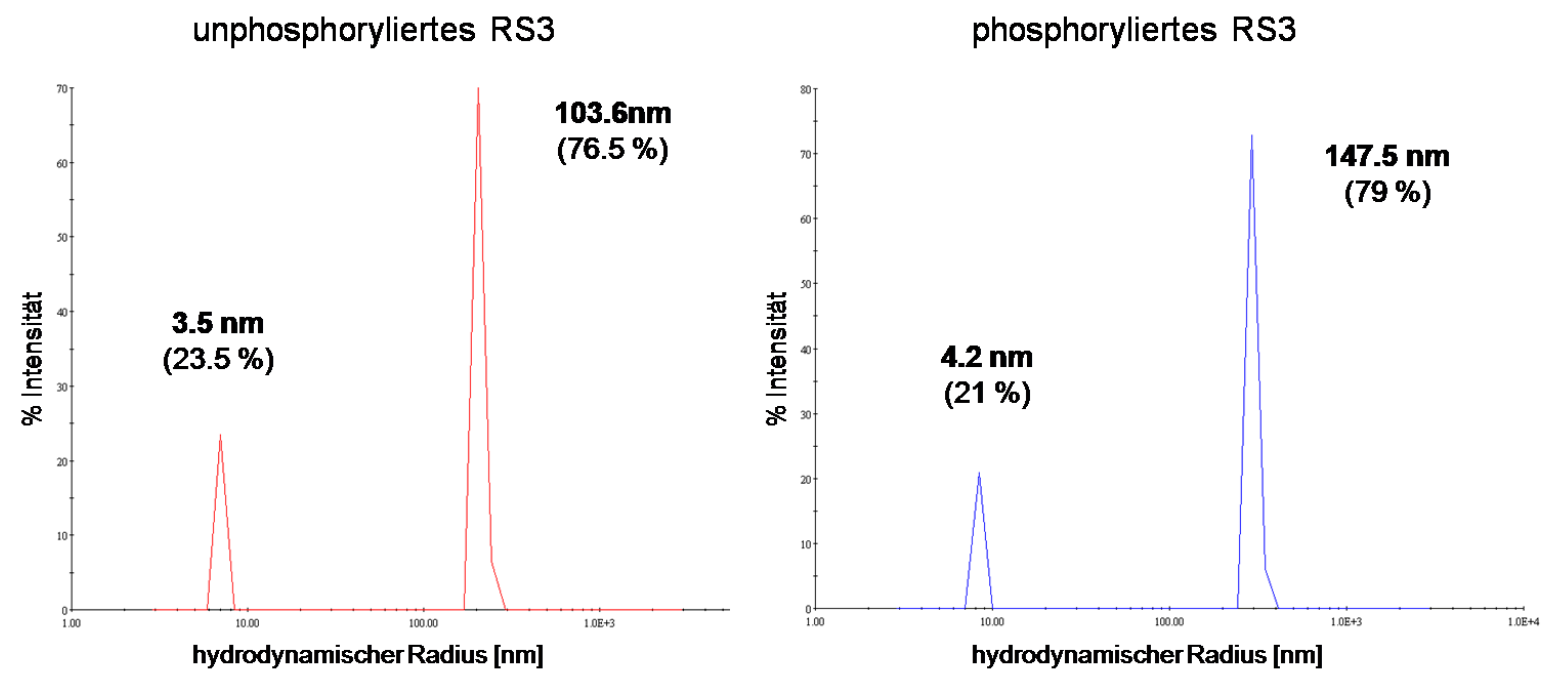

Abb. 3.46: Messung des hydrodynamischen Radius von RS3 mit DLS. Aufgetragen ist die Signalintensität auf der Y-Achse gegen den hydrodynamischen Radius [nm] auf der X-Achse. Unphosphoryliertes RS3 hatte einen Radius von 3,5 nm und phosphoryliertes RS3 von durchschnittlich 4,5 nm. Etwa $80 \%$ des Proteins lag in beiden Fällen als multimeres Aggregat vor (hydrodynamischer Radius von 100-150 nm). Die Messung wurde von HaiYoung Kim (MPI, Göttingen) durchgeführt.

Ein wichtiges Ergebnis der DLS-Messungen war außerdem, dass etwa $80 \%$ des RS3-Proteins - unabhängig davon, ob es phosphoryliert war oder nicht - in der Lösung in Form von großen multimeren Aggregaten mit einem hydrodynamischen Radius von 100-150 nm vorlag. Diese Beobachtung wurde auch bei niedrigen Proteinkonzentrationen $(1 \mathrm{mg} / \mathrm{ml})$ gemacht. Die Bildung solcher Aggregate ist oft für Kristallisationsversuche problematisch.

\subsubsection{Untersuchung des RS3-Fragments von hPrp28 über NMR-Spektroskopie}

Die RS-Domäne von hPrp28 bildete keine Kristalle, so dass ein Einblick in ihre Molekülstruktur mittels Röntgenbeugungsexperimenten nicht möglich war. Eine andere Methode zur Bestimmung von Proteinstrukturen ist die NMR-Spektroskopie (NMR: nuclear magnetic resonance, englisch für Kernspinresonanz). Vorteil dieser Methode ist es, dass die Messung in Lösung stattfindet, d.h. eine Kristallisation entfällt. Allerdings kann NMRSpektroskopie bisher nur für Proteine bis maximal etwa $30 \mathrm{kDa}$ zur Strukturlösung angewendet werden. Außerdem müssen die Proteine dafür spezielle Isotopenmarkierungen $\left({ }^{15} \mathrm{~N},{ }^{13} \mathrm{C}\right)$ enthalten.

Das RS3-Fragment von hPrp28 hat ein Molekulargewicht von $31 \mathrm{kDa}$. Deshalb könnte eine Strukturlösung über NMR-Spektroskopie möglich sein. Zu diesem Zweck wurde 
isotopenmarkiertes phosphoryliertes und unphosphoryliertes RS3-Protein gereinigt. Die Expression erfolgte in E. coli Zellen des Stammes Rosetta 2 (DE3), die mit dem Vektor hPrp28-RS3-pET-21a transformiert worden waren, in speziellen Minimalmedien (2.2.2.1.3.1). ${ }^{15} \mathrm{~N}$-markiertes RS3 wurde erhalten, indem als einzige Stickstoffquelle ${ }^{15} \mathrm{NH}_{4} \mathrm{Cl}$ zur Verfügung stand. ${ }^{15} \mathrm{~N}-{ }^{13} \mathrm{C}$-markiertes Protein erforderte zusätzlich ${ }^{13} \mathrm{C}$-Glucose als einzige Kohlenstoffquelle.

Nach dem Aufschluss erfolgte die Reinigung analog zu nicht-isotopenmarkiertem RS3 (3.4.1.1 und 3.4.2.4) über Hexahistidin-Affinitätschromatographie und anschließende Gelfiltration (Superdex 200). Abweichend war lediglich der bei der Gelfiltration verwendeten Puffer (500 mM NaCl, $10 \mathrm{mM}$ Natriumphosphatpuffer, pH 6,3). Dieser Puffer ist für NMRMessungen geeignet. Die Analyse über SDS-PAGE zeigte, dass isotopenmarkiertes RS3 mit und ohne Phosphorylierung in hoher Reinheit erhalten wurde (Abb. 3.47). Die Ausbeute pro Liter Minimalmedium betrug bei ${ }^{15} \mathrm{~N}$-Markierung $10 \mathrm{mg}$, bei ${ }^{15} \mathrm{~N}-{ }^{13} \mathrm{C}$-Markierung $4 \mathrm{mg}$.

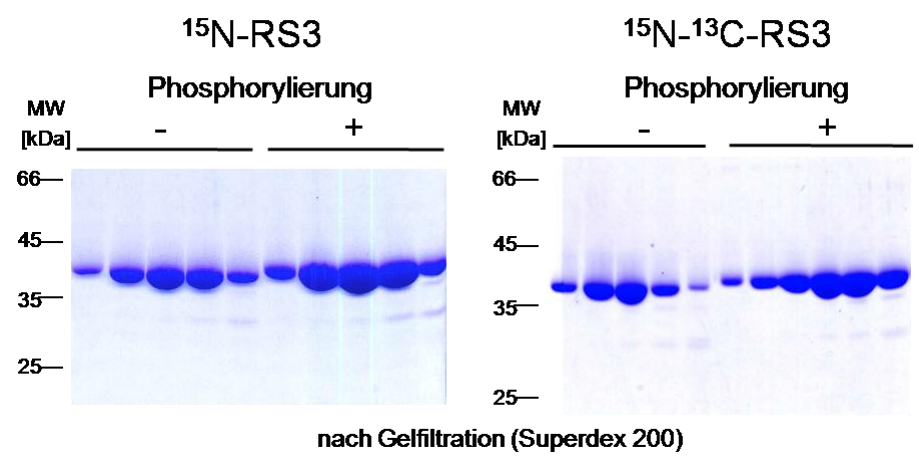

Abb. 3.47: Reinigung von ${ }^{15} \mathrm{~N}$ - und ${ }^{15} \mathrm{~N}-{ }^{13} \mathrm{C}$-markiertem RS3 für NMR-Messungen. Dargestellt ist jeweils die Analyse fraktionierter Proben über SDS-PAGE nach der Gelfiltration (Superdex 200). Es wurde sowohl phosphoryliertes als auch unphosphoryliertes Protein gereinigt.

Das isotopenmarkierte RS3-Protein wurde auf $15 \mathrm{mg} / \mathrm{ml}$ konzentriert (2.2.2.4) und für NMRSpektroskopie verwendet. Die Messungen wurden von Hai-Young Kim durchgeführt (MaxPlanck-Institut für biophysikalische Chemie, Göttingen, Abteilung Prof. C. Griesinger, AG Markus Zweckstätter). Sie erfolgten bei $25^{\circ} \mathrm{C}$ mit einer Proteinkonzentration von etwa $200 \mu \mathrm{M}$ (entspricht $6 \mathrm{mg} / \mathrm{ml}$ ). Die Lösung der Molekularstruktur des RS3-Proteins ist noch nicht abgeschlossen.

Erste Messungen haben keinen Hinweis darauf gegeben, dass sich die Struktur von RS3 durch die Phosphorylierung ändert. Die ${ }^{15} \mathrm{~N}-\mathrm{HSCQ}-S p e k t r e n$ von phosphoryliertem und unphosphoryliertem RS3 ähneln sich nämlich sehr (Abb. 3.48). Der größte Unterschied besteht darin, dass das Spektrum des phosphorylierten RS3-Proteins mehrere zusätzliche Signale enthält, die das Vorhandensein von 11-13 Phosphatgruppen zeigen. Weiterhin hatte auch die NaCl-Konzentration im Puffer keinen sichtbaren Einfluss auf die Struktur von RS3. Die Lage der Signale im Spektrum wies darauf hin, dass das RS3-Fragment keine Sekundärstrukturelemente enthält. 


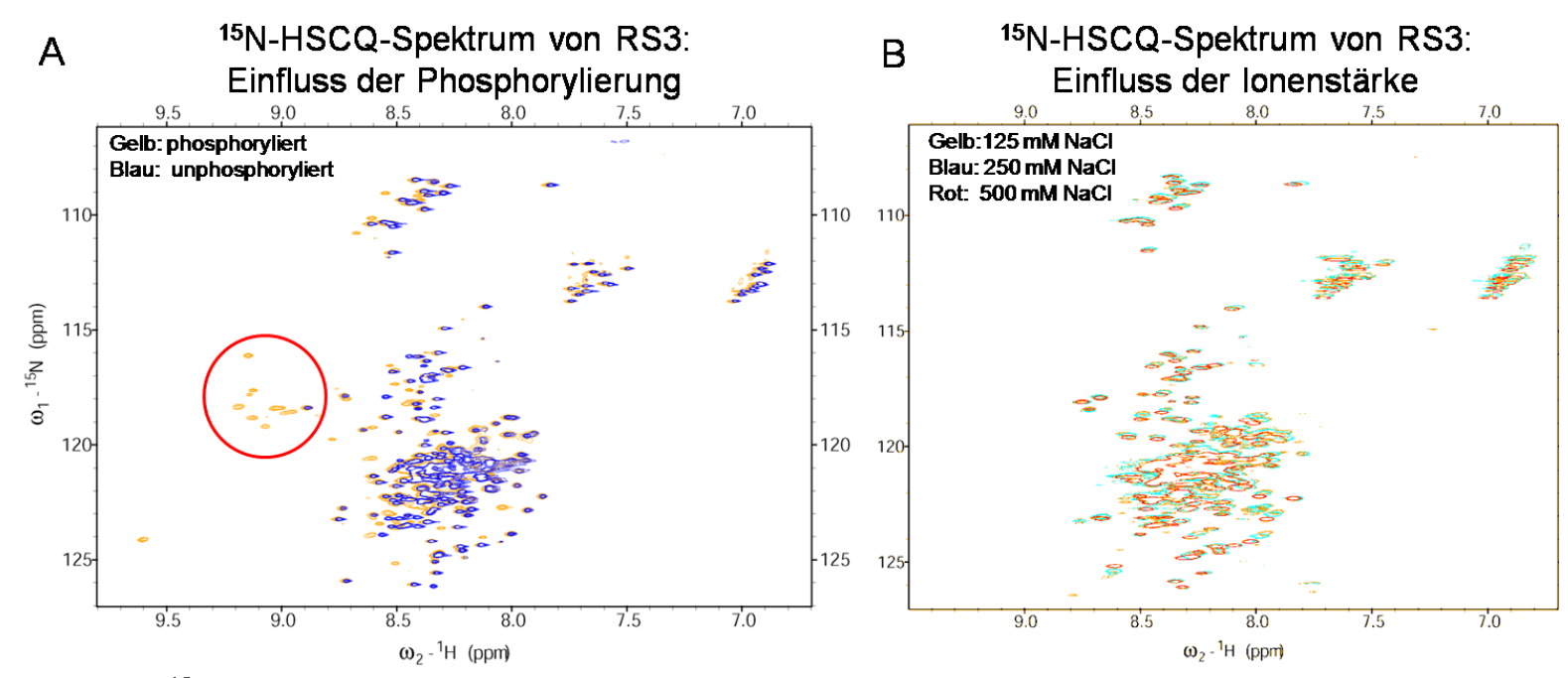

Abb. 3.48: ${ }^{15} \mathrm{~N}-\mathrm{HSCQ}-S p e k t r e n$ von RS3. (A) Überlagerung der Spektren für phosphoryliertes (gelb) und unphosphoryliertes (blau) RS3. Messung bei $25^{\circ} \mathrm{C}$ und $500 \mathrm{mM} \mathrm{NaCl}$. Es sind $11-13$ zusätzliche Signale erkennbar, die die Phosphatgruppen repräsentieren (rot gekennzeichnet). (B) Überlagerung der Spektren bei unterschiedlichen $\mathrm{NaCl}$-Konzentrationen (gelb $125 \mathrm{mM}$, blau $250 \mathrm{mM}$, rot $500 \mathrm{mM}$ ). Die Ionenstärke hatte keinen Einfluss auf die Signalverteilung.

Die Messung wurde von Hai-Young Kim (MPI, Göttingen) durchgeführt und die Abbildung freundlicherweise von ihr zur Verfügung gestellt.

\subsection{Funktion von hPrp28 beim Spleißen}

hPrp28 ist ein DEAD-Box Protein des humanen Spleißosoms. Es ist Bestandteil des U5 snRNP und des U4/U6.U5 tri-snRNP (Teigelkamp et al. 1997). Funktionelle Studien beschränken sich bisher auf das Hefe-Ortholog Prp28. Sie zeigten, dass das Protein für den Austausch der U1 snRNA gegen die U6 snRNA an der 5'-Spleißstelle wichtig ist, der während der Aktivierung des Spleißosoms stattfindet.

In diesem Abschnitt werden Experimente beschrieben, mit denen die Funktion von hPrp28 im humanen Spleißosom untersucht wurde. Dies erfolgte in Zusammenarbeit mit Rebecca Mathew (Max-Planck-Institut für biophysikalische Chemie, Göttingen, Abteilung Prof. Reinhard Lührmann). Im Fokus stand dabei die Aufgabe der RS-Domäne von hPrp28, die bei dem Hefe-Ortholog fehlt.

\subsubsection{Immunodeletion von hPrp28 und Komplementation mit rekombinantem Protein}

Um zu untersuchen, für welchen Schritt im Spleißzyklus hPrp28 notwendig ist, entfernte Rebecca Mathew zunächst das Protein über Immunopräzipitation aus HeLa-Zellkernextrakt. Anschließend wurde das Spleißen in diesem Kernextrakt analysiert. Genaue Angaben zu den Methoden finden sich in Mathew et al. (2008). Native Gelelektrophorese zeigte, dass der Komplex A gebildet wurde, aber der Komplex B nur in sehr geringer Menge vorlag. Dieser Defekt wurde durch Zugabe von rekombinantem hPrp28 (3.1.2) wieder aufgehoben (Abb. 3.49A). Folglich ist hPrp28 im Spleißzyklus bereits für die Bildung des B-Komplexes und somit für die Anlagerung des U4/U6.U5 tri-snRNP an das Spleißosom wichtig. Außerdem 
zeigte dieses Experiment, dass das rekombinante hPrp28 funktionell ist und somit vermutlich korrekt gefaltet vorliegt.

Im Gegensatz zum Volllängenprotein war das DEAD2-Fragment nicht in der Lage, die Immunodeletion von hPrp28 zu komplementieren (Abb. 3.49B). Weiterhin konnte Rebecca Mathew zeigen, dass in Gegenwart von Kinase- und Phosphatase-Inhibitoren nur phosphoryliertes rekombinantes hPrp28 (3.4.2.5) in der Lage war, die Bildung des BKomplexes wiederherzustellen (Abb. 3.49C). Diese Ergebnisse weisen darauf hin, dass die RS-Domäne von hPrp28 bei diesem Vorgang eine funktionelle Bedeutung hat.

A

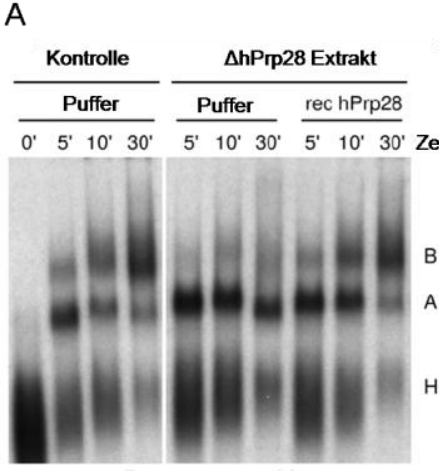

native Gelelektrophorese
B

$\triangle$ hPrp28 Extrakt

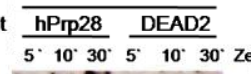

native Gelelektrophorese

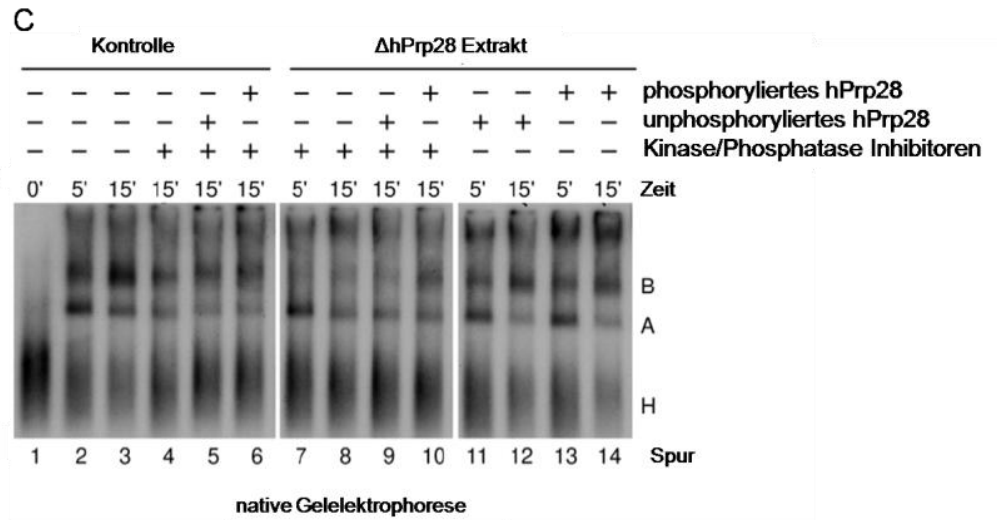

Abb. 3.49: Native Gelektrophorese zur Detektion von spleißosomalen Komplexen in vollständigem HeLaZellkernextrakt (Kontrolle) und in hPrp28-immunodepletiertem HeLa-Zellkernextrakt. Es wurden Proben nach verschiedenen Inkubationszeiten der Spleißreaktion untersucht. (A) Immunodepletion von hPrp28 verhindert die Bildung des B-Komplexes. Zugabe von rekombinantem hPrp28 stellt die B- Komplex-Bildung wieder her. (B) Das DEAD2-Fragment kann die Immunodelektion von hPrp28 nicht komplementieren. (C) Die Phosphorylierung von hPrp28 ist für die B-Komplex-Bildung notwendig. In Gegenwart von Kinase- und Phosphatase-Inhibitoren kann nur phosphoryliertes rekombinantes hPrp28 die B-Komplex-Bildung in immunodepletiertem Zellkernextrakt wiederherstellen.

Diese Experimente wurden von Rebecca Mathew (MPI, Göttingen) durchgeführt. Die Abbildungen wurden freundlicherweise von ihr zur Verfügung gestellt.

\subsubsection{Interaktionsstudien mit U snRNPs}

Die Immunodepletion von hPrp28 hatte gezeigt, dass die Phosphorylierung der RS-Domäne eine Funktion bei der Anlagerung des tri-snRNP an das Spleißosom hat. Um dies genauer zu analysieren, wurde untersucht, ob die Phosphorylierung einen Einfluss auf die Interaktion von hPrp28 mit spleißosomalen Komplexen hat.

\subsubsection{Ko-Immunopräzipitation des U4/U6.U5 tri-snRNP}

Es wurden Ko-Immunopräzipitations-Experimente von Rebecca Mathew durchgeführt. Genaue Angaben dazu befinden sich in Mathew et al. (2008). Phosphoryliertes und unphosphoryliertes hPrp28 wurden über ihre Hexahistidin-Markierung an eine Matrix gebunden und in Gegenwart von Kinase- und Phosphatase Inhibitoren mit HeLa- 
Zellkernextrakt inkubiert. Nach Waschen der Matrix wurde über Northern Blotting analysiert, welche U snRNAs von hPrp28 gebunden worden waren (Abb. 3.50).

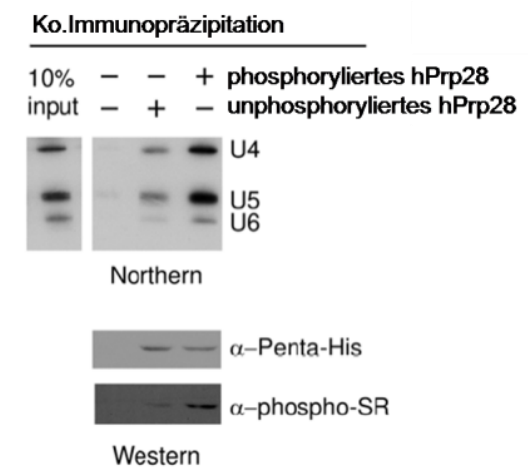

\begin{abstract}
Abb. 3.50: Ko-Immunopräzipitation von hPrp28 und U4/U6.U5 tri-snRNP in HeLa-Zellkernextrakt. Über Northern Blotting wurden gebundene U snRNAs nachgewiesen. Die Phosphorylierung von hPrp28 verstärkte die Bindung des tri-snRNP deutlich. Western Blotting mit Antikörpern, die spezifisch für Pentahistidin $(\alpha$-Penta-His) bzw. für phosporylierte RS-Domänen $(\alpha-$ phospho-SR) sind, zeigte die Konzentration und den Phosphorylierungsstatus von hPrp28 nach der Inkubation. Die Immunopräzipitation wurde von Rebecca Mathew (MPI,Göttingen) durchgeführt.
\end{abstract}

Phosphoryliertes hPrp28 zeigte deutlich eine Bindung an das U4/U6.U5 tri-snRNP, da alle drei entsprechenden U snRNAs detektiert wurden. Bei dem unphosphorylierten Protein war diese Bindung deutlich schwächer. Die Tatsache, dass eine kleine Menge gebundenes trisnRNP beobachtet wurde, hat seine Ursache vermutlich darin, dass das rekombinante hPrp28 in dem Zellkernextrakt trotz der Inhibitorzugabe in kleinem Umfang phosphoryliert wurde.

Folglich ist die Phosphorylierung der RS-Domäne notwendig, damit hPrp28 an das tri-snRNP bindet. Aus Abschnitt 3.5.1 folgt dann, dass die Bindung von hPrp28 wiederum notwendig ist, damit das tri-snRNP mit dem Spleißosom assoziieren kann.

\subsubsection{Untersuchung der Interaktion von hPrp28 mit dem U1 snRNP}

Eine mögliche Funktion von hPrp28 ist die Destabilisierung des Duplexes aus der U1 snRNA und der 5'-Spleißstelle. Dieses Duplex wird von Proteinen des U1 snRNP stabilisiert, insbesondere von U1C. Es sollte deshalb untersucht werden, ob hPrp28 mit dem U1 snRNP interagieren kann.

Phosphoryliertes hPrp28 wurde mit humanem U1 snRNP (Präparation von Dr. Achim Dickmanns, Universität Göttingen, Abteilung Molekulare Strukturbiologie) für $15^{\circ}$ bei $20^{\circ} \mathrm{C}$ inkubiert (Puffer: $300 \mathrm{mM} \mathrm{NaCl}, 10 \mathrm{mM}$ Tris-HCl, $\mathrm{pH}$ 7,5, $2 \mathrm{mM} \beta$-Mercaptoethanol). Über analytische Gelfiltration (2.2.2.3.3, Superdex 200 (10/30)) wurde anschließend untersucht, ob eine Assoziation zwischen dem U1 snRNP und hPrp28 stattfand. 

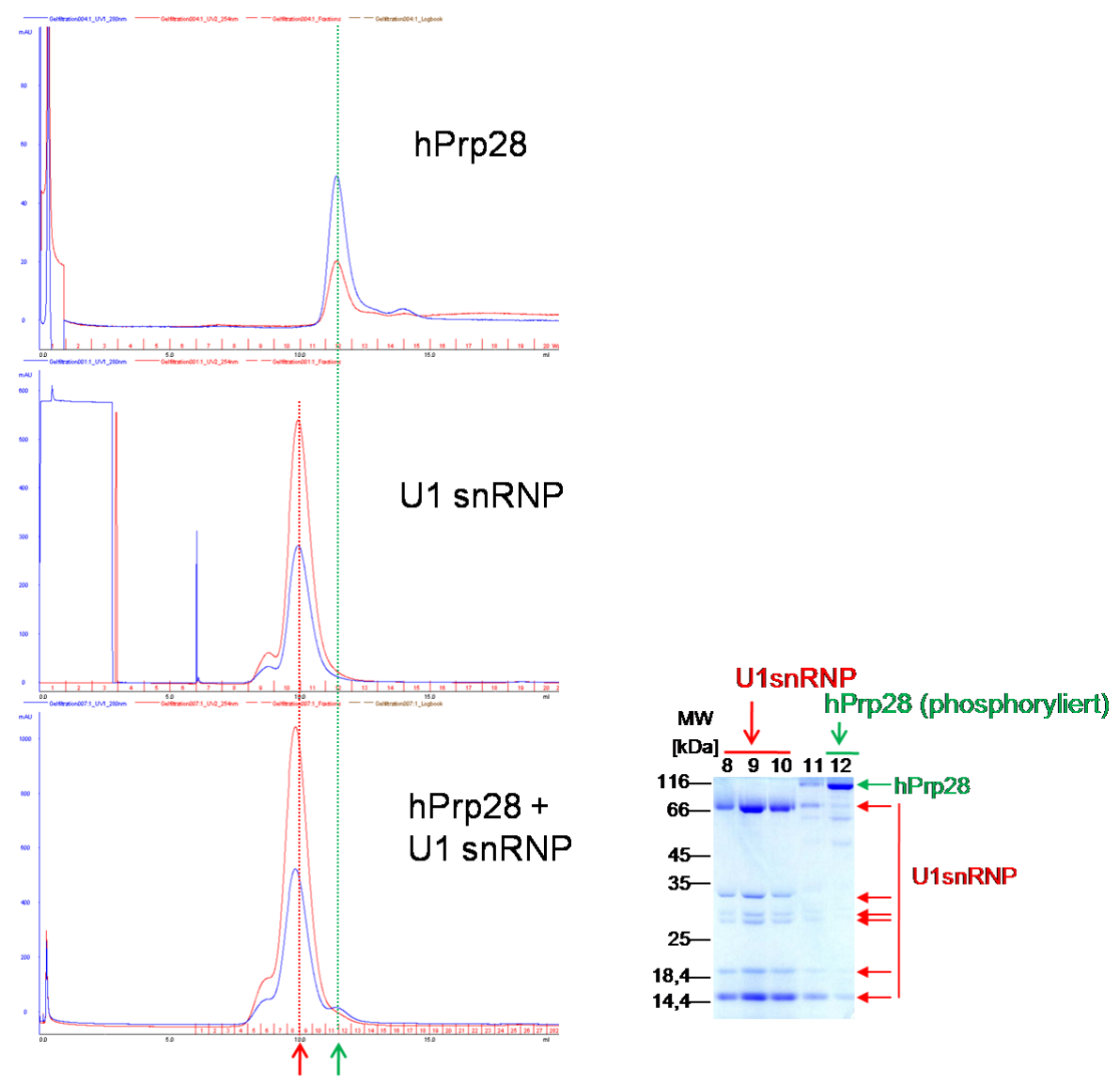

Abb. 3.51: Elutionsprofile der Gelfiltrationen (Superdex 200 (10/30)) zur Detektion von Komplexen zwischen phosphoryliertem hPrp28 und U1 snRNP. Aufgetragen ist die UV-Absorption [mAU] gegen das Elutionsvolumen [ml]. Die UV-Absorption wurde bei zwei verschiedenen Wellenlängen detektiert: $254 \mathrm{~nm}$ (rot und $280 \mathrm{~nm}$ (blau). Abgebildet ist das Elutionsprofil von hPrp28 (grün gekennzeichnet) bzw. dem U1 snRNP (rot gekennzeichnet) alleine sowie von dem zusammen inkubierten Ansatz. Das Elutionsvolumen des U1 snRNP betrug $10 \mathrm{ml}$, von hPrp28 11,5 ml. Beide verließen die Gelfiltrationssäule getrennt voneinander. Dies wurde durch Analyse fraktionierter Proben über SDS-PAGE bestätigt. Über dem Gel stehen die Fraktionsnummern. Die Elutionsvolumina von hPrp28 (grün) und den Proteinen des U1 snRNP (rot) sind gekennzeichnet.

Es wurde keine Interaktion zwischen dem U1 snRNP und phosphoryliertem hPrp28 beobachtet (Abb. 3.51). Das U1 snRNP hatte bei der analytischen Gelfiltration ein Elutionsvolumen von $10 \mathrm{ml}$, während hPrp28 getrennt davon erst nach 11,5 ml eluierte. Dieselben Elutionsvolumina ergaben sich in Kontrollversuchen mit hPrp28 bzw. dem U1 snRNP alleine.

\subsubsection{Mutanten von hPrp28}

Die Immunodeletion (3.5.1) hatte gezeigt, dass hPrp28 bereits eine Funktion bei der Anlagerung des U4/U6-U5 tri-snRNP an das Spleißosom hat. Der Einfluss der Phosphorylierung weist darauf hin, dass dabei die RS-Domäne eine Rolle spielt. Es stellt sich die Frage, ob für die Anlagerung des tri-snRNP auch die Helikaseaktivität von hPrp28 benötigt wird, oder ob diese erst in einem späteren Schritt des Spleißzyklus eine Funktion hat. Um dies untersuchen zu können, wurden Mutanten von hPrp28 konstruiert. Alle Mutationen betreffen die Helikasedomäne und sind in der Tabelle 3.7 zusammenfassend dargestellt. 
Tabelle 3.7: Mutanten von hPrp28. Die veränderten Aminosäuren von hPrp28 sowie die verwendeten Oligonukleotide sind angegeben. Außerdem ist dargestellt, welche Aminosäure(n) des DExD/H-Box-ProteinSequenzmotivs betroffen ist/sind.

\begin{tabular}{|c|c|c|c|}
\hline Bezeichnung & Mutation & Oligonukleotide & Veränderung des Motivs \\
\hline Motiv I & $\mathrm{K} 441 \rightarrow \mathrm{A}$ & $\begin{array}{l}\text { Motiv1-for } \\
\text { Motiv1-rev }\end{array}$ & 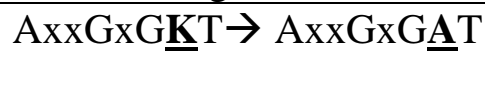 \\
\hline Motiv II & $\mathrm{D} 549 \rightarrow \mathrm{A}, \mathrm{E} 550 \rightarrow \mathrm{A}$ & $\begin{array}{l}\text { Motiv2-for } \\
\text { Motiv2-rev2 }\end{array}$ & 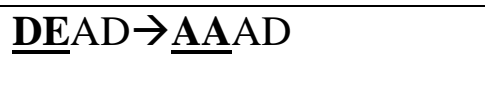 \\
\hline Motiv III & $\mathrm{T} 606 \rightarrow \mathrm{A}, \mathrm{T} 608 \rightarrow \mathrm{A}$ & $\begin{array}{l}\text { Motiv3-for } \\
\text { Motiv3-rev }\end{array}$ & $\underline{\mathbf{T}} \mathrm{A} \underline{\mathbf{T}} \rightarrow \underline{\mathbf{A}} \mathrm{A} \underline{\mathbf{A}}$ \\
\hline$\Delta$ Insert & $\begin{array}{l}\text { Deletion von } \\
\text { Aminosäure 576-599 }\end{array}$ & $\begin{array}{l}\text { Insert-for } \\
\text { Insert-rev }\end{array}$ & - \\
\hline
\end{tabular}

Die Motiv I-Mutation betrifft das konservierte Lysin in Motiv I. Diese Aminosäure ist für die ATP-Bindung wichtig, da ihre basische Seitenkette mit den Phosphatgruppen interagiert. Die Motiv II-Mutation betrifft das Aspartat und Glutamat des DEAD-Motivs. Bei diesen Aminosäuren handelt es sich um wichtige katalytische Reste für die ATPase-Aktivität. Bei der Motiv III-Mutante sind die beiden Threonine von Motiv III verändert. Diese Mutationen hatten bei den DExD/H-Box Proteinen yPrp22 und eIF4A zu einer stark reduzierten HelikaseAktivität geführt, während die ATPase-Aktivität hingegen nicht betroffen war (Schwer und Meszaros 2000, Pause und Sonenberg 1992).

Weiterhin wurde noch die $\Delta$ Insert-Mutante konstruiert. Diese Mutante betrifft keines der konservierten Sequenzmotive der DExD/H-Box Proteine, sondern wurde auf der Grundlage der Struktur des DEAD2-Fragments von hPrp28 konstruiert (3.3.5.4). Die Aminosäuren 576599 repräsentieren eine Besonderheit von Prp28 Orthologen höherer Eukaryoten. Dieser Sequenzabschnitt fehlt in anderen DExD/H-Box Proteinen und bildet in der DEAD2-Struktur eine kleine Kappe auf der N-terminalen Subdomäne (Abb. 3.29). Durch die Deletion in der $\Delta$ Insert-Mutante soll untersucht werden, ob diese Kappe eine funktionelle Bedeutung für hPrp28 hat.
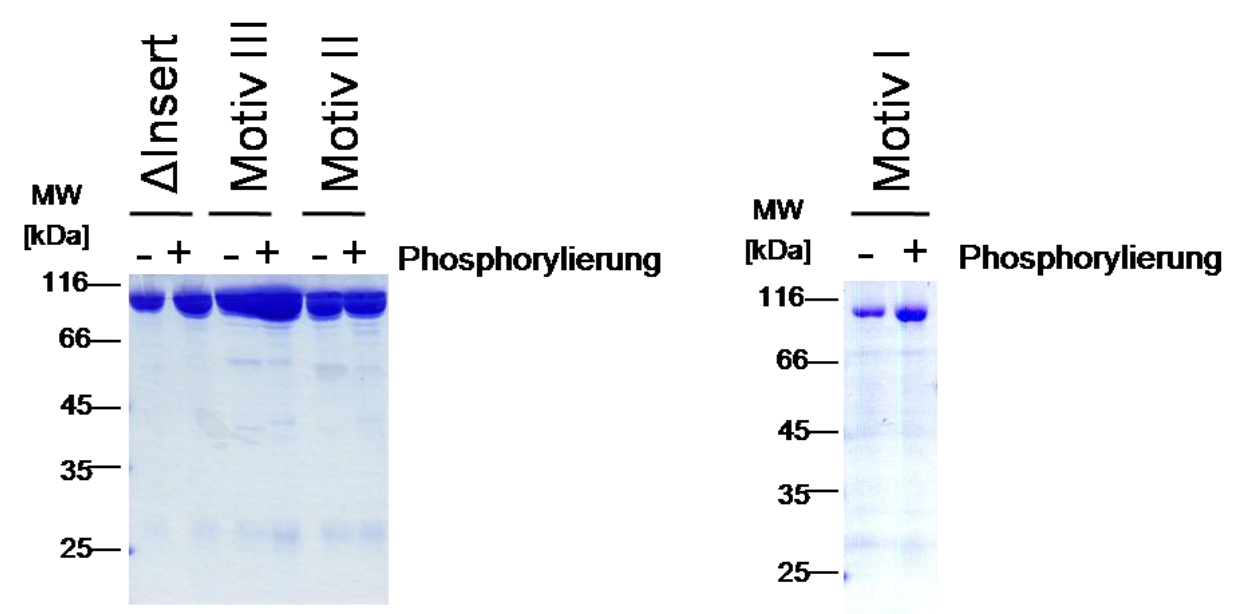

Abb. 3.52: SDS-PAGE mit Proben gereinigter hPrp28-Mutanten nach der Konzentration. Alle Proteine wurden mit und ohne Phosphorylierung erhalten. 
Die Mutationen wurden durch ortsgerichtete Mutagenese des hPpr28-pET-21a Vektors erhalten (2.2.1.10). Verwendete Oligonukleotide sind in der Tabelle 3.8 angegeben. Die Expression und Reinigung der Proteine erfolgte wie für das Wildtyp-hPrp28 beschrieben (3.1.2 und 3.4.2.5). In allen vier Fällen waren die mutierten Proteine löslich und die Reinigung unproblematisch (Abb. 3.52).

Die Untersuchungen zum Verhalten der hPrp28-Mutanten in der Spleißreaktion sind noch nicht abgeschlossen. Erste Ergebnisse von Rebecca Mathew (MPI für biophysikalische Chemie, Göttingen) zeigten sowohl für die Motiv I- als auch die Motiv II-Mutante einen dominant negativen Effekt auf die Bildung des B-Komplexes, wenn sie zu vollständigem HeLa-Zellkernextrakt zugegeben wurden. Für die Motiv III- und Insert-Mutation wurde unter diesen Bedingungen hingegen keine Inhibierung des Spleißens beobachtet. Diese Resultate sind jedoch noch vorläufig. 


\section{Diskussion}

In dieser Arbeit wurde das spleißosomale DEAD-Box Protein hPrp28 strukturell und funktionell untersucht.

Die C-terminale Helikasedomäne von hPrp28 wurde kristallisiert und ihre Molekularstruktur wurde über Röntgenbeugungsexperimente bestimmt. Außerdem wurden Bindungskonstanten für die Interaktion mit ADP und ATP gemessen. Dabei wurde gezeigt, dass die Helikasedomäne in vitro zwar ADP aber kein ATP bindet. Dementsprechend zeigte sie unter diesen Bedingungen auch keine ATPase Aktivität. Weiterhin wurde die Interaktion zwischen der Helikasedomäne und verschiedenen RNA-Substraten untersucht.

Die Kinasedomänen von SRPK1 und Clk1 wurden isoliert und dazu verwendet, die Nterminale RS-Domäne von hPrp28 in vitro zu phosphorylieren. Die Phosphorylierung durch SRPK1 wurde genauer durch Massenspektrometrie charakterisiert.

Die RS-Domäne von hPrp28 konnte weder mit noch ohne Phosphorylierung kristallisiert werden. Deshalb wurde ein isotopenmarkiertes Fragment der RS-Domäne gereinigt, um in Zusammenarbeit mit Hai-Young Kim und Markus Zweckstätter (MPI für biophysikalische Chemie, Göttingen) die Struktur über NMR zu bestimmen. Diese Analysen sind noch nicht abgeschlossen.

Funktionelle Untersuchungen in Zusammenarbeit mit Rebecca Mathew und Reinhard Lührmann (MPI für biophysikalische Chemie, Göttingen) führten zu dem Ergebnis, dass die Phosphorylierung der RS-Domäne notwendig ist, damit hPrp28 an das U4/U6.U5 tri-snRNP binden kann. Die Bindung von hPrp28 ist wiederum essentiell für eine stabile Integration des tri-snRNP in das Spleißosom. Um weiterführende funktionelle Untersuchungen zu ermöglichen, wurden vier verschiedene Mutanten von hPrp28 gereinigt. Endgültige Ergebnisse zu den Eigenschaften dieser Mutanten liegen noch nicht vor.

\subsection{Domänenstruktur von hPrp28}

Das DExD/H-Box Protein hPrp28 umfasst 820 Aminosäuren. Auf Grundlage von bekannten Sequenzmotiven lassen sich nach den Angaben in der NCBI-Proteindatenbank (Eintrag Nr. NP_004809) nur zwei Domänen identifizieren: Die N-terminale RS-Domäne (Aminosäuren 1-221) und die C-terminale DExD/H-Box Helikasedomäne (Aminosäure 393-767). Die Lokalisation der Helikasedomäne wurde in dieser Arbeit durch die Aufklärung der molekularen Struktur im Wesentlichen bestätigt. Sie umfasst die Aminosäuren 378-800.

Aufschluss über den möglichen Domänenaufbau des N-terminalen Abschnitts von hPrp28 gibt ein Vergleich mit den orthologen Proteinen aus anderen Organismen. In der Abb. 4.1 ist ein Sequenzalignment mit Proteinen aus D. melanogaster, C. elegans und S. cerevisiae gezeigt. Neben der am höchsten konservierten C-terminalen DExD/H-Box-Helikasedomäne (Aminosäuren 378-820) lassen sich zwei Bereiche unterscheiden (Grenzen gekennzeichnet durch rote Pfeile). 


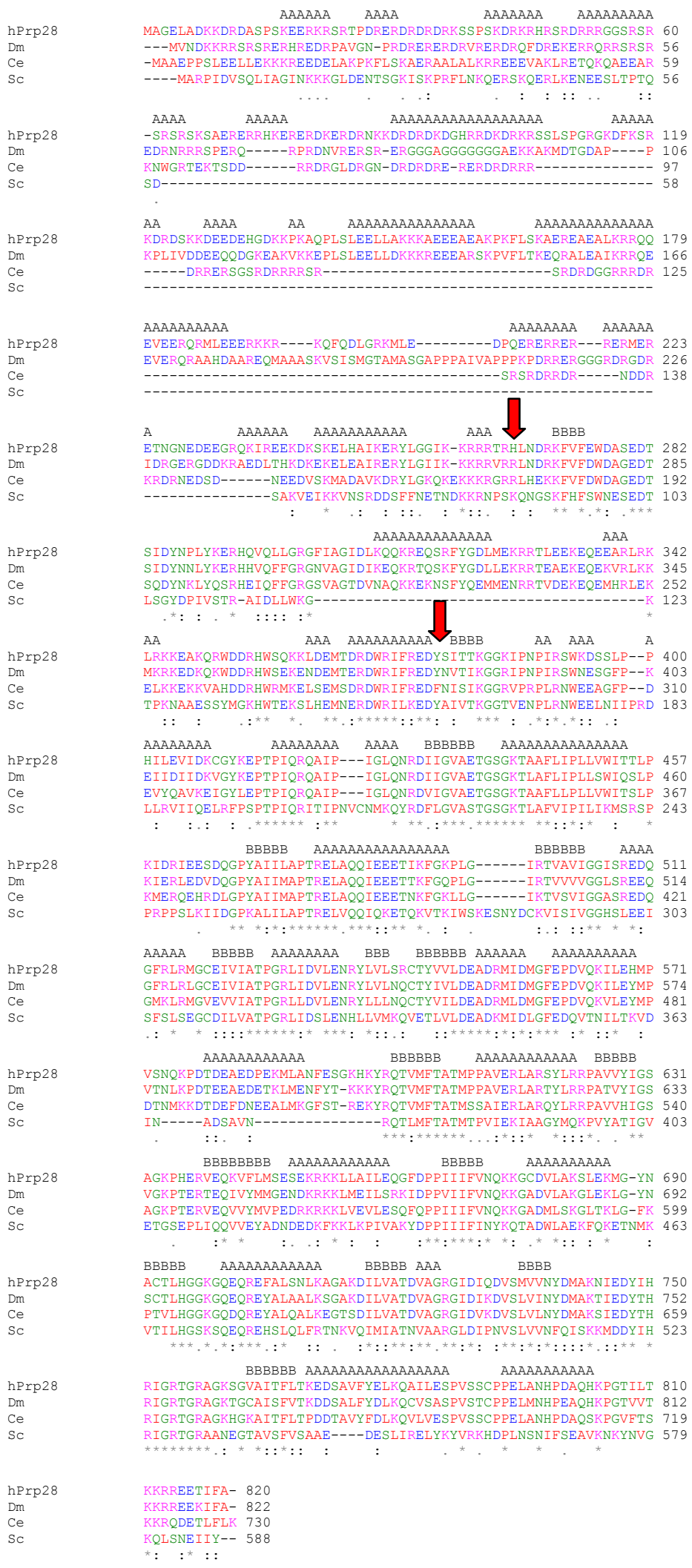

Abb. 4.1: Sequenzalignment (verwendetes Programm: ClustalW) von hPrp28 mit Orthologen aus $D$. melanogaster $(\mathrm{Dm})$, C. elegans $(\mathrm{Cs})$ und S. cerevisiae $(\mathrm{Sc})$. Unterhalb der Sequenzen ist die Konservierung angegeben (* 100\% Identität, : 100\% Ähnlichkeit, . 75\% Ähnlichkeit), überhalb die vorhergesagte Sekundärstruktur für hPrp28 (verwendetes Programm: PSIPRED) mit $\mathrm{A}=\alpha$-Helix und $\mathrm{B}=\beta$-Faltblatt. Die Aminosäuren sind gemäß den Eigenschaften ihrer Seitenketten gefärbt: Hydrophob (rot), sauer (blau), basisch (violett) und hydrophil (grün). Die roten Pfeile geben mögliche Domänengrenzen an (siehe Text). 
Die N-terminalen ca. 260 Aminosäuren von hPrp28 zeichnen sich durch einen hohen Gehalt an Arginin, Lysin, Glutamat und Aspartat aus. Diese besondere Aminosäurezusammensetzung, die typisch für RS-Domänen ist, findet sich zwar in den orthologen Proteinen aus D. melanogaster und $C$. elegans wieder. Konservierte Sequenzbereiche, die auch andere Aminosäuren umfassen, lassen sich aber nicht identifizieren und in S. cerevisiae fehlt ein analoger Abschnitt. Nach den Angaben der NCBI Proteindatenbank umfasst die RS-Domäne von hPrp28 nur den Bereich 1-221. Das Alignment und die Aminosäuresequenz weisen allerdings darauf hin, dass die RS-Domäne möglicherweise bis zu 260 Reste enthält. Eine genaue Festlegung der Domänengrenzen ist auf dieser Grundlage aber nicht möglich.

Der Abschnitt zwischen der RS- und Helikasedomäne (Aminosäure ca. 260-377) weist bei allen vier Proteinen Sequenzkonservierung auf. Ein Teil davon (ab Aminosäure 353) wurde zusammen mit der Helikasedomäne kristallisiert und strukturell charakterisiert. Allerdings entspricht die Faltung dieses Fragments in DEAD2 vermutlich nicht der Faltung im vollständigen Protein (3.3.5.4). Ob es sich bei dem Abschnitt zwischen der RS- und Helikasedomäne tatsächlich um eine eigenständige Faltungseinheit handelt, ist fraglich. Zum einen war ein Fragment von hPrp28, das die Aminosäuren 221-405 umfasste, unlöslich (3.2.1). Außerdem wurden bei der Reinigung des DEAD1-Fragments (207-820) Abbauprodukte erhalten, die im N-terminalen Abschnitt bis Aminosäure 302 degradiert waren (Ergebnis nicht gezeigt). Möglicherweise bildet der Bereich 260-377 von hPrp28 darum zusammen mit der RS-Domäne oder mit einem Teil davon eine Faltungseinheit.

\subsection{Kristalle des DEAD2-Fragments von hPrp28}

In dieser Arbeit wurde das DEAD2-Fragment von hPrp28 kristallisiert, das die Aminosäuren 338-820 umfasst. Diese Kristalle wurden verwendet, um die Struktur des Fragments mittels Röntgenbeugungsanalyse zu bestimmen.

\subsubsection{Kristallpackung}

DEAD2 kristallisierte in der orthorhombischen Raumgruppe C222 1 (3.3.5.2). Die Einheitszelle dieser Raumgruppe enthält acht asymmetrische Einheiten, die durch Symmetrieoperationen ineinander überführt werden können. In jeder asymmetrischen Einheit befindet sich dabei ein einzelnes DEAD2-Protein (Abb. 4.2A).

Ein Kristall bildet sich durch spezifische Interaktionen zwischen den Proteinmolekülen. In der Kristallpackung ist jedes Protein von mehreren benachbarten Molekülen umgeben. Bei den Kristallen von DEAD2 ist dabei die Interaktion mit jeweils einem Nachbar-Protein besonders ausgeprägt (Abb. 4.2B). Die Kontaktstelle zwischen den beiden Proteinen befindet sich jeweils auf der den konservierten Sequenzmotiven abgewandten Seite von NTD und CTD. Diese Dimerisierung ist vermutlich die Ursache für die weit geöffnete Konformation der Helikase-Subdomänen im Kristall (3.3.5.4). Solche Dimere von DEAD2 existieren aber offensichtlich nicht in Lösung, da sich das Protein bei der Gelfiltration wie ein Monomer verhielt (3.3.1). 
A

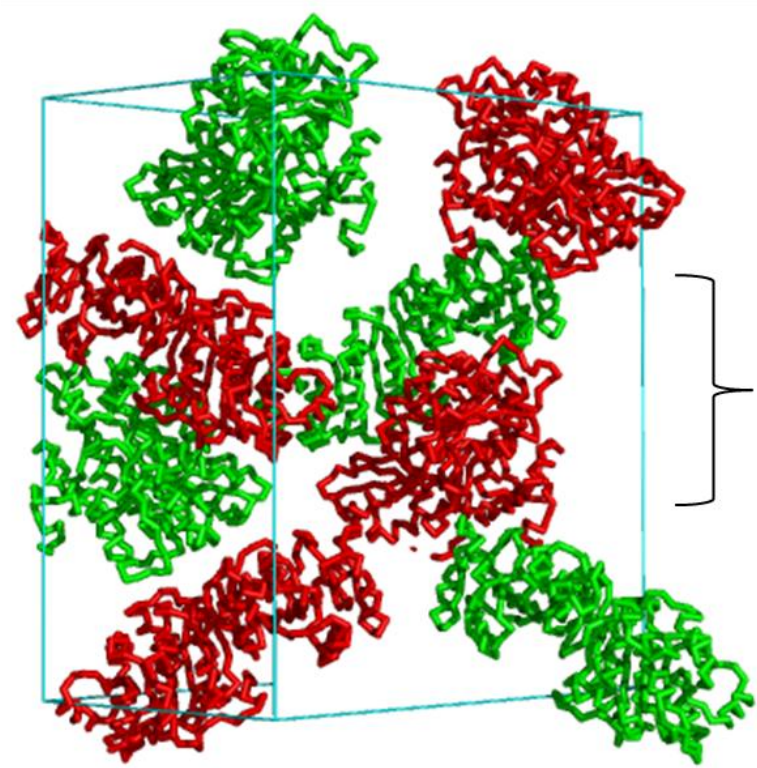

B

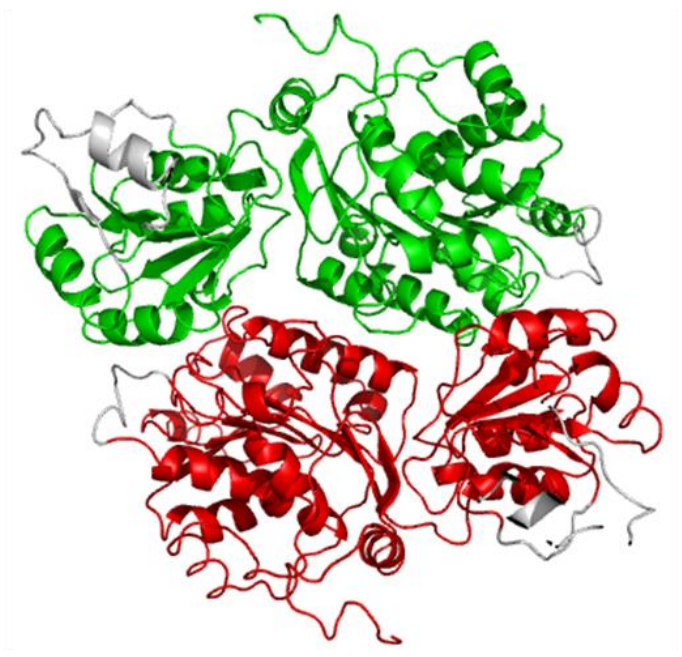

Abb. 4.2: Kristallpackung von DEAD2. Zur besseren Übersicht sind die Proteine abwechselnd rot und grün dargestellt. (A) Einheitszelle der Raumgruppe C222 1 mit acht DEAD2-Proteinen. (B) Dimer innerhalb der Kristallpackung. Die Interaktionen zwischen jeweils zwei DEAD2-Proteinen sind besonders ausgeprägt. Grau: Im Modell von DEAD2 fehlende Sequenzbereiche.

Die Auflösung einer durch Röntgenstrukturanalyse erhaltenen Elektronendichte wird davon bestimmt, wie geordnet die Proteine innerhalb des Kristallgitters vorliegen. Die DEAD2Kristalle zeigten bei der Datensammlung ein anisotropes Streuverhalten (3.3.5.2). Die Auflösung in Richtung der a-Achse der Einheitszelle war nur 2,6 Å, während sie in Richtung der b-und c-Achse 2,2 A betrug. Dies zeigt, dass die Position der Proteinmoleküle entlang der a-Achse offensichtlich flexibler war als entlang der anderen Achsen. Die Analyse der Kristallpackung macht die Ursache dafür sichtbar (Abb. 4.3). In Richtung der b- und c-Achse wird die Kristallpackung durch intensive Kontakte zwischen den Proteinen stabilisiert. In Richtung der a-Achse aber sind diese Kontakte sehr begrenzt.

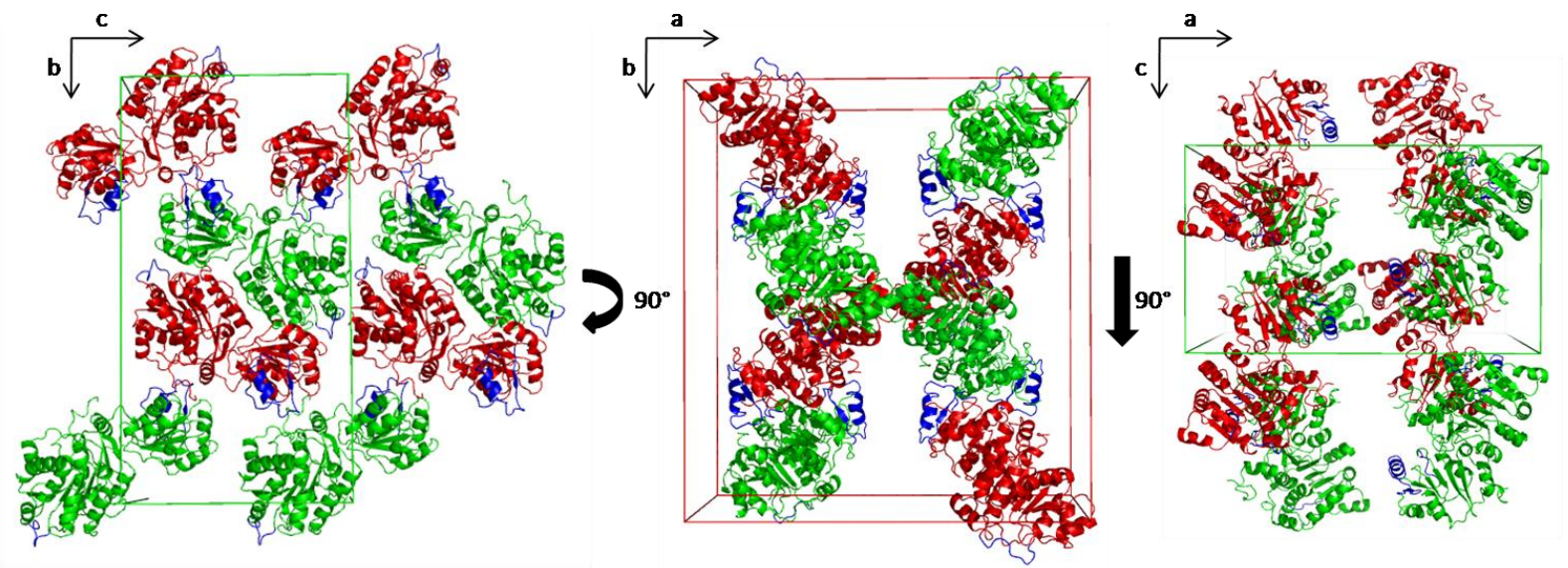

Abb. 4.3: Die Kristallpackung aus drei verschiedenen Perspektiven. Die DEAD2-Proteine sind abwechselnd rot und grün dargestellt. Die Abmessung der Einheitszelle ist in grün oder rot dargestellt. Blaue Bereiche der DEAD2-Modelle sind in der Elektronendichte aufgrund von hoher Flexibilität nicht sichtbar.

Diese relativ lockere Kristallpackung ist vermutlich auch die Ursache dafür, dass die Elektronendichte in vielen Bereichen schwierig $\mathrm{zu}$ interpretieren war und darum die Verfeinerung des Modells für DEAD2 noch nicht abgeschlossen ist (3.3.5.3). Durch fehlende 
Kontakte im Kristallgitter sind nämlich einzelne Teile des Proteins offensichtlich sehr flexibel und darum in der Elektronendichte nur schwach oder gar nicht sichtbar. Diese Flexibilität betrifft einerseits verschiedene Aminosäuren auf der Proteinoberfläche, bei denen die Konformation der Seitenkette unklar ist (rote Bereiche in Abb. 3.29A). Besonders problematisch sind allerdings die Sequenzabschnitte 690-715 und 723-729 in der Cterminalen Subdomäne. Für diesen Bereich ist nur sehr begrenzt Elektronendichte sichtbar, so dass er im bisherigen Strukturmodell von DEAD2 fehlt. In der Abb. 4.3 erkennt man, dass der entsprechende Abschnitt des Proteins (blau) dem Lösungsmittel zugewandt ist und somit kaum Kontakte mit benachbarten Proteinmolekülen eingeht. Um ein besseres Strukturmodell von DEAD2 zu erhalten, wären Kristalle hilfreich, in denen die Proteine in einer anderen Packung vorliegen, so dass die Interaktionen zwischen den Molekülen im Kristallgitter intensiver sind. Alternative Kristallformen von DEAD2 wurden jedoch nicht erhalten.

Hohe Flexibilität in der C-terminalen Helikasesubdomäne wurden auch bei der Strukturlösung von eIF4A als Volllängenprotein beobachtet (Caruthers et al. 2000). Dort wurde die Struktur der CTD erst aufgeklärt, nachdem sie getrennt von der NTD kristallisiert worden war. Möglicherweise könnte dasselbe Vorgehen auch bei hPrp28 zu einem besseren Modell der Helikasedomäne führen.

Die Ursache für die Flexibilität der CTD von DEAD2 ist vermutlich auch die fehlende Interaktion mit Substraten bzw. mit der NTD. Entsprechend könnten Kristalle, die zusätzlich ein RNA-Substrat enthalten oder in denen die Subdomänen in einer geschlossenen relativen Orientierung vorliegen, eine bessere Grundlage für die Strukturlösung bieten.

\subsubsection{Schwermetallderivatisierung}

Um die Struktur des DEAD2-Fragments zu lösen, musste ein Schwermetallderivat der Kristalle hergestellt werden (3.3.5.2.2). Die hohe Ammoniumsulfatkonzentration und der basische $\mathrm{pH}-$ Wert im Kristallisationspuffer waren dabei schwierige Voraussetzungen, da unter diesen Umständen nukleophiles Ammoniak entsteht, das die Schwermetallionen maskiert (Sigler und Blow 1965). Dementsprechend wurde eine große Anzahl an verschiedenen Substanzen getestet, bevor schließlich ein Derivat mit Phenylquecksilberacetat erhalten werden konnte.
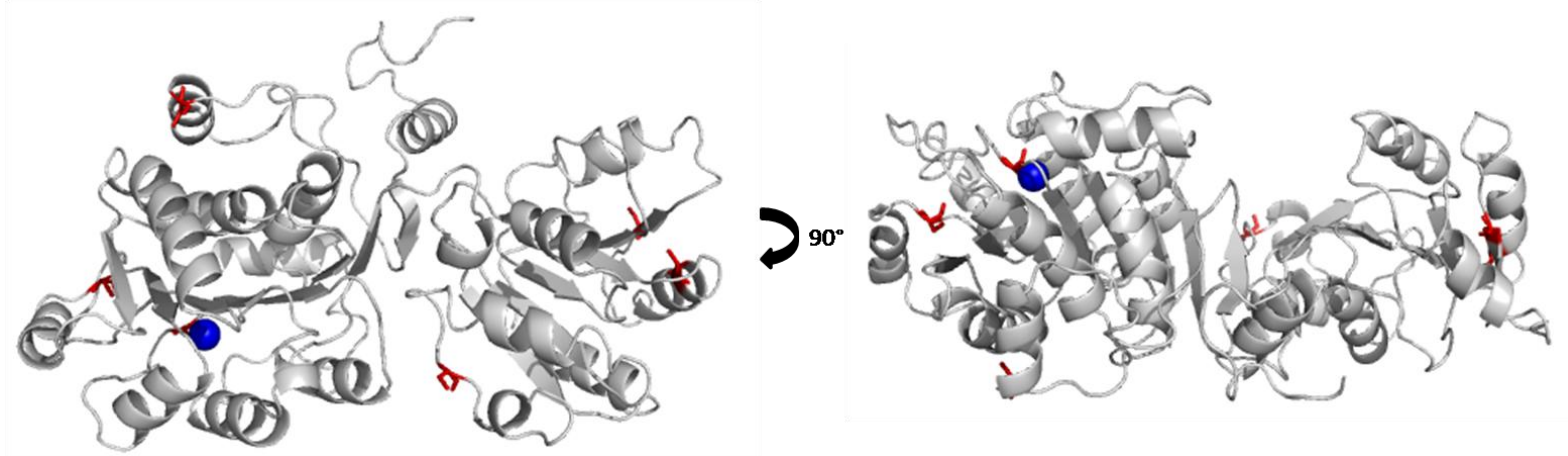

Abb. 4.4: Die Lage der sechs Cysteine (rot) im DEAD2-Fragment. Darstellung in zwei verschiedenen Orientierungen. Nur das relativ im Inneren des Proteins gelegene Cystein 543 band ein Quecksilberion (blau). 
Quecksilber bindet üblicherweise an Proteine, indem es eine kovalente Bindung mit der Sulfhydrylgruppe eines Cysteins eingeht. Das DEAD2-Fragment enthält sechs Cysteine, jedoch reagierte nur Cystein 543 mit dem Quecksilber. Dieses Cystein liegt ziemlich weit im Inneren des Proteins, während sich die übrigen Cysteine eher an der Oberfläche befinden und darum eigentlich für eine Derivatisierung besser zugänglich sind (Abb. 4.4). Vermutlich ermöglichte erst die besondere chemische Umgebung im Protein die Reaktion mit dem Quecksilber, da seine Reaktivität unter diesen Bedingungen größer war als im Kristallisationspuffer.

\subsection{Die ATPase-Aktivität von hPrp28}

Die Helikasedomäne von hPrp28 umfasst die Aminosäuren 378-800 und damit die Cterminale Hälfte des Proteins. Ihre Aminosäuresequenz enthält alle konservierten Motive der DEAD-Box Proteinfamilie (1.1.1). Das weist darauf hin, dass hPrp28 in vivo eine ATPaseAktivität besitzt. Bestätigt wurde dies durch erste vorläufige Ergebnisse aus Mutationsstudien (3.5.3). Demnach führte die Mutation von Aminosäuren in Motiv I oder II zu einem Spleißarrest. Die mutierten Reste sind für die ATP-Bindung bzw. -Hydrolyse essentiell (Rozen et al. 1989, Hotz und Schwer 1998, Schneider et al. 2002). Jedoch hatte hPrp28 oder sein DEAD2-Fragment in vitro keine ATPase-Aktivität (3.3.2), weder in Ab- noch Anwesenheit von RNA. Dieses Verhalten ist ungewöhnlich, da andere DEAD-Box Proteine in vitro in den meisten untersuchten Fällen eine ATPase-Aktivität zeigen. Die Aktivität wird außerdem häufig durch RNA erhöht (Übersicht in Cordin et al. 2005). Im Fall von hPrp28 ist dagegen zur Aktivierung offenbar mehr als RNA notwendig. Vermutlich wird es erst nach Bindung an bestimmte Interaktionspartner innerhalb des Spleißosoms aktiv.

Die fehlende Aktivität des isolierten hPrp28 bzw. seiner Orthologe wurde in anderen Arbeiten bestätigt. Für Prp28 aus S. cerevisiae konnte in vitro keine eindeutige ATPase Aktivität nachgewiesen werden. Entsprechend zeigte es auch keine Helikaseaktivität, die eine ATPaseAktivität voraussetzt (Strauss und Guthrie 1994). Zudem wurde für humanes hPrp28, das aus HeLa-Zellkernextrakt isoliert worden war, keine Helikaseaktivität beobachtet (Laggerbauer et al. 1998).

Es stellt sich die Frage nach der Ursache für die fehlende in vitro Aktivität von hPrp28. Erklärungen lieferten die Untersuchung der Interaktion mit ATP und ADP sowie die molekulare Struktur der Helikasedomäne von hPrp28.

\subsection{1 hPrp28 bindet in vitro kein ATP}

Voraussetzung für eine ATPase-Aktivität ist die Bindung von ATP. In Untersuchungen (3.3.3) mit zwei verschiedenen Methoden, Fluoreszenztitration und isothermer Titrationskalorimetrie (ITK), zeigte das DEAD2-Fragment von hPrp28 aber keine nachweisbare Interaktion mit ATP. Allerdings sind die verwendeten Methoden nur geeignet, um Dissoziationskonstanten von bis zu $100 \mu \mathrm{M}$ zu bestimmen. Darüber hinaus werden die Fehlerquellen $\mathrm{zu}$ groß (s.u.). Bei anderen DEAD-Box Helikasen liegen die Dissoziationskonstanten für die Interaktion mit ATP zwischen $50 \mu \mathrm{M}$ und $1000 \mu \mathrm{M}$ (Cordin 
et al. 2005). Es könnte also sein, dass mit sensitiveren Methoden eine Interaktion zwischen ATP und DEAD2 nachweisbar ist.

Für ADP hingegen war die Bindung an DEAD2 detektierbar und es ergaben sich Dissoziationskonstanten von 24 $\pm 2,5 \mu \mathrm{M}$ (Fluoreszenztitration) bzw. 50-70 $\mu \mathrm{M}$ (ITK). Offensichtlich kann DEAD2 folglich zwar Adeninnukleotide binden, jedoch liegt die Bindestelle in vitro in einer Konformation vor, die die Bindung des Triphosphats weitgehend ausschließt.

Für die Dissoziationskonstante von ADP ergaben sich mit den beiden Methoden unterschiedliche Werte. Die Messung von Dissoziationskonstanten im mikromolaren Bereich ist mit den Methoden relativ ungenau, da für die Detektion dieser schwachen Interaktionen hohe Konzentrationen an Protein oder Ligand verwendet werden müssen.

Bei der Fluoreszenztitration führen hohe Ligandenkonzentrationen zu einem hohen inner filter effect (2.2.2.10.1.2). Die Anwendung von Korrekturfaktoren, um diesen Effekt auszugleichen, beruht auf Näherungen, die mit zunehmendem inner filter effect ungenauer werden (Birdsall et al. 1983).

Bei der ITK ist besonders problematisch, dass für die Berechnung die genaue Konzentration der Proteine bekannt sein muss. Zur Bestimmung wurde die Methode von Gill und Hippel verwendet, bei der es sich aber nur um eine Näherung handelt (Pace et al. 1995). Außerdem mussten relativ hohe Proteinkonzentrationen eingesetzt werden. Dadurch nahm die Neigung zur Bildung unspezifischer Aggregate zu. Zudem führte das Rühren während der Messung zur teilweisen Denaturierung der Proteine. Nach den Messungen wurden entsprechend stets Präzipitate in der Lösung beobachtet. Dadurch war die effektive Konzentration des Proteins kleiner als angenommen.

Die Aufklärung der molekularen Struktur des DEAD2-Fragments von hPrp28 gab Einblick in die Ursache für die fehlende Bindung von ATP (3.3.5.4). Es wurde gezeigt, dass die Konformation eines Aminosäureabschnitts, der als P-Schleife bezeichnet wird und die Reste des konservierten Motivs I umfasst, mit der dritten Phosphatgruppe eines in die NukleotidBindestelle modulierten ATP-Analogons kollidieren würde. Die Bindung von ADP wäre dagegen entsprechend möglich.

Eine „geschlossene“ Konformation der P-Schleife wurde auch in anderen Strukturen von DExD/H-Box Helikasen gefunden. Allerdings wird davon ausgegangen, dass sich die PSchleife öffnet, sobald ein Nukleotid bindet. Dies ist direkt in den Strukturen von eIF4A und UAP56 sichtbar, die jeweils mit und ohne Nukleotid kristallisiert wurden (Caruthers et al. 2000, Benz et al. 1999, Shi et al. 2004). Ein Vergleich mit den P-Schleifen bei dem DEAD2Fragment und bei Vasa ist in Abb. 4.5 dargestellt. Erkennbar ist, dass die Konformation der PSchleife in allen Fällen sehr unterschiedlich ist. Die Ursache für diese Flexibilität ist vermutlich der hohe Glycingehalt dieses Aminosäureabschnitts. Die Struktur von Vasa, das zusammen mit einem ATP-Analogon kristallisiert wurde (Sengoku et al. 2006), ist maximal geöffnet. Die Konformation bei DEAD2 ist dagegen mit den geschlossenen P-Schleifen von UAP56 und eIF4A in Abwesenheit eines Nukleotids vergleichbar. 

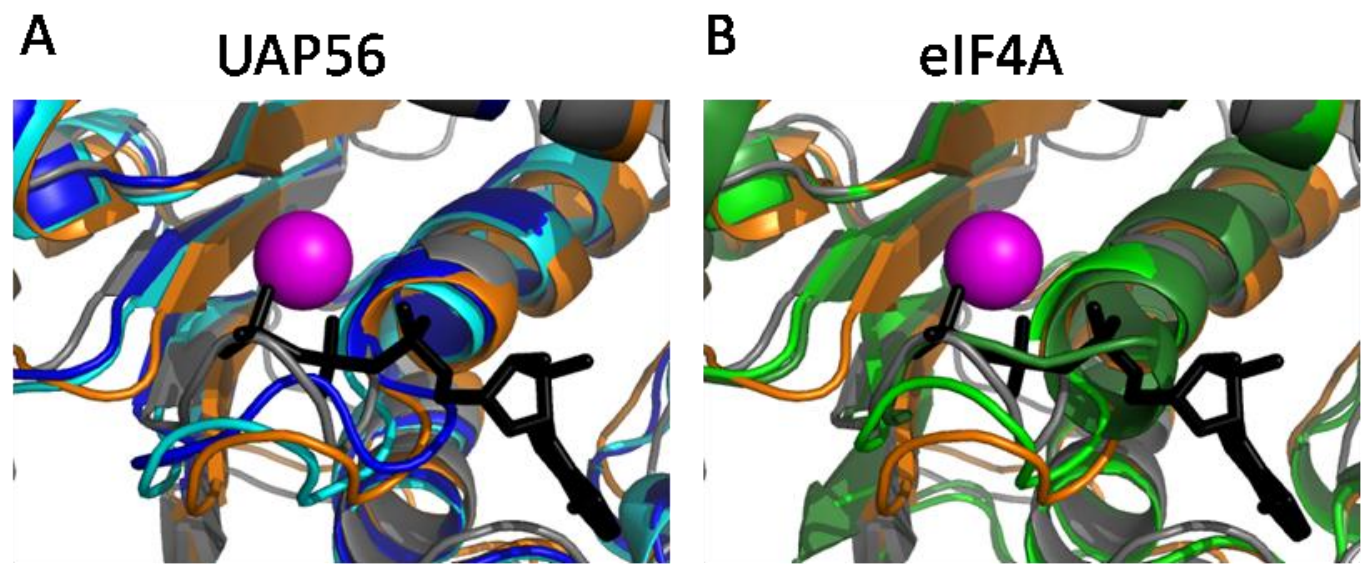

Abb. 4.5: Strukturelle Überlagerung der P-Schleife von verschiedenen DExD/H-Box Proteinen. Grau bzw. orange dargestellt sind die Strukturen von DEAD2 bzw. Vasa (Sengoku et al. 2006, PDB-Eintrag 2DB3). Außerdem ist das $\mathrm{Mg}^{2+}$-Ion (violett) und ATP (schwarz) aus der Struktur von Vasa abgebildet. (A) Vergleich mit Strukturen von UAP56. Dunkelblau: ohne Nukleotid (PDB-Eintrag 1XTI). Hellblau: mit gebundenem ADP (PDB-Eintrag 1XTJ). (B) Vergleich mit Strukturen von eIF4A. Dunkelgrün: ohne Nukleotid (PDB-Eintrag 1FUU). Hellgrün: mit gebundenem ADP (PDB-Eintrag 1QDE).

UAP56 und eIF4A haben in vitro eine schwache ATPase-Aktivität, die durch RNA stimuliert wird (Shi et al. 2004, Korneeva et al. 2004). DEAD2 hingegen zeigt auch in Anwesenheit von RNA keine ATPase-Aktivität (3.3.2) oder ATP-Bindung (3.3.3.1.2). Die geschlossene Konformation der P-Schleife ist in hPrp28 also ungewöhnlich stabil. Eine detailierte Analyse von Interaktionen zwischen der P-Schleife und benachbarten Resten, die seine Konformation stabilisieren könnten, ist auf der Grundlage des vorläufigen Modells nicht möglich, da die PSchleife zu denjenigen Bereichen der Struktur von DEAD2 gehört, für die die genaue Konformation der Seitenketten noch unklar ist (3.3.5.3).

Eine Öffnung der ATP-Bindestelle erfordert bei hPrp28 offenbsichtlich nicht nur die Bindung von RNA, sondern von weiteren Cofaktoren. In ähnlicher Weise ist für eIF4A beobachtet worden, dass seine ATPase- und Helikaseaktivität durch Cofaktoren deutlich gesteigert wird (Rogers et al. 2001, Korneeva et al. 2004). Solche Cofaktoren für hPrp28 befinden sich vermutlich innerhalb des Spleißosoms. Allerdings genügt die Bindung an das U4/U6.U5 trisnRNP offensichtlich nicht. Denn in tri-snRNP Partikeln, die aus humanem Zellkernextrakt isoliert worden waren, wurde zwar ein deutliches crosslinking zwischen hBrr2 und radioaktiv markiertem ATP beobachtet, das durch Zugabe von RNA noch verstärkt wurde. Hingegen wurde für ein $100 \mathrm{kDa}$ umfassendes Protein, bei dem es sich vermutlich um hPrp28 handelt, nur ein sehr schwaches crosslinking detektiert, das auch nicht durch RNA stimuliert wurde. Möglicherweise handelt es sich hierbei zudem nicht um eine Bindung von ATP, sondern von bei der Inkubation entstandenem ADP (Laggerbauer et al. 1996). Offensichtlich wird also die ATP-Bindestelle von hPrp28 erst aktiviert, wenn das tri-snRNP mit dem A-Komplex interagiert.

Bei eIF4A wird davon ausgegangen, dass die Cofaktoren die Helikase u.a. dadurch aktivieren, dass sie die Orientierung der Subdomänen zueinander in einer aktiven Konformation stabilisieren (Oberer et al. 2005). In ähnlicher Weise könnte auch bei hPrp28 eine Aktivierung erreicht werden. Die Umorientierung der Subdomänen könnte dann die Öffnung der ATPBindestelle bewirken (s.u.). 


\subsubsection{Die Helikasesubdomänen bilden kein katalytisches Zentrum}

Das katalytische Zentrum und die RNA-Bindestelle der DExD/H-Box Proteine werden von den konservierten Sequenzmotiven gebildet. Die Motive sind auf die beiden Subdomänen der Helikasedomäne verteilt (1.1.2). Um eine RNA-Bindestelle sowie ein funktionelles ATPaseZentrum zu bilden, müssen die Subdomänen eine relative Orientierung zueinander haben, in der die entsprechenden Aminosäuresequenzmotive räumlich zusammenliegen. Diese katalytisch aktive Konformation wird durch die molekulare Struktur von Vasa repräsentiert, das zusammen mit einem RNA-Substrat und einem ATP-Analogon kristallisiert wurde (Abb. 1.1, Sengoku et al. 2006).

Die Orientierung der Subdomänen des DEAD2-Fragments weicht erheblich von dieser aktiven Konformation ab. Die konservierten Sequenzmotive sind weit voneinander entfernt und bilden folglich kein katalytisches Zentrum (3.3.5.4). Diese Konformation könnte also neben der Konformation der P-Schleife - eine weitere Ursache für die fehlende ATPaseAktivität von hPrp28 sein.

Vergleicht man die Strukturen verschiedener DExD/H-box Helikase, so ist die relative Orientierung der Subdomänen sehr unterschiedlich. Dies verdeutlicht die Abb. 4.6, in der die N-terminalen Subdomänen jeweils übereinandergelegt wurden.

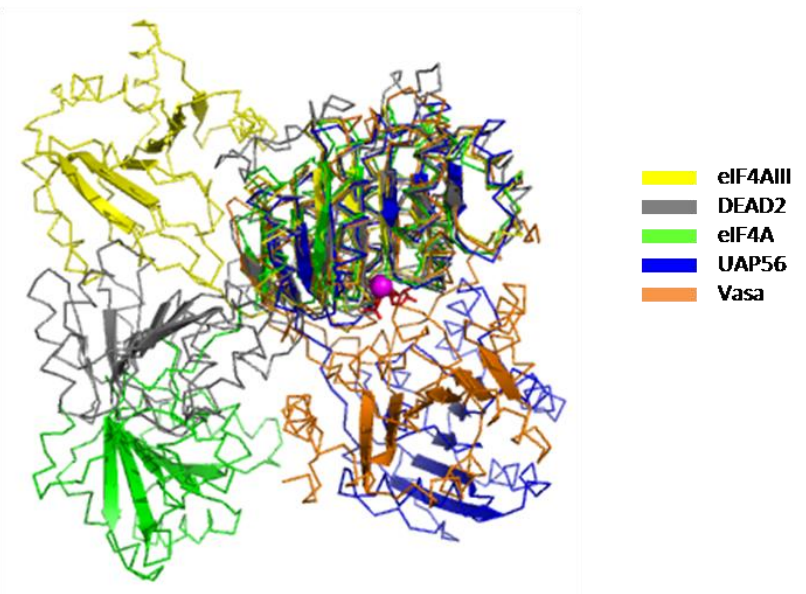

Abb. 4.6: Überlagerung der N-terminalen Domäne verschiedener DExD/H-Box Proteine. Gelb: eIF4AIII (PDB-Eintrag 2HXY). Grau: DEAD2-Fragment von hPrp28. Grün: eIF4A (1FUU). Blau: UAP56 (1XTI). Orange: Vasa (2DB3). Vasa repräsentiert die katalytisch aktive Konformation. In violett bzw. rot sind das an Vasa gebundene $\mathrm{Mg}^{2+}$ bzw. ADPNP gezeigt.

Offensichtlich ist ein sehr breites Spektrum inaktiver Konformationen für DExD/H-Box Helikasen möglich. Unterschiedliche Konformationen könnten die spezifische Erkennung der jeweiligen Helikase durch Cofaktoren ermöglichen. Insbesondere bei den sehr offenen Orientierungen ist aber die Interaktionsfläche zwischen den beiden Subdomänen sehr gering. Möglicherweise kommen die unterschiedlichen Konformationen daher aufgrund der Kristallpackung zustande, während in Lösung die Orientierung der Subdomänen flexibel ist (Caruthers et al. 2000). Bei DEAD2 wird die Konformation vermutlich durch Dimerinteraktionen innerhalb des Kristalls stabilisiert (4.2.1).

Damit DEAD2 ein katalytisch aktives Zentrum ausbilden kann, müssen sich seine Subdomänen analog zu der Struktur von Vasa anordnen. Diese aktive Konformation wurde durch entsprechende Drehung der C-terminalen Subdomäne moduliert. Die Drehung ist ohne sterische Hindernisse möglich. Sowohl die Insertion in der NTD von hPrp28 als auch die Nterminal an die Helikasedomäne anschließende Sequenz befinden sich an Positionen, die diese 
Bewegung zulassen (Abb. 4.7A). Analog zu der Struktur von Vasa liegen die Motive Q, I, II und VI in der geschlossenen Konformation von DEAD2 in räumlicher Nähe und bilden folglich die ATP-Bindestelle (Abb. 4.7B). Da sich die P-Schleife an der Kontaktstelle zwischen den beiden Subdomänen befindet, könnte sie durch Interaktionen mit Resten der CTD eine offene Konformation annehmen, die dann ATP-Bindung ermöglicht.
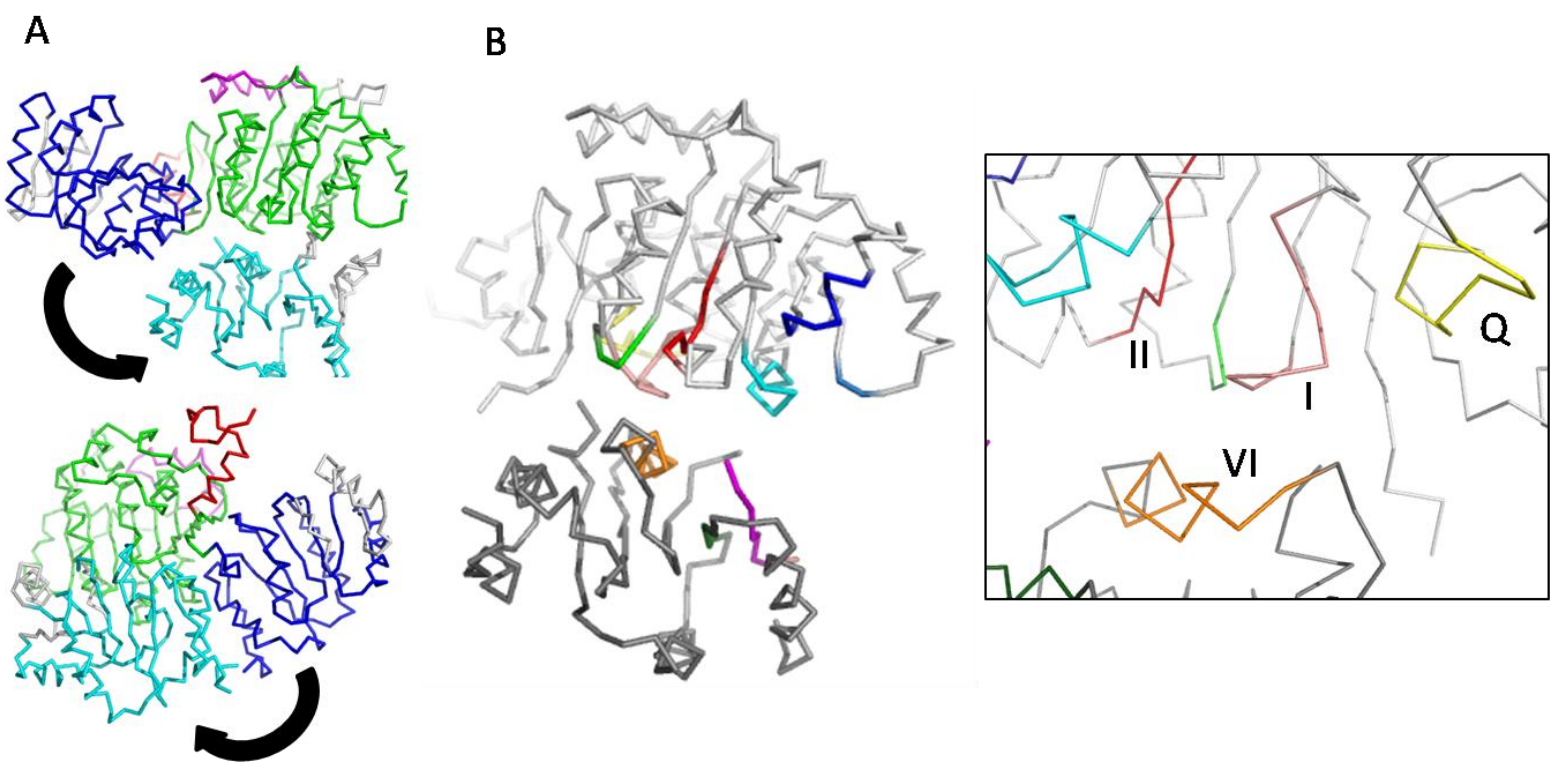

Abb. 4.7: Modulierung der geschlossenen, aktiven Konformation des DEAD2-Fragments von hPrp28. (A) Die C-terminale Subdomäne wurde um ca. $180^{\circ}$ gedreht. Die Darstellungen aus zwei verschiedenen Perspektiven zeigen, dass weder die Insertion (violett) noch die N-terminal anschließende Sequenz (rot) die Drehung behindern. Grün: NTD. Dunkelblau bzw hellblau: CTD vor bzw. nach Drehung. Grau: Fehlende Sequenzbereiche des Modells. (B) Hervorhebung der Position der konservierten Sequenzmotive in der geschlossenen Konformation. Dargestellt sind nur die in der Elektronendichte sichtbaren Bereiche des Modells. Farbkodierung siehe Abb. 3.30. Motiv Q, I, II und VI liegen in räumlicher Nähe zueinander. Hellgrau: NTD. Dunkelgrau: CTD.

\subsection{RNA-Bindung durch die Helikasedomäne von hPrp28}

Die RNA-Bindestelle der DEAD-Box Helikasen wird von mehreren konservierten Sequenzmotiven gebildet, die sich sowohl auf der NTD als auch der CTD befinden (1.1.1). In den Strukturen von zwei DEAD-Box Proteinen, Vasa und eIF4AIII, wurden dabei die gleichen Interaktionen mit einem kokristallisiertem einzelsträngigem RNA-Molekül beobachtet (Sengoku et al. 2006, Bono et al. 2006, Andersen et al. 2006). In der Struktur von Vasa wurden sieben Nukleotide der RNA von der Helikase gebunden. Die Bindung erfolgte sequenzunspezifisch über das Ribose-Phosphat-Rückgrat. Aminosäurereste von Motiven auf der CTD (IV, QxxR, V) bzw. NTD (Ia, GG, Ib) interagierten mit Nukleotid 1-5 bzw. 4-7. Durch die Konformation der $\alpha$-Helix, auf der sich das Sequenzmotiv Ib befindet, wurde eine starke Biegung der RNA beobachtet, die dazu führte, dass zwischen Nukleotid fünf und sechs keine Basenstapelung auftrat. Es wird vermutet, dass Vasa durch Erzeugung dieser Biegung eine RNA-Doppelhelix destabilisiert (Sengoku et al. 2006).

In der Struktur des DEAD2-Fragments sind diejenigen Bereiche der CTD, die in Analogie zu Vasa an der RNA-Bindung beteiligt sind, weitgehend nicht sichtbar. Vermutlich ist ihre Konformation folglich in Abwesenheit von RNA flexibel. Der Sequenzbereich des QxxR- 
Motivs fehlt vollständig. Für Motiv IV und einen Teil von Motiv V ist zwar Elektronendichte sichtbar, jedoch ist die Konformation der Seitenketten unsicher (3.3.5.3). Die Struktur der RNA-bindenden Motive auf der NTD ist dagegen gut definiert.

Ein Vergleich mit Vasa zeigt, dass im DEAD2-Fragment alle Aminosäuren von Motiv Ia und $\mathrm{Ib}$, die direkt an der RNA-Bindung beteiligt sind, konserviert sind. Zudem liegen sie in der Struktur an nahezu exakt derselben Stelle (Abb. 4.8). Diese Reste sind hauptsächlich für die Biegung der RNA in der Vasa-Struktur verantwortlich. Insbesondere ist die Position der $\alpha$ Helix, auf der Motiv Ib liegt, in beiden Strukturen gleich. Daraus folgt, dass vermutlich auch hPrp28 bei der Bindung an RNA eine Biegung erzeugt.
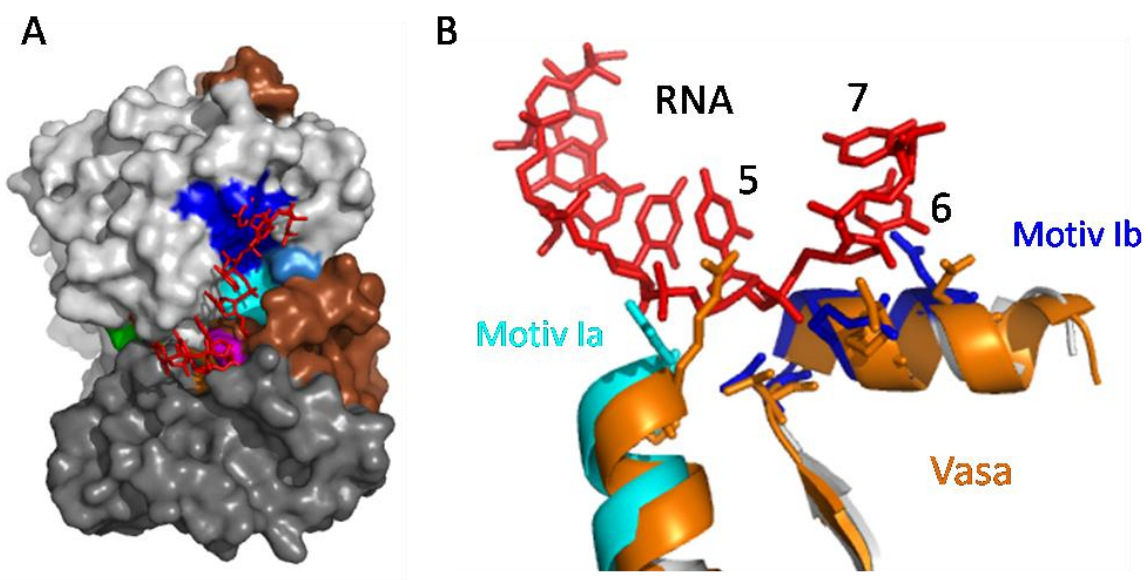

Abb. 4.8: Die RNA-Bindestelle der Helikasedomäne von hPrp28. Die Lage des RNA-Moleküls ( $\mathrm{U}_{7}-\mathrm{RNA}$, rot) wurde der Struktur von Vasa entnommen (Sengoku et al. 2006). Die konservierten Sequenzmotive sind entsprechend Abb. 3.30 gefärbt. (A) Oberflächendarstellung. In der geschlossenen Subdomänen-Konformation bilden Motive der NTD (hellgrau) und CTD (dunkelgrau) gemeinsam die RNA-Bindestelle auf der Oberfläche von DEAD2. Braun dargestellt sind Sequenzbereiche, deren Struktur nicht in der Elektronendichte sichtbar ist. Zur Vollständigkeit ist ihre ungefähre Lage angegeben. Die fehlenden Sequenzbereiche betreffen insbsondere Motive der CTD, die an der RNA-Bindung beteiligt sind. (B) Detailierte Darstellung der RNA-Bindung durch Motiv Ia (hellblau) und Ib (dunkelblau) der NTD von DEAD2. Zum Vergleich ist die Struktur von Vasa überlagert (orange). Sichtbar sind die Seitenketten derjenigen Aminosäuren, die in Vasa Interaktionen mit der RNA eingehen. Alle diese Reste sind in hPrp28 konserviert. Die Bindung erzeugt eine Biegung der RNA zwischen Nukleotid fünf und sechs.

Allgemein wird davon ausgegangen, dass DExD/H-Box Proteine sequenzunspezifisch mit RNA interagieren. Dies ist für Proteine wie beispielsweise eIF4A und eIF4AIII sinnvoll, da diese Helikasen als Translationsfaktor bzw. als Bestandteil des exon junction-Komplexes (Bono et al. 2006, Andersen et al. 2006) viele unterschiedliche RNA-Abschnitte binden müssen. Die spleißosomalen DExD/H-Box Proteine haben im Gegensatz dazu ein einzelnes bestimmtes RNA-Substrat. Darum wäre es möglich, dass sie RNA sequenzspezifisch binden können. Für Prp5 aus Saccharomyces cerevisiae wurde entsprechend gezeigt, dass seine ATPase-Aktivität durch U2 snRNA etwa siebenfach stärker aktiviert wird als durch eine Vielzahl anderer getesteter RNA-Substrate (O’Day et al. 1996).

Um eine mögliche Spezifität der Helikasedomäne von hPrp28 zu untersuchen, wurden mit verschiedenen RNA-Molekülen und dem DEAD2-Fragment Interaktionsstudien durchgeführt (3.3.4). Das genaue RNA-Substrat von hPrp28 in vivo ist noch unbekannt, aber vermutlich umfasst es die 5'-Spleißstelle und die damit gepaarte U1 oder U6 snRNA (1.3). Es wurde untersucht, ob DEAD2 und entsprechende RNA-Moleküle bei einer Gelfiltration gemeinsam die Säule durchwandern. 
Keine Interaktion wurde detektiert mit einer RNA, die lediglich die Sequenz der 5'Spleißstelle umfasste (,5'SS-RNA“). Wurde diese Sequenz dagegen zu einer HaarnadelStruktur erweitert, die das Duplex aus der 5'-Spleißstelle und der U6-snRNA enthielt, fand eine starke Bindung an DEAD2 statt (,5'SS-U6-RNA“). Ein entsprechendes Duplex aus der 5'-Spleißstelle und der U1 snRNA zeigte nur eine schwache Interaktion (,5'SS-U1-RNA“). Eine mögliche Folgerung ist, dass hPrp28 im Spleißosom spezifisch das Duplex aus der 5'Spleißstelle und der U6 snRNA erkennt. Diese Interpretation würde mit Ergebnissen von Ismaili et al. (2001) übereinstimmen. Dort wurde ein crosslink zwischen hPrp28 und der Intronposition +7 einer prä-mRNA nachgewiesen, der abhängig von der U6 snRNA, nicht aber der U1 snRNA war (1.3). Demnach könnte eine Funktion von hPrp28 sein, das Duplex aus 5'-Spleißstelle und U6 snRNA zu stabilisieren.

Gegen eine sequenzspezifische Bindung spricht allerdings, dass DEAD2 auch Interaktionen mit einem großen Anteil eines RNA-Gesamtextrakts aus Hefezellen zeigt.

Die Ergebnisse aus den Interaktionsstudien könnten zudem nur eine Korrelation zwischen Bindungsstärke und RNA-Länge wiedergeben. Denn die drei RNA-Substrate unterscheiden sich in ihrer Länge. Während die 5'SS-RNA nur zehn Nukleotide enthält, umfassen die 5'SSU1- und 5'SS-U6-RNA 25 bzw. 33 Nukleotide. Entsprechend zeigten Studien mit der DEAHBox Helikase Prp22, dass erst ab einer Nukleotidlänge von zwanzig eine deutliche Bindung der RNA und eine Stimulation der ATPase-Aktivität detektierbar wurde (Tanaka und Schwer 2005). Die Ursache dafür ist unklar, da verschiedene Kristallstrukturen von RNA- und DNAHelikasen zeigten, dass die Helikasedomänen nur mit einer Sequenz aus bis zu acht Nukleotiden eine feste Bindung eingehen (Sengoku et al. 2006, Bono et al. 2006, Andersen et al. 2006, Korolev et al. 1997, Kim et al. 1997). Offensichtlich finden über die in den Strukturen sichtbaren Kontakte hinaus noch weitere Interaktionen statt. Für hPrp28 ergibt sich aus den Studien dann entsprechend der 5'SS-U1-snRNA eine Mindestlänge von 25 Nukleotiden. Mit einer Poly-Uridin RNA aus 20 Nukleotiden wurde nämlich ebenfalls keine Interaktion detektiert.

Bei der Analyse der Gelfiltrationen durch SDS-PAGE konnte lediglich die 5'SS-U6-RNA sichtbar gemacht werden, die übrigen spezifischen RNA-Moleküle wurden offensichtlich vor oder während der Gelelektrophorese degradiert (3.3.4). Eine Degradation könnte darum auch erklären, warum keine Interaktion mit DEAD2 detektiert wurde. Allerdings fand diese Degradation vermutlich erst nach der Gelfiltration statt. Degradierte RNA hätte die Säule nämlich zusammen mit den Pufferbestandteilen der aufgetragenen Probe verlassen. Im Gegensatz dazu wurden für die RNA-Moleküle UV-Absorptionsmaxima beobachtet, deren Elutionsvolumina entsprechend ihrer Größe variierten. Folglich fand die Degradation vermutlich erst während der Gelelektrophorese statt.

Die 5'SS-U1- und 5'SS-U6-RNA sollten unter den Bedinungen, die für die Interaktionsstudien gewählt wurden, als Haarnadelstrukturen vorliegen. Die Basenpaarungen in der 5'SS-U6-RNA sind dabei etwas stabiler als diejenigen in der 5'SS-U1-RNA (3.3.4). Folglich korreliert also die Stärke der Interaktion mit DEAD2 auch mit der DoppelhelixStabilität. Daraus ergibt sich die interessante Möglichkeit, dass DEAD2 spezifisch an doppelsträngige RNA bindet. Allerdings bewirkt die Interaktion mit der RNA-Bindestelle in Analogie zu Vasa vermutlich eine Biegung der RNA, die nicht mit einer DoppelhelixKonformation vereinbar ist. Darum bindet DEAD2 möglicherweise an dem Übergang 
zwischen Duplex und einzelsträngiger RNA. Der doppelsträngige Bereich würde entsprechend von den Motiven auf der CTD gebunden werden, während sich der Übergang zum einzelsträngigen Bereich zwischen Motiv Ia und Ib auf der NTD befindet. Es stellt sich allerdings die Frage, wie die Helikasedomäne von hPrp28 doppelsträngige RNA erkennt. Bisher gibt es nur Kristallstrukturen von DExD/H-Box Helikasen im Komplex mit einzelsträngiger RNA. Die Struktur von DEAD2 lässt auch keine Hypothesen hinsichtlich der Erkennung einer doppelsträngigen RNA zu, da gerade derjenige Bereich der Helikasedomäne, der diese Interaktion eingehen würde, in der Elektronendichte weitestgehend fehlt. Eindeutig geklärt werden kann diese Frage nur, indem die Struktur eines Komplexes mit einer doppelsträngigen RNA aufgeklärt wird. Kristallisationsbedingungen für einen entsprechenden Komplex aus DEAD2 und der 5'SS-U6-RNA wurden jedoch nicht gefunden.

\subsection{Die Insertion in der N-terminalen Helikasesubdomäne von hPrp28}

Eine Besonderheit von hPrp28 und seiner Orthologe ist eine etwa 24 Aminosäuren umfassende Insertion in der N-terminalen Helikasesubdomäne. Strukturell bildet sie eine kleine Kappe auf der Oberfläche der NTD aus, die aus einer $\alpha$-Helix und einer Schleifenregion besteht (3.3.5.4). Diese Kappe fehlt bei anderen DEXD/H-Box Proteinen.

Welche Funktion könnte diese Kappe haben? Sie befindet sich auf der NTD genau auf der entgegengesetzten Seite wie die konservierten Sequenzmotive. Folglich ist sie von den Substrat-Bindestellen weit entfernt. Diese Position schließt eine direkte Beteiligung an der ATP- oder RNA-Bindung aus.

Möglicherweise geht die Kappe Interaktionen mit Bindungspartnern von hPrp28 ein. Bei der Erkennung könnte die auffällige Akkumulation negativ geladener Aminosäuren in der Mitte der Insertion eine wichtige Rolle spielen (Aminosäure 578-586: DTDEAEDPE).

Aufschluss über die Funktion der Kappe könnte das Verhalten einer in dieser Arbeit gereinigten Deletions-Mutante von hPrp28 geben (3.5.3). Vorläufige Ergebnisse beschränken sich auf die Beobachtung, dass diese Proteine keinen negativen Effekt auf die Spleißreaktion haben. Dies könnte einerseits bedeuten, dass die Kappe keine essentielle Funktion für hPrp28 hat. Andererseits könnte die Mutante aber auch nicht in der Lage sein, an das tri-snRNP zu binden. Weitere Experimente mit diesem Protein sollten Einblick in die Funktion der hPrp28spezifischen Kappe geben.

\subsection{Die RS-Domäne von hPrp28}

Die RS-Domäne von hPrp28 befindet sich N-terminal und umfasst bis zu 260 Aminosäuren. Eine typische RS-Domäne wie bei dem SR-Protein ASF/SF2 zeichnet sich durch ArgininSerin-(RS)-Dipeptid Wiederholungen aus, deren Serine in vivo stark phosphoryliert vorliegen. Die „RS“-Domäne von hPrp28 enthält aber nur einen kurzen Bereich (57-65) mit solchen (RS)-Wiederholungen. Vorrangig finden sich dagegen (RD)- und (RE)-DipeptidWiederholungen. Dabei ist gelegentlich das Arginin (R) auch durch ein Lysin (K) ersetzt (Abb. 4.9). Solche modifizierten RS-Domänen sind auch in anderen SR-ähnlichen spleißosomalen Proteinen (1.2.3) vorhanden, beispielsweise in U1-70K, hSad1 (65K) und 
hPpr22. Die negativ geladenen Aminosäuren Aspartat (D) oder Glutamat (E) haben dabei möglicherweise ähnliche Eigenschaften wie ein phosphoryliertes Serin.

Die RS-Domäne von hPrp28 zeigt eine weitere Besonderheit, die zu einer Unterteilung in zwei Abschnitte führt. Die beschriebenen Dipeptid-Wiederholungen befinden sich nämlich vorrangig innerhalb der N-terminalen 125 Aminosäuren. Der zweite Teil der RS-Domäne besteht dagegen hauptsächlich aus kurzen Folgen von negativ (D, E) oder positiv $(\mathrm{R}, \mathrm{K})$ geladenen Aminosäuren. Auch diese Besonderheit findet sich in anderen SR-ähnlichen Proteinen wieder, sie umfasst in hPrp28 allerdings einen ungewöhnlich großen Bereich.

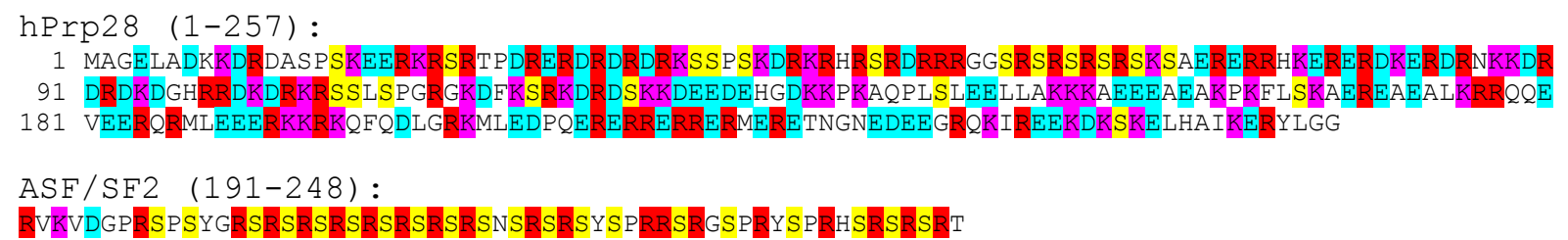

U1-70K (187-437):

WRPRRLGGGLGGTRRGGADVN IRHSGRDDTSRYDERPGPSPLPHRDRDRDRERERRERSRERDKERERRRSRSRDRRRRSRSRDKEERRRSRER
SKDKDRDRKRRSSRSRERARRERERKEELRGGGGDMAEPSEAGDAPPDDGPPGELGPDGPDGPEEKGRDRDRERRRSHRSERERRRDRDRDRDR DREHKRGERGSERGRDEARGGGGGQDNGLEGLGNDSRDMYMESEGGDGYLAPENGYLMEAAPE

Abb. 4.9: Die Aminosäuresequenzen der RS-Domänen von hPrp28, ASF/SF2 und U1-70K. Besondere Aminosäuren sind farblich hervorgehoben: Serin (gelb), Arginin (rot), Lysin (violett), Aspartat und Glutamat (beide blau).

\subsubsection{Reinigung und Kristallisationsversuche}

In dieser Arbeit wurden fünf verschiedene N-terminale Fragmente von hPrp28 gereinigt (RS 1-5), die die gesamte oder Teile der RS-Domäne umfassen (3.2.1). Alle diese Fragmente waren löslich, erforderten während der Reinigung aber einen hohen Salzgehalt $(500 \mathrm{mM}$ $\mathrm{NaCl}$ ), um nicht auf der Gelfiltrationssäule zurückzubleiben. Die Ursache dafür ist vermutlich die Bildung makromolekularer Aggregate aufgrund elektrostatischer Wechselwirkungen zwischen den stark ionischen Proteinen. Diese Wechselwirkungen werden mit zunehmender NaCl-Konzentration destabilisiert. Mehrere experimentelle Ergebnisse weisen auf solche Aggregatbildung hin: Einerseits befinden sich alle N-terminalen Fragmente (RS1-5) von hPrp28 bei einer Gelfiltration mit Superdex 75 als Säulenmaterial im Ausschlussvolumen. Dies sollte eigentlich erst ab einem Molekulargewicht von $75 \mathrm{kDa}$ auftreten, das kleinste Fragment (RS1) umfasst aber rechnerisch nur $17 \mathrm{kDa}$. Bei Verwendung von Superdex 200 als Säulenmaterial, das größere Poren hat, befinden sich die Proteine zwar nicht im Ausschlussvolumen, eluieren jedoch eher von der Säule als es ihrem Molekulargewicht entspricht (3.4.1.1). Weiterhin konnte nach Phosphorylierung der RS-Domäne die während der Reinigung benötigte Salzkonzentration gesenkt werden $(300 \mathrm{mM} \mathrm{NaCl}$, Abschnitt 3.4.2.4). Die Phosphorylierung verändert die Ladungseigenschaften der Fragmente und senkt dadurch möglicherweise bestimmte ionische Wechselwirkungen, so dass die Aggregatbildung instabiler ist. Schließlich wurden in Lösungen des RS3-Fragments bei DLS-Messungen direkt makromolekulare Aggregate beobachtet (3.4.3). Senkte man in konzentrierten Lösungen des RS3-Fragments die Salzkonzentration auf $150 \mathrm{mM} \mathrm{NaCl}$, so wurden diese Aggregate als deutliches Präzipitat sichtbar. 
Kristallisationsversuche konzentrierten sich auf das RS3-Fragment von hPrp28. Dieses umfasst Aminosäure 1-257 und damit die gesamte RS-Domäne. Weder mit noch ohne Phosphorylierung konnten Kristalle erhalten werden. Ursachen könnten sein, dass die RSDomäne ohne Bindungspartner in ihrer Struktur sehr flexibel ist und darum keine geordneten Kristalle bildet. Hinderlich für eine Kristallbildung sind auch die insgesamt eher abstoßenden Kräfte zwischen den positiv geladenen Proteinen. Eine andere Ursache wird hingegen durch die Beobachtung von Aggregaten bei DLS-Messungen sichtbar. Aufgrund von ionischen Interaktionen zwischen entgegengesetzt geladener Aminosäureabschnitte ist die Bildung unspezifischer Aggregate möglich. Solche unspezifischen Aggregate in einer Proteinlösung verringern die Wahrscheinlichkeit, dass sich ein geordnetes Kristallgitter bildet. Darum wäre es vorteilhaft, wenn zunächst Pufferbedingungen für RS3 gefunden werden könnten, in denen keine Aggregate mehr auftreten. Zu diesem Zweck könnten verschiedene Zusätze zugegeben werden und das Ausmaß der Aggregatbildung jeweils über eine DLS-Messung bewertet werden.

Die Aggregatbildung durch die RS-Domäne könnte auch die Ursache dafür sein, dass keine Kristalle von hPrp28 in Volllänge erhalten wurden (3.1.3). RS-Domänen verhinderten bei anderen Proteinen ebenfalls die Kristallisation. So wurde von der Kinase Clk1 nur ein Fragment ohne ihre RS-Domäne kristallisiert (PDB-Eintrag 1z57, Debreczeni et al., unveröffentlicht). Ganz allgemein ist bisher noch keine Struktur einer RS-Domäne bekannt.

Aufgrund der Probleme bei der Kristallisation wurden Vorbereitungen getroffen, um die Struktur des RS3-Fragments alternativ über NMR-Untersuchungen zu bestimmen (3.4.4).

\subsubsection{Phosphorylierung}

Die RS-Domäne von hPrp28 ist in vivo stark phosphoryliert und es lassen sich mehrere verschiedene Phosphorylierungszustände beobachten. Außerdem wurde gezeigt, dass hPrp28 in vitro von Clk1 und einer U1 snRNP-assoziierten Kinase, bei der es sich vermutlich um SRPK1 handelt, phosphoryliert wird (Teigelkamp et al. 1997, Mathew et al., unveröffentlicht). In analoger Weise wurde auch in dieser Arbeit in vitro phosphoryliertes hPrp28 und RS3-Fragment hergestellt (3.4.2.3.2). Dazu wurden allerdings Fragmente von SRPK1 und Clk1 verwendet, die lediglich die Kinasedomäne enthielten (3.4.2.3.1).

Mit beiden Kinasen wurde während der in vitro Phosphorylierung des RS3-Fragments zu jedem Zeitpunkt nur eine Bande bei der SDS-PAGE beobachtet. Das bedeutet, dass alle RS3Fragmente in der Lösung im selben Ausmaß phosphoryliert wurden. Dies zeigt, dass die bei der DLS-Messung beobachteten Aggregate (3.4.3) in ihrer Zusammensetzung dynamisch sein müssen. Würde es sich nämlich um stabile Aggregate handeln, so sollte zumindestens ein Teil der Proteine nicht für die Kinase zugänglich sein und somit unphosphoryliert bleiben.

Das RS3-Fragment wurde ganz allgemein von SRPK1 in stärkerem Ausmaß phosphoryliert als von Clk1. Diese Beobachtung ist ungewöhnlich, da Clk1 im Allgemeinen eine weitgefächertete Substratspezifität aufweist als SRPK1 (Colwill et al. 1996, Velazquez-Dones et al. 2005). Möglicherweise kann Clk1 durch das Fehlen seiner RS-Domäne nicht stabil an hPrp28 binden. Außerdem könnte Clk1 seine RS-Domäne benötigen, um vollständig aktiv zu sein. Im Widerspruch dazu wurde aber gezeigt, dass die Entfernung der RS-Domäne eher eine 
starke Aktivierung der Kinaseaktivität bewirkt (Menegay et al. 2000). Dabei wurden allerdings nur 128 Aminosäuren deletiert, während bei dem in dieser Arbeit verwendeten Clk1-Fragment, dessen Abgrenzung auf der kristallisierten Kinasedomäne (PDB-Eintrag 1z57, Debreczeni et al., unveröffentlicht) beruht, N-terminal 147 Aminosäuren fehlen.

Eine weitere Beobachtung war, dass die Stärke der Phosphorylierung des RS3-Fragments mit der Salzkonzentration des Puffers abnahm. Dies weist darauf hin, dass die RS-Domäne verschiedene Sequenzabschnitte enthält, die von den Kinasen erkannt werden und dass diese sich in ihrer Affinität zur Kinase unterscheiden. Bei hohen Salzkonzentrationen wird dann die Bindung an schwache Erkennungssequenzen unterdrückt. Auf die Existenz getrennt voneinander phosphorylierter Sequenzabschnitte wies auch die Beobachtung hin, dass sich bei der Phosphorylierung mit SRPK1 die Bande von RS3 auf dem SDS-Gel mit der Zeit weiter nach oben bewegte. Da in den Ansätzen das molare Verhältnis von 1:100 zwischen Kinase und RS3 bestand, wurden also offenbar alle in der Proteinlösung vorhandenen RS3-Moleküle zunächst an hochaffinen Sequenzabschnitten phosphoryliert und erst danach an weiteren weniger guten Erkennungssequenzen. Dies zeigt, dass die RS-Domäne von hPrp28 nicht vollständig prozessiv von SRPK1 phosphoryliert wird, wie es für das SR-Protein ASF/SF2 beobachtet wurde (Aubol et al. 2003). Solche Prozessivität gilt vermutlich nur für einen Sequenzabschnitt aus reinen (RS)-Dipeptid-Wiederholungen, der bei hPrp28 lediglich in einem Bereich (Aminosäure 57-65) auftritt. Die Existenz von verschiedenen Sequenzabschnitten, die von SRPK1 erkannt werden, könnte auch das Auftreten unterschiedlich stark phosphorylierter hPrp28-Varianten in vivo erklären (Teigelkamp et al. 1997).

Die weitaus meisten Serine und damit potentiellen Phosphorylierungsstellen von hPrp28 befinden sich im ersten Abschnitt der RS-Domäne (Aminosäure 1-125). Massenspektrometrie bestätigte diese Vorhersage (3.4.2.3.2.1). Die Regulation durch Phosphorylierung findet folglich vermutlich über diesen Teil statt. Die Phosphorylierung ist offensichtlich sowohl für Interaktionen mit anderen Proteinen als auch mit RNA wichtig (Xiao und Manley 1996, Shen und Green 2006). Die entscheidende Frage ist, auf welche Weise sie die Funktion der RSDomäne reguliert. Mit zwei verschiedenen Methoden wurde gezeigt, dass die Phosphorylierung den hydrodynamischen Radius des RS3-Fragments vergrößert (3.4.3). Dies entspricht zunächst nicht den Erwartungen, da die Phospatgruppen die positive Nettoladung der RS-Domäne verringern und man darum eher eine kompaktere Struktur vorhersagen würde. Möglicherweise bewirkt die Phosphorylierung die teilweise Entfaltung im Nterminalen Bereich der RS-Domäne. Dadurch kann dieser Sequenzabschnitt dann Interaktionen mit anderen RS-Domänen oder mit RNA eingehen. Erste Ergebnisse aus NMRUntersuchungen gaben aber bisher keine Hinweise auf strukturelle Unterschiede aufgrund der Phosphorylierung (3.4.4). Genau geklärt werden kann dies erst, wenn die vollständige Strukturlösung für die RS-Domäne gelingt.

\subsubsection{Funktion}

Die Funktionsweise von RS-Domänen ist noch nicht eindeutig geklärt. Experimentelle Daten weisen einerseits darauf hin, dass es sich um Protein-Protein-Interaktionsmodule handelt, die 
bevorzugt an andere RS-Domänen binden. Andererseits gibt es Hinweise, dass RS-Domänen sequenzunspezifisch mit doppelsträngiger RNA interagieren (1.2.3).

In dieser Arbeit wurde gezeigt, dass hPrp28 nur dann an das U4/U6.U5 tri-snRNP binden kann, wenn seine RS-Domäne phosphoryliert ist (3.5.2.1). Dies weist darauf hin, dass die RSDomäne die Interaktion des Proteins mit dem tri-snRNP vermittelt. Vollkommen unklar ist aber, welche Proteine des tri-snRNP Bindungspartner von hPrp28 sind. Bisher konnten weder in Yeast-two-hybrid- noch in in vitro-Bindungsstudien Interaktionspartner identifiziert werden (Liu et al. 2006). Wenn hPrp28 das tri-snRNP tatsächlich über die RS-Domäne bindet, sind Proteine, die ebenfalls eine RS-Domäne besitzen, mögliche Bindungspartner. Dies trifft lediglich für die drei tri-snRNP-spezifischen Proteine hSnu66, hSad1 und $27 \mathrm{~K}$ zu.

Allerdings ist hPrp28 auch Bestandteil des U5 snRNP und muss darum bereits in diesem Komplex Interaktionspartner haben. Das U5 snRNP enthält jedoch außer hPrp28 kein Protein mit einer RS-Domäne. Entweder bindet hPrp28 darum das U5 snRNP unabhängig von seiner RS-Domäne, beispielsweise über den konservierten Sequenzabschnitt zwischen der RS- und Helikasedomäne. Alternativ interagiert die RS-Domäne in diesem Fall mit der U5 snRNA oder mit einem Proteinmodul, das keine RS-Domäne darstellt. Ein sehr wahrscheinlicher Interaktionspartner von hPrp28 ist hPrp8, da beide Proteine genetisch interagieren (Strauss und Guthrie 1991, Kuhn et al. 1999 und 2002).

Das orthologe Protein aus S. cerevisiae hat keine RS-Domäne. Entsprechend zeigt es auch keine stabile Bindung an das tri-snRNP (Strauss und Guthrie 1999). Das Protein muss dennoch in der Lage sein, an das Spleißosom zu binden, um seine Funktion zu erfüllen. Dazu könnte sein N-terminaler Aminosäureabschnitt dienen. Diese Überlegung zeigt, dass die RSDomäne möglicherweise eine Erweiterung der ursprünglichen Interaktionsdomäne aus der Hefe darstellt, die die Möglichkeit bietet, die Interaktion über Phosphorylierung zu regulieren. Ist die RS-Domäne nämlich nicht phosphoryliert, so wirkt sie offensichtlich sogar inhibierend auf die Bindung an das Spleißosom, da in diesem Fall keine Bildung eines B-Komplexes beobachtet wurde (3.5.1).

Die RS-Domäne könnte nicht nur Interaktionen mit dem tri-snRNP eingehen, sondern auch direkt bei der Bindung an den spleißosomalen Komplex A beteiligt sein. Mögliche Interaktionspartner wären SR-Proteine, für die gezeigt wurde, dass sie die Assoziation des trisnRNP vermitteln (1.2.3). Alternativ könnte die RS-Domäne aber auch Interaktionen mit RNA eingehen, beispielsweise mit einem Duplex aus der 5'-Spleißstelle der prä-mRNA und der U1 oder U6 snRNA. Um diese Frage zu klären, sind weitere Interaktionsstudien notwendig. 


\section{Zusammenfassung}

DEAD-Box Proteine gehören zur Superfamilie der Helikasen. Sie verwenden die Energie aus der ATP-Hydrolyse, um RNA-RNA- oder RNA-Protein-Interaktionen aufzulösen und katalysieren auf diese Weise Konformationsänderungen in Ribonukleoproteinkomplexen.

Das DEAD-Box Protein hPrp28 ist Bestandteil des U5 snRNP des humanen Spleißosoms. Es ist notwendig für die Integration des U4/U6.U5 tri-snRNP in diesen makromolekularen Komplex und die anschließend stattfindende Konformationsänderung, die zum aktiven Spleißosom und zur ersten Transester-Reaktion führt. Vermutlich katalysiert hPrp28 dabei an der 5'-Spleißstelle der prä-mRNA den Austausch der U1 snRNA gegen die U6 snRNA.

In dieser Arbeit wurde die C-terminale Helikasedomäne von hPrp28 kristallisiert und seine Struktur durch Röntgenbeugungsexperimente bestimmt. Sie umfasst zwei Subdomänen, die jeweils ein zentrales $\beta$-Faltblatt enthalten, das von mehreren $\alpha$-Helices umgeben wird. Dieser Aufbau ist sehr ähnlich zu demjenigen in bekannten Strukturen anderer DEAD-Box Proteine. Unterschiedlich ist aber die relative Orientierung der Subdomänen zueinander. In der erhaltenen Struktur von hPrp28 liegen die Subdomänen in einer sehr offenen Konformation vor.

Zur biochemischen Charakterisierung der Helikasedomäne von hPrp28 wurden Interaktionsstudien mit möglichen Liganden duchgeführt. Die Untersuchung der RNABindung mit verschiedenen Substraten weist darauf hin, dass sie möglicherweise mit doppelsträngiger RNA interagiert. Weiterhin wurde gezeigt, dass die Helikasedomäne von hPrp28 in vitro ADP bindet, nicht aber ATP. Dementsprechend konnte auch keine ATPaseAktivität nachgewiesen werden. Die Molekularstruktur macht sichtbar, dass die ATPBindestelle der Helikasedomäne durch die Konformation der P-Schleife geschlossen ist und darum die Bindung von ATP sterisch inhibiert wird.

N-terminal hat hPrp28 eine Arginin-Serin-reiche Domäne. In dieser Arbeit wurde gezeigt, dass sie in vitro durch die Kinasen SRPK1 und Clk1 vielfach phosphoryliert werden kann und dass sich die Phosphorylierung durch SRPK1 auf die ersten 125 Aminosäuren konzentriert. In Zusammenarbeit mit Rebecca Mathew und Reinhard Lührmann (MPI, Göttingen) ergab sich, dass diese Phosphorylierung essentiell für die Bindung von hPrp28 an das U4/U6.U5 trisnRNP ist und damit auch für die Integration des tri-snRNP in das Spleißosom. 


\section{Summary}

DEAD-box proteins belong to the helicase superfamily. They use the energy of ATP hydrolysis to dissociate RNA-RNA or RNA-protein interactions and therefore to catalyze rearrangements in riboncleoprotein complexes.

The DEAD-box protein hPrp28 is part of the U5 snRNP of the human spliceosome. It is necessary for the integration of the U4/U6.U5 tri-snRNP into this macromolecular complex and for the subsequent rearrangements leading to an active spliceosome and the first transesterification reaction. It is assumed that hPrp28 catalyzes the exchange of the U1 for the U6 snRNA at the 5' splice site of the pre-mRNA.

In this work, the C-terminal helicase domain of hPrp28 was crystallized and its structure was determined by x-ray diffraction experiments. It contains two subdomains each consisting of a central $\beta$-sheet surrounded by $\alpha$-helices. Their structures are very similar to those found in other DEAD-box proteins. Different is the relative orientation of the subdomains which is very open in hPrp28.

To characterize the helicase domain of hPrp28 biochemically, interaction studies with putative ligands where undertaken. The investigation of the RNA binding properties using different substrates suggests that it may interact with double stranded RNA. Furthermore, it was shown that the helicase domain of hPrp28 in vitro only binds ADP but not ATP. Correspondingly, no ATPase activity was observed. The molecular structure revealed that the ATP binding site on the helicase domain is in a closed conformation. This is due to the conformation of the P loop which sterically inhibits ATP binding.

At the N-terminus, hPrp28 contains an arginine-serine-rich domain. Here it was shown that this domain can be heavily phosphorylated in vitro by the kinases SRPK1 and Clk1. The phosphorylation by SRPK1 concentrates on the first 125 amino acids of hPrp28. In cooperation with Rebecca Mathew and Reinhard Lührmann (MPI, Göttingen) was shown that this phosphorylation is essential for the binding of hPrp28 to the U4/U6.U5 tri-snRNP and therefore for the integration of the tri-snRNP into the spliceosome. 


\section{Danksagung}

Herrn Prof. Dr. Ralf Ficner danke ich für die interessante Aufgabenstellung, seiner ständigen Hilfs- und Gesprächsbereitschaft und die Begeisterung, die er dem Projekt entgegenbrachte. Insbesondere danke ich ihm für die Organisation von interessanten Kooperationen mit dem Max-Planck-Institut für biophysikalische Chemie.

Bei Herrn Prof. Oliver Einsle bedanke ich mich für die Übernahme des Korreferats und seine Hilfsbereitschaft bei der Lösung von kristallographischen und computertechnischen Problemen.

Dr. Rebecca Mathew, Herrn Prof. Dr. Reinhard Lührmann, Hai-Young Kim und Dr. Markus Zweckstätter danke ich für die sehr freundliche und interessante Zusammenarbeit. Dr. Sunbin Liu danke ich für die erbrachten Vorarbeiten hinsichtlich der Klonierung von hPrp28.

Dr. Achim Dickmanns danke ich für seine kompetente Hilfe bei allen Fragen rund um das Labor und Dr. Jana Schmitzova für das Interesse und die Unterstützung, die sie meiner Arbeit entgegenbrachte.

Ganz besonders bedanken möchte ich mich bei Kristina Lakomek für unzählige hilfreiche Diskussionen, die mentale Unterstützung in schwierigen Phasen meiner Doktorarbeit und schließlich für die sehr gründliche Korrektur des Manusskripts.

Meinen Laborkollegen danke ich für eine entspannte und freundliche Arbeitsatmosphäre und der gegenseitigen Unterstützung bei labortechnischen Problemen.

Schließlich möchte ich mich herzlich bei meinen Eltern und Freunden für ihre ständige Unterstützung und Aufmunterung während meiner Doktorandenzeit bedanken. 


\section{Abkürzungsverzeichnis}

․

Abb.

ADP

ADPNP

APS

ATP

bp

BESSY

${ }^{\circ} \mathrm{C}$

$\mathrm{C}-$

CAPS

C. elegans

CIAP

cps

CTD

$\mathrm{Da}$

DESY

DLS

D. melanogaster

DNA

DTT

$\varepsilon$

E. coli

EDTA

et al.

FL

GSH

GST

GTP

$\mathrm{h}$

HPLC

H. sapiens

I

IPTG

ITK

K

$\mathrm{K}_{\mathrm{D}}$

LB

$\mathrm{M}$

MAD

MALDI

MIR

M. jannaschii

MOPS
Minuten

Sekunden

Abbildung

Adenosindiphosphat

Adenosin- 5'-( $\beta, \gamma$-imido)triphosphat

Ammoniumperoxodisulfat

Adenosintriphosphat

Basenpaare

Berliner Elektronensynchrotron

Grad Celsius

carboxy-

3-(Cyclohexylamino)-1-propansulfonsäure

Caenorhabditis elegans

calf intestinal alkaline phosphatase

counts per second

C-terminale Helikasesubdomäne

Dalton (g/mol)

Deutsches Elektronen Synchrotron

dynamic light scattering

Drosophila melanogaster

Desoxyribonukleinsäure

Dithiothreitol

Extinktionskoeffizient

Escherichia coli

Ethylendiamintetraacetat

et alteres

full length

Glutathion Sepharose

Glutathion-S-Transferase

Guanosintriphosphat

Stunden

high performance liquid chromatography

Homo sapiens

Intensität

Isopropyl- $\beta$-D-thiogalactopyranosid

isotherme Titrationskalorimetrie

Kelvin

Dissoziationskonstante

Luria Bertani Medium

Molarität

multiple wavelength anomalous dispersion

matrix assisted laser desorption/ionization

multiple isomorphous replacement

Methanococcus jannaschii

3-(N-Morpholino)propansulfonsäure 


\begin{tabular}{ll} 
MR & molecular replacement \\
mRNA & messenger RNA \\
MS & Massenspektrometrie \\
N- & amino- \\
NMR & Kernspinresonanz \\
NTA & Nitrilotriessigsäure \\
NTD & N-terminale Helikasesubdomäne \\
NTP & Nukleosidtriphosphat \\
OD & optische Dichte \\
PCR & Polymerasekettenreaktion \\
PDB & RCSB-Proteindatenbank \\
Prp & pre-mRNA processing \\
RNA & Ribonukleinsäure \\
rpm & Umdrehungen pro Minute \\
RS & Arginin-Serin-reich \\
S & Svedberg \\
SAD & single wavelength anomalous dispersion \\
S. cerevisiae & Saccharomyces cerevisiae \\
SDS-PAGE & Natriumdodecylsulfat-Polyacrylamidgelelektrophorese \\
SF & Superfamilie \\
SIR & single isomorphous replacement \\
snRNA & small nuclear RNA \\
snRNP & small nuclear ribonucleoprotein particle \\
SR & Serin-Arginin-reich \\
S/R & Signal/Rauschen \\
SRPK & SR-Protein Kinase \\
SS & Spleißstelle \\
Tab. & Tabelle \\
TEMED & N,N,N',N'-Tetramethylethylendiamin \\
TOF & time offlight \\
Tris & Tris(hydroxymethyl)aminomethan \\
$\%(v / v)$ & Volumenprozent \\
$\%$ (w/v) & Masse/Volumen in Prozent \\
$\AA$ & Angstrom (10-10m) \\
& \\
\hline &
\end{tabular}




\section{Literaturangaben}

Achsel T., K. Ahrens, H. Brahms, S. Teigelkamp, R. Lührmann (1998): The human U5-200kD protein (hPrp8) forms a stable RNA-free complex with several U5-specific proteins, including an RNA unwindase, a homologue of ribosomal elongation factor EF-2, and a novel WD-40 protein. Mol Cell Biol 18(11): 6756-6766.

Alvi R. K., M. Lund, R. T. O'Keefe (2001): ATP-dependent interaction of yeast U5 snRNA loop 1 with the 5' splice site. RNA 7: 1013-1023.

Andersen C. B. F., L. Ballut, J. S. Johansen, H. Chamieh, K. H. Nielsen, C. L. P. Oliveira, J. S. Pedersen, B. Seraphin, H. Le Hir, G. R. Andersen (2006): Structure of the exon junction core complex with a trapped DEAD-box ATPase bound to RNA. Science 313: 1968-1972.

Ast G., A. M. Weiner (1997): A novel U1/U5 interaction indicates proximity between U1 and U5 snRNAs during an early step of mRNA splicing. RNA 3: 371-381.

Aubol B. E., S. Chakrabarti, J. Ngo, J. Shaffer, B. Nolen, X.-D. Fu, G. Ghosh, J. A. Adams (2003): Processive phosphorylation of alternative splicing factor/splicing factor 2. PNAS 100(22): 1260112606.

Bartels C., C. Klatt, R. Lührmann, P. Fabrizio (2002): The ribosomal translocase homologue Snu114p is involved in unwinding U4/U6 RNA during activation of the spliceosome. EMBO 3(9): 875-880.

Bartels C., H. Urlaub, R. Lühmann, P. Fabrizio (2003): Mutagenesis suggests several roles of Snu114p in pre-mRNA splicing. J Biol Chem 278(30): 28324-28334.

Behzadnia N., M. M. Golas, K. Hartmuth, B. Sander, B. Kastner, J. Deckert, P. Dube, C. L. Will, H. Urlaub, H. Stark, R. Lührmann (2007): Composition and three-dimensional EM structure of double affinity-purified, human prespliceosomal A complexes. EMBO 26: 1737-1748.

Benz J., H. Trachsel, U. Baumann (1999): Crystal structure of the ATPase domain of translation initiation factor 4A from Saccharomyces cerevisiae--the prototype of the DEAD box protein family. Structure 7(6): 671-679.

Birdsall B., R. W. King, M. R. Wheeler, C. A. Lewis, S. R. Goode, R. B. Dunlap, G. C. K. Roberts (1983): Correction for light absorption in fluorescence studies of protein-ligand interactions. Anal Biochem 132: 353-361.

Blencowe B. J. (2000): Exonic splicing enhancers: mechanism of action, diversity and role in human genetic diseases. Trends Biochem Sci 25(3):106-10.

Boggon T. J., L. Shapiro (2000): Screening for phasing atoms in protein crystallography. Structure 8: R143-R149. 
Bono F., J. Ebert, E. Lorentzen, E. Conti (2006): The crystal structure of the exon junction complex reveals how it maintains a stable grip on mRNA. Cell 126: 713-725.

Boucher L., C. A. Ouzounis. A. J. Enright, B. J. Blencowe (2001): A genome wide survey of RS domain proteins. RNA 7: 1693-1701.

Bradford M. M. (1976): A rapid and sensitive method for the quantification of microgram quantities of protein utilizing the principle of protein-dye binding, Anal Biochem 72: 248-254.

Brahms S., J. Brahms (1980): Determination of protein secondary structure in solution by vacuum ultraviolet circular dichroism. J Mol Biol 138(2):149-78.

Brenner T. J., C. Guthrie (2005): Genetic analysis reveals a role for the C terminus of the Saccharomyces cerevisiae GTPase Snu114 during spliceosome activation. Genetics 170: 1063-1080.

Büttner K., S. Nehring, K.-P. Hopfner (2007): Structural basis for DNA duplex separation by a superfamily-2 helicase. Nat Struct Mol Biol 14: 647-652.

Caruthers J. M., E. R. Johnson, D. B. McKay (2000): Crystal structure of yeast initiation factor 4A, a DEAD-box RNA helicase. PNAS 97(24): 13080-13085.

Caruthers J. M., D. B. McKay (2002): Helicase structure and mechanism. Curr Opin Struct Biol 12: 123-133.

Chen J. Y.-F., L. Stands, J. P. Staley, R. R. Jackups, L. J. Latus, T.-H. Chang (2001): Specific alterations of U1-C protein or U1 small nuclear RNA can eliminate the requirement of Prp28p, an essential DEAD box splicing factor. Mol Cell 7: 227-232.

Cheng Z., J. Coller, R. Parker, H. Song (2005): Crystal structure and functional analysis of DEAD-box protein Dhh1p. RNA 11: 1258-1270.

Colwill K., L. L. Feng, J. M. Yeakley, G. D. Gish, J. F. Caceres, T. Pawson, X.-D. Fu (1996): SRPK1 and $\mathrm{Clk} /$ Sty protein kinases show distinct substrate specificities for serine/arginine-rich splicing factors. J Biol Chem 271(40): 24569-24575.

Cordin O., J. Banroques, N. K. Tanner, P. Linder (2005): The DEAD-box protein family of RNA helicases. Gene 367: 17-37.

Crispino J. D., J. E. Mermoud, A. I. Lamond, P. A. Sharp (1996): Cis-acting elements distinct from the 5' splice site promote U1-independent pre-mRNA splicing. RNA 2: 664-673.

Deckert J., K. Hartmuth, D. Boehringer, N. Behzadnia, C. L. Will, B. Kastner, H. Stark, H. Urlaub, R. Lührmann (2006): Protein composition and electron microscopy structure of affinity-purified human spliceosomal B complexes isolated under physiological conditions. Mol Cell Biol 26(14): 5528-5543.

Du H., D. F. Tardiff, M. J. Moore, M. Rosbash (2004): Effects of the U1C L13 mutation and temperature regulation of yeast commitment complex formation. PNAS 101(41): 14841-14846. 
Dumont S., W. Cheng, V. Serebrov, R. K. Beran, I. Tinoco, A. M. Pyle, C. Bustamante (2006): RNA translocation and unwinding mechanism of HCV NS3 helicase and its coordination by ATP. Nature 439(5): 105-108.

Emsley P., K. Cowtan (2004): Coot: model-building tools for molecular graphics. Acta Cryst D60: 2126-2132.

Fairman M. E., P. A. Maroney, W. Wang, H. A. Bowers, P. Gollnick, T. W. Nilsen, E. Jankowsky (2004): Protein displacement by DExH/D "RNA helicases" without duplex unwinding. Science 304: 730-734.

Fetzer S., J. Lauber, C. L. Will, R. Lührmann (1997): The [U4/U6.U5] tri-snRNP-specific 27K protein is a novel SR protein that can be phosphorylated by the snRNP-associated protein kinase. RNA 3: 344-355.

Frilander M. J., J. A. Steitz (2001): Dynamic exchanges of RNA interactions leading to catalytic core formation in the U12-dependent spliceosome. Mol Cell 7: 217-226.

Gill S. C., P. H. von Hippel (1989): Calculation of protein extinction coefficients from amino acid sequence data. Anal Biochem 182(2): 319-326.

Gouet P., E. Courcelle, D. I. Stuart, F. Metoz (1999): ESPript: analysis of multiple sequence alignments in PostScript. Bioinformatics 15(4): 305-308.

Grainger R. J., J. D. Beggs (2005): Prp8 protein: At the heart of the spliceosome. RNA 11: 533-557.

Graveley B. R., T. Maniatis (1998): Arginine/serine-rich domains of SR proteins can function as activators of pre-mRNA splicing. Mol Cell 1: 765-771.

Graveley B. R. (2000): Sorting out the complexity of SR protein functions. RNA 6: 1197-1211.

Hartmuth K., H. Urlaub, H.-P. Vornlocher, C. L. Will, M. Gentzel, M. Wilm, R. Lührmann (2002): Protein composition of human prespliceosomes isolated by a tobramycin affinity-selection method. PNAS 99(26): 16719-16724.

Hertel K. J., B. R. Graveley (2005): RS domains contact the pre-mRNA throughout spliceosome assembly. Trends Biochem Sciences 30(3): 115-118.

Hogbom M., R. Collins, S. van den Berg, R.-M. Jenvert, T. Karlberg, T. Kotenyova, A. Flores, G. B. Karlsson Hedestam, L. H. Holmberg Schiavone (2007): Crystal structure of conserved domains 1 and 2 of the human DEAD-box helicase DDX3X in complex with the mononucleotide AMP. RNA 7: 182193.

Hotz H.-R., B. Schwer (1998): Mutational Analysis of the yeast DEAH-Box splicing factor Prp16. Genetics 149: 807-815.

Ismaili N., M. Sha, E. H. Gustafson, M. M. Konarska (2001): The 100-kDa U5 snRNP protein (hPrp28p) contacts the 5' splice site through its ATPase site. RNA 7: 182-193. 
Jankowsky E., C. H. Gross, S. Shuman, A. M. Pyle (2001): Active disruption of an RNA-protein interaction by a DExH/D RNA helicase. Science 291: 121-125.

Johnson T. L., J. Abelson (2001): Characterization of U4 and U6 interactions with the 5' splice site using a S. cerevisiae in vitro trans-splicing system. Genes Dev 15: 1957-1970.

Jurica M. S., L. J. Licklider, S. P. Gygi, N. Grigorieff, M. J. Moore (2002): Purification and characterization of native spliceosomes suitable for three-dimensional structural analysis. RNA 8: 426439 .

Jurica M. S., M. J. Moore (2003): Pre-mRNA splicing: Awash in a sea of proteins. Mol Cell 12: 5-14.

Kabsch W. (1993): Automatic processing of rotation diffraction data from crystals of initially unknown symmetry and cell constants. J Appl Cryst 26: 795-800.

Kambach C., S. Walke, R. Young, J. M. Avis, E. de la Fortelle, V. A. Raker, R. Lührmann, J. Li, K. Nagai (1999): Crystal structures of two Sm protein complexes and their implications for the assembly of the spliceosomal snRNPs. Cell 96: 375-387.

Kim J. L., K. A. Morgenstern, J. P. Griffith, M. D. Dwyer, J. A. Thomson, M. A. Murcko, C. Lin, P. R. Caron (1997): Hepatitis C virus NS3 RNA helicase domain with a bound oligonucleotide: the crystal structure provides insights into the mode of unwinding. Structure 6: 89-100.

Kim D.-H., J. J. Rossi (1999): The first ATPase domain of the yeast 246-kDa protein is required for in vivo unwinding of the U4/U6 duplex. RNA 5: 959-971.

Kojima T., T. Zama, K. Wada, H. Onogi, M. Hagiwara (2001): Cloning of human PRP4 reveals interaction with Clk1. J Biol Chem 276(34): 32247-32256.

Konforti B. B., M. M. Konarska (1994): U4/U5/U6 snRNP recognizes the 5' splice site in the absence of U2 snRNP. Genes Dev 8: 1962-1973.

Konforti B. B., M. M. Konarska (1995): A short 5'splice site RNA oligo can participate in both steps of splicing in mammalian extracts. RNA 1: 815-827.

Korneeva, N. L., E. A. First, C. A. Benoit, R. E. Rhoads (2005): Interaction between the NH2-terminal domain of eIF4A and the central domain of iEF4G modulates RNA-stimulated ATPase activity. J Biol Chem 280(3): 1872-1881.

Korolev S., J. Hsieh, G. H. Gauss, T. M. Lohman, G. Waksman (1997): Major domain swiveling revealed by the crystal structures of complexes of E. coli Rep helicase bound to single-stranded DNA and ADP. Cell 90: 635-647.

Kuhn A. N., Z. Li, D. A. Brow (1999): Splicing factor Prp8 governs U4/U6 RNA unwinding during activation of the spliceosome. Mol Cell 3: 65-75. 
Kuhn A. N., E. M. Reichl, D. A. Brow (2002): Distinct domains of splicing factor Prp8 mediate different aspects of spliceosome activation. PNAS 99(14): 9145-9149.

Laggerbauer B., T. Achsel, R. Lührmann (1998): The human U5-200kD DEXH-box protein unwinds U4/U6 RNA duplices in vitro. PNAS USA 95: 4188-4192.

Laskowski R. A., D. S. Moss, J. M. Thornton (1993): Main-chain bond lengths and bond angles in protein structures. J Mol Biol 231(4): 1049-1067.

Lee J. Y., W. Yang (2006): UvrD helicase unwinds DNA one base pair at a time by a two-part power stroke. Cell 127: 1349-1360.

Li Z., D. A. Brow (1996): A spontaneous duplication in U6 spliceosomal RNA uncouples the early and late functions of the ACAGA element in vivo. RNA 2: 879-894.

Linder P. (2006): Dead-box proteins: a family affair- active and passive players in RNP-remodeling. Nucleic Acids Res 34(15): 4168-4180.

Liu Z.-R., B. Sargueil, C. W. J. Smith (1998): Detection of a novel ATP-dependent cross-linked protein at the $5^{\text {' }}$ splice site-U1 small nuclear RNA duplex by methylene blue-mediated photo-crosslinking. Mol Cell Biol 18(12): 6910-6920.

Liu Z.-R. (2002): p68 RNA helicase is an essential human splicing factor that acts at the U1 snRNA-5' splice site duplex. Mol Cell Biol 22(15): 5443-5450.

Liu S., R. Rauhut, H.-P. Vornlocher, R. Lührmann (2006): The network of protein-protein interactions within the human U4/U6.U5 tri-snRNP. RNA 12: 1418-1430.

Liu S., P. Li, O. Dybkov, S. Nottrott, K. Hartmuth, R. Lührmann, T. Carlomagno, M. C. Wahl (2007): Binding of the human Prp31 Nop domain to a composite RNA-protein platform in U4 snRNP. Science 316(5821): 115-120.

Makarov E. M., O. M. Makarova, H. Urlaub, M. Gentzel, C. L. Will, M. Wilm, R. Lührmann (2002): Small nuclear ribonucleoprotein remodeling during catalytic activation of the spliceosome. Science 298: 2205-2208.

Makarova O. V., E. M. Makarov, R. Lührmann (2001): The 65 and $110 \mathrm{kDa}$ SR-related proteins of the U4/U6.U5 tri-snRNP are essential for the assembly of mature spliceosome. EMBO 20(10): 25532563.

Makarova O. V., E. M. Makarov, S. Liu, H. P. Vornlocher, R. Lührmann (2002): Protein 61K, encoded by a gene (PRPF31) linked to autosomal dominant retinitis pigmentosa, is required for U4/U6.U5 tri-snRNP formation and pre-mRNA splicing. EMBO 21: 1148-1157.

Makarova O. V., E. M. Makarov, H. Urlaub. C. L. Will M. Gentzel, M. Wilm, R. Lührmann (2004): A subset of human 35S U5 proteins, including Prp19, function prior to catalytic step 1 of splicing. EMBO 23: 2381-2391. 
Malca H., N. Shomron, G. Ast (2003): The U1 snRNP base pairs with the 5' splice site within a pentasnRNP complex. Mol Cell Biol 23: 3442-3455.

Maroney P. A., C. M. Romfo, T. W. Nilsen (2000): Functional recognition of the 5' splice site by U4/U6.U5 tri-snRNP defines a novel ATP-dependent step in early spliceosomal assembly. Mol Cell 6: 317-328.

Martin A., S. Schneider, B. Schwer (2002): Prp43 is an essential RNA-dependent ATPase required for release of lariat-intron from the spliceocome. J Biol Chem 277(20): 17743-17750.

Mathew R., K. Hartmuth, S. Möhlmann, H. Urlaub, R. Ficner, R. Lührmann (2008): Phosphorylation of hPrp28 by SRPK2 is required for integration of the U4/U6.U5 tri-snRNP into the spliceosome. Nat Struct Mol Biol (in Druck)

Matthews B. W. (1968): Solvent content of protein crystals, J Mol Biol 33(2): 491-497.

McGuffin L.J., K. Bryson, D.T. Jones (2000): The PSIPRED protein structure prediction server. Bioinformatics 16: 404-405.

Menegay H. J., M. P. Myers, F. M. Moeslein, G. E. Landreth (2000): Biochemical characterization and localization of the dual specificity kinase CLK1. J Cell Science 113: 3241-3253.

Newman A. (1998): RNA splicing. Curr Biol 8(25): R903-R905.

Ngo J. C. K., S. Chakrabarti, J.-H. Ding, A. Velazquez-Dones, B. Nolen, B. E. Aubol, J. A. Adams, X.-D. Fu, G. Ghosh (2005): Interplay between SRPK and Clk/Sty kinases in phosphorylation of the splicing factor ASF/SF2 is regulated by a docking motif in ASF/SF2. Mol Cell 20: 77-89.

Nielsen T. K., S. Liu, R. Lührmann, R. Ficner (2007): Structural basis for the bifuntionality of the U5 snRNP 52K protein (CD2BP2). J Mol Biol 369: 902-908.

Nilsen T. W. (1998): RNA-RNA interactions in nuclear pre-mRNA splicing. RNA Structure and Function, Cold Spring Harbor: 279-307.

Nottrott S., H. Urlaub, R. Lührmann (2002): Hierarchical, clustered protein interactions with U4/U6 snRNA: a biochemical role for U4/U6 proteins. EMBO 21(20): 5527-5538.

Oberer M., A. Marintchev, G. Wagner (2005): Structural basis for the enhancement of eIF4A helicase activity by eIF4G. Genes Dev 19: 2212-2223.

O’Day, C. L., G. Dalbadie-McFarland, J. Abelson (1996): The Saccharomyces cerevisiae Prp5 protein has RNA-dependent ATPase activity with specificity for U2 small nuclear RNA. J Biol Chem 271(52): 33261-33267.

Pace C. N., F. Vajdos, L. Fee, G. Grimsley, T. Gray (1995): How to measure and predict the molar absorption coefficient of a protein. Protein Science 4: 2411-2423. 
Pause A., N. Sonenberg (1992): Mutational analysis of a DEAD box RNA helicase: the mammalian translational initiation factor eIF-4A. EMBO 11(7): 2643-2654.

Pearson W. R, D. J. Lipman (1988): Improved tools for biological sequence comparison. PNAS USA 85(8): 2444-2448.

Pena V., S. Liu, J. M. Bujnicki, R. Lührmann, M. C. Wahl (2007): Structure of a multipartite proteinprotein interaction domain in splicing factor Prp8 and its link to Retinitis Pigmentosa. Mol Cell 25: 615-624.

Philipps D., A. M. Celotto, Q.-Q Wang, R. S. Tarng, B. R. Graveley (2003): Arginine/serine repeats are sufficient to constitute a splicing activation domain. Nucl Acids Res 31(22): 6502-6508.

Raghunathan P. L., C. Guthrie (1998): RNA unwinding in U4/U6 snRNPs requires ATP hydrolysis and the DEIH-box splicing factor Brr2. Curr Biol 8(15): 847-855.

Reidt U., K. Reuter, T. Achsel, D. Ingelfinger, R. Lührmann, R. Ficner (2000): Crystal structure of the human U47U6 small nuclear ribonucleoprotein particle-specific SnuCyp-20, a nuclear cyclophilin. J Biol Chem 275: 7439-7442.

Reidt, U., M. C. Wahl, D. Fasshauer, D. S. Horowitz, R. Lührmann, R. Ficner (2003): Crystal structure of a complex between human spliceosomal cyclophilin $\mathrm{H}$ and a U4/U6 snRNP-60K peptide. J Mol Biol 331: 45-56.

Reuter K., S. Nottrott, P. Fabrizio, R. Lührmann, R. Ficner (1999): Identification, characterization and crystal structure analysis of the human spliceosomal U5 snRNP-specific $15 \mathrm{kDa}$ protein. J Mol Biol 294: 515-525.

Reyes J. L., P. Kois, B. B. Konforti, M. M. Konarska (1996): The canonical GU dinucleotide at the 5 'splice site is recognized by p220 of the U5 snRNP within the spliceosome. RNA 2: 213-225.

Reyes J. L., E. H. Gustafson, J. R. Luo, M. J. Moore, M. M. Konarska (1999): The C-terminal region of hPrp8 interacts with the conserved GU dinucleotide at the 5'splice site. RNA 5: 167-179.

Rocak S., P. Linder (2004): DEAD-box proteins: The driving forces behind RNA metabolism. Mol Cell Biol 5: 232-241.

Rogers, G. W., N. J. Richter, W. F. Lima, W. C. Merrick (2001): Modulation of the helicase activity of eIF4A by eIF4B, eIF4H, and eIF4F. J Biol Chem 276: 30914-30922.

Roscigno R. F., M. A. Garcia-Blanco (1995): SR proteins escort the U4/U6.U5 tri-snRNP to the spliceosome. RNA 1: 692-706.

Rossi F., E. Labourier, T. Forne, G. Divita, J. Derancourt, J. F. Riou, E. Antoine. G. Cathala, C. Brunel, J. Tazi (1996): Specific phosphorylation of SR proteins by mammalian DNA topoisomerase I. Nature 381: 80-82. 
Rossi F., T. Forne, E. Antoine, J. Tazi, C. Brunel, G. Cathala (1996): Involvement of U1 small nuclear ribonucleoproteins (snRNP) in 5' splice site-U1 snRNP interaction. J Biol Chem 271(39): 2398523991.

Rozen F., J. Pelletier, H. Trachsel, N. Sonenberg (1989): A lysine substitution in the ATP-binding site of eucaryotic initiation factor 4A abrogates nucleotide-binding activity. Mol Cell Biol 9(9): 40614063.41

Sander B., M. M. Golas, E. M. Makarov, H. Brahms, B. Kastner, R. Lührmann, H. Stark (2006): Organization of core spliceosomal components U5 snTNA loop I and U4/U6 di-snRNP as revealed by electron cryomicroscopy. Mol Cell 24: 267-278.

Sanford J. R., J. Ellis, J. F. Caceres (2005): Multiple roles of arginine/serine-rich splicing factors in RNA processing. Biochem Soc Trans 33(3): 443-446.

Schneider S., H.-R. Hotz, B. Schwer (2002): Characterization of dominant-negative mutants oft he DEAH-box splicing factors Prp22 and Prp16. J Biol Chem 277(18): 15452-15458.

Schwer B., T. Meszaros (2000): RNA helicase dynamics in pre-mRNA splicing. EMBO 19(23): 65826591.

Sengoku T., O. Nureki, A. Nakamura, S. Kobayashi, S. Yokoyama (2006): Structural basis for RNA unwinding by the DEAD-box protein Drosophila Vasa. Cell 125: 287-300.

Sha M., T. Levy, P. Kois, M. M. Konarska (1998): Probing of the spliceosome with site-specifically derivatized 5' splice site RNA oligonucleotides. RNA 4: 1069-1082.

Shen H., J. L. C. Kan, M. R. Green (2004): Arginine-serine-rich domains bound at splicing enhancers contact the branchpoint to promote prespliceosome assembly. Mol Cell 13: 367-376.

Shen H., M. R. Green (2004): A pathwas of sequential arginine-serine-rich domain-splicing signal interactions during mammalian spliceosome assembly. Mol Cell 16: 363-373.

Shen H., M. R. Green (2006): RS domains contact splicing signals and promote splicing by a common mechanism in yeast through humans. Genes Dev 20: 1755-1765.

Shi H., O. Cordin, C. M. Minder, P. Linder, R.-M. Xu (2004): Crystal structure of the human ATPdependent splicing and export factor UAP56. PNAS 101(51): 17628-17633.

Sigler P. B., D. M. Blow (1965): A means of promoting heavy-atom binding in protein crystals. J Mol Biol 14(2):640-644.

Silverman E., G. Edwalds-Gilbert, R.-J. Lin (2003): DExD/H-box proteins and their partners: helping RNA helicases unwind. Gene 312: 1-16.

Small E. C., S. R. Leggrett, A. A. Winans, J. P. Staley (2006): The EF-G-like GTPase Snu114p regulates spliceosome dynamics mediated by Brr2p, a DExD/H box ATPase. Mol Cell 23: 389-399. 
Staley J. P., C. Guthrie (1998): Mechanical devices of the spliceosome: motors, clocks, springs, and things. Cell 92: 315-326.

Staley J. P., C. Guthrie (1999): An RNA switch at the 5' splice site requires ATP and the DEAD box protein Prp28p. Mol Cell 3: 55-64.

Stevens S. W., D. E. Ryan, H. Y. Ge, R. E. Moore, M. K. Young, T. D. Lee, J. Abelson (2002): Composition and functional characterization of the yeast spliceosomal penta-snRNP. Mol Cell 9: 3144.

Story R. M., T. A. Steitz (1992): Structure of the recA protein-ADP complex. Nature 355: 374-376.

Story R. M., H. Li, J. N. Abelson (2001): Crystal structure of a DEAD box protein from the hyperthermophile Methanococcus jannaschii. PNAS 98(4): 1465-1470.

Strauss E. J., C. Guthrie (1991): A cold-sensitive mRNA splicing mutant is a member of the RNA helicase gene family. Genes Dev 5: 629-641.

Straus E. J., C. Guthrie (1994): PRP28, a 'DEAD-box' protein, is required for the first step of mRNA splicing in vitro. Nucleic Acids Res 22(15): 3187-3193.

Strong M., M. R. Sawaya, S. Wang, M. Phillips, D. Cascio, D. Eisenberg (22006): Towards the structural genomics of complexes: Crystal structure of a PE/PPE protein complex from Mycobacterium tuberculosis. PNAS 103(21): 8060-8065.

Stura E. A., G. R. Nemerow, I. A. Wilson (1992): Strategies in the crystallization of glycoproteins and protein complexes. J Crystal Growth 122: 273-285.

Talavera M. A., E. M. de la Cruz (2005): Equilibrium and kinetic analysis of nucleotide binding to the DEAD-box RNA helicase DbpA. Biochemistry 44: 959-970.

Tanaka N., B. Schwer (2005): Characterizaiton of the NTPase, RNA-binding, and RNA helicase activities of the DEAH-box splicing vactor Prp22. Biochemistry 44: 9795-9803.

Tanner N. K., P. Linder (2001): DExD/H box RNA helicases: From generic motors to specific dissociation functions. Mol Cell 8: 251-262.

Tarn W.-Y., J. A. Steitz (1995): Modulation of 5' splice site choice in pre-messenger RNA by two distinct steps. PNAS USA 92: 2504-2508.

Teigelkamp S., C. Mundt, T. Achsel, C. L. Will, R. Lührmann (1997): The human U5 snRNP-specific $100-\mathrm{kD}$ protein is an RS domain-containing, putative RNA helicase with significant homology to the yeast splicing factor Prp28p. RNA 3: 1313-1326.

Thomas J. M., M. E. Hodes (1981): A new discontinuous buffer system for the electrophoresis of cationic proteins at near-neutral pH. Anal Biochem 118: 194-196. 
Tycowski K. T., N. G. Kolev, N. K. Conrad, V. Fok, J. A. Steitz (2006): The ever-growing world of small nuclear ribonucleoproteins. The RNA world, $3^{\text {rd }}$ edition, Cold Spring Harbor: 327-368.

Urlaub H., K. Hartmuth, S. Kostka, G. Grelle, R. Lührmann (2000): A general approach for identification of RNA-protein cross-linking sites within native human spliceosomal small nuclear ribonucleoproteins (snRNPs). J Biol Chem 275(52): 41458-41468.

Valadkhan S., J. L. Manley (2001): Splicing-related catalysis by protein-free snRNAs. Nature 413: 701-707.

van Nues R. W., J. D. Beggs (2001): Functional contacts with a range of splicing proteins suggest a central role for Brr2p in the dynamic control of the order of events in spliceosomes of Saccharomyces cerevisiae. Genetics 157: 1451-1467.

Velankar S. S., P. Soultanas, M. S. Dillingham, H. S. Subramanya, D. B. Wigley (1999): Crystal structures of complexes of PcrA DNA helicase with a DNA substrate indicate an inchworm mechanism. Cell 97: 75-84.

Velazquez-Dones A., J. C. Hagopian, C.-T. Ma, X.-Y. Zhong, H. Zhou, G. Ghosh, X.-D. Fu, J. A, Adams (2005): Mass Spectrometric and kinetic analysis of ASF/SF2 phosphorylation by SRPK1 and Clk/Sty. J Biol Chem 280 (50): 41761-41768.

Vidal V. P. I., L. Verdone, A. E. Mayes, J. D. Beggs (1999): Characterization of U6 snRNA-protein interactions. RNA 5: 1470-1481.

Vidovic I., S. Nottrott, K. Hartmuth, R. Lührmann, R. Ficner (2000): Crystal structure of the spliceosomal $15.5 \mathrm{kDa}$ protein bound to a U4 snRNA fragment. Mol Cell 6:1331-1342.

Wang, Y., C. Guthrie (1998): PRP16, a DEAH-box RNA helicase, is recruited to the spliceosome primarily via its nonconserved N-terminal domain. RNA 4: 1216-1229.

Wilkins, D. K., S. B. Grimshaw, V. Receveur, C. M. Dobson, J. A. Jones, L. J. Smith (1999): Hydrodynamic radii of native and denatured proteins measured by pulse field gradient NMR techniques. Biochemistry, 38 (50): 16424 -16431.

Will C. L., R. Lührmann (2006): Spliceosome structure and function. The RNA world, $3^{\text {rd }}$ edition, Cold Spring Harbor: 369-400.

Wu J., A. K. Bera, R. J. Kuhn, J. L. Smith (2005): Structure of the Flavivirus helicase: implications for catalytic activity, protein interactions, and proteolytic processing. J Virol 79(16):10268-10277.

Wyatt J. R., E. J. Sontheimer, J. A. Steitz (1992): Site-specific cross-linking of mammalian U5 snRNP to the 5' splice site before the first step of pre-mRNA splicing. Genes Dev 6: 2542-2553.

Xiao S.-H., J. L. Manley (1997): Phosphorylation of the ASF/SF2 RS domain affects both proteinprotein and protein-RNA interactions and is necessary for splicing. Genes Dev 11: 334-344. 
Yao N., H. M. Cabie, Z. Hong, A. D. Kwong, H. V. Le, P C. Weber (1997): Structure of the hepatitis C virus RNA helicase domain. Nat Strut Biol 4(6): 463-467.

Yue B.-G., P. Ajuh, G. Akusjärvi, A. I. Lamond, J.-P. Kreivi (2000): Functional coexpression of serine protein kinase SRPK1 and its substrate ASF/SF2 in Escherichia coli. Nucleic Acids Res 28(5): E14.

Zhang D., M. Rosbash (1999): Identification of eight proteins that cross-link to pre-mRNA in the yeast commitment complex. Genes Dev 13: 581-592. 


\section{Lebenslauf}

Name:

Adresse:
Sina Möhlmann

Otto-Lauffer-Str. 4c

37077 Göttingen

Eltern: Werner und Marliese H. Möhlmann

Geburtsdatum: $\quad$ 03.02.1978

Geburtsort: Westerstede

Staatsangehörigkeit: deutsch

Beruflicher Werdegang:

1990-1997:

1997-1999:

1999-2004:

2001-2002:

März 2004:

seit 2004:
Erlangung der allgemeinen Hochschulreife am Gymnasium Westerstede Studium der Biochemie an der Universität Bielefeld Studium der Biologie an der Georg-August-Universität, Göttingen Auslandsstudium an der Universität Umeå, Schweden

Diplom in der Abteilung für Entwicklungsbiologie an der GeorgAugust-Universität Göttingen unter Anleitung von PD Dr. Sigrid Hoyer-Fender.

Thema der Diplomarbeit: Interaktionen von HP1 $\beta$ (Heterochromatinprotein $1 \beta$ ) und Chromatinkondensation

Doktorarbeit in der Abteilung für Molekulare Strukturbiologie an der Georg-August-Universität Göttingen unter Anleitung von Prof. Dr. Ralf Ficner 